$\mathrm{DOE} / \mathrm{R} 4 / 10224--\mathrm{Tl}$

DE84 000406

A HYBRID SPACE HEATIRG/COOLIAG SYSTEM NITH

TROMBE WALL, UNDERGROUND VERTIKG, AND ASSISTED HEAT PUMP
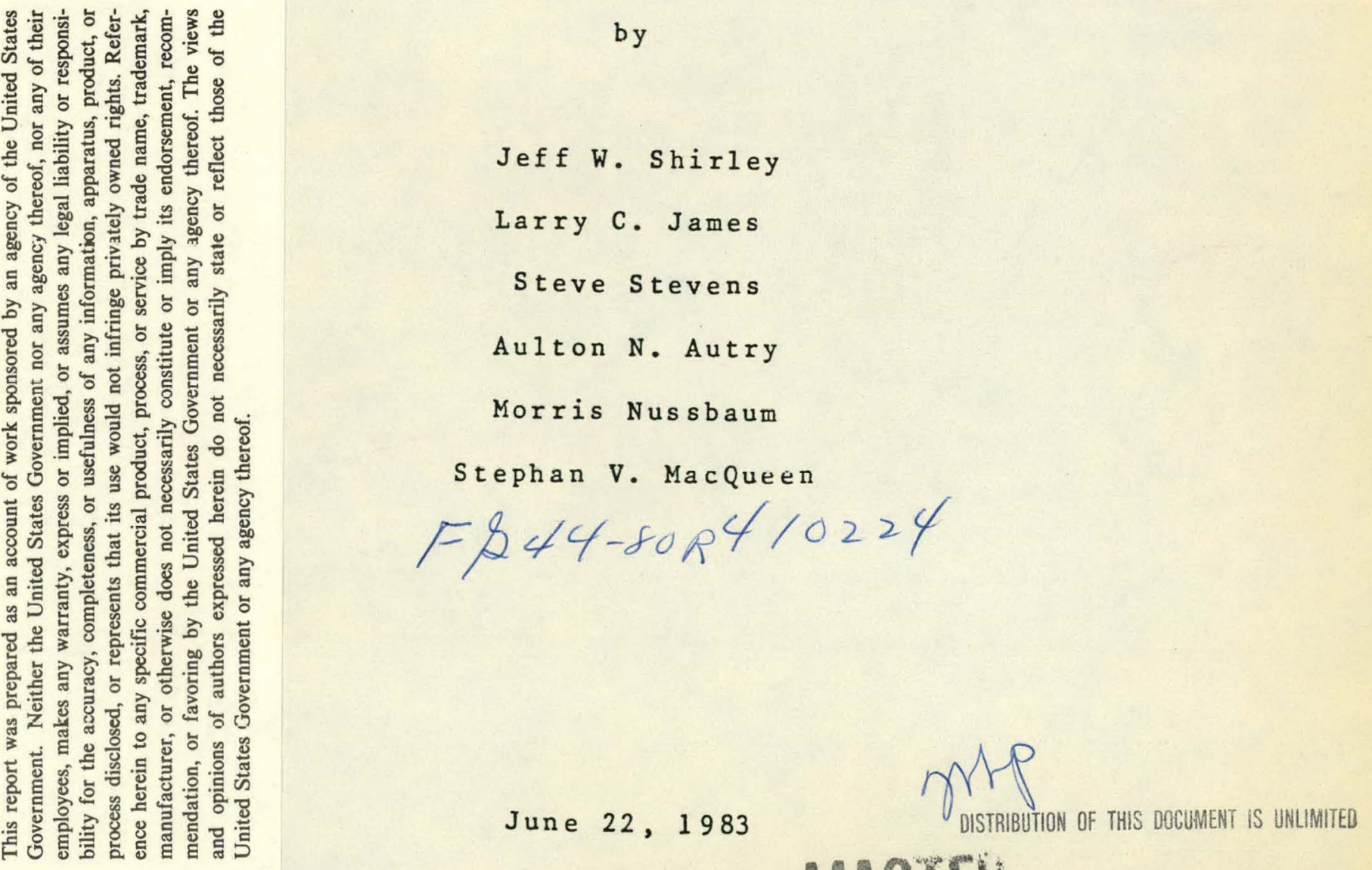

June 22,1983 


\section{DISCLAIMER}

This report was prepared as an account of work sponsored by an agency of the United States Government. Neither the United States Government nor any agency Thereof, nor any of their employees, makes any warranty, express or implied, or assumes any legal liability or responsibility for the accuracy, completeness, or usefulness of any information, apparatus, product, or process disclosed, or represents that its use would not infringe privately owned rights. Reference herein to any specific commercial product, process, or service by trade name, trademark, manufacturer, or otherwise does not necessarily constitute or imply its endorsement, recommendation, or favoring by the United States Government or any agency thereof. The views and opinions of authors expressed herein do not necessarily state or reflect those of the United States Government or any agency thereof. 


\section{DISCLAIMER}

Portions of this document may be illegible in electronic image products. Images are produced from the best available original document. 


\title{
A HYBRID SPACE HEATING/COOLING SYSTEM WITH TROMBE WALL, UNDERGROUND VENTING, AND ASSISTED HEAT PUMP
}

\author{
by \\ Jeff W. Shirley \\ Larry C. James \\ Steve Stevens \\ Aulton N. Autry \\ Morris Nussbaum \\ Stephan V. MacQueen
}

June 22,1983

Work Performed Under Grant No.

\author{
U.S. Department of Energy \\ Appropriate Technologies Small Grants Program
}


THIS PAGE

\section{WAS INTENTIONALLY}

\section{LEFT BLANK}


ITEM

PAGE

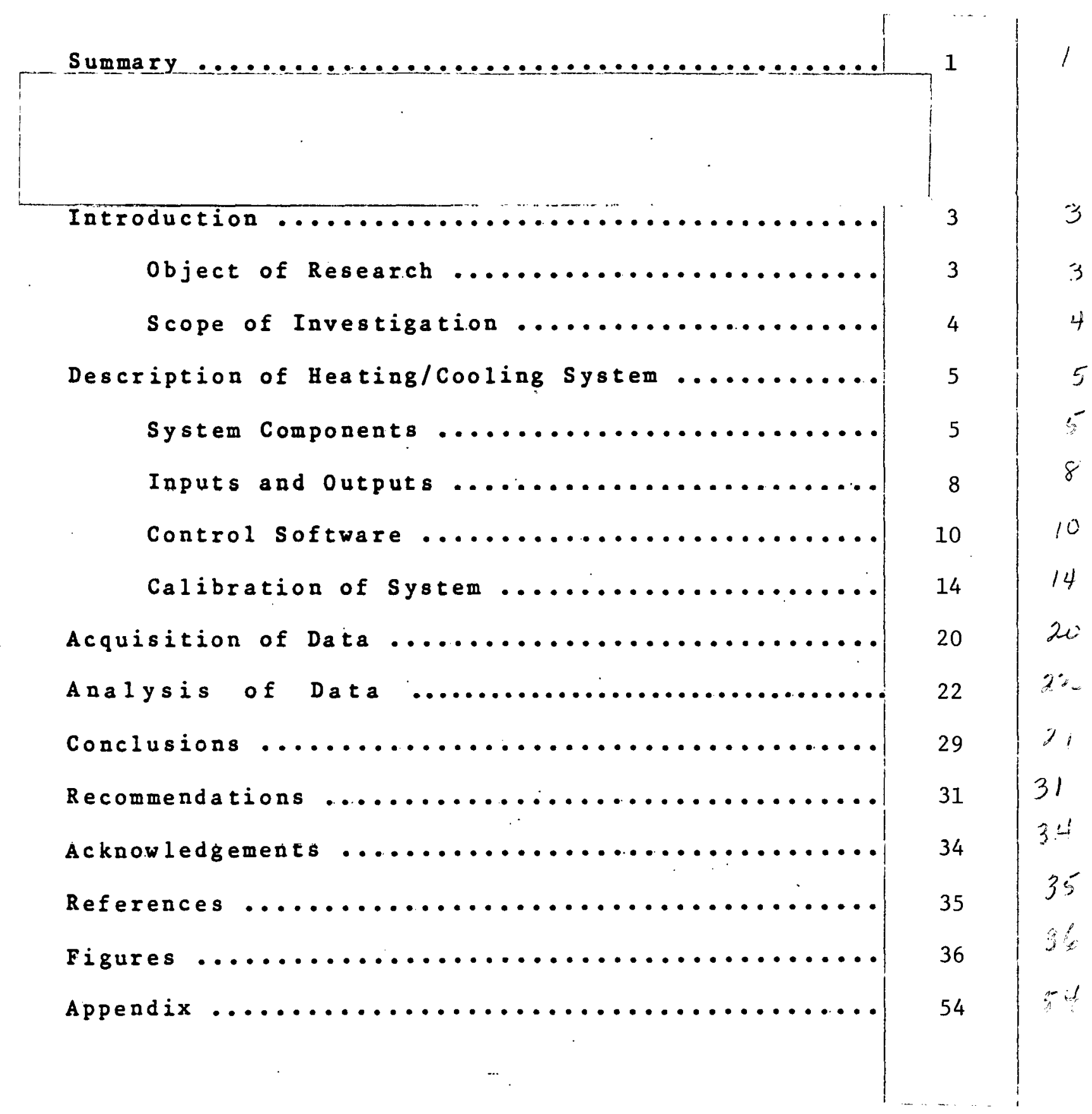




\section{THIS PAGE}

\section{WAS INTENTIONALLY}

LEFT BLANK 


\section{LIST OF FIGURES}

PIGORE

1

2

3

4

5

6

7

8

9

10

11

12

13

14

15

1

4

5

6

7

8

9

0

1

2

3

4

5

IITLE

PAGE

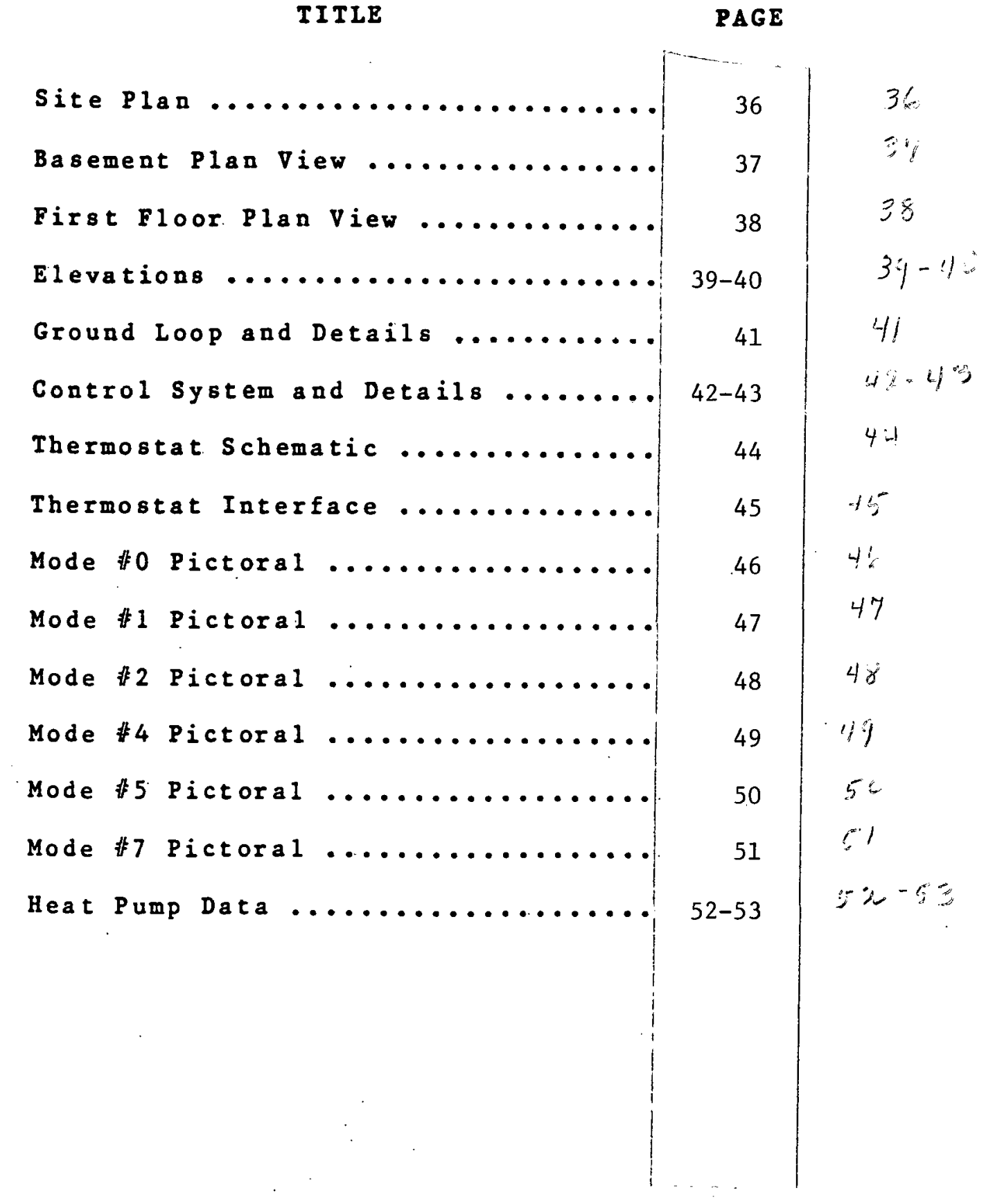




\section{SOMMARY}

Our goal wa to design and monitor a hybrid solar system/ground loop which automatically assists the standard, thermostatically controlled home heating/cooling system. The input from the homeowner was limited to normal thermostat operations. During the course of the project it was determined that to effectively gather data and control the various component interactions, a micro-computer based control system would be required. The choice of a micro-computer based control system would also allow the HVAC system to be optimised by simple changes to software. This flexibility in an untested concept helped us to achieve optimum system performance.

Control ranged from direct solar heating and direct ground loop cooling modes, to assistance of the heat pump by both solar space and ground loop. Sensors were stategically placed to provide data on response of the Trombe wall (surface, 4" deep, 8" deep), and the ground loop (inlet, $3 / 4$ length, outlet).

Micro-computer hardware and computer programs were developed to make cost effective decisions between the various modes of operation. Although recent advances in micro-computer hardware make similar control systems more readily achievable utilizing standard components, attention to the decision making criteria will always be required.

The ground loop was found to resist fluctuations in temperature and quickly recover from minor temperature variations caused by air flow through the loop. System performance is most sensitive to volume of air flow through the ground loop, and 


\section{A HYBRID SPACE HEATING/COOLING SYSTEM}

design emphasis should primarily be placed on air flow requirements.

The use of a Trombe wall to supply heat to the heat pump excluded subsequent dicect use of the solar space. The additional benefit supplied to the heat pump did not justify the additional effort required to tie the systems together. our final conclusion includes a recommendation for a separate Trombe wall with manul or automatic controls and two separate ground 10ops. A closed system ground loop is felt to offer the best interior cooling assistance, when integrated into the inside circulationsystem, while a passive opensystem ground loop is felt to provide the most cost effective assistance to the outside unit of a heat pump or the interior shell of a double wall structure. 


\section{IATRODUCTION}

\section{OBJECT OF RESEARCH}

The research reported herein was initiated to experimentally determine the performance of a Hybrid space Heating/Cooling system. During the design of the shirley home, two Heat Pump based mechanical systems were considered. A liquid based oolar assisted heat pump was quickly eliminated after preliminary pricing, and it was felt that possibly a cost effective air based solar assisted heat pump system could be developed. The 3 ton heat pump system was sized to provide $100 \%$ of the homes heating/cooling and the 200 SF Trombe Wall was estimated to provide up to $30 \%$ of the estimated heating load for the residence, assuming optimal conditions. Due to the lack of available design information for ground tubes, the "loop" was sized to provide a cross-sectional area equal to the area of the heat pump outdoor coil fan, approximately 3 SF.

The Shirley residence (see figures 1-4) is located in Columbia, South Carolina, latitude 34 degrees, longitude 81 degrees 1 minute. The house was designed with energy conservation and passive solar energy considerations as well as the Hybrid/active systems primarily analyzed herein. The residence contains approximately 2350 SF of heated floor space and $3000 \mathrm{SF}$ of total floor space. The house is oriented with the long axis facing South 10 degrees West with overhang and double glazing designed to maximize heat gain on the southern exposure whlle winimizing heat gain/loss un all other exposures. The two story structure is placed on a sloping lot with the lower level 
bermed to a depth of approximately 6 ft on the north walland transitioning from 6 ft to 3 ftonthe west wallandfrom 6 ft to 4 ft on the east garage wall. The building envelope is insulated as follows: Basement floor averages R8, Basement level walls average R12, First floor walls Rl7, First floor ceiling R30. The lot does suffer some shading from Southern Pines which has tended to reduce the direct radiation on the Trombe Wali in the mornings and late afternoons, the estimatefor shading penalty is set at 35 percent.

\section{SCOPE OF IRVESTIGATION}

The research program consisted of the following phases:

1) Design and Construction of the Micro-processor based. mechanical control/monitoring system and the placement of sensor devices.

2) Monitoring and optimization of the mechanical system.

3) Analysis of the recorded data. 


\section{DESCRIPIIOH OF RBATIEG/COOLIEG STSTBM}

\section{SYSTBM COKPONERTS}

The mechanical system can be separated into four separate units for purposes of discussion: 1) Ground Loop, 2) Trombe Wall(solar Space), 3) Heat Pump, and 4) Control and Monitoring system.

The design of the ground loop (see figure 5) required little additional excavation during the construction of the structure, the loop simply wraps around the structure at the foundation level separated from the structure by a distance of 12 inches. The Ground Loop inlet is located at the southeast corner of the structure. A Venturi fan with a 12 inch blade and a $1 / 4$ hp motor rated at 1430 CFM free air was provided to circulate the air through the ground loop. A motorized damper placed immediately in front of the fan insures a positive seal when the loop is not operating. The initial 30 feet of the loop running from the southeast corner to the northeast corner is made up of an open changel with a cross section of 3 SF (see figure 5). At the northeast corner a 90 degree turn leads into a section of loop designed as 12" concrete blocks stacked in a pyamid fashion creating 3 SF of opening for an air channel (seefigure 5). This arrangement runs 60 feet from the northeast corner to the northwest corner then through a 90 degree junction box with a deflector and continues on 30 feet to the southwest corner of the structure through another 90 degree junction box and exiting into the solar space. The average mid-depth of the loop is 
approximately 5 feet below the ground surface over the entire 120 foot loop. The "loop" continues through the solar space for 25 feet and exits through the solar space outlet, a motorized damper which exhausts air flow to the outside coils of the Heat Pump Bystem.

The Solar space (see figure 6) consists of a 200 SF 12" concrete block wall which is fully grouted and functions as a structural wall for $25^{\circ}$ along the south side of the basement. The wall has a 32 " overhang computed to eliminate any direct sunlight during the summer months, but effectively reducing the solar wall height to $6.25^{\circ}$ : The design called for the placing of the inside unit and ouplyandreturnductworkinthe solar space with insulation on the inside of the duct. The outside was painted to match the wall, to provide quick heatup in the morning sun and therefore early useful temperatures for the structure. The ductwork occupies the upper $2^{\circ}$ of the solar space and projects $22^{\prime \prime}$ out from the wall, effectively utilizing $1.5^{\circ}$ of the upper $2^{\prime}$ for solar collection during the winter months, while remaining shaded during the summer months. The effective maximum collector area was 187.5 SF. The entire wall, ductwork, and air handler unit were painted with Sherwin Williams Metalatex Black (\#B42B3) with an absorptance of approximately 0.90. The entire wall was double glazed with the inside glazing consisting of 3/16" low-iron glass at a distance of appoximately 28" from the solar wall and the outside glazing consisting of $0.025^{\prime \prime}$ Ralwall Sun-Lite Premium II (fiberglass reinforced plastic) locatedat approximately $32 "$ from the wall surface. The total transmittance, at normal incidence, for this system was 
calculated to be 0.78 . The Ground Loop enters on the west end and a motorized damper allows air flow to leave at the east end of the wall, exiting to the outside unit of the Heat Pump. Two motorized dampers were provided in the returnduct, one at the west end of the solar space, the other at the east end of the Solar space. These dampers are opened simultaneously to pull returnair through the Solar space, or to allowground loop air to flow directly into the house, with the return air being exhausted outside the Solar Space. The Ground Loop damper and Solar Spaceoutlet dampermust alsobe open to effect this mode:

The "3 Ton" Heat Pump system consists of an un-modified YORK Champion split-system high efficiency Heat Pump, model CHPI36/CHPO36. The heat pump is rated at 22,000 BTUH for heating at the Columbia, South Carolina design temperature of $20 \mathrm{~F}$, assuming 70F returnair. The heat pump is rated at 32,800 BTUH for total cooling capacity at the Columbia, South Carolina design temperature of $95 \mathrm{~F}$ dry bulb, assuming a $72 \mathrm{~F}$ indoor design temperature. The inside unit blower is rated at 1200 CFM, and the outside unit bluwer is rated a 2440 CFM for a dry coil.

The Control/Data-Acquisition System consists of two microcomputer based units which interact in a master/slave arrangement during programing, initialization, and a receive/broadcast arrangement for data-acquisition. During programming and initialization, an Intertec Superbrain QD micro-computer system is used to develop and download assembly language programs for use in the Control unit. During data-acquisition, this microcomputer system becomes the receiver of data broadcast at 10 
second intervals from the control unit, recording data on floppy diskettes acording to its operating program. Alldataacquisition and analysis software (see appendix) was written in PL/l due to the ease of creation and modification. Communications between the two micro-computer systems is provided via an RS232-C serial link at 1200 baud using software handshaking. The Control Unit is a custom creation, based on a Miller Technology M-80 Microcomputer, consisting of a single board 280 based micro-computer system with 2 R bytes of RAM and a separate power supply board. Custom Analog to Digital(A/D) hardware and output control hardware were designed and built to perform the interfacing to the "Real World". The A/D board uses a National Semiconductor ADC0816 8-b.it Analog-to-Digital converter chip which multiplexes 16 analog inputs. The output control section consists primarily of 24 volt relays to control the system dampers and to interface to the Heat Pump thermostat for control. All inputs and outputs arememory mapped. The system is designed so that removal of power from the microcomputer control system causes a reversion back-to the normal heat pump thermostat control system.

\section{IAPUTS ARD OOTPOTS}

The Control system inputs (see figures 6-8) are provided by 16 multiplexed analog inputs. (IO-I15) and one additiönal Direct Memory Access input (I16).

The inputs are:

I0 - Thermister, Solar Wall surface temperature.

I1 - Thermister, Solar Wall 4" depth temperature. 
I2 - Thermister, Solar Wall 8" depth temperature.

13 - Photo-Resistor, Day/Night sensor.

I4 - Thermistor, Solar Space temperature at 4 ft. height.

I5 - Thermister, Ambient temperature at Ground Loop inlet.

I6 - Thermister, Ground Loop Outlet temperature.

I7 - Thermister, Solar space outlet temperature at 1 ft. height.

I8 - Thermister, HP outside coil air temp. / Ground temp.

I9 - Thermister, Inside return air temperature.

I10 - Relay, Thermostat mode (Heating/Cooling).

I11. - Relay, Thermostat state (on/off).

Il2 - DPDT Switch, Software override switch\#4 (Disable Heat Pump ).

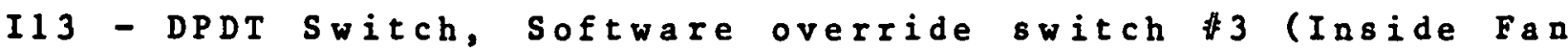
on $(\circ f f)$.

I1 4 - DPDT Switch, Software override switch \#2 (Return Dampers).

I15 - DPDT Switch, Software override switch 1 (Ground Loop Fan).

I16 - Display switches, 4 bit input to memory reading.

Switch 4 - Dowil = Cooling, Up = Heating.

Switch 3 - Down = Auto, Up = Manual (affects Sw 2, Sw 1).

Switch 2 - Down $=$ off, $U_{p}=$ on (relay 5 ).

Switch 1 - Down $=$ off, $U_{p}=$ on (relay 6$)$.

The Control system outputs (see figures 6-8) are provided by

six 24 volt relay outputs:

01 - Relays, cascaded 24 volt relay into a 120 volt relay to control Fan and Damper at. Ground Loop Entrance, Damper at Solar Space outlet to Heat pump (on / off \& open/lclosed).

02 - Relay, controls Dampers in Heating Systems Return. in Solar space (open/ closed).

03 - Relay, controls thermostat output to Air Handler Fan (Enable/Don't Care, inside circulation fan). 
04 - Relay, controls thermostat output for Beat Pump Control (Disable / Enable Heat Pump operation).

05 - Not used.

06 - Not used.

Additionally, an override switch was provided which places the system in either a manal modefor testing or an automatic mode for software operation. In the manual mode, 4 additional switches similar to Il2 - Ils described above control relay outputs 1 through 4 .

\section{CONTROL SOFTHARE}

The control software consists of approximately 2 k bytes of 280 Assembler code (see appendix). The control algorithm is essentially a simple loop which performs the control functions approximately 2.1 times per second and transmits down the communication link the 21 st evaluation, on a 10 second interval. The display count is then incremented indicating that the unit is functioning and there is a 14 hundredths of a second delay loop after the display update to insure a constant cycle of 1.0 seconds.

The primary subroutine used to control the system, SCYCLE, and its functional approach are described. The system cycle routine first calls UPREADS which updates all of the A/D readings and insures that a consistent snapshot of the system is acquired. (This technique eliminates any drift in the readings which typically occur when taking multiple readings of the same sensor for several different evaluations.) Using the fixed A/D readings the UPDAY routine updates the DAY/NIGHT values. The UPSFSW 
routine then updates the SOFThAE SwITH values, the UPDMS routine updates the MODE and STATE values, and the various MODE VALUES are calculated by EVAL. The BEAT PUMP is now either disabled or enabled by CTRLBP, the CONTROL routine is activated to determine if manual override is in effect or mode change has occured, and the RELAYS are updated by UPREL as required.

The logical control of the system is centered in the routines EVAL and CONTROL. EVAL computes the values of the seven modes possible for the system, and "programs" the action to be taken should the thermostat call for heating or cooling. EvAL first calls VALMS which computes the numeric values for the seven modes based on the current A/D readings. The numeric temperature values for the non-linear thermistor readings are computed using a table look-up with interpolation to the nearest $1 / 10$ th degree Centigrade.

Each mode has a simple numeric value based on addition, subtraction, multiplication, and division, and the choice between modes is based on the computed value and the order of evaluation. Specifically, the modes are checked in ascending order and the first heating/cooling mode with a positive value is selected. The seven modes are:

MODEO - (see figure 9). Heating by circulating house air through the sun space with Heat Pump DISABLED. (The value for MODEO is defined as the difference between the s.olar space Temperature and the Inside Temperature of the house less a constant of 2.0 degrees Centigrade.) The constant provides a "dcadband" between this mode and MODEl.

MODEl - (see figure 10) Heating by circulating bouse air 
through the Solar space with the Heat PumpenABLED. (The value for MODEl is defined as the difference between the solar space Temperature and the Inside Temperature of the house.) Should the Solar space temperature drop to within 2.0 degrees of the inside temperature the Heat Pump is enabled. This mode is provided to insure that a lockout of the beat pump with subsequent heat loss exceeding heat gain does not occur.

MODE2 - (seefigure 11) Heating by circulating outside air through the Ground Loop, through the Solar space, and through the outside coil of the Heat Pump. This circulation patternserves to assist the Heat Pump by tempering part of the air used by the Heat Pump. This mode is enabled only when the DAY/NIGHT sensor indicates NIGHT. This definition insures that the direct modes, MODEO and MODEl, will have a chance to operate and provide maximum benefit through direct heating. (The value of MODE2 is defined as the difference between the solar space outlet to the Heat Pump and the Ambient Temperature less a constant of 10.0 degrees Centigrade.) The 10.0 degree constant was empirically determined by measuring the current draw of the Ground Loop fan and Damper ( 1.8 Amps) and establishing the volume of air delivered to the Heat Pump by the fan ( -660 CFM). This information along with the performance data of the YORK Heat Pump (see figure 15) was used to determine the necessary temperature differential for operation of the Ground Loop with "payback". This Balance Point temperature was determined to be 2.65 degrees Centigrade if $100 \%$ of the required air is provided. Since the Ground Loop fan on ly provided $27 \%$ of the HP outside fan ( 2440 
(FM), the Balance Point temperature was factored up accordingly, establishing a required constant of 10.0 degrees Centigrade for operation. This is a severe criteriabut insures that when the Ground Loop operates, a positive Return On Investment for the current used is achieved.

MODE3 - This is a currently unused heating mode provided for expansion purposes.

MODE4 - (see figure 12) Cooling provided by the circulation of outside air through the Ground Loop and directly into the house. (The value of MODE4 is defined as the difference between the Inside Temperature and the Ground Loop outlet less a constant of 2.0 degrees (entigrade.) This mode is enabled only when the Ambient Temperature is less than 21.0 degrees Centigrade.

MODE5 - (see figure 13) Cooling provided by the circulation of outside air through the Ground Loop, through the shaded Solar Space, and across the outside.coils of the Heat Pump. (The value of MODES is defined as the difference between the Ambient Temperature and the Ground Loop outlet temperature less.a constant of 10.0 degrees (entigrade.)

MODE6 - This is a currently usused cooling mode provided for expansion purposes.

MODE7 - (see figure 14) This is the default mode of. beating/cooling with only the Heat pump in operation and is selected only if all other modes fail to produce a non-zero; positive value.

The Evaluation routine determines if the system is calling for heating or cooling (If Cooling is required, EVAL skips over the first four mode values.) and then locates the first value 
which is greater than zero. This mode is used to "program"the system for response when the thermostat calls for action. This evaluation takes place approximately 2.1 times per second continuously. To prevent "toggling" between any modes, the system is provided with a timeout mechanism which allows the system to move to a mode with a larger mode number, but forces a time delay when the system tries to move to a mode of lower value. The delay is approximately 13 minutes of operation.

The CTRLHP routine is the only routine which operates continuously in "Real-Time". This routine serves to predetermine the status of the Heat Pump when the thermostat next calls for Heating/Cooling and enable or disable its operation. This serves to eliminate the unnecessary strain induced by providing a power surge to the leat Pump which is subsequently powered off within 1.0 second by the selection of a direct beating/cooling mode.

The CONTROL routine next determines if the state of the system is on or off. If the system is on, Control checks and sets the appropriate action as determined by Eval, and by checking certain conditions and blocking the "toggling" from one mode to another, and by reseting the "system" to all off (shutdown) when the system thermostat no longer requires action.

Finaliy the UPREL routine executes the current software settings of the relays if the system is. on and the software 6.witches are set to auto, or UPREL will immediately execute the current manul setting of a sofware switch. 


\section{CAL IBRATIOA OF STSTEM}

Calibration of the system initiated with the initial establishment of the A/D conversion routine delay, and still continues as more information points to improvements.

The first calibration was required when it was noticed that multiple A/D readings of known different temperatures were reporting the same value. The solution required a $1 / 100$ th second delay when the A/D port was selected and a $1 / 100 t h$ second delay at the End of Conversion flag.following the A/D reading. These delays insured that first the address and then the 1 atched tristate output data provided by the ADC0816 were stable on the M80 bus.

The temperature look-up table was established at 10 degree Centigrade increments by comparing a given input thermistor reading to the known temperature established by thermometer. The control program table was adjusted to reflect the proper thermistor reading at the known temperature, and the calibrated value was dated.

The photo-resistor, DAY/NIGBT sensor, was calibrated by determining the A/D reading at the desired time of day. The current setting toggles at dusk. (Due to the lack of early morning and late afternoon direct radiation this setting may soon be reset, extending the NIGHT reading.)

The calibration of the control unit required determining the values of A/D readings on the DPDT software overide 8 witches which represented ON/AUTO/OFF positions. Additional input values for the SPST switches located below the display unit were established which represent oN/OFF positions. 
During the system implementation, the original procedure for mode evaluation was to determine each A/D reading as needed during the evaluation of each mode. It was noticed that during the mode evaluations that any given sensor might report different values when read at different conversions within the same evaluation cycle causing inconsistent mode comparisons. The solution to this problem was to establish a sapshot of the system by reading all of the sensors at one time and then evaluation all of the modes using the consistent data.

A major problem arose when the heat pump first went into its defrost mode. This input appeared to the control system as a call for cooling, and in February the system decided to disable the heat pump and provide outside air directly into the house. Once the control unit disabled the lieat pump, the defrost cycle was disabled and the control unit recognized the heating mode once more. This cycling continued for about 45 seconds until the problem was identified and the control unit disabled. The solution was to use one of the then unused switches under the display on the control Unit to set manualy the desired mode, HEATING or COOLING. When the Heat Pump indicates a mode other than the switch setting, the control unit assumes the defrost cycle and remains passive.

Another calibration was required to establish a constant time interval for transmission of data to the monitoring unit. Simple timing delays were implemented to insure a constant transmission cycle of 10 seconds.

Another major problem occurred when thc tcmperature was at a 
point where the system could toggle from one mode to another and back again. Toggling occured during interpolation of temperature values when system resolution causes two successive A/D readings to be different. Toggling also occurs when a reduction of temperature is caused by system cooling. When cold air flow is introduced a mode change may occur and air flow stops, the subsequent warming of the sensor causes the mode to toggle back. The solution to this problem was to allow the first mode change to occur, but to prevent the toggling back. This scheme was implemented by allowing modes of increasing value to occur freely but to lock-out for approximately 13 minutes the return to a lower mode.

Once the current required to drive the ground loop fan had been determined and the performance of the loop was established, the break-even point from an energy standpoint for runging the ground loop was calculated. This temperature difference was determined to be approximately 10 degrees centigrade and the modes involving the ground loop were appropriately calibrated.

During the early calibration of the system the Ambient tenperature sensor was initially placed at the mid-depth elevation of the structure, as is the Inside temperature sensor. Later it was decided that since the performance of the Ground Loop was of considerable importance, the Ambient sensor was moved to the Inlet of the Ground Loop, at an elevation approximately 2 feet from the slab, or approximately 6 feet lower than its initial placement. The current placement allows both the inlet and outlet air temperatures of the loopair to easilybe determined, while still representing Ambient conditions. 
Another loop problem arose when the original relay was exposed tomoist conditions for a few months. The relaystuckin the on condition and required replacement. The replacement relay was of the sealed variety and has operated satisfactorily until recently. The switching of 120 VAC tends to cause pitting of the contacts over time and the relay has recently required filing of these contacts. A. Euture electronic relay may resolve this minor maintenance problem.

After the aystem was operational, it was noticed that the house would occasionally overheat during the daytime. Analysis determined that a natural circulation loop had developed between the lower level inlet registers and the upper level inlet registers. A partial solution tothis problem was to installa gravity damper in the upper level supply trunk prior to the registers.

In August of 1982 , the ADC0816 chip failed and required replacement. An ADC0817 chip was substituted while a replacement was ordered. The ADCO817 chip is still functioning satisfactorily at this writting, implying that 7-bit or 8-bit resolution would be satisfactory for this application over the temperature ranges involved.

During the calibration of the cooling modes, it was determined that a situation could arise whereby outside air could be cooler than the inside air but insufficient to cool the structure to a comfortable temperature. Additionaly, a situation was envisioned where a simple temperature difference would not suffice. This condition could oceur when the structure 
had additional load, such as solar, causing the inside temperature to increase, while the ambient air temperature was also rising but remaining below the threshold that would allow the heat pump system to intervene. To mitigate this problem an absolute temperature point which would enable the direct cooling mode was implemented. The temperature chosen was 21.0 degrees Centigrade and direct cooling is possible only when the Ambient temperature is below this value.

During the analysis of data it was determined that the ground loop outlet sensor bad been influenced during the summer months due to its proxmity to the ground.surface. The initial placement had the sensor placed in the concrete box which terminated the ground loop prior to inlet to the solar space, at a depth of approximately 2 feet below the surface. The box, however, was covered by only a thin layer of soil and could therefore be subjected to considerable direct radiation during summer months. The current placement is approximately 6 feet into the ground loop and at a depth below ground surface of approximately 4 feet, consisting of soil and the concrete block which constitutes the loop.

Finally, during late spring and early fall, it is often undesirable for the solar sace to beatup. A large piece of metal with both a dark and light side was placed on the floor of the solar space. When this absorber/reflector exposes its dark borizontal surface, the solar space has anearlier heatupand a greater total absorber area. When this beat is not desirable, the white side is exposed as a vertical reflector which aignificanty reduces the heat buildup. 


\section{ACQUISITIOR OP DATA}

The data collection for the SYSTEM began February 8, 1982 and continues to this date. The period which this report covers is the timefrom $02 / 08 / 82$ to $05 / 21 / 83$. Osually twoor threedays of data were gathered each month. An attempt was then made to select the best day of recorded data each month which represented clear weather. The choice of clear days allowed the system a chance to illustrate best performance by removing noisy data, and hence providing an upper bound on the net savings. The data acquisition continued from February until october when the SYSTEM was retuned for optimum cooling performance. Data acquisition continued until November when the first versions of the PLOT program were operational and preliminary analyais of the data began.

Data analysis caused movement of some sensors in the Ground Loop to occur. Analysis continued in January of 1983 with the movement of the sensor from the outside Heat Pump coil to the NorthWest corner of the structure and inside the Ground Loop. This sensor had been used to establish the delta-T across the loop by providing useful Temperature delivered to the Beat Pump, as measured from the Inlet Temperature. This information with other data provided by the Heat Pump manufacturer had previously allowed the breakeven point for the Ground Loop to be determined. This sensor currently measures the ground temperature at the $3 / 4$ point in the ground $100 \mathrm{p}$.

Additionally, preliminary analysis mandated the movement of the Ground Loop outlet sensor, avoiding the future effects of direct. radiation which affected early sensor placement. Data 
acquisition continues on a random basis in this new configuration. 


\section{ARALTSIS OP DATA}

The analysis of data which follows consists of a presentation of selected dates of recorded data and associated observations and conclusions which were drawn from the data.

The plots of the data represent the significant data recorded during the testing period. Following is a description of the graph data from left to right:

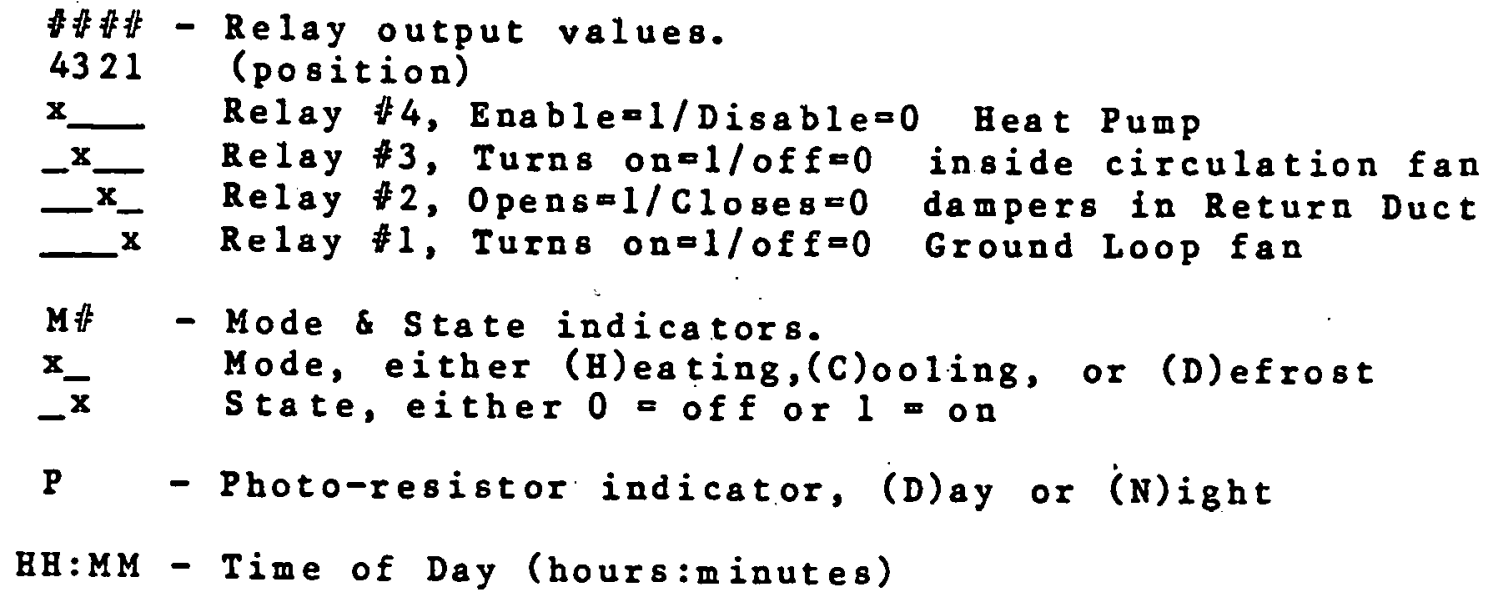

\section{PLOT LEGEND}

* Photo-resistor relative value

M Heat Pum temperature at condensor coil or Ground temperature ( $04 / 30 / 83$ and subsequent data)

A Ambient temperature

G Ground Loop outlet temperature

$X$ Solar space outlet temperature

8 Solar wall temperature at 8 inch depth

4 Solar wall temperature at 4 inch depth

o Solar wall temperature at 0 inch depth (surface)

+ Solar Space Air temperature at mid-depth

I Inside temperature 
The analysis which follows discribes the performance of the gystem for selected dags and represents the typical system behavior for various times throughout the 1982 year.

$$
02 / 11 / 82
$$

As can be seen from the plots in the Appendix, several interesting features will be present inall graphs. First one should note the shading which occured. This shading is best illustrated during the winter months by the plot of the surface wall temperature. This sensor consisted of a thermister placed directly on the surface of the solar wall and exposed todirect solar radiation. Next it can be observed that the Photo-resister was designed to be insensitive to shading, due to its field of view, and measures primarily difube radiation. Additionaly, one should note that the 4" depth peak temperature lags the surface peak temperature by approximately 30 min. The 8" depth peak temperature value typically lagged the 4" depth peak temperature by approximately 45 min and would hold its maximum value for around 4 hrs. Additionally, one should note that the inside temperature was increased due to "passive heating" as described earlier. Specific data for $2 / 11 / 83$ are: Wall surface temperature peaks at appoximately 104F at 2:08 PM. Solar space contributed to house heating for approximately 6 hrs. System recognized contribution for approximately 5 hrs. (Difference due to passive heating.) Ambient temperature peaked at 64 at 4:00PM. Duration of day was approximalely 9 hrs. For all subsequent days, only sumary data and notable differences will be listed.

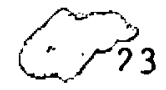


$02 / 13 / 82$

Surface temperature peaked at 2:12PM at 99F. 4" temperature peaked at 80F. 8" temperature peaked at $75 \mathrm{~F}$. Maximum inside temperature achieved as 75F. Solar contributed for approximately 6.63 hrs. Solar system contribution duration was 5.52 hro. Ambient temperature peaked at 4:13PM at 57F. Solar Space temperature peaked at $89 \mathrm{~F}$ at $1: 10 \mathrm{PM}$. Duration of day was approximately 10 hrs. Minimum wall surface temperature was $57 \mathrm{~F}$ at 6:40AM. Minimum Ambient temperature was 28F at 6:40AM. Minimum Solar Space temperature was $53 \mathrm{~F}$ at $6: 40 \mathrm{AM}$. System was in Ground Loop assist mode to Beat pump for approximately 8.95 hrs. Duration of night was $13.9 \mathrm{hrs}$.

$$
03 / 08 / 83-03 / 0.9 / 82
$$

It should be noted that the bigher sun angles were allowing earlier morning heatup by reduction of shading. Daytime data reported is for $03 / 09 / 82$ while nightime values are for the evening of $03 / 08 / 82-03 / 09 / 82$. Surface temperature of solar Wal 1 peaked at 12:40PM at 100F. 4" deptb Solar Wall temperature peaked at 84F. 8" depth Solar Wall temperature peaked at $80 \mathrm{~F}$. Maximum inside temperature achieved was 77F, Solar contributed for approximately 10.22 hrs. Solar system contributed for approximately $9.18 \mathrm{hrs.} \mathrm{Ambient} \mathrm{temperature} \mathrm{peaked} \mathrm{at} 3: 13 \mathrm{PM}$ at 62F. Solar Space temperature peaked at 94F at 1:10PM. Duration of day was approximately 11.15 hrs. Minimum wall surface temperature was $56, F$ at $6: 43 \mathrm{AM}$. Minimum Ambient temperature was 26F at 6:19AM. Minimum Solar Space temperature was 52F at 5:33AM. System was in Ground Loop as ist mode to Heat Pump for approximately 11.83 hrs. Duration of night was 12.87 hrs. 
$04 / 07 / 82$

Again, it should be noted that the higher sunangles were causing earliest morning heatup by reduction of shading. Solar radiation no longer directly strikes the surface temperature sensor. The temperature of the air in the solar space exceeds the temperature on the surface of the solar wall. Surface temperature of Solar wall peaked at 1:23PM at 87F, 4" depth Solar Wall temperature peaked at $1: 38 \mathrm{PM}$ at $81 \mathrm{~F}$, and 8 "depth Solar Wall temperature peaked at 1:54PM at 77F. Maximum inside temperature achieved was 77F. Solar contributed for appoximately 8.75 hrs. Solar system contributed for approximately 8.25 hrs. Ambient temperature peaked at 5:14PM at 65F. Solar space temperature peaked at 91F at 1:08PM. Duration of day was approximately 11.68 hrs. Minimum wali surface temperature was $62 \mathrm{~F}$ at 6:24AM. Minimum Ambient temperature was $27 \mathrm{~F}$ at 4:56AM. Minimum Solar space temperature was 55F at 5:40AM. System was in Ground Loop as ist mode to Heat Pump for approximately $6.67 \mathrm{hrs}$. (Note: recording period was not a full 24 hours.) Duration of night was 12.32 hrs.

\section{$05 / 14 / 82$}

Cooling mode was entered, and the wall was mostly shaded. Note that solar contribution did interfere with cooling. (This problem has been corrected by the addition of a reflector usedin the late spring and early fal1. Surface temperature of Solar Wall peaked at 2:10PM at 89F. 4" depth Solar Wall temperature peaked at $86 \mathrm{~F}, 8 "$ depth Solar Wall temperature peaked at 83 F. Maximum inside temperature achieved was 82F. Ground cooling did 
not contribute to the system at all. Ambient temperature peaked at 4:08PM at 86F. Solar space temperature peaked at 93F at 3:25PM. Duration of day was approximately 12.5 hrs. Minimum wall burface temperature was 75F at 6:35AM. Minimum Ambient temperature was 63F at 6:35AM. Minimum Solar space temperature was 73F at 5:34AM. System was never in mode of Ground Loop to assist Heat Pump. Duration of night was 11.5 hrs.

$06 / 15 / 82$

Allsolar space temperatures approximated ambient conditions. Maximum inside temperature achieved was 76F. Ambient temperature peaked at 2:40PM at 84F. Solar space temperature peaked at $86 \mathrm{~F}$ at $3: 24 \mathrm{PM}$. Duration of day was approximately 12.6 brs. Minimum ambient temperaturewas $72 \mathrm{~F}$ at $1: 44 \mathrm{AM}$. Minimum Solar Space temperature was 75F at 00:12AM. System was never in mode of Ground Loop assist to Heat Pump. Duration of night was $11.4 \mathrm{hrs}$.

\section{$07 / 27 / 82$}

Maximum inside temperature achieved was 77F. Ambient temperature peaked at 12:48PM at 87F. Solar Space temperature peaked at $86 \mathrm{~F}$ at $1: 23 \mathrm{PM}$. Duration of day was approximately 12.3 brs. Minimum Ambient temperature was 76F at 5:58AM. Minimum Solar Space temperature was $76 \mathrm{~F}$ at $6: 50 \mathrm{AM}$. System was never in mode of Ground Loop assist to Heat Pump. Duration of night was $11.7 \mathrm{hrg}$.

$$
08 / 20 / 82
$$

Maximum inside temperature achieved was 77 F. Ambient temperature peaked at 2:00PM at 85F. Solar space temperature peaked at 97F at 2:08PM. Duration of day wao approximately 12.08 
brs. Minimum wall surface temperature was 78 at 5:23AM. Minimum ambient temperature was 72F at 5:58AM. Minimum solar space temperature was 76F at 3:58AM. System was never in mode of Ground Loop assist to Heat Pump. Duration of night was 11.92 hrs .

\section{$04 / 30 / 83$}

It should be noted that this and subsequent data reflects revised sensor placement. System in direct cooling mode for 28.22 hrs. The relative humidity increased from approximately $55 \%$ to $70 \%$ during this run. This date provides typical data for cooling mode analysis. The inside temperature tended to rise on $5 / 01 / 83$ along with the ambient temperature rise, indicating a failure of the system to satiofy the cooling load requirement. Ground temperature did increase by $4 \mathrm{~F}$ from $62 \mathrm{~F}$ to $66 \mathrm{~F}$ over the 28.22 hour runtime. Daytime data reported is for 04/30/83$05 / 01 / 83^{\circ}$ wile nightime values are for morning/evening of 04/30/83-05/01/83. Maximum inside temperature acbieved was $79 \mathrm{~F}$ at run termination, indicating a $2 F$ rise from the starting temperature of 77F. Ambient temperature peaked at 2:42PM at 82F. solar space temperature peaked at 77F at 1:04PM. Duration of day was approximately 11.35 hrs. Minimum Ambient temperature was $65 F$ at 6:04AM. Minimum Solar Space temperature was 68F at 2:45AM. System was in Ground Loop assist mode to Heat Pump for approximately 28.22 hrs. Duration of night was 12.65 hrs.

$$
5 / 20 / 83-5 / 21 / 83
$$

Again this date provides typical data for the system in the direct cooling mode. Relative bumidity increased from the normal 
$50 \%-60 \%$ to approximately $70 \%$ during this run. Minimum inside temperature occured at 00:27AM at 75F. Maximum inside temperature occurred at 4:56PM at 80F. Ambient temperature peaked at 4:09PM at 84F. Minimum ambient temperature occurred at 3:38AM at 69F. The ground temperature started at approximately $68 F$ and increased $3 F$ over a 10.07 hour runtime. 


\section{CORCLUSIORS}

Based on the test data reported herein, the following observations are made:

1) The ground loop used in this system only assisted the beat pump in the heating/cooling mode when the computer control Bystem determined that the cost of operation of the ground loop would be overcome. This constraint assured that the loop would be utilized only in a cost effective manner. The analyzed system provided approximately $33 \%$ of the air required by the outside coil of the heat pump. Due to ingufficient volume, a temperature differential of loc (18F) was required for cost effective operation during the heat pumpassist mode. The conditions required for operation of the system in the heat pump heating assist mode therefore occured only when the ambient temperature approached freezing. Bad the volume supplied been $100 \%$ of demand, a required temperature differential of $3 \mathrm{C}$ ( $5.4 \mathrm{~F})$ would have been adequate for cost effective operation during the heat pumpassist mode. Thesystem has not yet been observed to assist the heat pump in the cooling mode. The lack of operation of the beat pump cooling assist mode is attributed to the large temperature differential required by the insufficient air volumes and the high efficiency of the heat pump in the cooling mode. The primary temperature variations noted in the ground loop were caused by anual variation in ground temperature and were only temporarily influenced by airflow through the loop.

2) The ground 100p supplied approximately $50 \%$ of the required CFM for the inside circulation system of the structure. 
Since the volume of air supplied to the structure was inadequate, the loop did not always meet the cooling load of the structure even though the temperature conditions were optimum Additionaly, during some days of operation of the direct cooling mode, the relative bumidity has been observed torise from the normal of approximately $55 \%$ to as high as $70 \%$.

3) The syotem of ducts contained within the heated space of the Trombe wall system performed as expected and can be designed to effectively control temperature owings within the living space. The estimated optimal thickness for a Trombe wall in a system of this type is 6". The control system for heating MODEO (direct oolar beating) and heating MODEl (direct solar heating with heat pump heating) could be implemented utilizing a two stage thermostat assuming the thermosiat had a temperature sensor for the first stage. This type of design would eliminate the need for a micro-computer control system for these modes. The presence of metal in the solar space allowed quick heatup once sunlight had access to the solar space and would have provided earlier morning heat were it not for shading.

4) Computerized control of HVAC systems for light commercial and residential structures is now feasible using standard off the shelf hardware such as the TIMEX. SINCLAIR $2 \times 81$, COMMODORE VIC 20, or other low cost micro-computers in conjunction with standard or custom A/D and D/A interfaces. Although the hardware used in this project was of custom designand construction, today this system could be implemented using standard interfaces. Systems of this type will allow both sophisticated optimizing control and cost effective design to be easily achieved. 


\section{RBCOHMBNDATIONS}

Based on the analysis of data berein and the experience of the authors in the design of this system, several design recommendations are given:

Ground loops which supplyair to a closedsystem should be sized to provide $100 \%$ of the rated CFM supplied by the heat pump system. This volume of air will be requiredif the loop is to meet all loads on the structure, when temperature conditions call for utilization. In a cooling mode, a closed loop powered system will provide at least two additional benefits. First, a lower temperature inside returnair will usualy be supplied to the loop inlet. This reduced temperature can be significant in hot summer months. Second, potential humidity problems would be eliminated. Although bumidity has not been a problem on this project, high humidity air (relative humidity of $70 \%$ or more) delivered to the interior of the structure bas presented marginally comfortable conditions on some days during the direct cooling mode. The normal summertime relative bumidity values utilizing only the heat pump run $50 \%$ to $60 \%$.

Open ground loops which supply air to the exterior coils of a heat pump or which cool a structure by convection and conduction through the exterior walls should be designed in such a way that the flow through the loop is induced by passivemeans, if possible. A powered ground loop can assist a standard Air-toAir heat pump syotem in cost effective manner if the winter season typically experiences many days with the ambient temperature near freezing. A powered ground loop could be cost effective at a temperature differential of approximately $3 \mathrm{C}$ 
(5.4F) assuming $100 \%$ of air flow is provided.

It is felt that a better design would use a closed 100 p return air system utilizing a basement wall or sub-floor slab as the thermal mass with power being derived from the circulation fan of the structures BVAC system. A separate open ground loop should also be utilized to assist the outside coil of the heat pump withairflow being induced by the vacumereated by the fan on the outside unit. Another form of outside cooling only loop could utilize passive airflow aound the internal shell of a hollow wall structure.

specific recomendations for the design of an outside. 100 p includes the use of a loop cross-sectional area equal to or greater than the outside coil area, for heat pumpasistance. For the loop reported herein, and at the airflow reported, a length of $90^{\circ}$ instead of $120^{\circ}$ could have been utilized. It is suggested that if the loop is wapped around the structure that a separation distance of at least $6^{\circ}$ be utilized to insure minimum impact on the ground temperature profile surrounding the structure. For inside loops, the maximum available surface area should be utilized to minimize temporary variations in loop temperature. Additionally, in both loop designs, frictional losses should be considered more important than heat transfer charastics of the materials involved.

A 12" Irombe wall is an effective tool for moderating excessive peak temperatures. For a design wherehigh residual temperatures would contribute to a longer carry over into the night, an optimal thickness of approximately 6" should be used. 
A Trombe wall system should be designed s a separate gystem with no interaction with ground loops. A two stage thermostat in conjunction with duct and dampers enclosed in a solar space can be a cost effective way of controlling temperature swings and eliminating distribution problems normally asociated witha totally passive Trombe wall systems. Insystems wheresupply ducts are designed inside the Trombe wall environment, analysis should consider potential convective loops. 


\section{ACKMORLRDGEMEATS}

The authors wish to express their thanks to the south Carolina Solar Energy Group, for assistance during the design and implementation of this project. Also, thanks is given to Dr. H. R. McMillan of the University of South Carolina, College of Engineering, for his assistance and support during this project.

Special thank and appreciation are given to the United States Department of Energy for funding and assistance during this research project.

Special thanks are also given to Wilbur Smith and Associates for assistance during the preparation of this report. 


\section{REFERERCRS}

ROMBBR

1

2

3

4
IITLE

Solar Energy Thermal Processes

by J. A. Duffie and W. A. Beckman

John Wiley \& Sons, 1974

Solar Beating Design By The f-Chart Method by W. A. Beckman, S. A. Rlein, J.A. Duffie John Wiley \& Sons, 1977

Technical Notes On Brick Construction. Set 43A-43B, Passive Solar Heating With Brick Masonry

by Brick Institute of America, 1979

The Passive Solar Energy Book

Expanded Professional Edition

by Edward Mazria

Rodale Pres8, 1979

M-80 Single Board Microcomputer Instruction Manual

Miller Technology, 1980

Application Data Split-System Beat Pump

Champion Indoor Evap-Blower

Form 515. 21-AD2 coded 979

York Division Borg-Warner 


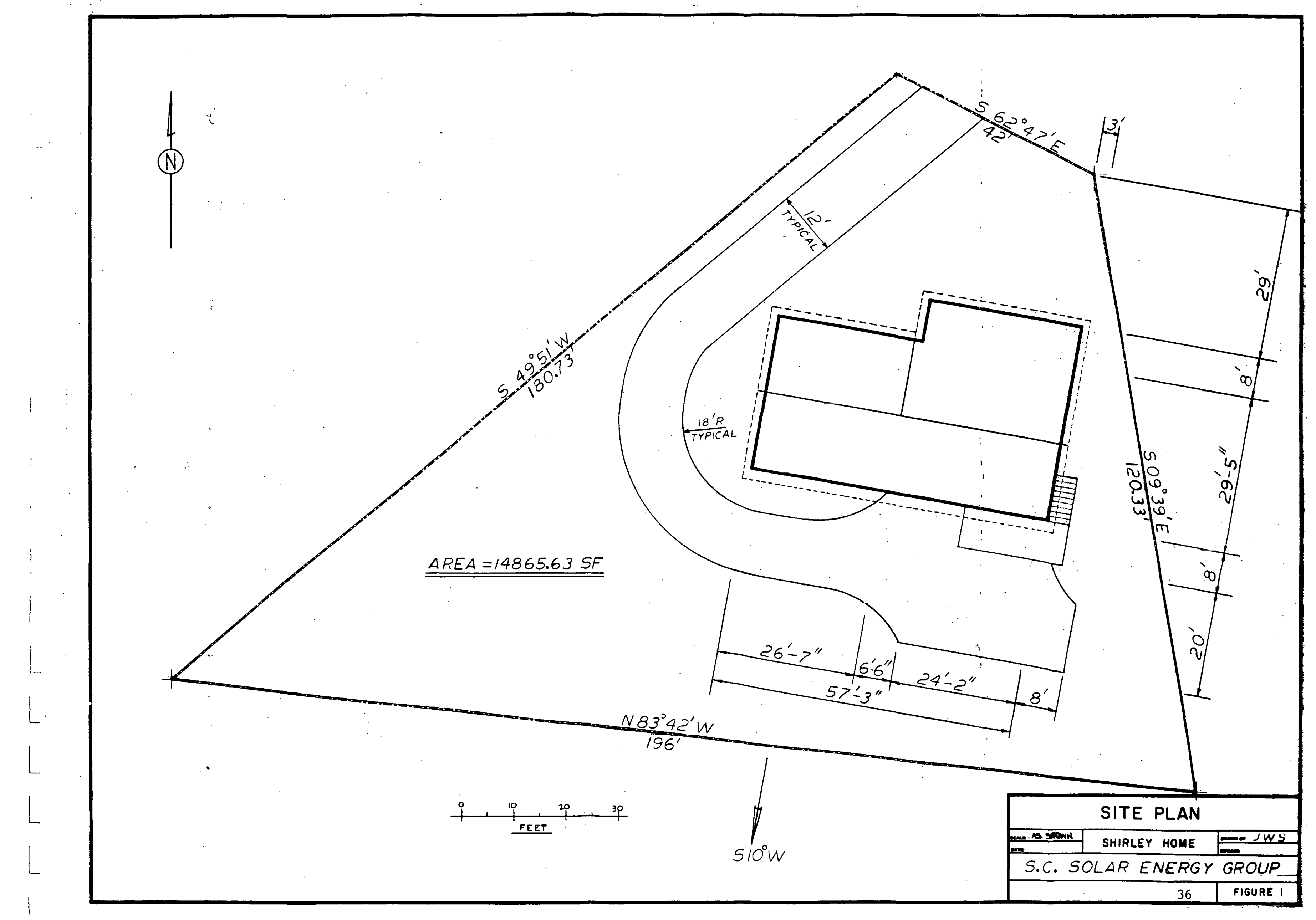




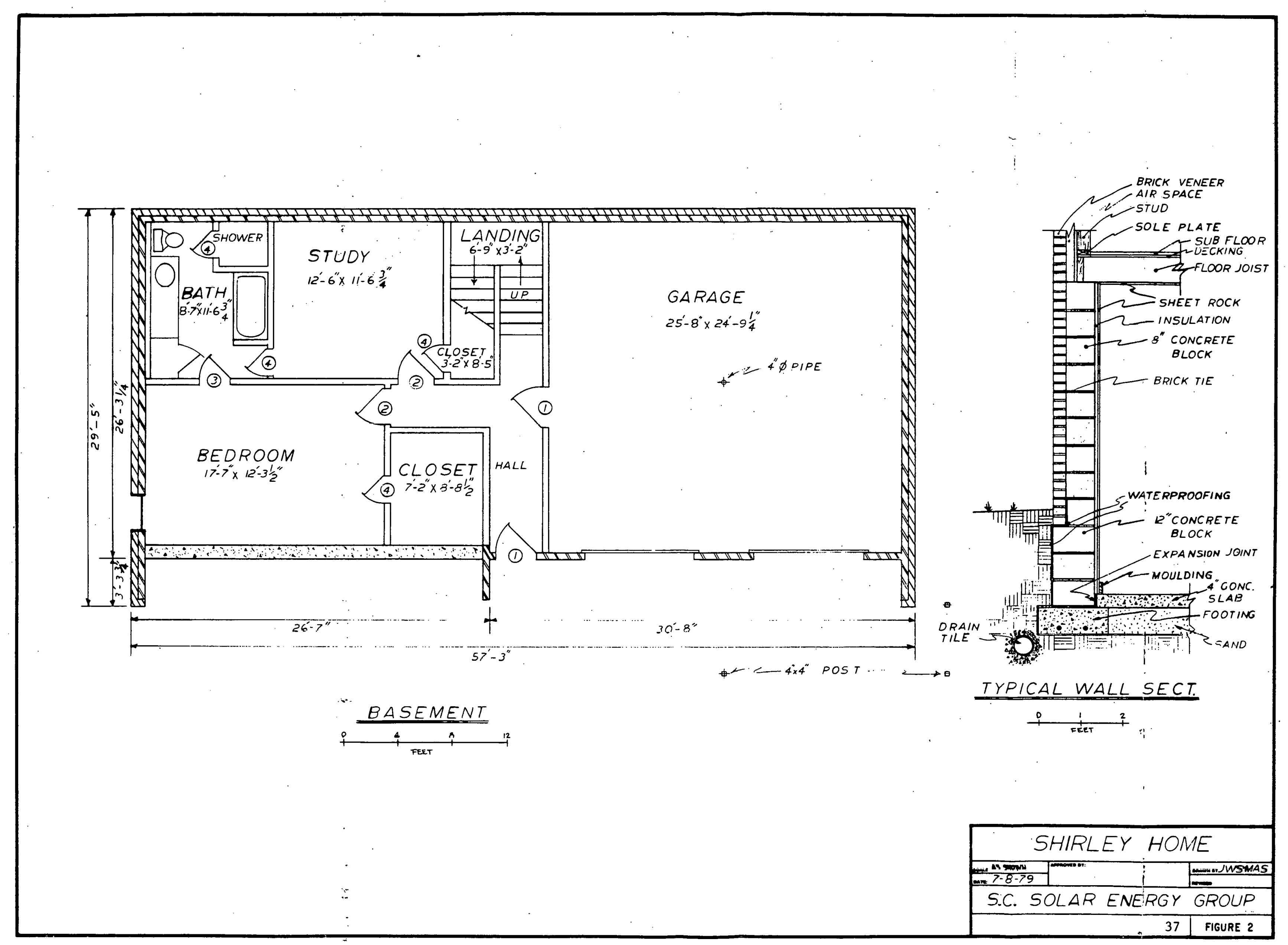




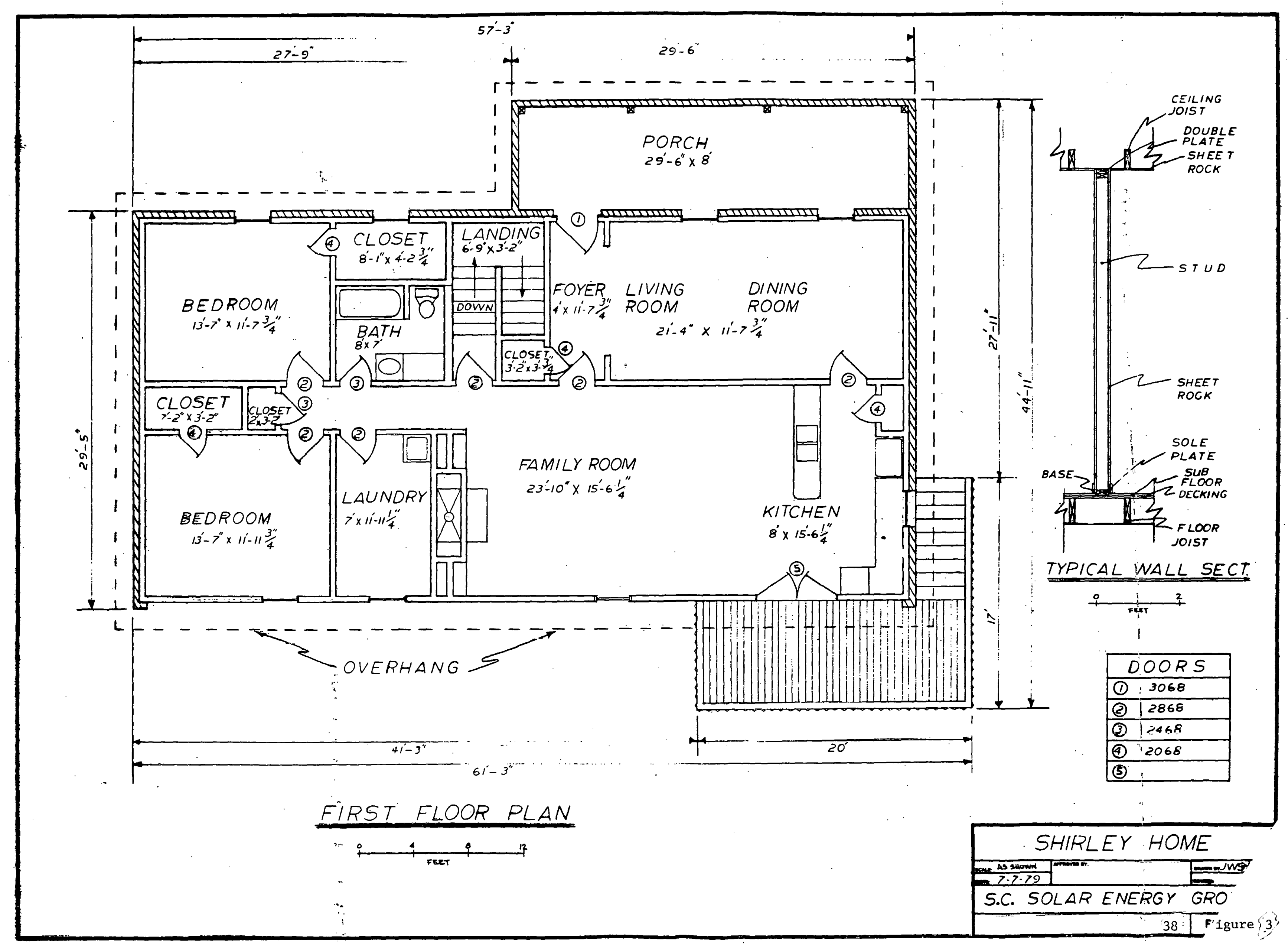




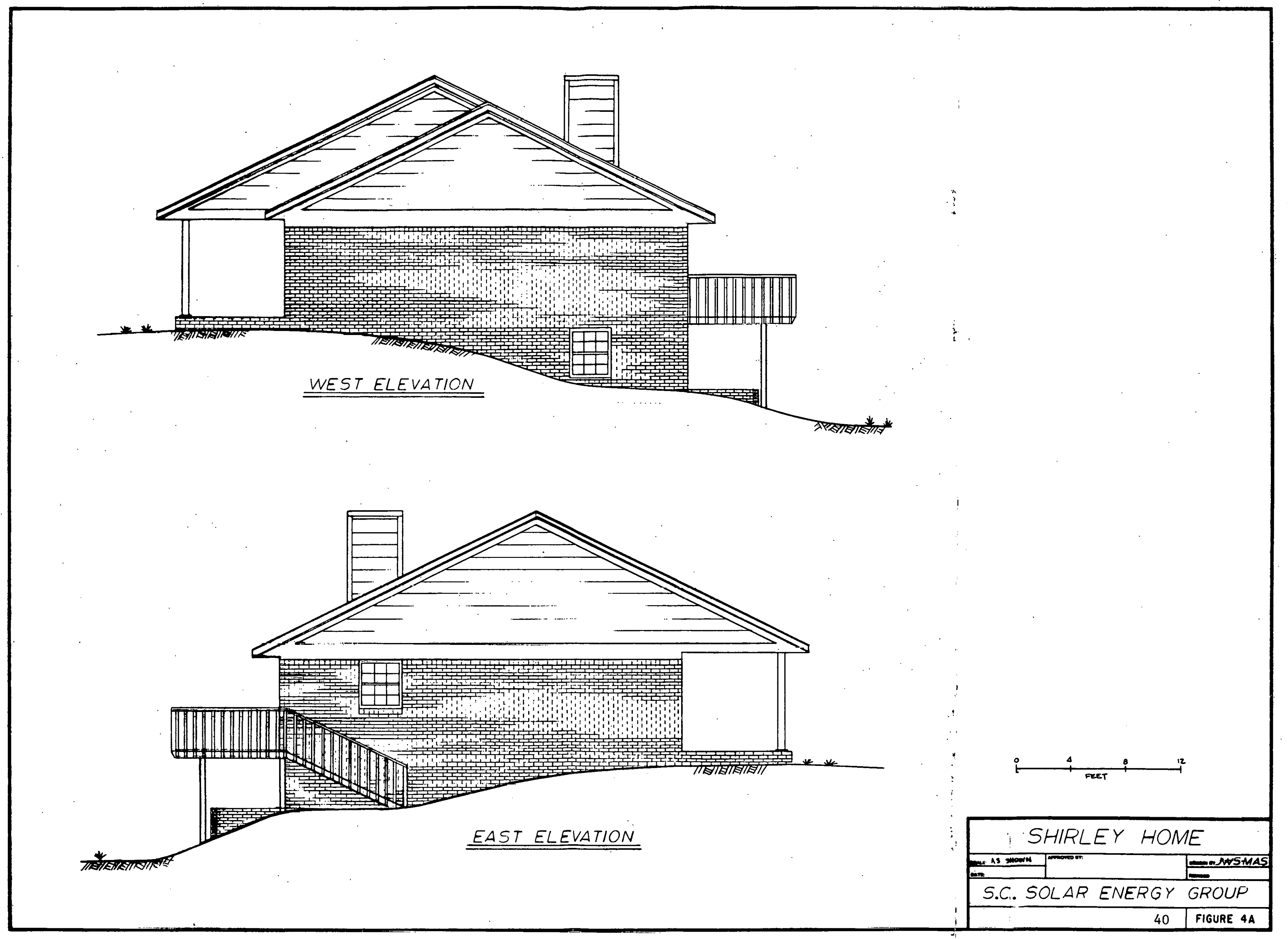



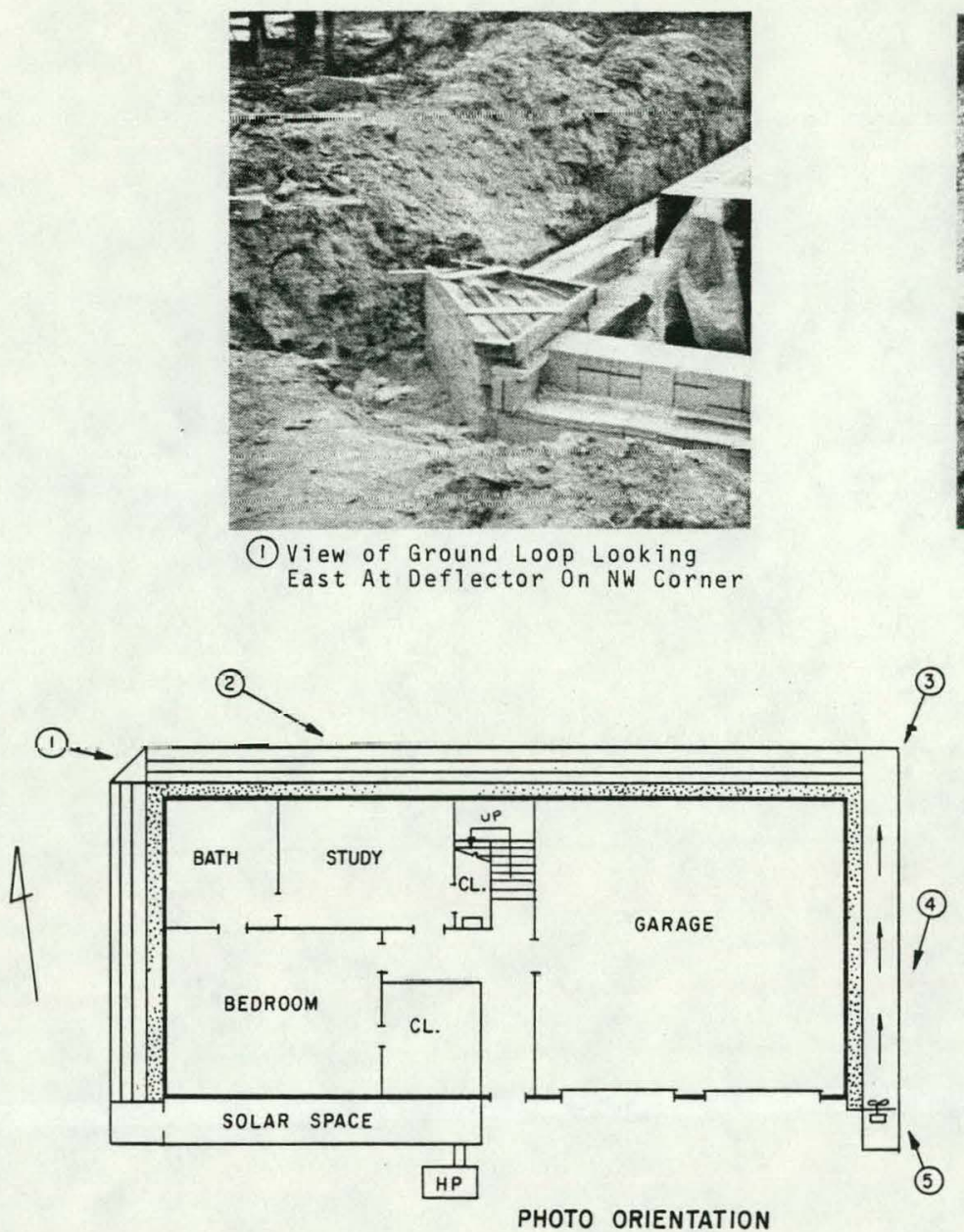

PHOTO ORIENTATION

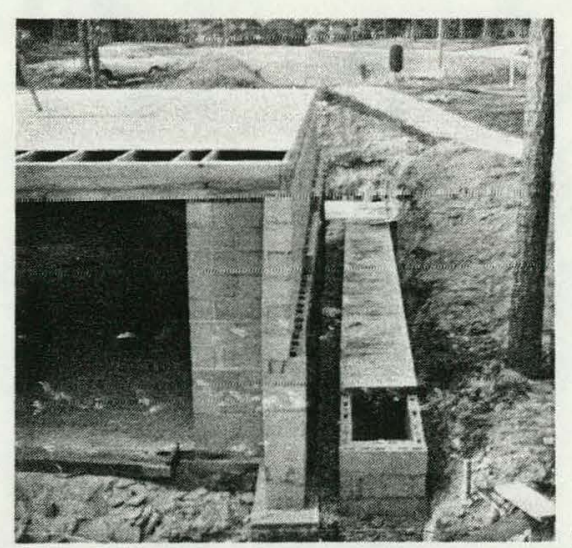

(5) Ground Loop Looking North

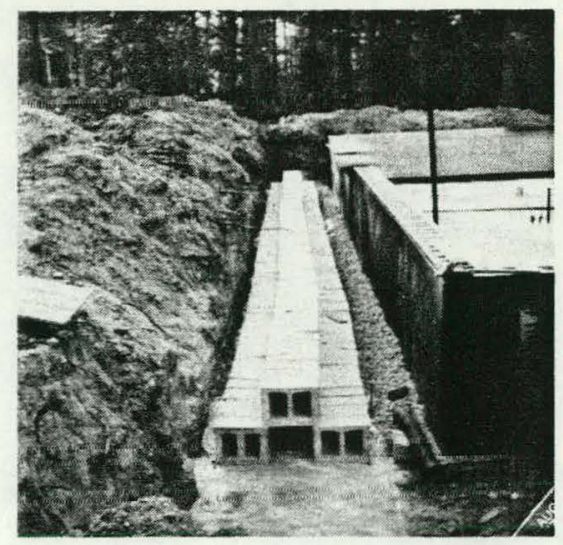
(2) View of Ground Loop On
North Side Looking East
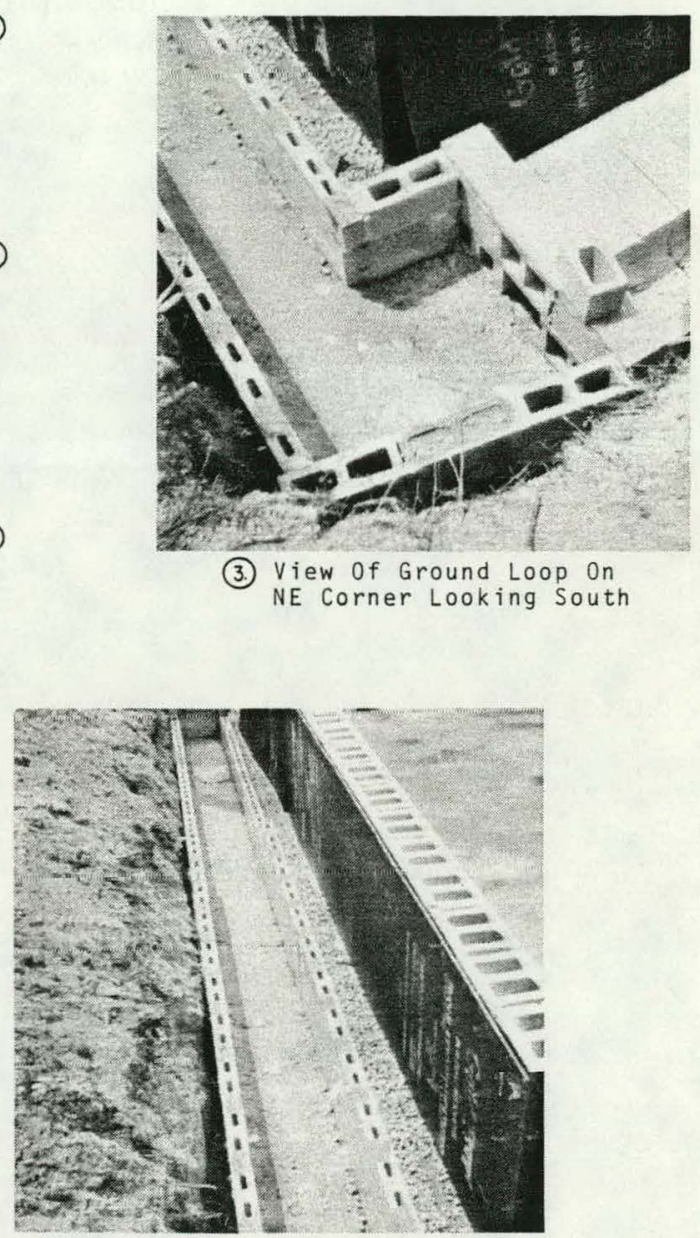

(4) Ground Loop Looking South

GROUND LOOP AND DETAILS 


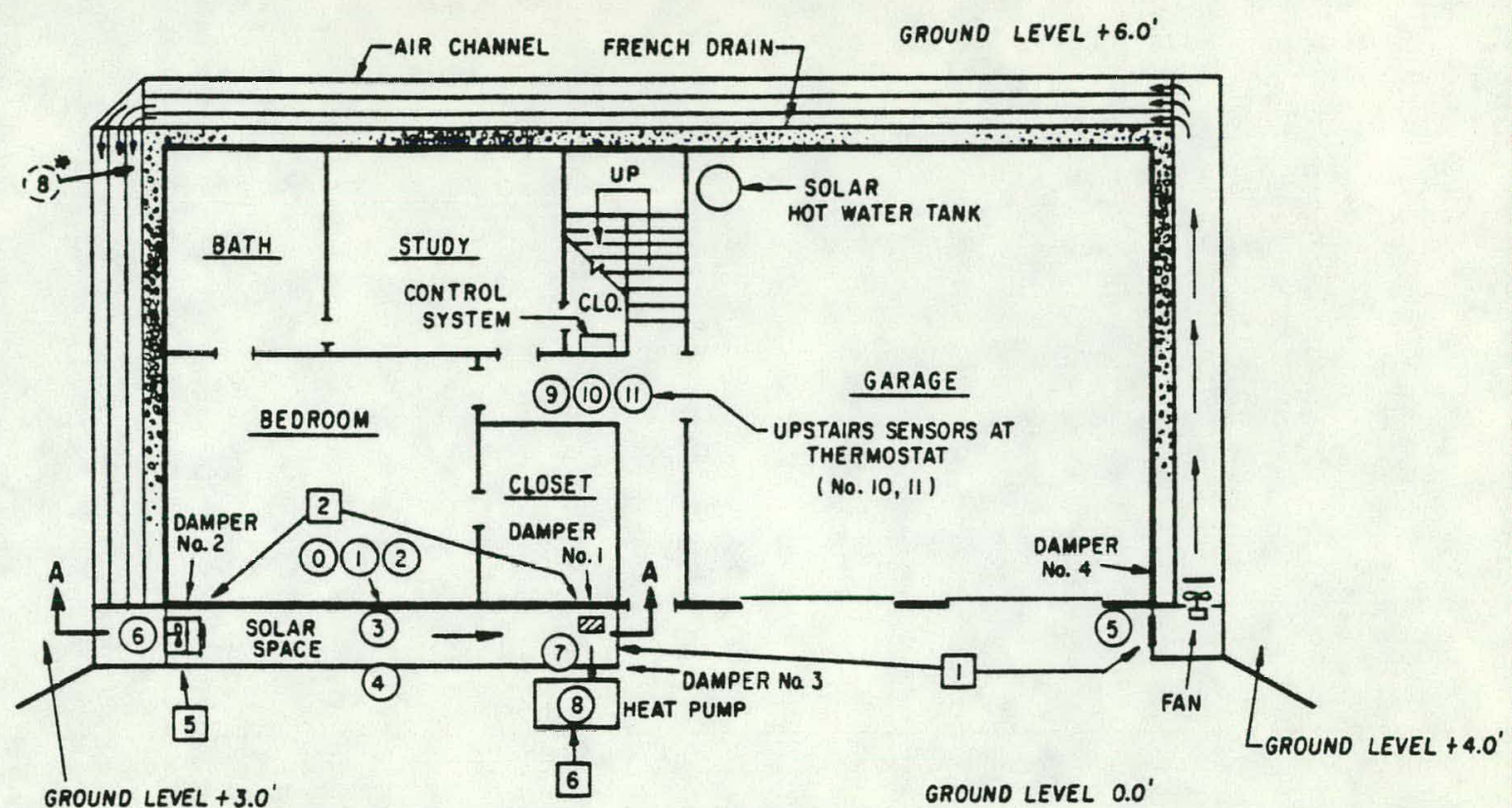

BASEMENT FLOOR PLAN

\section{O INPUT}

NN. DESCRIPTION

0-Solar Wall Surfoce Temperature@ 3' Height

1 - Solor Wall 4" Depth Temperature @ 3' Height

2 - Solar Wall 8" Depth Temperature@ 3' Height

3 - Photo-Resistor Sunlight Sensor@4' Height

4 - Solar Space Temperature @ 5' Height

5 - Ambient Temperature (Loop Inlet)@2' Height

6 - Loop Outlet \& Solar Space Inlet Temperature @I' Height

7 - Solar Space Outlet Temperature To Heot Pump@ I' Height

8 - HP Coil Air Temperature (Actual Mixed Inlet Temperature / Ground Temp. After January 1983)

9 -Inside Temperature @8' Height (Return Air)

10 - Thermostat Mode (Heating Or Cooling)

II - Thermostat State (On Or off)

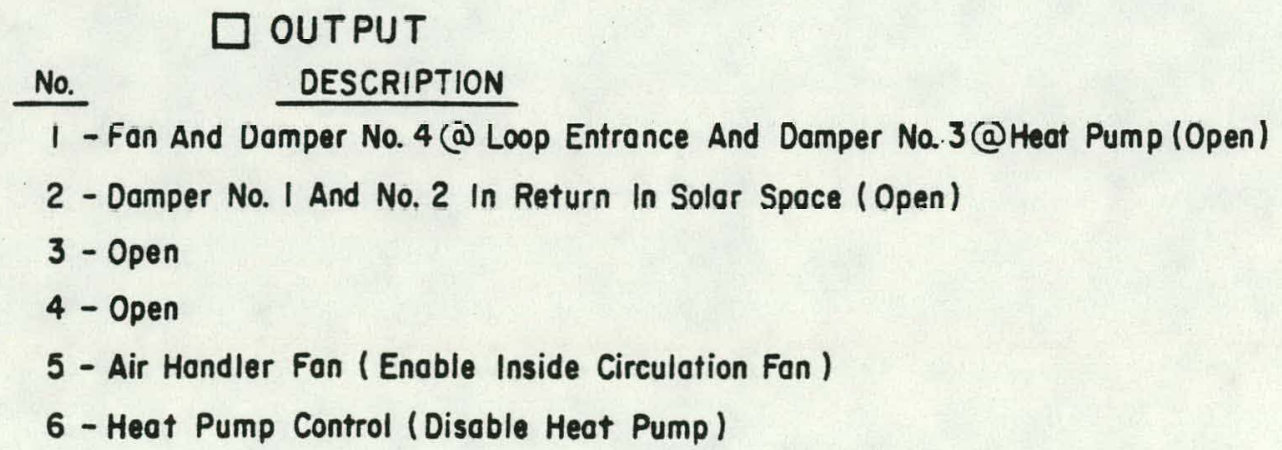

CONTROL SYSTEM 


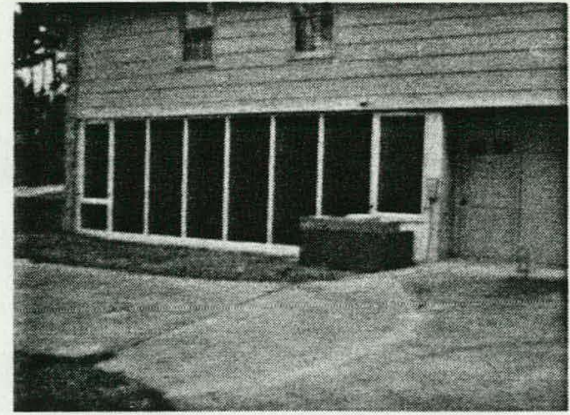
(1) Exterior View Showing Solar
Space and Heat Pump

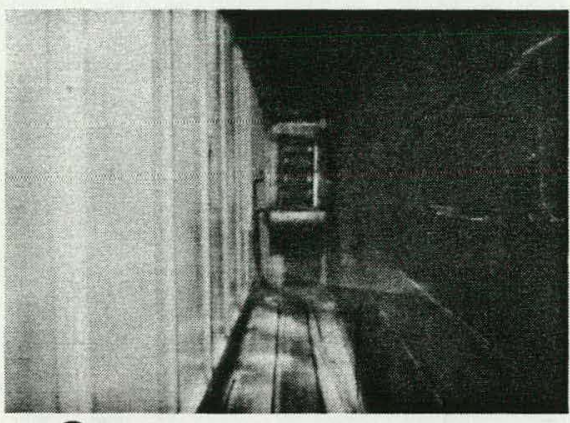

(3) Interior View of Solar Space Looking West - Shows Damper (No. 2) At Air Handler

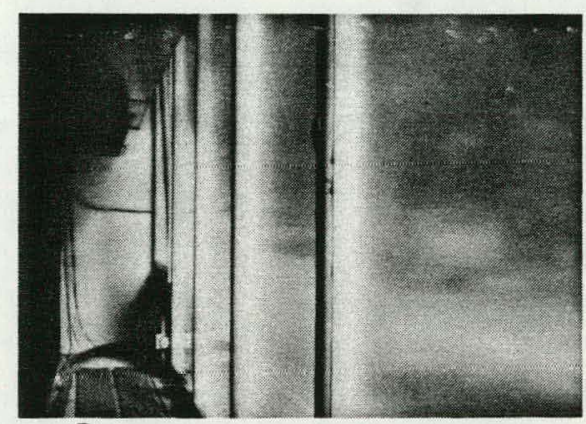

(4) Interior View of Solar Space Showing Outlet To Heat

Pump And Sensors

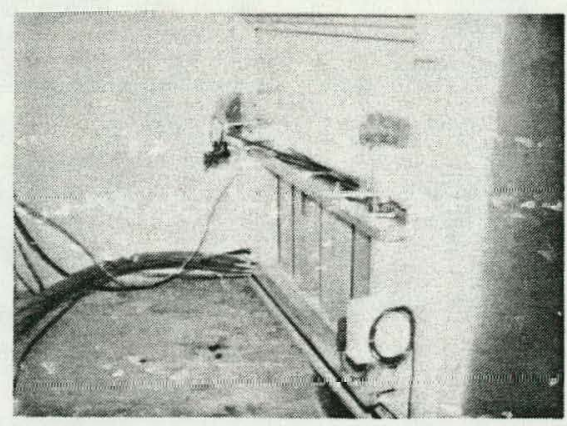

(5) Interior View of Solar Space Showing Outlet To Heat Pump. Damper (No.3) And Outlet Sensor (No.7)

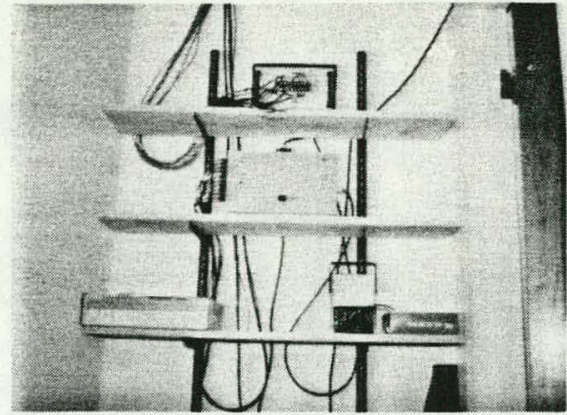

(2) View of Control system

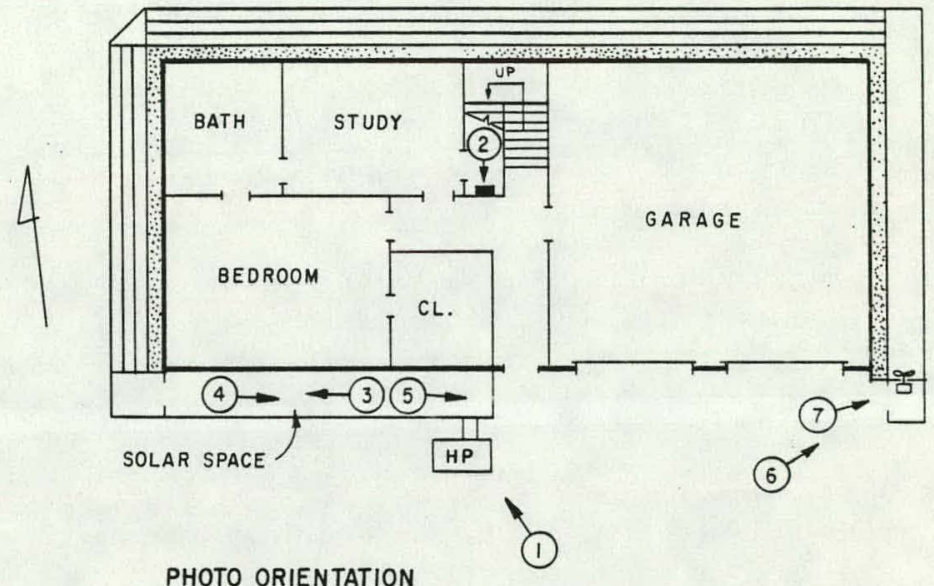

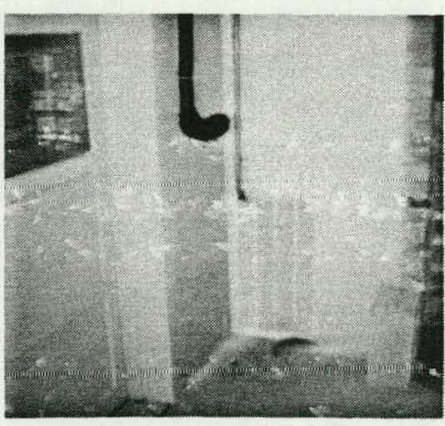

(6) View of Ground Loop Air Inlet

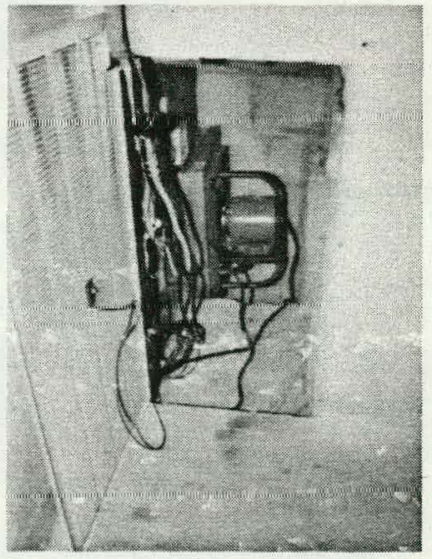

(7) View of Air Inlet, Fan And Ambient Temperature Sensor (No. 5)

\section{CONTROL SYSTEM DETAILS}




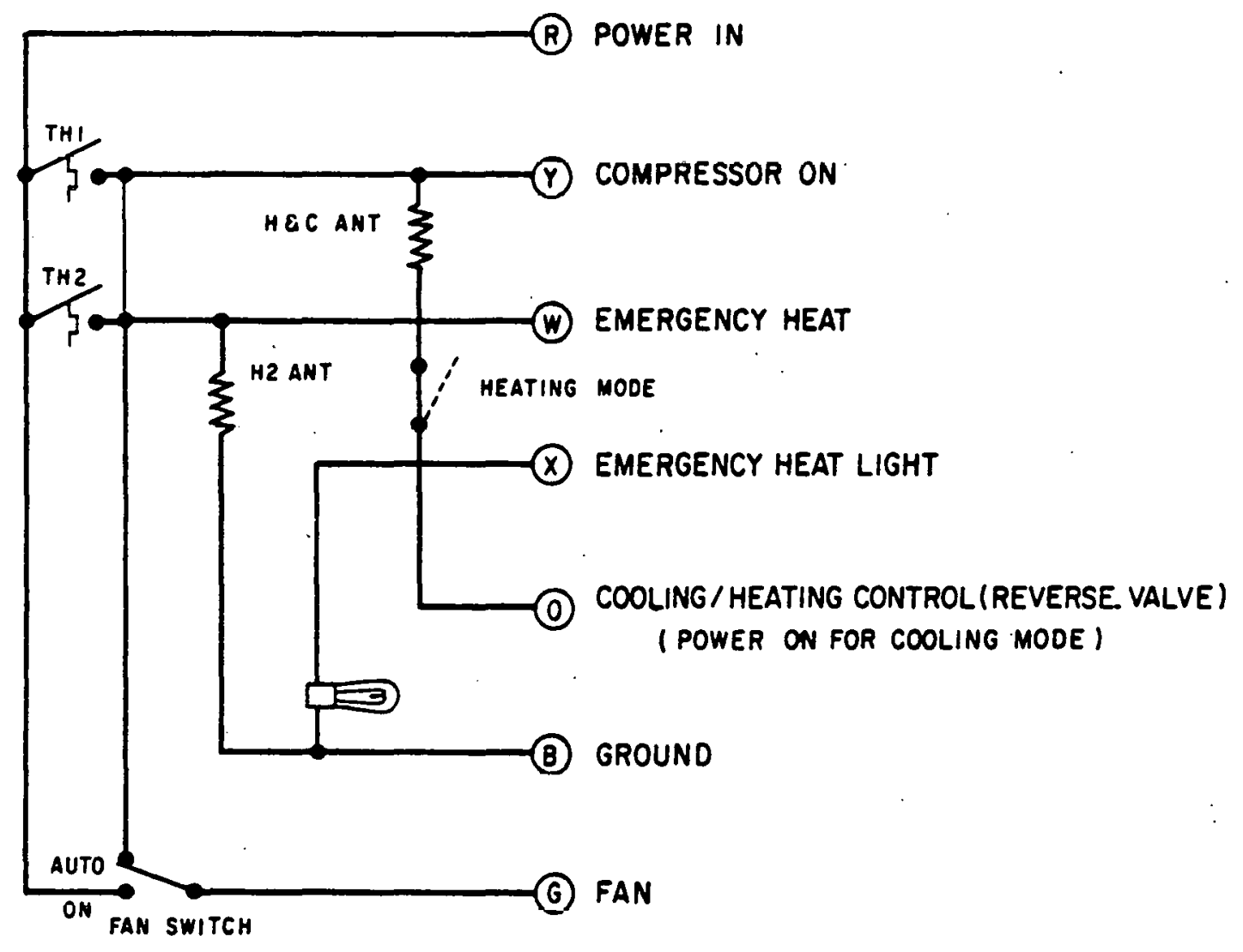

TH I - I st STAGE THERMOSTAT

TH 2 - 2nd STAGE THERMOSTAT

\section{THERMOSTAT SCHEMATIC}




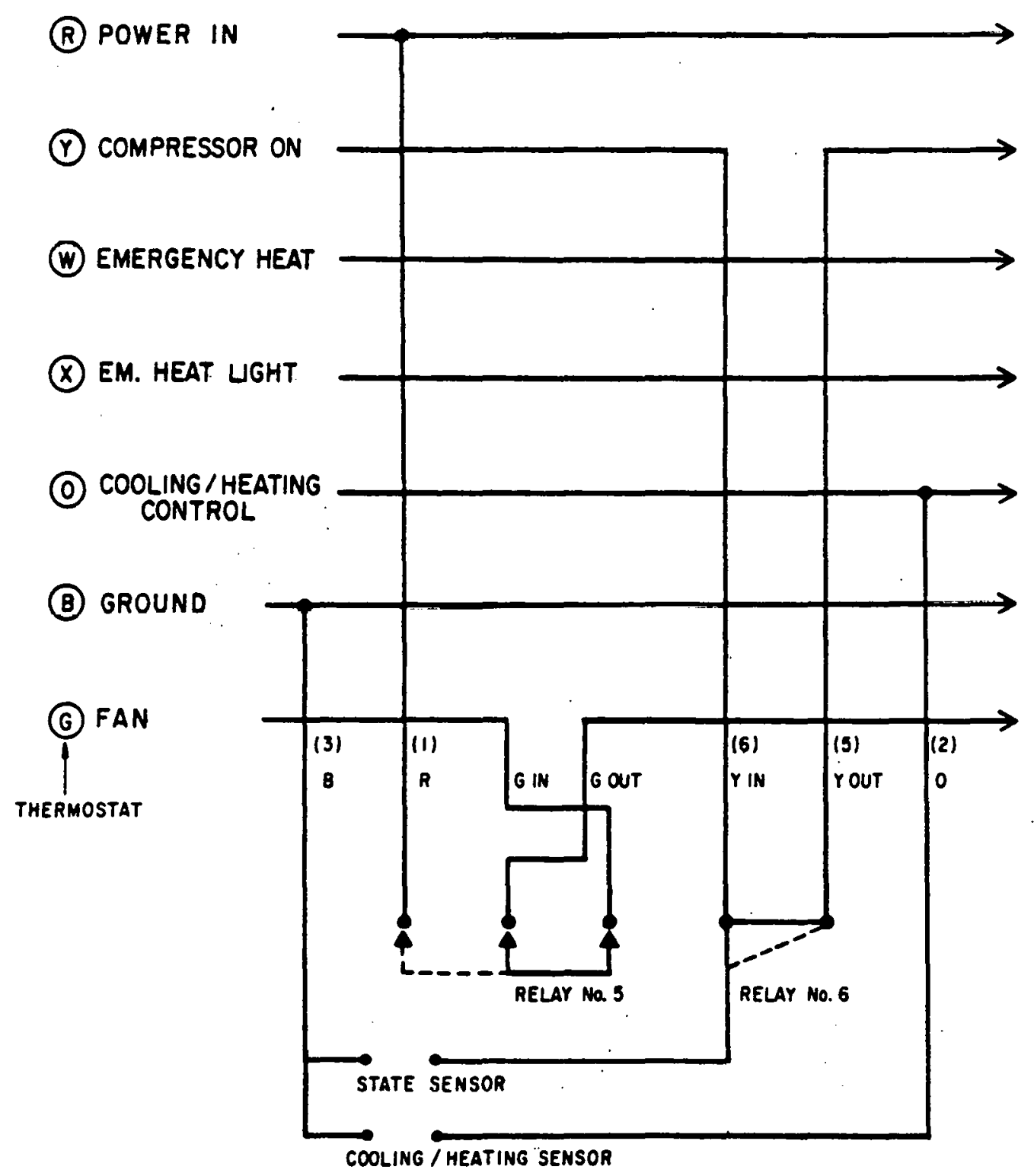

\section{THERMOSTAT INTERFACE}




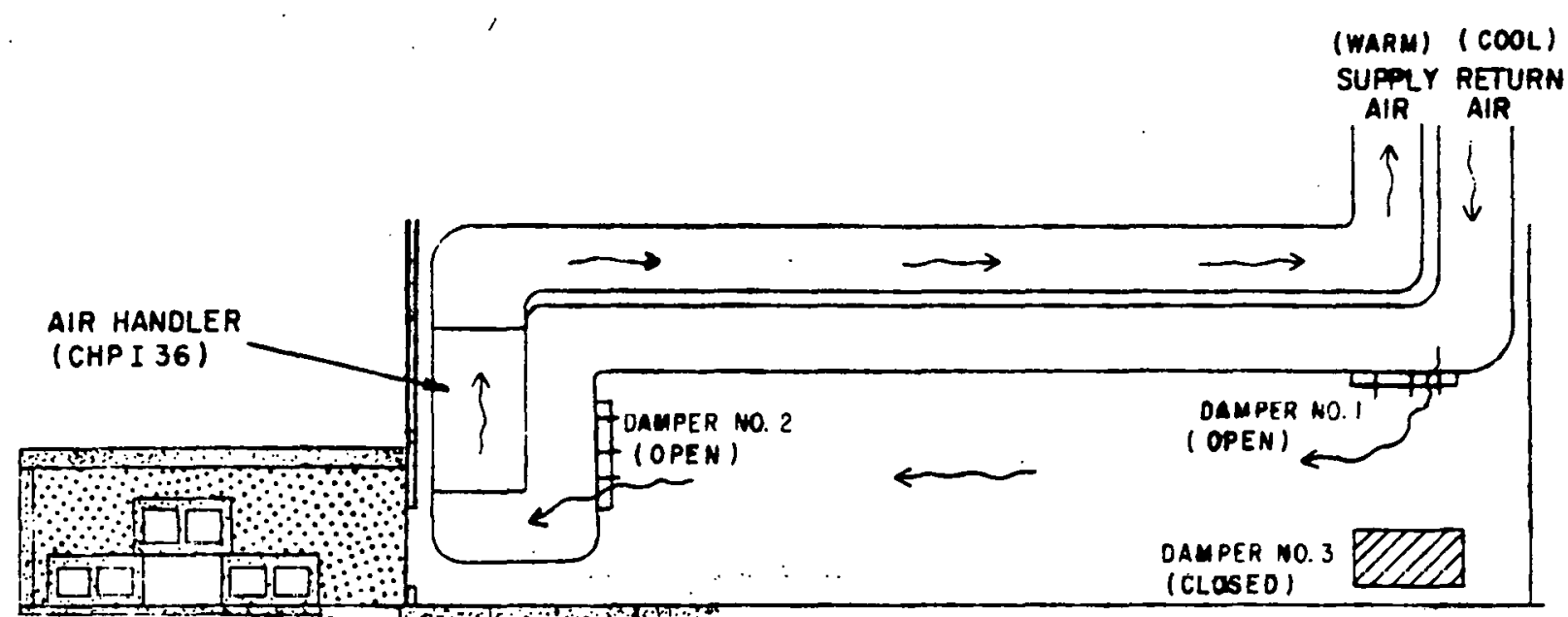

ELEVATION

(SECTION A-A, SEE FIG, 6)

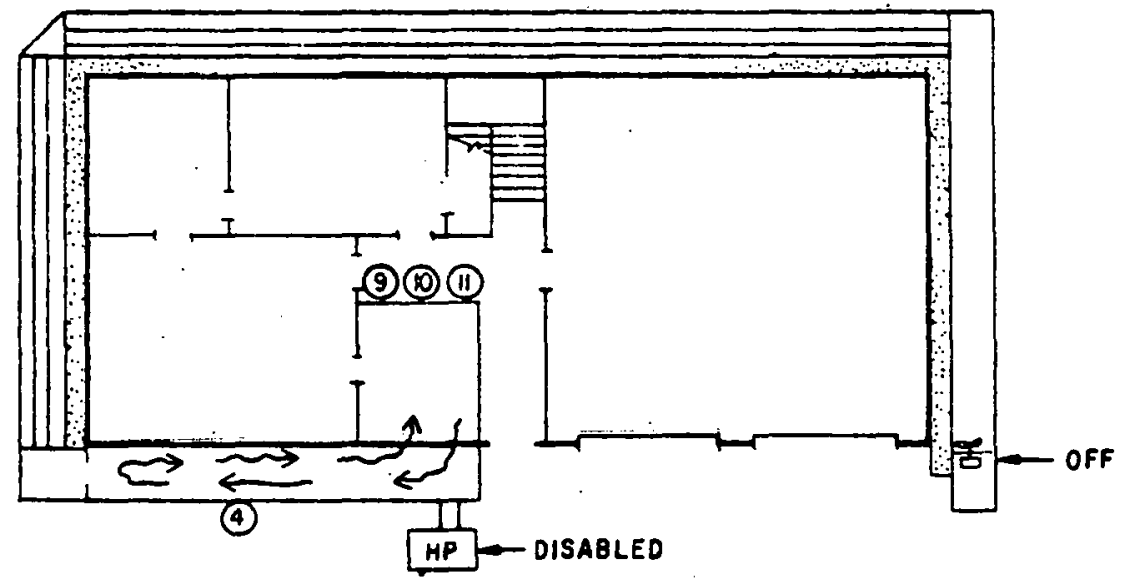

PLAN

\section{HEATING RETURN AIR \\ USING ONLY SOLAR SPACE}

(MODE O) 


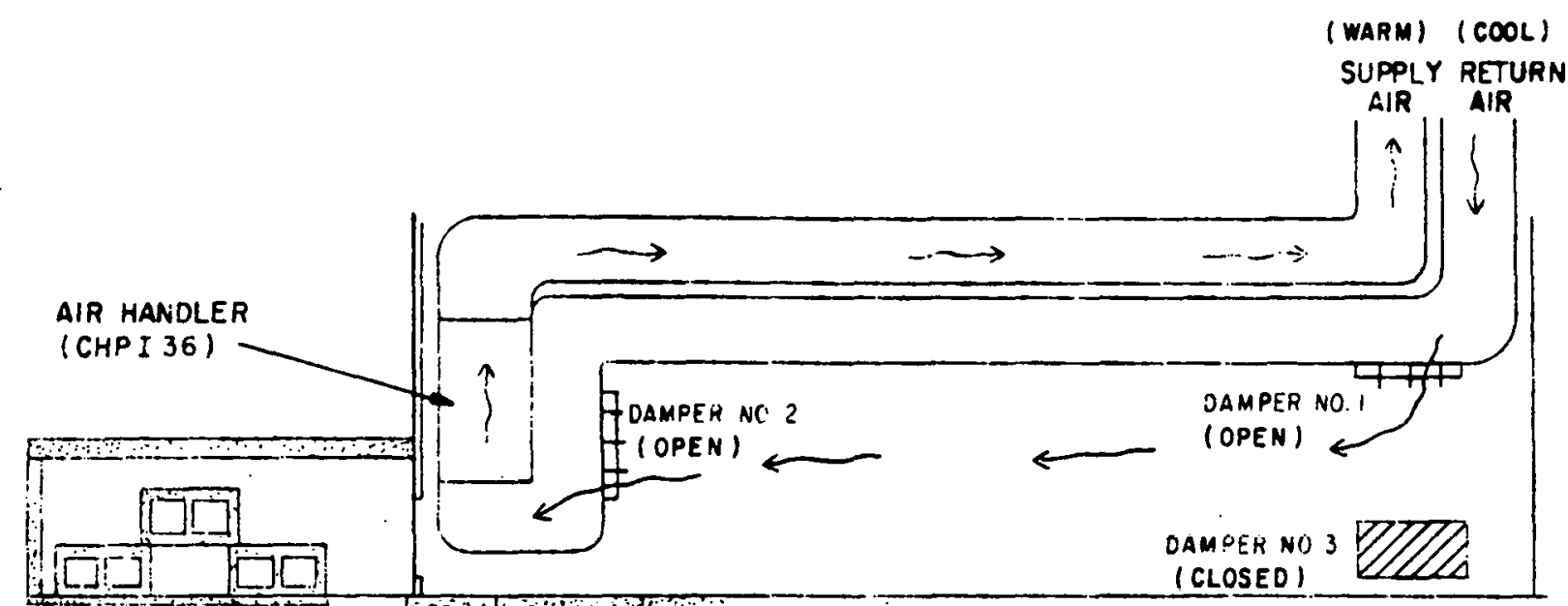

$\therefore 40$

ELEVATION

(SECTION A-A, SEE FIG.6)

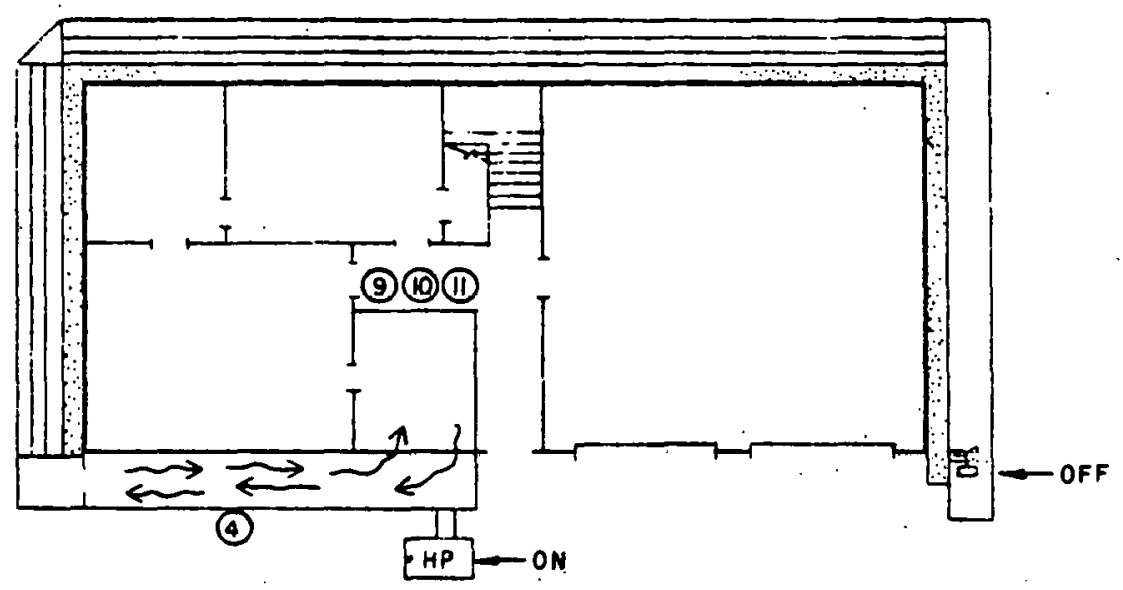

PLAN

HEATING RETURN AIR
USING SOLAR SPACE AND HEAT PUMP

(MODE I) 


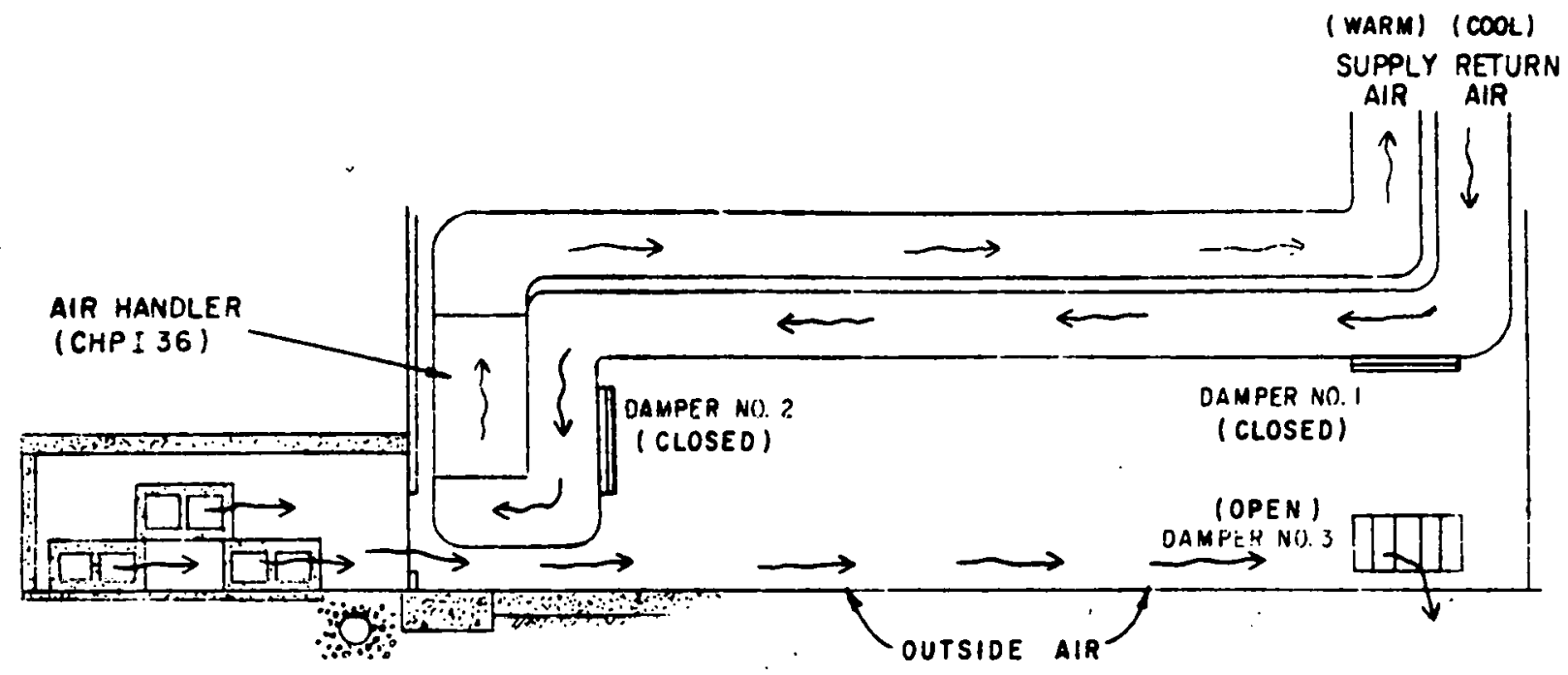

ELEVATION

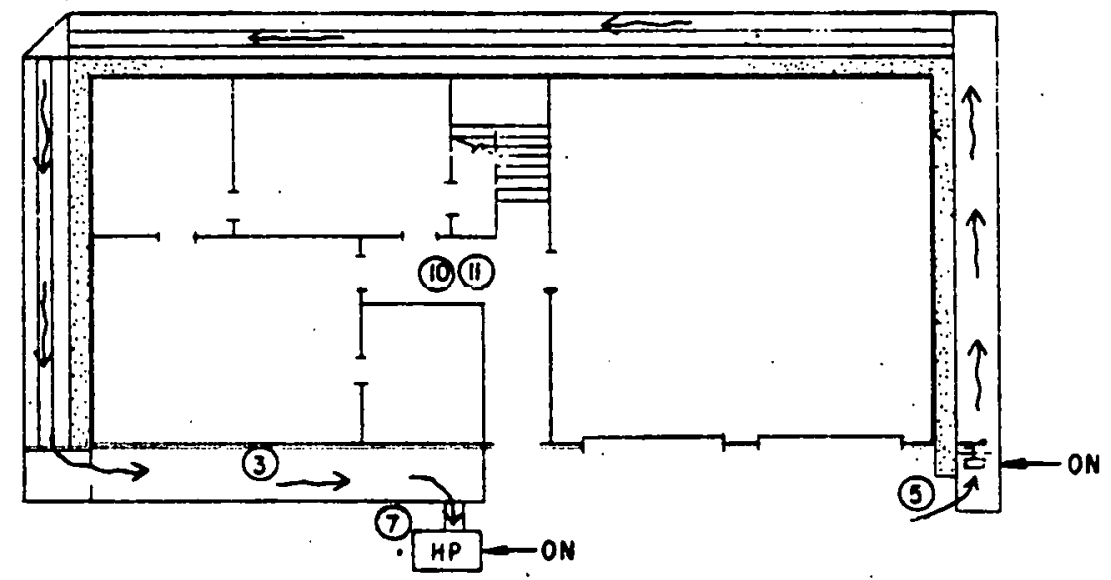

PLAN

\section{HEATING RETURN AIR USING HEAT PUMP AND GROUND LOOP ASSIST \\ ( MODE 2)}




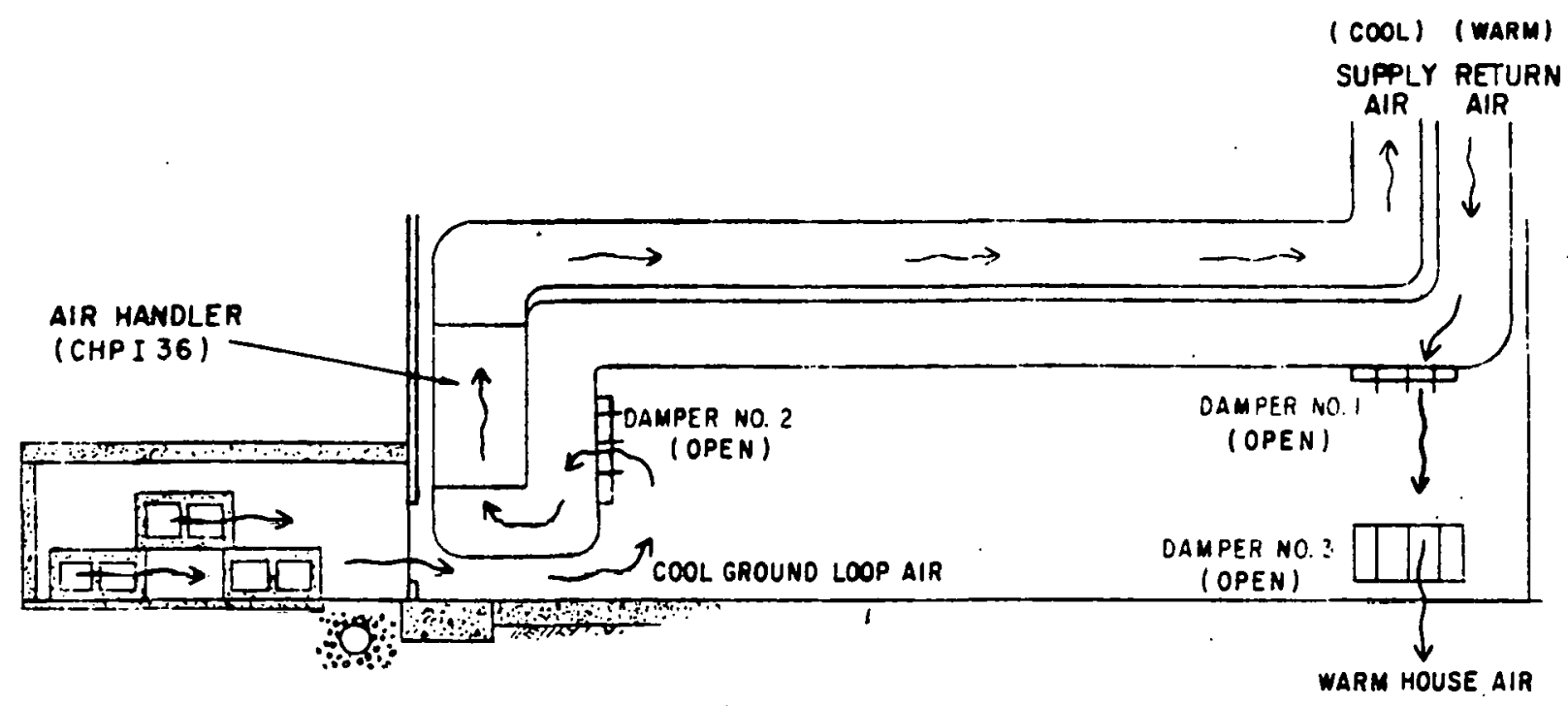

ELEVATION

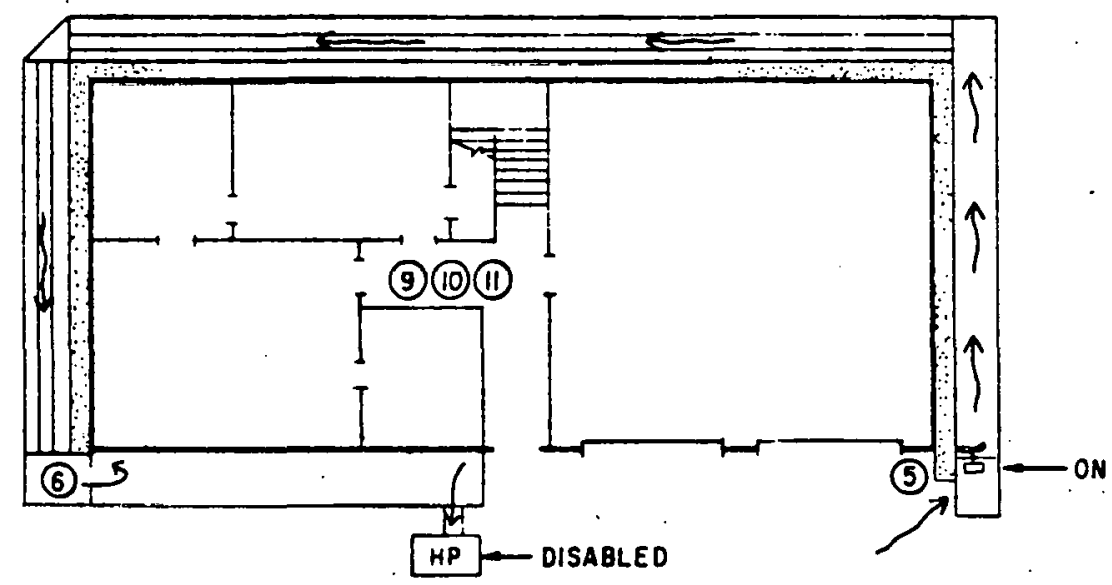

PLAN

\section{COOLING USING OUTSIDE AIR THROUGH GROUND LOOP AND EXHAUSTING RETURN AIR}

(MODE 4) 


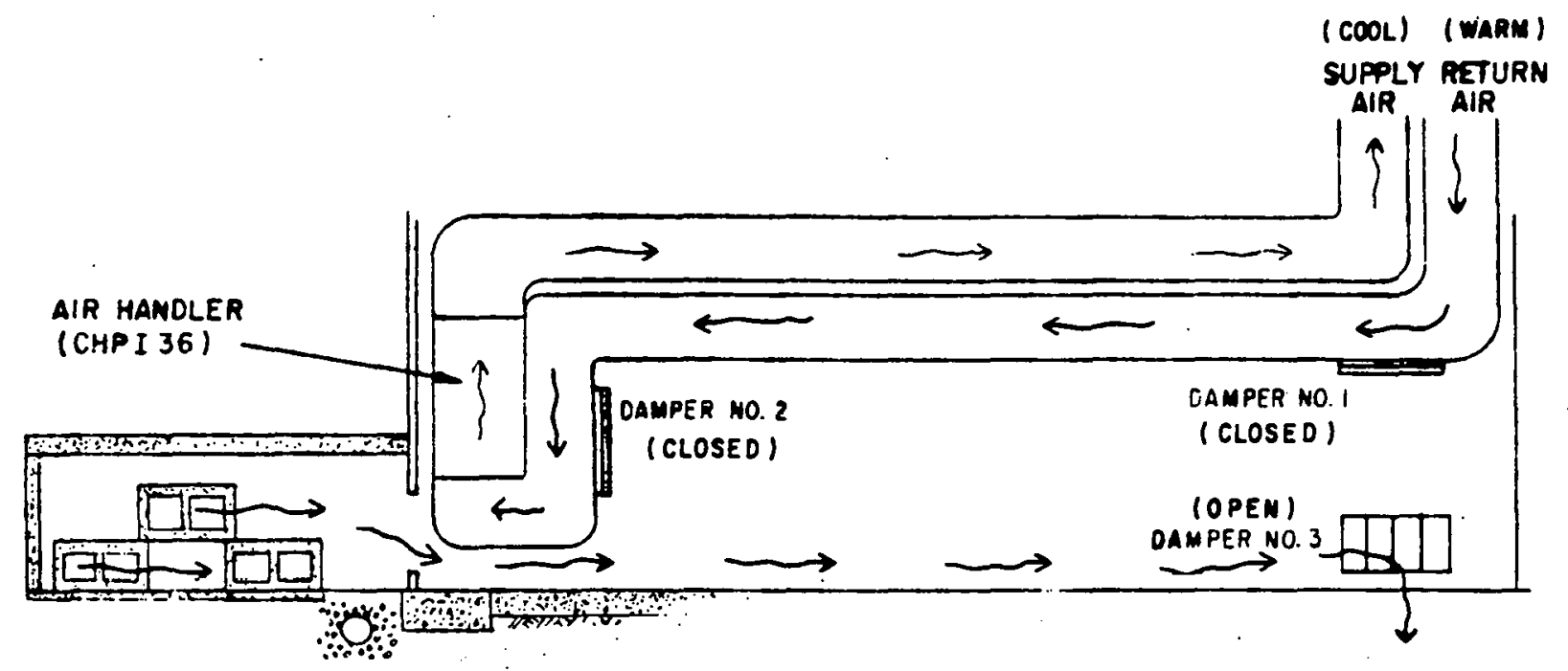

ELEVATION

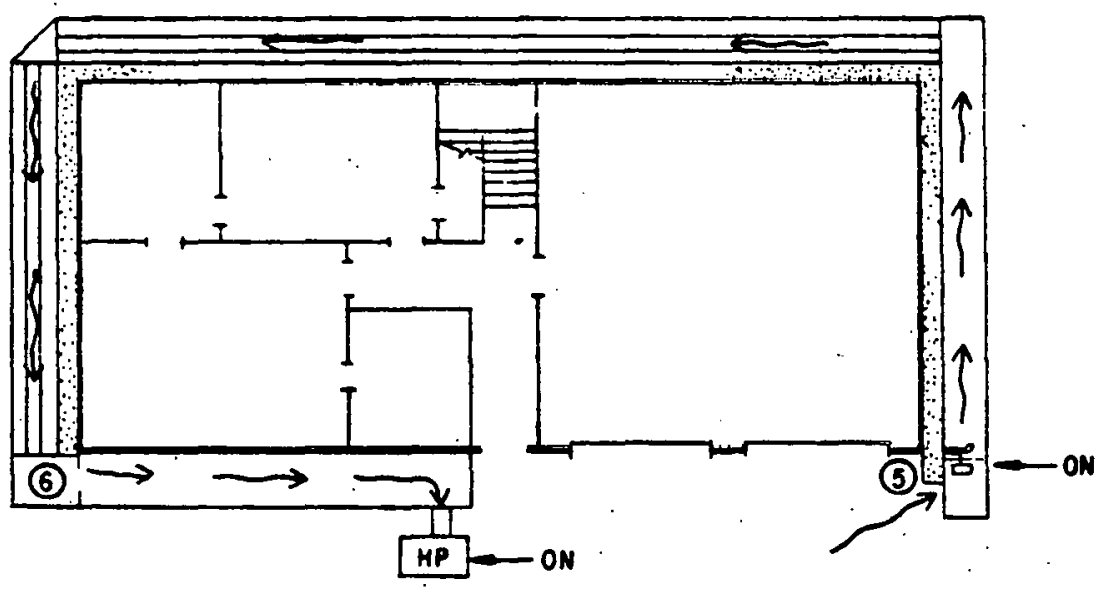

PLAN

\section{COOLING RETURN AIR \\ USING HEAT PUMP AND GROUND LOOP ASSIST \\ (MODE 5.)}




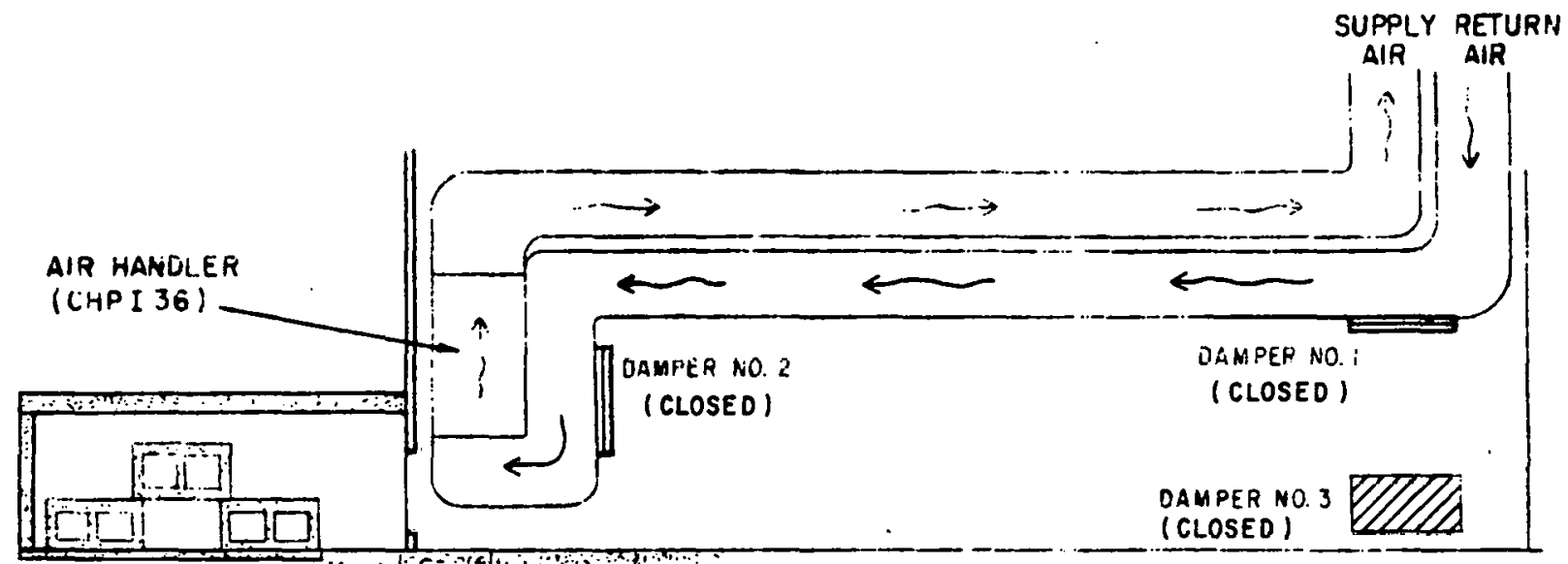

in

ELEVATION

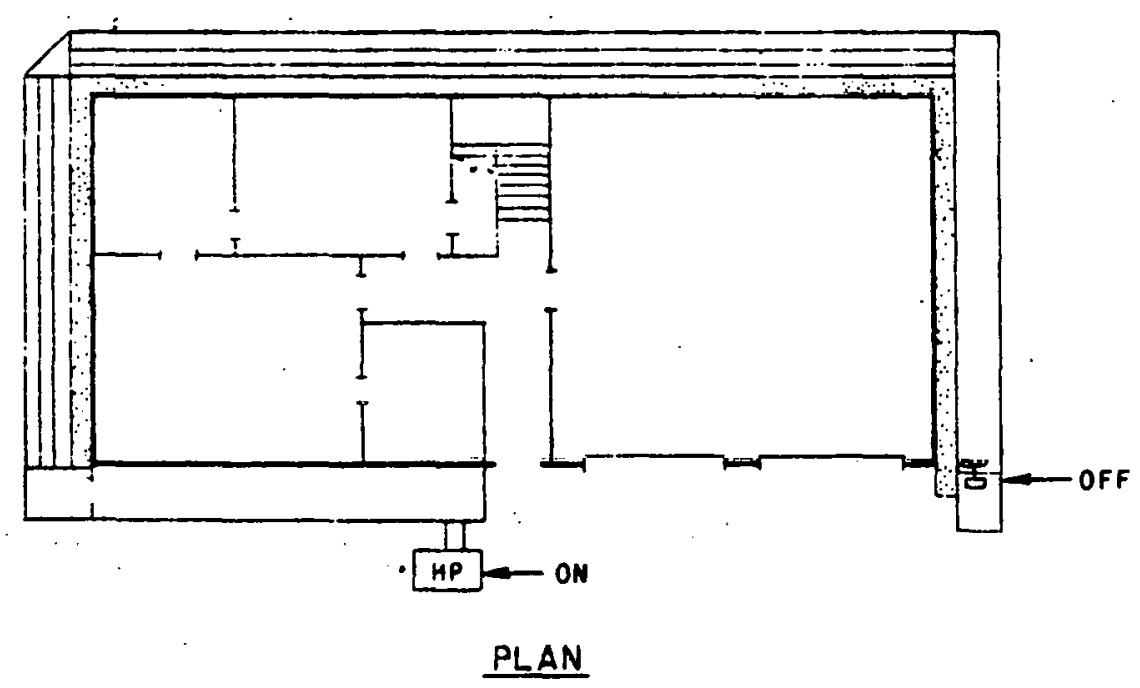

HEATING / COOLING RETURN AIR

USING HEAT PUMP ONLY

( MODE 7 ) 


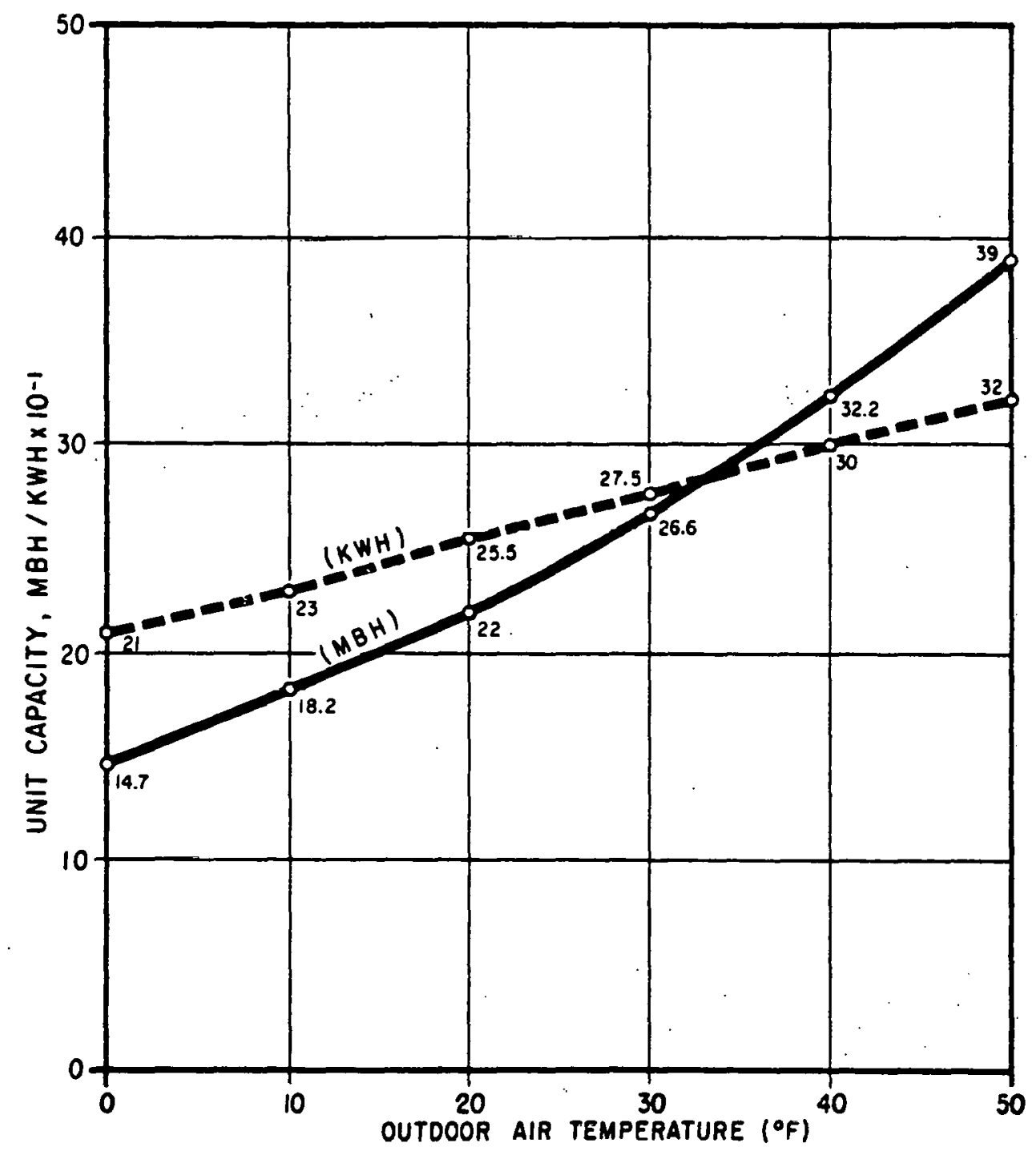

HEAT PUMP DATA

HEATING PERFORMANCE DATA

(YORK CHPO36 / CHPI 36 ) 


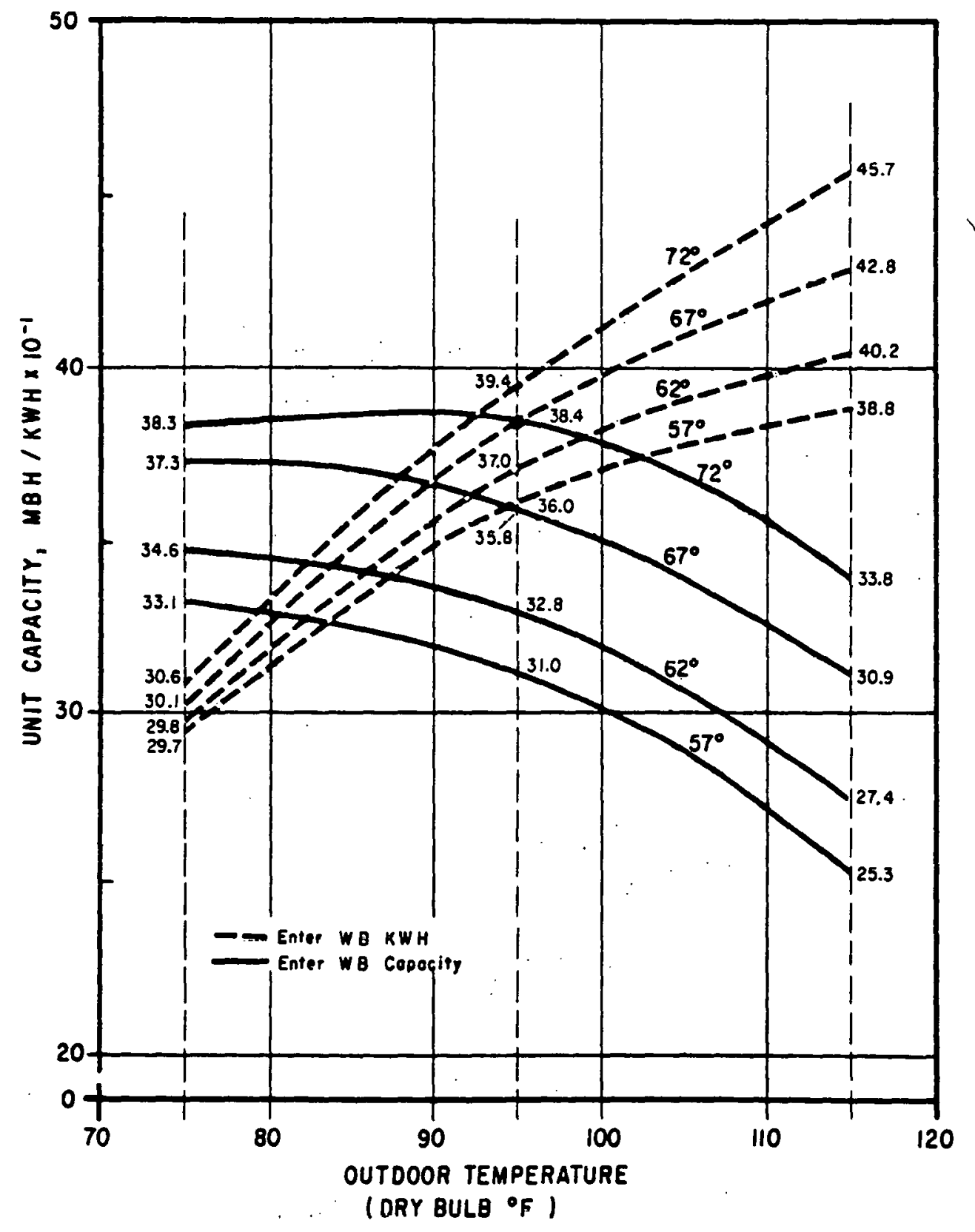

HEAT PUMP DATA

COOLING PERFORMANCE DATA

(YORK CHPO36 / CHPI 36)

FIGURE ISA 
AP PERDIX

ITEM

PAGE

DOWNLOAD assembly language communications program ... 58

SYSTEM assembly language control program ......... 65

RECORD PL/l language data acquisition program ....... 91

PLAYBACR PIll language data display program ........ 98

PLOT PL/1 language graphics plot program ........... 100

List of Recorded Data ....................... 104

Data Plots ......................................... 105

54 


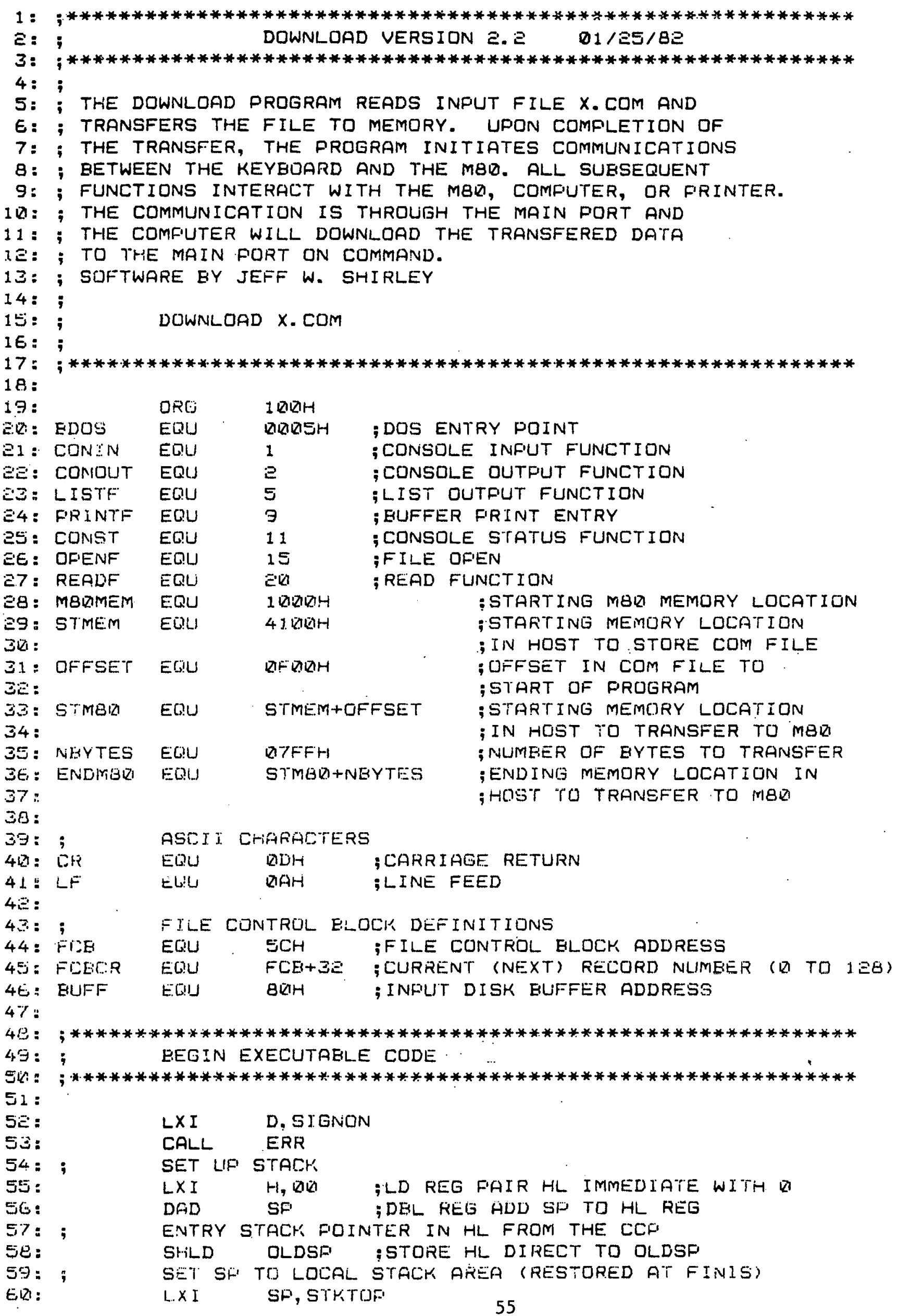




\begin{tabular}{|c|c|c|}
\hline 61: & ; & READ AND PRINT SUCCESSIVE BUFFERS \\
\hline E2: & & SETUF ;SET UF INPUT FILE \\
\hline 63: & & ;ESE IF FILE NOT PRESENT \\
\hline E4: & & ;SKIP IF OPEN IS OK \\
\hline 65: & ; & \\
\hline $\begin{array}{l}6 E: \\
67:\end{array}$ & ; & $\begin{array}{l}\text { FILE NOT THERE, GIVE ERROR MESSAGE AND RETURN } \\
\text { LXI } \quad \text { D, OPNMSG }\end{array}$ \\
\hline$E 8=$ & & ERR \\
\hline ES: & & ; TO RETURN \\
\hline $70:$ & & \\
\hline $71:$ & OFENOK: & ;OPEN OFERATION OK, SET BUFFER INDEX TO END \\
\hline 7:2: & & $A, 1 \geq 8$ \\
\hline $73:$ & & ; SET BUFFER FOINTER TO $1 E \bar{B}$ \\
\hline 74: & ; & INITIALIZE STARTING MEMORY TRANSFER LOCATIUN \\
\hline 75 : & & LXI H, STMEM \\
\hline $7 \in:$ & & MEMLUC \\
\hline $77:$ & & \\
\hline 78: & MAINLOOF & \\
\hline $79:$ & ; & CHECK FOR BREAK KIEY \\
\hline $8 Q 1$ & & CALL CONINE ; CHECK CONSOLE STATUS \\
\hline 81: & ; & $A=$ DFFH CHARACTER READY, $A=$ DUH ND CHARACTER READY \\
\hline $8 E:$ & ; & ACCUM LAST BIT $=1$ IF CHARACTER READY \\
\hline 8ङ: & & ; ROTATE ACCUM RIGHT, INTO CARRY \\
\hline $\begin{array}{l}\text { 84: } \\
\text { 85: }\end{array}$ & & ; TERMINATE FILE TO MEMORY TRANSFER \\
\hline $8 E:$ & & ; RETURNS CHARACTER IN ACCUM \\
\hline $87:$ & & ;CARRY SET EY GNB IF END FILE \\
\hline 88: & & \\
\hline $89:$ & ; & TRANSFER EYTE TO MEMORYY \\
\hline $90:$ & & CALL STOREBYTE \\
\hline $\begin{array}{l}91: \\
9 \Xi:\end{array}$ & & MAINLOOF' \\
\hline $\begin{array}{l}9 \pm: \\
93:\end{array}$ & FINIS: & :BEGIN MER COMMUNICATIONS \\
\hline $94:$ & 1N13: & 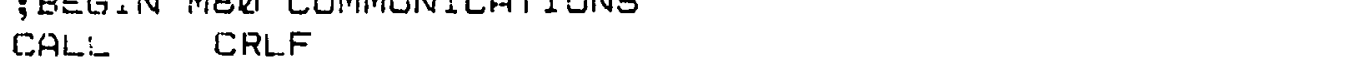 \\
\hline $95:$ & & LXI $\quad$ D, SIGNONE: \\
\hline$\exists \in:$ & & CALL \\
\hline $97:$ & & $D$, SIGNDNS \\
\hline $98:$ & & CALLL \\
\hline $99:$ & & D, SIGNONít \\
\hline 1вй: & & EFR \\
\hline $1011:$ & & CAI.LL \\
\hline $1.00:$ & & $A, R^{\prime}$ \\
\hline $103=$ & & ; RESET MBQ \\
\hline 1014: & & \\
\hline $105:$ & MLOOF: & ; MBQ I/O LOOF \\
\hline 1DE: & & \\
\hline $10 \%:$ & ; & CHECK FOR KEYEUARD INFUT \\
\hline IRIO: & & ;DIRECT CONSOLE I/O \\
\hline $129=$ & & ; INFUT MODE \\
\hline $110:$ & & ;GET CONEOLE STATUS \\
\hline $111=$ & & ; ZERO IF NO INPUT \\
\hline $112:$ & & ;NO OUTFUT, CHECK FOR INFUT FROM FORT \\
\hline $113:$ & & \\
\hline $1.14:$ & ; & CONSOLE INFUT, CLEAR HIGH EIT \\
\hline 115: & & ;CLEAR HIGH BIT \\
\hline $11 \in:$ & ; & DUTHUT TO MAIN FOKT INFIIT FROM KEYEOARD \\
\hline $117:$ & & ; CHECK FUR CONTROLL D (DOWNLOAD) \\
\hline 118: & & ;CHECK \#E' \\
\hline $129:$ & & \\
\hline $1 \div 0$ & & ;DOWN-LOAD MEO \\
\hline
\end{tabular}




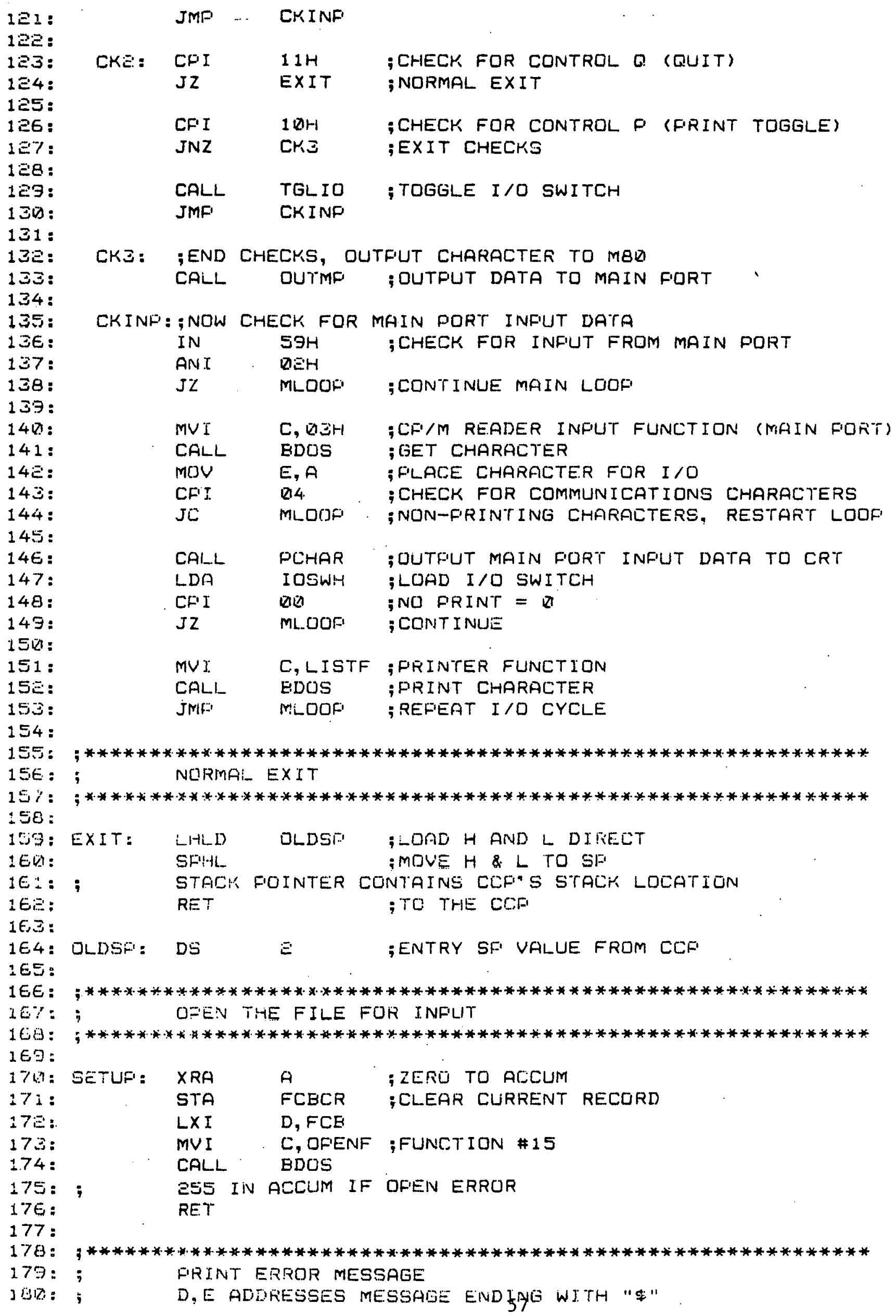


181:

18:

183

184:

185 :

$18 E:$

187:

188:

189:

190:

191 :

19e:

193:

194:

195:

19E:

197:

198:

199:

EVD:

201:

ZQRE:

2013:

ent:

205:

EQRE:

$207:$

टबह:

201:

210:

ट)1: ;

리르:

리:

E14:

E.15:

EIE:

러궁

218:

2.19:

Ean:

Ee1:

EE:

Eis:

204:

3:5:

ЕE:

2:7:

อยง:

르으:

E⿹勹冫

E⿰氵工⿺ :

2งอ:

$233=$

234 :

Eง5:

องE:

E.5:

238:

e3:

$246:$

ERR: $\quad$ MUI C, PRINTF; PRINT BUFFER, FUNCTION \# 9

CALL BDOS

RET

; *************************************************************

; GET NEXT BYTE

; $* * * * * * * * * * * * * * * * * * * * * * * * * * * * * * * * * * * * * * * * * * * * * * * * * * * * * * * * * * * *$

GNE: LDA IBF $\quad$;LDA WITH INFUT BUFFER POINTER

CFI 1 IE ;COMPARE IMMEDIATE A WITH 1EB

; CHECK TO DETERMINE IF NEW RECORD NEEDS TO BE READ

JNZ GD

; READ ANOTHER BUFFER

CALL DISKR

ORFA $A$;ZERO VALUE IF READ OK

JZ GD FFR ANOTHER BYTE

; END OF- DATA, RETURN WITH CARRY SET FOR EDF

STC ;SET CARRY FLAG TO 1

JMF EXITGNE

GQ: ;READ THE EYTE AT EUFF+REG A

MOV E, A ;LOW EYTE OF BUFFER INDEX

MUI D, DOUELE PRECISION INDEX TO DE

INR $\quad A \quad$;INDEX $=$ INDEX+1

STA IEP ;BACK TO MEMORY

; POINTER IS INCREMENTED

; SAVE THE CURRENT FILE AUDRESS

LXI H,EUFF ;LD HL IMMEDIATE WITH BUFF ADDRESS

DAD D FDBL REG ADD DE TO HL

; aBgolute character address is in hl

MOV A,M ;MOVE MEMORY TO ACC, ADDRESS IN HL

; EYTE IS IN THE aCCUMULATOR

EXITGNE: ;FUNCTION COMFLETE ; RESET CARRY EIT

RET

IBFI: DS 1 ;INFUT EUFFER FOINTER ( 8 EIT COUNTER)

; $* * * * * * * * * * * * * * * * * * * * * * * * * * * * * * * * * * * * * * * * * * * * * * * * * * * * * * * * * * * *$ ; READ DISK FILE RECORD

; $* * * * * * * * * * * * * * * * * * * * * * * * * * * * * * * * * * * * * * * * * * * * * * * * * * * * * * * * * * * *$

DIGHR: PUSH H! FUSH D! FUSH E

LXI D, FCB

MUI C, READF ; FUNCTION \#ED

CALL BDOS

POF B! FUF D! FUF $H$

RET

;************************************************************

; PERFORM CARRIAGE RETURN AND LINE FEED ON CONSOLE

; ***************************************************************10

CRLF: $\quad M U I$ A, CR

RAILL FICHAR

MVI $A, L F$ 
241 .

24己:

243 :

244:

ت45:

246:

247 :

ट4B:

249:

ESD:

已51:

อت:

253:

254:

255:

E5E:

로:

$258:$

로․

टGW:

टE 1 :

¿EË:

อย :

อ6 4:

E. 5 :

ZEE :

Eี7:

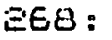

टE?:

$\Xi 70$.

อ71:

루을

273:

$=74:$

오:

ETF:

277:

278:

$=73$ :

c.810:

201:

EBE:

$28 \%:$

련

$285:$

टहE:

टघ7 :

EC\&:

도:

Don:

ㅋ1:

크:

อง :

294:

295:

EᄏE :

E37:

298 :

$297:$

इथाप:
CALL

RET

*************************************************************

CHECK CONSOLE INPUT STATUS

ANY INPUT, ACCUM $=$ QRFFH

ND INFUT, ACCUM $=$ QIBH

;************************************************************

CONINF: PUSH H! PUSH D! PUSH B; ENVIRONMENT SAVED

MVI C, CONST ;FUNCTION \#11

CALL BDOS

POF B! POP D! POF H; ENUIRONMENT RESTORED

RET

; $* * * * * * * * * * * * * * * * * * * * * * * * * * * * * * * * * * * * * * * * * * * * * * * * * * * * * * * * * * * *$ ; OUTPUT A CHARACTER TO THE CONSOLE

; $* * * * * * * * * * * * * * * * * * * * * * * * * * * * * * * * * * * * * * * * * * * * * * * * * * * * * * * * * * *$

PCHAK: FUSH H! PUSH D! PUSH B; SAVED

MUI C, CONOUT FFUNCTION \#E

MOV E, A

CALL BDOS

POP E! POF D! FOF H; RESTORED

RET

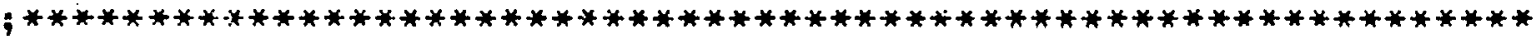
; TRANSFER A EYTE TO MEMORY

; $* * * * * * * * * * * * * * * * * * * * * * * * * * * * * * * * * * * * * * * * * * * * * * * * * * * * * * * * * * *$

STOREEYTE:

FUSH H FAVE HL

LHLD MEMLOC ; LOAD CURRENT VALUE OF FOINTER

MUV MIA TTRANSFER ACCUM TO MEMURY

INX H INCREMENT FOINTER

STLD MEMLOC ;STORE INCREMERTED FIOINTER

FOF H H HESTORE HL

MEMLOC: DS E ;MEMÜY FOINTER TO STORE CURFENT EYTE

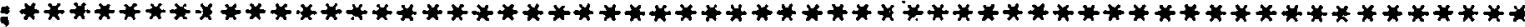

; COMFARE HL TO DE, ACO LOST. AND FLGGS SET

; $* * * * * * * * * * * * * * * * * * * * * * * * * * * * * * * * * * * * * * * * * * * * * * * * * * * * * * * * * * *$

CH:LDE: MUV A, D

CMP H

JNZ ECMF

MOV $\quad A, E$

CMF L

ECMP: RET

; $* * * * * * * * * * * * * * * * * * * * * * * * * * * * * * * * * * * * * * * * * * * * * * * * * * * * * * * * * * * *$

; DOWN-L_OAD MER (SEE MSQ MANUAL P. 46)

: *************************************************************

DINLD: MVI A, BËH ;CONTROL. E

CALL OUTMF ;SEND TO MAIN PORT

1P1: IN $53 \mathrm{H}$

Ain I Q DË 


\begin{tabular}{|c|c|c|c|c|}
\hline \multicolumn{2}{|l|}{$\begin{array}{l}301: \\
3 \square 2:\end{array}$} & $\mathrm{JZ}$ & LPI & $\cdots$ \\
\hline Зロこ: & & IN & $58 \mathrm{H}$ & ; READ CHAR \\
\hline 304: & & $L \times I$ & \multicolumn{2}{|c|}{ D, DWNMSG } \\
\hline 3Ф5: & & CALL & \multicolumn{2}{|l|}{ ERR } \\
\hline उU6: & & $L X I$ & \multicolumn{2}{|c|}{ H, NEYTES; NUMEER OF EYTES TO DOWNLOAD } \\
\hline $\begin{array}{l}397: \\
308:\end{array}$ & & $\begin{array}{l}\text { MOV } \\
\text { CALL }\end{array}$ & $\begin{array}{l}\text { A, H } \\
\text { QUTMF }\end{array}$ & ;HIGH BYTE OF (NUMBER OF BYTES) \\
\hline $329:$ & & mav & $A, L$ & ; LOW BYTE OF (NUMBER OF BYTES) \\
\hline $310:$ & & CALL & DUTMP & \\
\hline $311:$ & $\cdot$ & LXI & H, MQRMEI & M; STARTING MBO MEMORY LOCATION \\
\hline $312:$ & & MOV & $A, H$ & ;HIGH BYTE OF (START ADDRESS) \\
\hline $313:$ & & CALL & QUTMF & ;DOWNLOAD BYTE \\
\hline $314:$ & & MOV & $A, L$ & ;LOW BYTE OF (START ADDRESS) \\
\hline ت15: & & CAILL & QUTMF' & ;DOWNLOAD BYTE \\
\hline 31E: & & LXJ: & H, STMBЙ & \\
\hline $317:$ & & $L X I$ & D, ENDMBQ ; ENDING HOST MEMORY LOCATION & $\begin{array}{l}\text {;STARTING HOST MEMORY LOCATION } \\
\text { П; ENDING HOST MEMORY LOCATION }\end{array}$ \\
\hline $318:$ & SDLF': & ; LOOOP & TO TRANSFE & $\begin{array}{l}\text { ER ELOCK OF MEMURY } \\
\text { GEET BYTE FROM MEMORY }\end{array}$ \\
\hline $319:$ & & MOV & $A, M$ & ; GET BYTE FROM MEMORY \\
\hline $3 E D:$ & & CAILL & DUTMF' & ; DOWNLOAD EYTE \\
\hline ここさ: & & $\operatorname{INX}$ & $\cdot \mathrm{H}$ & ; INCREMENT COUNTER \\
\hline $\begin{array}{l}\Xi \subset \Xi: \\
3 \Xi \Xi:\end{array}$ & & $\begin{array}{l}\text { CALLL } \\
\text { JNZ }\end{array}$ & $\begin{array}{l}\text { CHLDE } \\
\text { SDL.F }\end{array}$ & ;COMFIARE HL TO DE, FLAGS SET \\
\hline $324:$ & & & & \\
\hline $3 \Xi 5:$ & & RE.T & & ; RETURN WHEN TRANSFER COMFLETE \\
\hline उE: : & & & & 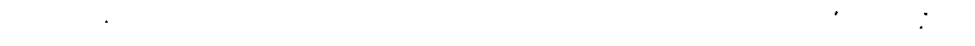 \\
\hline $3 \because 7:$ & $; * * * * * * *$ & $* * * * * * *$ & $* * * * * * * * *$ & $* * * * * * * * * * * * * * * * * * * * * * * * * * * * * * * * * * * * * * *$ \\
\hline उЁ: & ; & QUTFUT & DATA TO I & MAIN FORT \\
\hline $\begin{array}{l}3=3: \\
330:\end{array}$ & $; * * * * * *$ & $* * * * * * *$ & $* * * * * * * * *$ & $* * * * * * * * * * * * * * * * * * * * * * * * * * * * * * * * * * * * * *$ \\
\hline $331:$ & QUTMF: & F'USH & F'SW & ; SAVE DATA \\
\hline るここ: & & CALL & MFSTAT & ; CHECK MAIN FORT OUTPUT STATUS \\
\hline$\Xi \Xi \Xi:$ & & FOF & FSW & ;RECALL DATA \\
\hline $334:$ & & QUT & 5eH & ; OUTFUT DATA TO MAIN PORT \\
\hline $355:$ & & RET & & \\
\hline$\Xi \Xi \in:$ & & & & \\
\hline 337 & $; * * * * * * ;$ & $* * * * * * *$ & $* * * * * * * * * *$ & *************************************** \\
\hline $330:$ & ; & CHECKK & MAIN FORT & OUTPUT STATUS (HOLDS HERE UNTIL CLEAR) \\
\hline $\begin{array}{l}325: \\
348:\end{array}$ & $; * * * * * *$ & $* * * * * * * * *$ & $* * * * * * * * *$ & $* * * * * * * * * * * * * * * * * * * * * * * * * * * * * * * * * * * * * *$ \\
\hline $341:$ & MESTAF & Iid & $59 ! \cdot i$ & ; CHECK MAIN PUKT STATUS \\
\hline $342:$ & & ANI & Q1H & \\
\hline $343:$ & . & $\mathrm{JZ}$ & MFISAT & FINFINITE LOOF UNTIL CLEAR \\
\hline $34.4:$ & & RET & & \\
\hline $345:$ & & & & $\cdot$ \\
\hline$\Xi 4 E:$ & $; * * * * * * 7$ & $* * * * * * *$ & $* * * * * * * * * *$ & 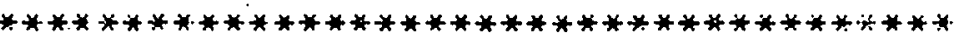 \\
\hline $347:$ & ; & TOGGiE & $I / O S W I T C$ & \\
\hline$\Xi \Leftrightarrow$, & $F * * \times \times \times x$ & $x * * * * * *$ & $* * * 3 * * * * * *$ & $* * * * * * * * * * * * * * * * * * * * * * * * * * * * * * * * * * * * * *$ \\
\hline $349:$ & & & & \\
\hline 3501 & TGLIO: & PUSiol & FISW & \\
\hline$\Xi 51:$ & & LDA & IOSWH & ;GET SWITCH \\
\hline $35:$ & & CPI & Den & ;CHECK FOR QTL = NO FRINT \\
\hline $353:$ & & $J \mathbf{Z}$ & TGL 1 & \\
\hline $354:$ & & & & \\
\hline $\begin{array}{l}355: \\
356:\end{array}$ & & $\begin{array}{l}\text { MVI } \\
\text { STA }\end{array}$ & $\begin{array}{l}\text { A, घूA } \\
\text { T.OSWH }\end{array}$ & ;NOT ZERO, MAKE ZERO \\
\hline $357:$ & & JMO & TGLE & \\
\hline $358:$ & & & & \\
\hline $359=$ & TGL $1=$ & MVI & $A ; P_{1}$ & ; ZERO, MAKE ONE \\
\hline 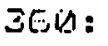 & & STA & IOSWH & \\
\hline
\end{tabular}




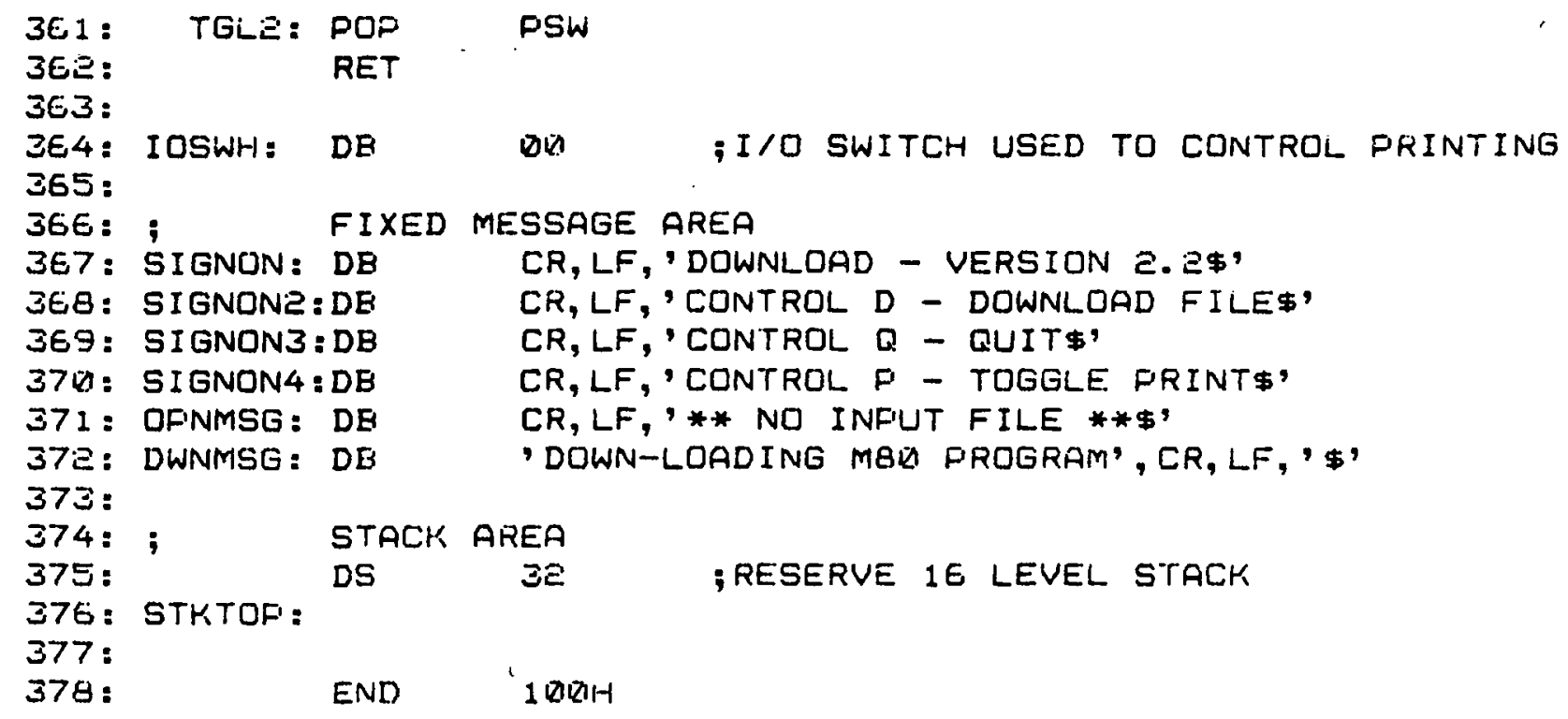




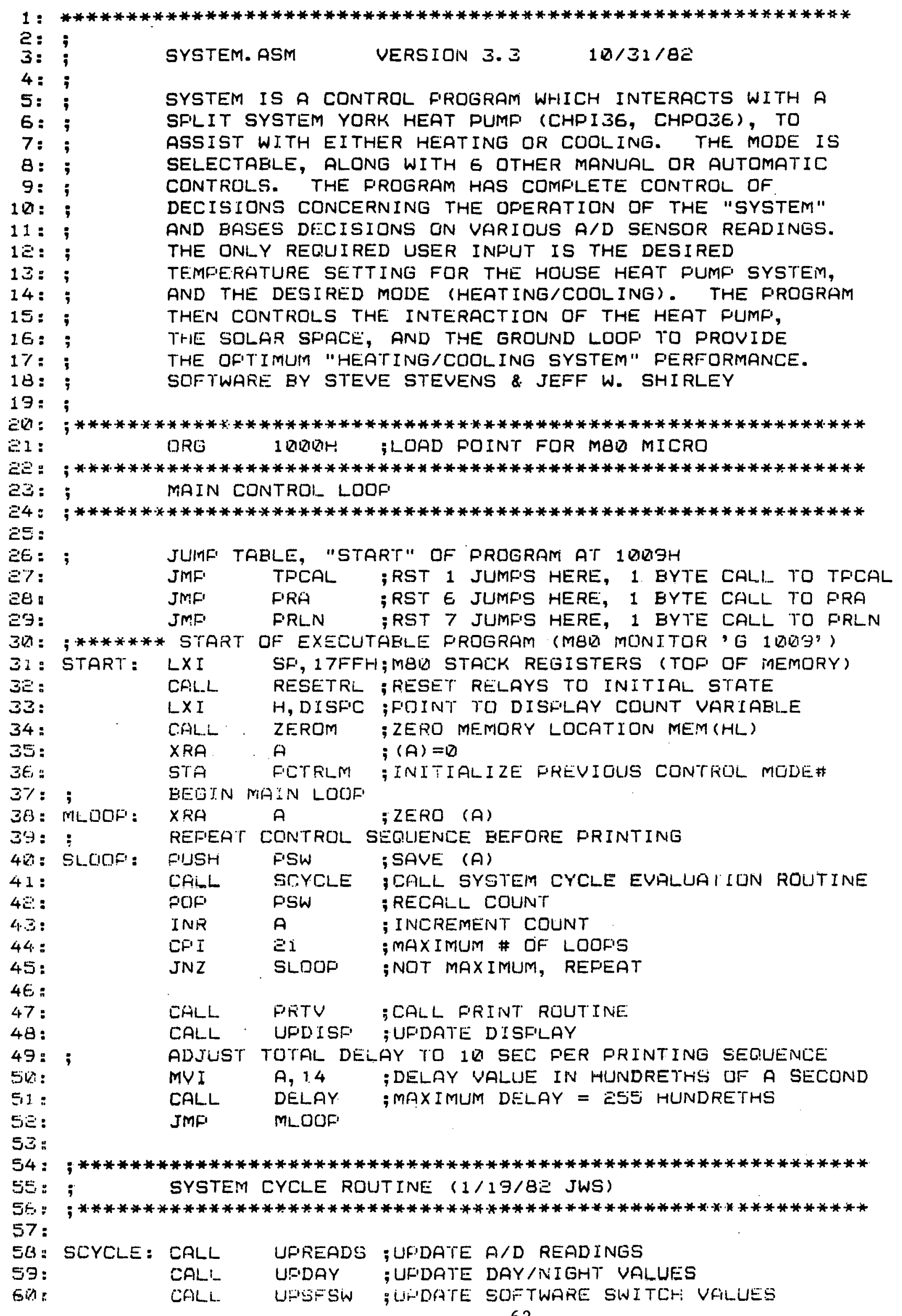




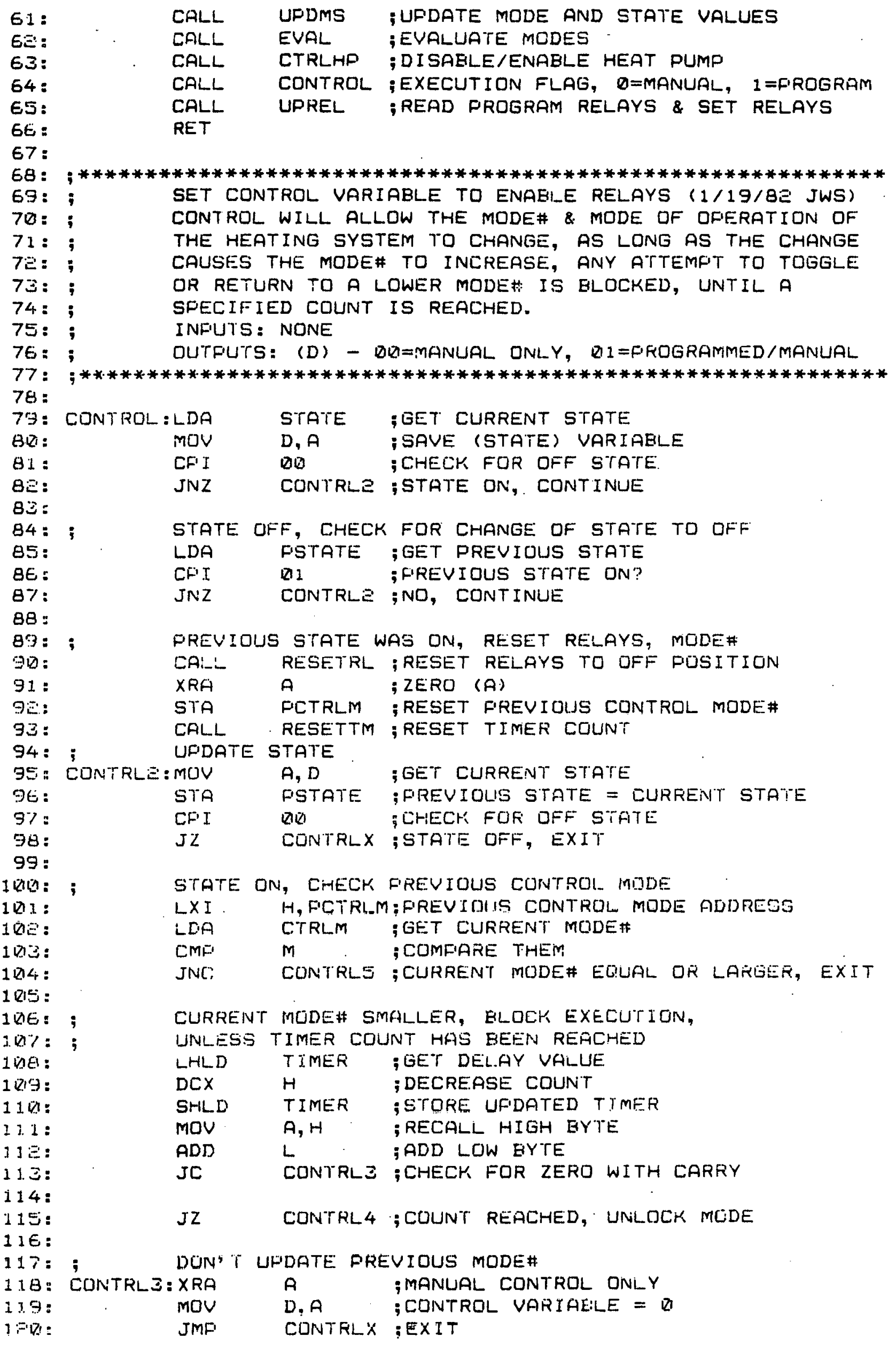


1อコ:

124:

$125:$ CONTRL 4:CALL RESETTM ; RESET TIMER COUNT ; UFIDATE FREVIOUS CONTROL MODE

1 1टE:

$1 \Xi 7:$

$12 \theta$ :

1อง:

1.3D:

$131:$

$133:$

$134:$

$135:$

13E:

$13 \%:$

$133:$

$1 \Xi 9:$

CUNTRLS : LDA

CTRLM ;GET CURRENT MODE\#

CONTRLX:RET

PC.TRL_M ;FREVIOUS MODE\# = CURRENT MODE\#

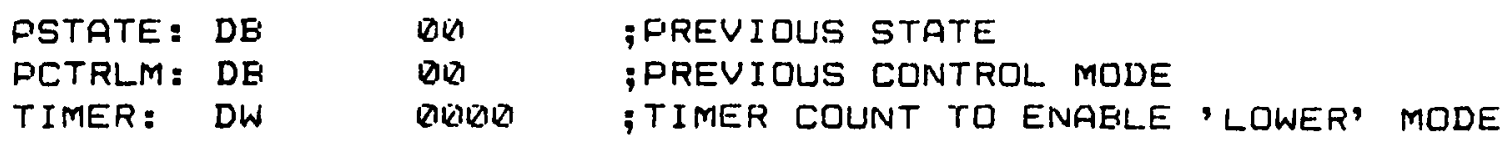

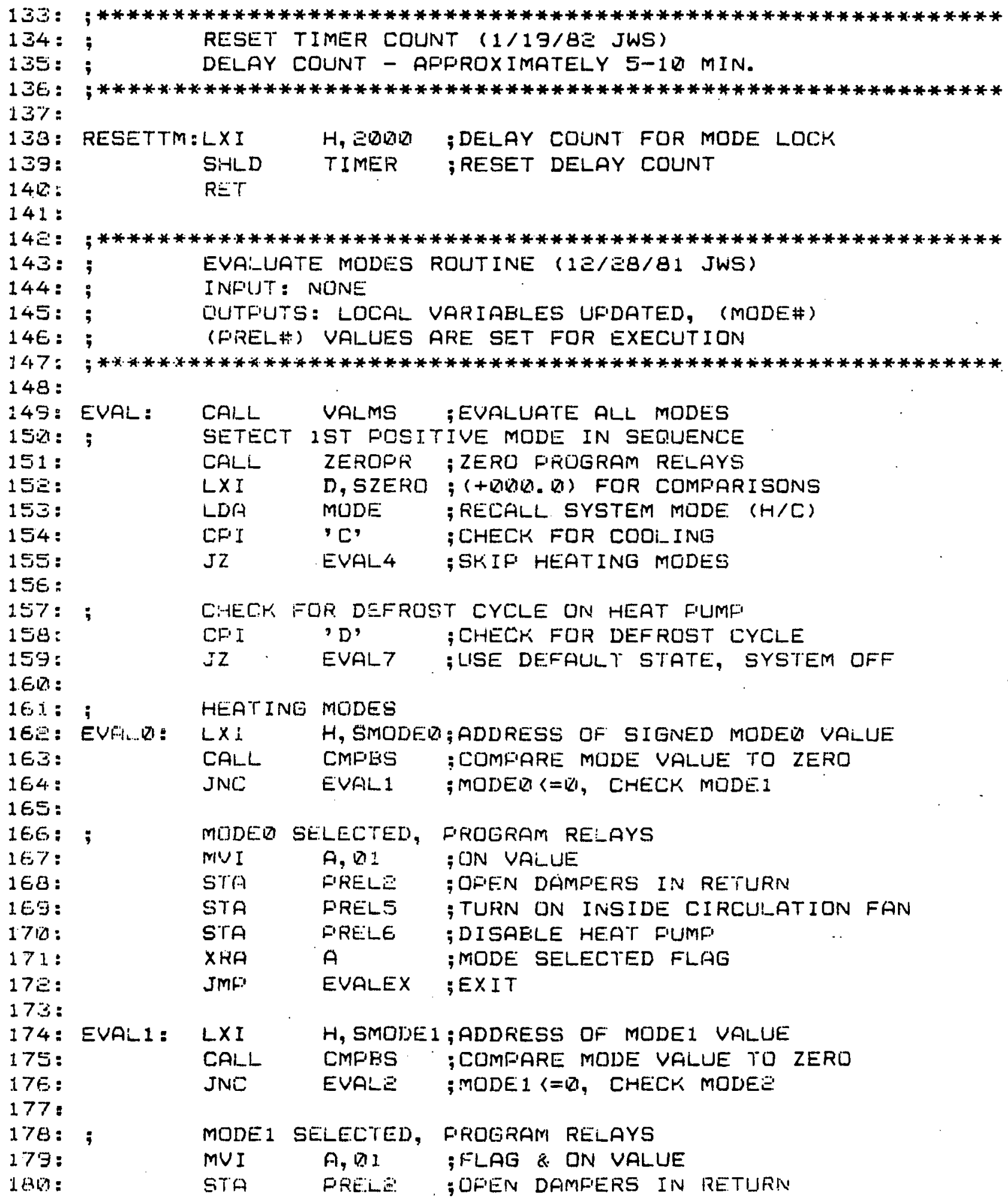




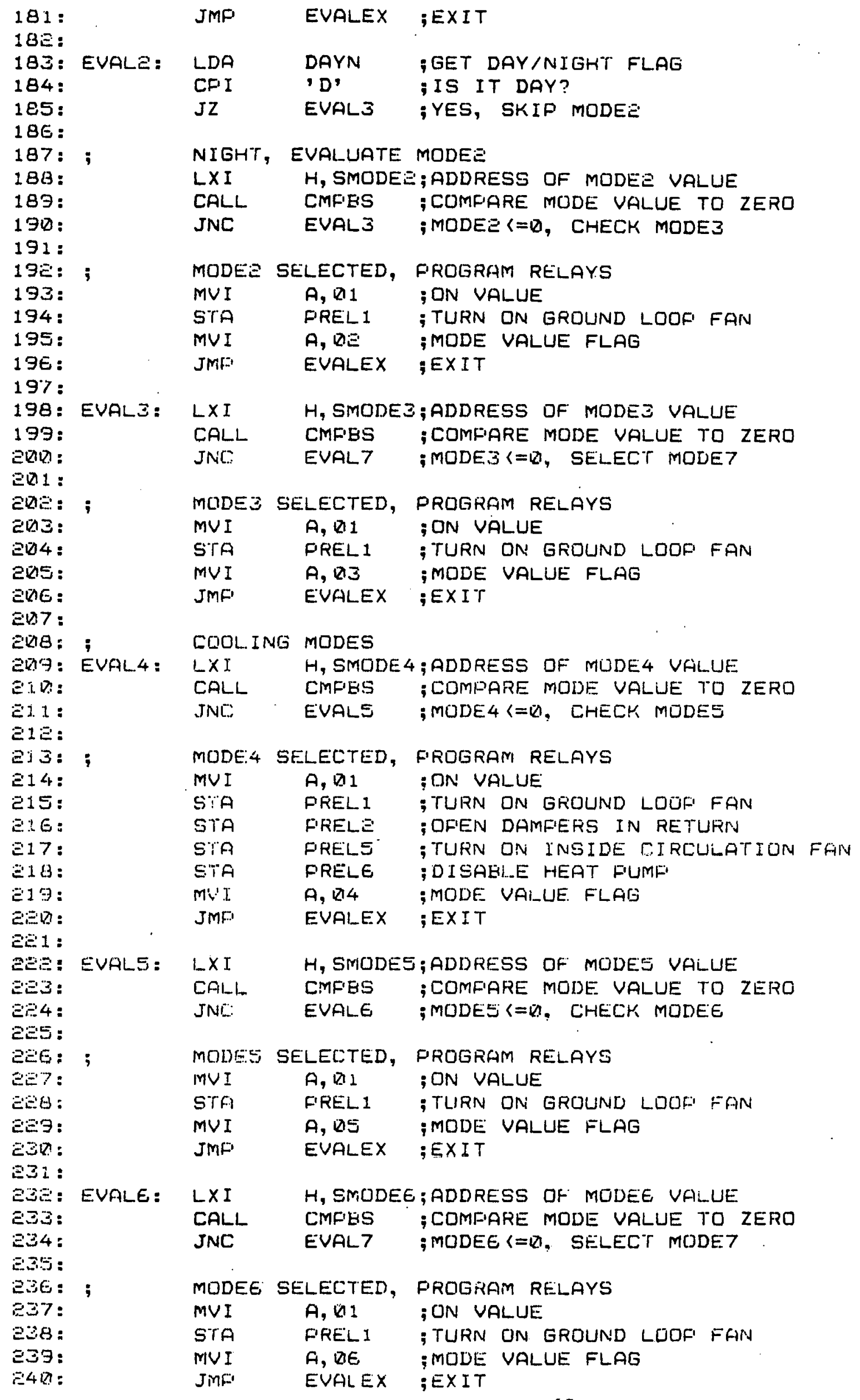


$241:$

242: EVAL7: ;MODE7 DEFAULT MODE, (HEAT PUMF SYSTEM ONLY)
243:

244:

245:

246:

247 :

248:

눙

25n:

ट5 1 :

돌:

론 :

254:

롱:

255:

터7:

동

루보.

2ER :

eE 1:

EE:

EES:

라

EES:

PEE :

DET:

$\sum \in \Theta$ :

อe :

$270:$

E7:

루르:

273:

274:

능

구 :

루궁

궁

279:

e日b:

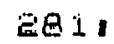

르:

E83:

랜

부응

라:

루:

루 :

텁

Eल3

E91:

อง湿:

쿠:

อ34:

2055:

ت96:

Ë"

E)

exas:

$306=$

MVI A, QT TMODE FLAG VALUE

EVALEX: STA

RET

CTRLM: DE

CTRLM

;SET MODE SELECTED FLAG

Q16

; NUMEER OF MODE SELECTED
$* * * * * * * * * * * * * * * * * * * * * * * * * * * * * * * * * *$
ZERO PROGRAM RELAYS (1/14/8己 JWS)

; ************************************************************

ZEROFR: XRA

STA

STA

STA

STA

STA

STA

A IZERO (A), OFF VALUE

PREL 1 ;GROUND LODP FAN OFF

PRELE ;CLOSE DAMFERS IN RETURN

PRELS ;TURN OFF OPEN RELAY

PREL4 ;TUFN DFF OFEN RELAY

PREL5

PRELE

; CIRCULATION FAN TO AUTO

RET 


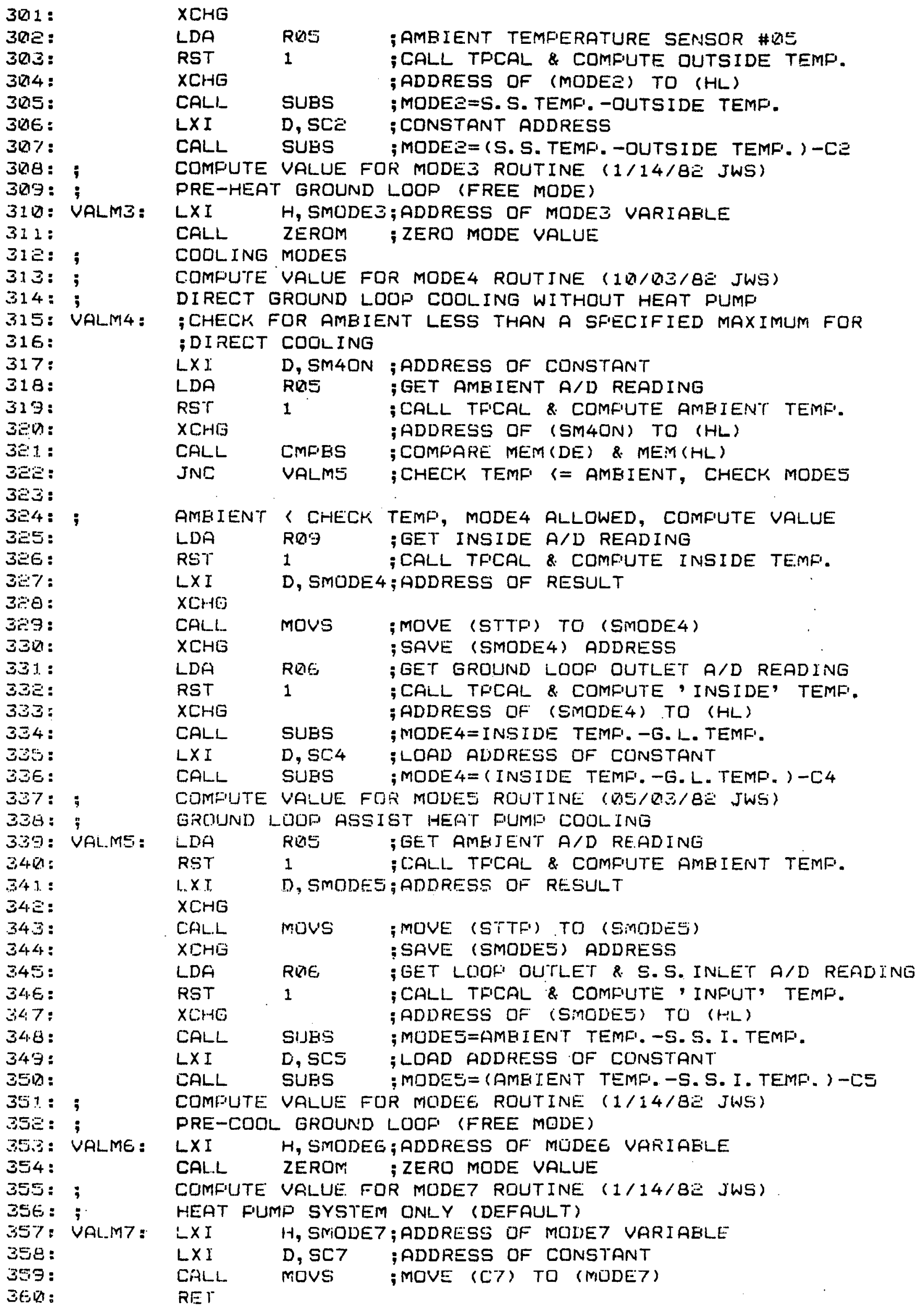


JU1:

3E: : SMODED: DE

365: MODED: DW

364: SMODE1: DE

355: MODE1: DW

उEE: SMODEE: DB

3E7: MODEE: DW

3E,B: SMODEZ: DE

उEF: MODEJ: DW

370: SMODE4: DE

371: MODE4: DW

37:ः SMODEE: DE

373: MODES: DW

374: SMODEE: DE

375: MODEE: DW

37E: SMODE7: DE

377: MODE7: DW

378: SCQ: DE

379: CE: DB

उBV: DE

381: SCE: DB

ЗBE: C CE: DE

उBड: DB

384: SC4: DE

385: C4: DB

उBE: DE

387: SC5: DE

उB日: C5: DE

उE?:

390

391

उ习:

39:

394

395 :

כэE:

397:

$398:$

ت99:

4D0:

401:

$4 \nabla=$

$4 B_{1} 4$

485

4 LIE:

4Q7\%:

4DB:

489:

410:

$411:$

$41=$

$413:$

414 :

415:

41E:

417 :

418 :

413:

$480:$ $\nabla 0$

ariva

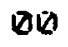

aravia

DIR

DQB日a

DU

ODDR

QDis

QRIRIR MODE4 VARIABLE

DQ

gavisa

DQ

DQIZIZ

Qin

DRIRIC

प्राप

QIQIH

छڤ⿱艹H

ais

Q). $\mathrm{H}$

Diart

Dण

$\nabla|x|-1$

EQH

Din

(D)

Rient

Dis

ज्ञात

$1 \nabla H$

QDar-1

घ배

$1 \mathrm{BH}$

SIGN OF MODED

MODED VARIABLE

;SIGN OF MODEI

MDDE 1 VARIABLE

; SIGN OF MODEZ

;MODEE VARIAELE

;SIGN DF MODE3

; MODE 3 VARIABLE

;SIGN OF MODE4

;SIGN OF MODES

;MODES VARIABLE

;SIGN QF MODEE

; MODEE VARIABLE

;SIGN OF MOLE?

;MODE7 VARIABLE

- ECD CONSTANT

; BCD CONSTANT

; ECD CONSTANT

- BCD CONSTANT

- ECD CONSTANT

ECD COONSTANT
;SIGN OF CONSTANT

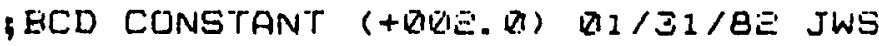

SIGN OF ECD CONSTANT

; BCD CONSTANT $(+\$ 10.0)$ D1/31/8E JWS

;SIGN OF CONSTANT

; ECD CONSTANT (+QRZE. Q) 10/QE/BE JWS

; SIGN OF CONSTANT

; BCD CONSTANT (+D1D. D) QS/QI/BE JWS

; SIGN OF CONSTANT

; ECD CONSTANT (+BOA1. B) $1 / 14 / 8 E$ JWS

; SIGN OF CONSTANT

;ECD CONSTANT (+DE1. Q) 1Q/Z1/QE JWS

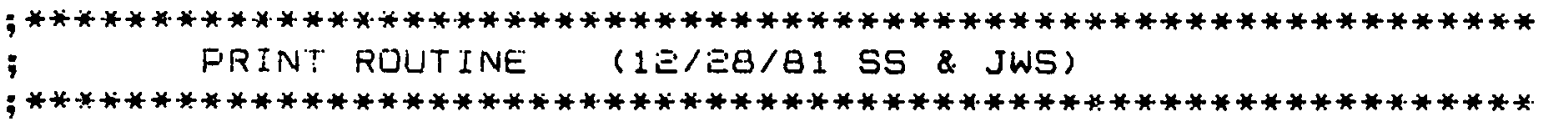

RST 5

;FRINT (A) AS TWO HEX DIGITS

;FOINT TO END EYTE

;PRINT" (Fi) AS TWO HEX DIGITS

;POINT TO LOW BYTE

;GET LOW BYTE

;FIRINT (A) AS TWO HEX DIGITS

; CALL XMTR \& TRANSMIT (A)

; CALL XMTR \& TRANSMIT (A)

RST 5

; CALL XMTR \& TRANSMIT (A) 


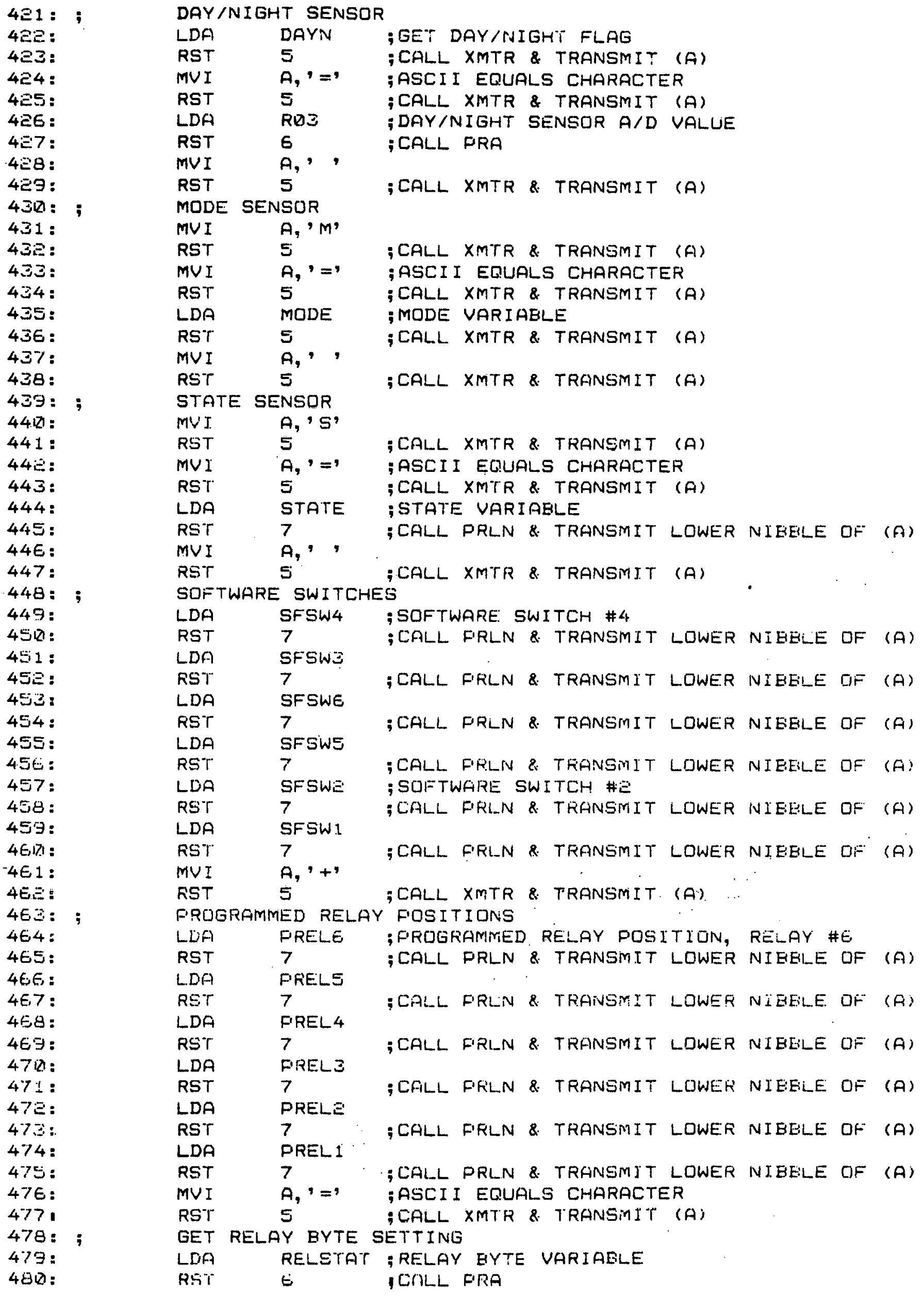




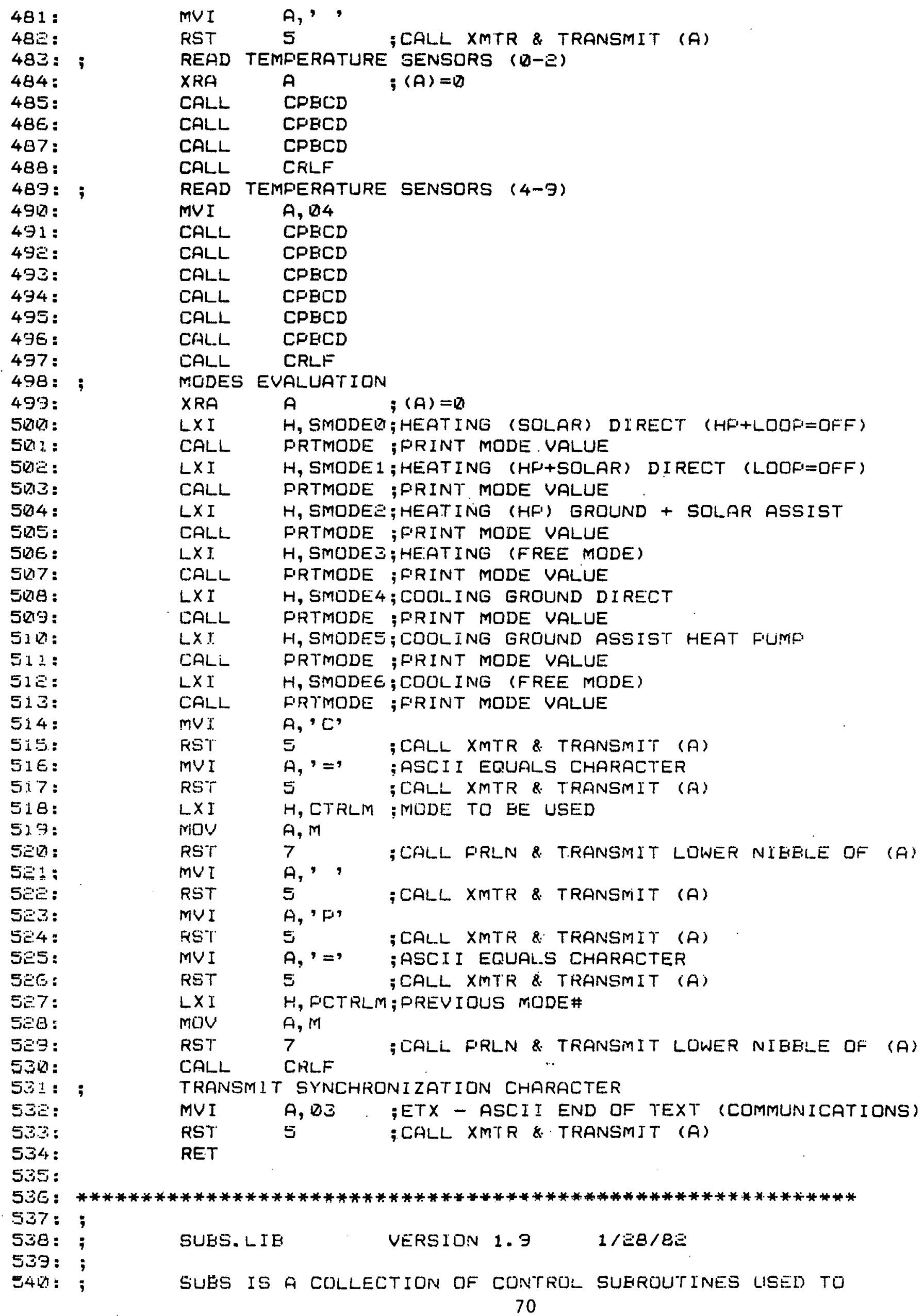




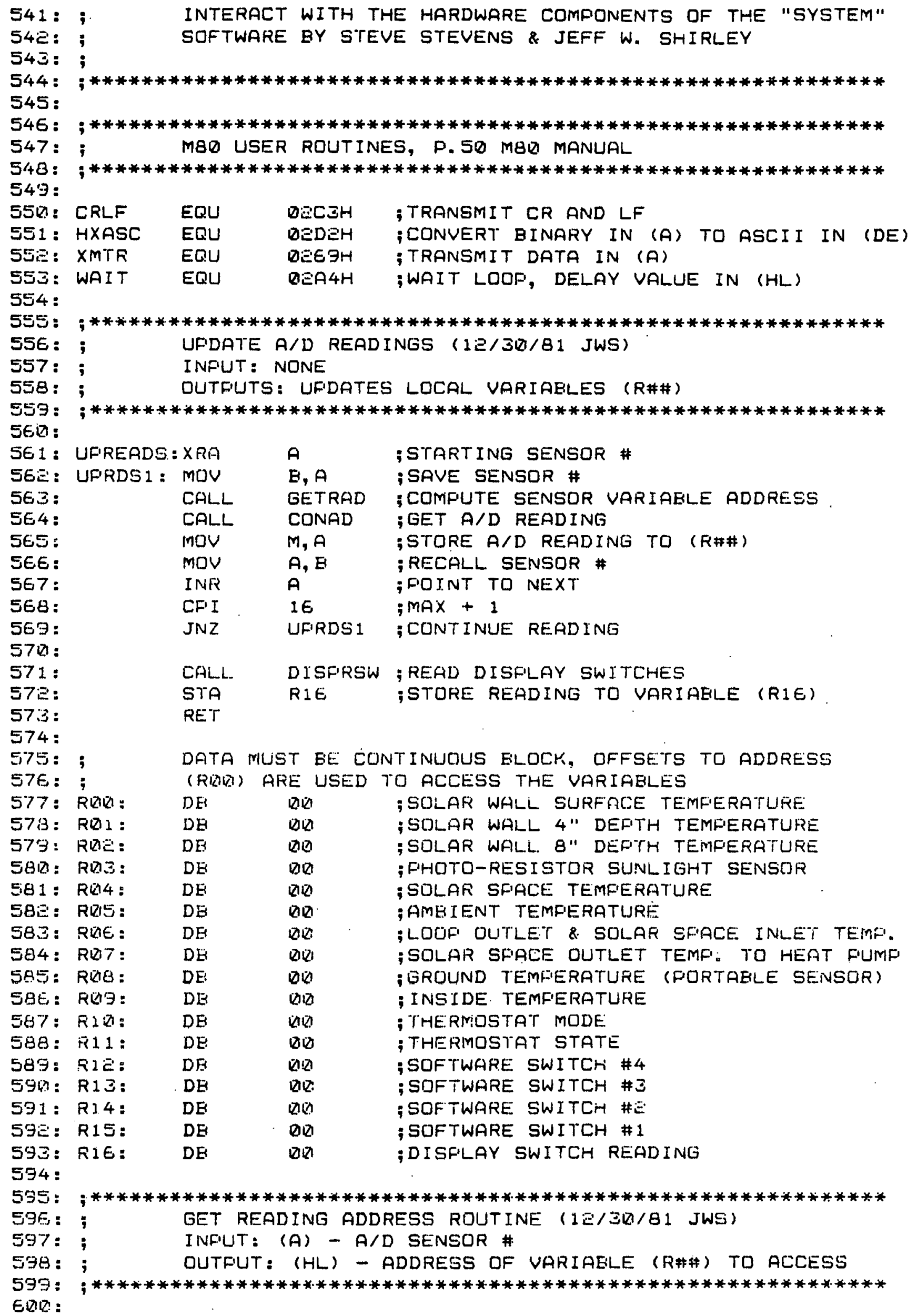




\begin{tabular}{|c|c|c|c|c|}
\hline $\begin{array}{l}\text { 6O1: } \\
\text { EQIE: }\end{array}$ & GETRAD: & $\begin{array}{l}\text { PUSH } \\
\text { LXI }\end{array}$ & $\begin{array}{l}\text { PSW } \\
\text { H, RQRe }\end{array}$ & $\begin{array}{l}\text {;SAVE SENSOR \# } \\
\text {; LDAD STARTING A/D SENSOR ADDRESS }\end{array}$ \\
\hline 6QI: & & ADD & L & ;COMFUTE LOW EYTE ADDRESS \\
\hline ER4: & & MOV & L, A & ;STORE LOW BYTE OF ADDRESS \\
\hline 6டிs: & & JNC & RADEX & ;NO CARRY, EXIT \\
\hline 606: & & INR & $H$ & ;CARRY, INCREMENT (H) \\
\hline GRB: & RADEX: & POP & F'SW & ;RESTORE SENSOR \# \\
\hline 609: & & RET & & \\
\hline 610: & & & & \\
\hline 511: & ; *******1 & $* * * * * * *$ & $* * * * * * * * * *$ & 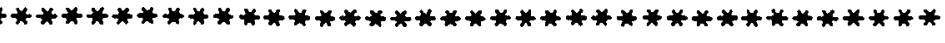 \\
\hline E1Z: & ; & UPDATE & DAY/NIGHT & T VALUES ROUTINE ( $1 / \Xi / 8 \Xi$ SS \& JWS) \\
\hline $613:$ & ; *******1 & $* * * * * * *$ & $* * * * * * * * * *$ & 光* \\
\hline $614:$ & DAYVAL & EQU & $\mathrm{EQH}$ & ;DAY VALUE UFPER LIMIT ( $1 / \Xi / 8 E$ JWS $)$ \\
\hline $\begin{array}{l}\text { 615: } \\
616:\end{array}$ & $; * * * * * *$ & $* * * * * * *$ & $* * * * * * * * * *$ & $* * * * * * * * * * * * * * * * * * * * * * * * * * * * * * * * * * * * *$ \\
\hline $\begin{array}{l}\text { E17: } \\
\text { E18: }\end{array}$ & UPDAY: & $\begin{array}{l}\text { LDA } \\
\text { CFI }\end{array}$ & $\begin{array}{l}\text { RUZ } \\
\text { DAYVAL }\end{array}$ & $\begin{array}{l}\text {; DAY/NIGHT PHOTO CELL A/D READING } \\
\text {;DAY VALUE UPFER LIMIT }\end{array}$ \\
\hline 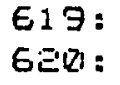 & & $\mathrm{JC}$ & UFDAY 1 & ; VALUE \& DAYVAL \\
\hline GË1: & & $M \cup I$ & $A, ' N$ ' & ; ITS NIGHT \\
\hline Gシこ: & & JMF & UFDAYこ & \\
\hline Бここ: & & & & \\
\hline $6 \overline{4}:$ & UFDAY1: & $M V I$ & $A, ' D$ ' & ; ITS DAY \\
\hline 6อ5: & UFDAYE: & STA & DAYN & \\
\hline GEG : & & RE.T & & \\
\hline 6อ7: & & & & \\
\hline 6อB: & DAYN: & $D E$ & D44H & ; DAY =' D', NIGHT=' $N$ ' \\
\hline EЕヨ: & & & & \\
\hline Eシ̆: & ; *******1 & $* * * * * * * *$ & $* * * * * * * * * * *$ & \\
\hline Eこ1: & ; & UFIDATE & THERMOSTA & AT MODE AND STATE (1E/EE/B1 SS \& JWS ) \\
\hline E3E: & 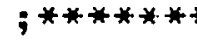 & $* * * * * * *$ & $* * * * * * * * * *$ & (*) \\
\hline Eこコ: & ; & MUDE A & AND STATE E & EQUATES AND VALUES \\
\hline E34: & ; & ACTUAL & READINGS: & MODE - $Q F=$ COOLINE, FF=HEATING, \\
\hline 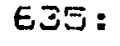 & ; & STATE & $-F F=O F F$, & QIE $=O N \quad(1 \Xi / \Xi E / B 1$ JWS $)$ \\
\hline EZE: & MIDVRL & EOL & $\nabla G Q H$ & ;ON/OFF LIMIT VALUE \\
\hline 637 & $; * * * * * * *$ & $* * * * * * *$ & $* * * * * * * * * * *$ & 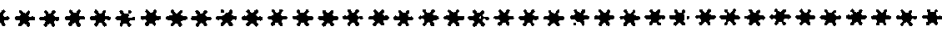 \\
\hline EבE: & & & & \\
\hline $6.39:$ & UFDINS: & LDA & R1 & ;MODE AID READING \\
\hline 64ia: & & CFI I & MIDVAL & \\
\hline $\begin{array}{l}6 / 1: \\
64::\end{array}$ & & JC & UFDIISI & \\
\hline 64.3: & & $M V I$ & $A, H^{\prime}$ & ; (A) $>=$ MIDVAL, HEATING MULE \\
\hline E44: & & JMF & LFDMSE & \\
\hline E45: & & & & \\
\hline E4E: & UFDrisi: & $M \vee I$ & $A,{ }^{\prime}$, & ; $(A)$ \& MIDVAL, COOLING MODE \\
\hline 6.47: & UFDMEE : & $\operatorname{Sin}$ & MODE & \\
\hline Ei4 $\varepsilon=$ & & $\operatorname{irlOU}$ & E, A & ; SAVE A/D READING MODE \\
\hline E49: & & LDA & SMODE & ; RECALL SOFTWARE MODE \\
\hline EED: & & CMFF & E & ¡SAME MULE? \\
\hline$E \Xi 1:$ & & $\mathrm{JZ}$ & UFDMSE & ; YES, CONTINUE \\
\hline$E 5 E:$ & & & & \\
\hline $\begin{array}{l}653: \\
654:\end{array}$ & ; & $\begin{array}{l}\text { MODES } \\
\text { MVI }\end{array}$ & $\begin{array}{l}\text { NOT SFME, } \\
\text { A, 'D' }\end{array}$ & $\begin{array}{l}\text { DEFROST MODE } \\
\text {;DEFROST }\end{array}$ \\
\hline $655:$ & & STA & MUDE & ; DFFRUST MODE \\
\hline $6.56=$ & UFDMSZ: & LDA & R11 & :STATE A/D READING \\
\hline ES7: & & CFI I & MIDVAL & \\
\hline $658=$ & & $\mathrm{JC}$ & UPDMS4 & \\
\hline $659:$ & & & & \\
\hline $660:$ & & $X R \cdot F_{1}$ & A & $;(A)>=\underset{72}{\text { MIDVAL, SYSTEM OFF }}$ \\
\hline
\end{tabular}


$E \in 1:$

6G:

663: UPDIMS4: MVI

6E4: UPDMSE: STA

E.S:

$6 \in 6:$

MODE: $D B$

RET

A, DI
STATE (A) \& MIDVAL, SYSTEM ON

$\in \in \ni$ :

$E 7 D$

STATE: DE

Q 4 Q

; HEAT I NG = ' $H$ ',

COOLING=' C', DEFROST=' D'

DU

;D=QIFF, $\quad 1=\mathrm{ON}$

671:

67こ: :

E73:

674:

E75: ;

$676: A D$

678:

$679:$

6817:

E81:

GB: :

683 :

684 :

685:

6BE,

687:

688:

689:

E9D:

691:

69อ:

E93:

694:

$695:$

EFE:

697:

698:

699:

$700:$

701 : ;

70: :

$703:$

7014 :

$705:$

7QE:

707 :

7na:

780:

710 :

711 :

;*************************************************************

; CONUERT A/D CHANNEL $(11 / 24 / 81$ SS $)$

; INFUT: (A) - CHANNEL TO CONVERT. (DIF)

; DUTFUT: (A) CONVERTED VALUE FROM A/D CHANNEL SELECTED

; ********************************************************1

; A/D ADDRESSES

ADPTS EQU 34 UIDH

anscon eql zBdidh

ADECON egla joldon

ADFORT EQU 3CQRAT-1

;A/D PORT SELECT

;START A/D CONUERSION

;END OF A/D CONVERSION FLAG

; $* * * * * * * * * * * * * * * * * * * * * * * * * * * * * * * * * * * * * * * * * * * * * * * * * * * * * * * * * * * *$

CONAD: PUSH H

STA ADETS ;SELECT A/D FORT

; WAIT FOR ADDRESS TO STAEILIZE ON BUS

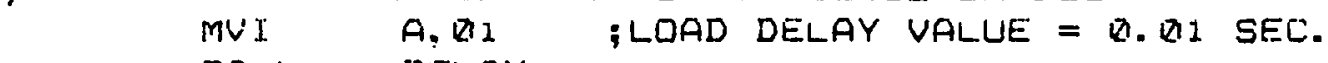

CALL DELAY

STA ADSCON ; START CONVERSION

CKEOC: LDA

AN].

ADECON ;END OF CONVERSION?

$J N Z$

; WAIT FOR DATA TO STAEILIZE ON ELLS

MUI $A, D_{1}$;LOAD DELAY VALUE $=0.01 \mathrm{sEC}$.

CALL DELAY

IDA

FOE

ADFORT ;READ A/D PORT

RET

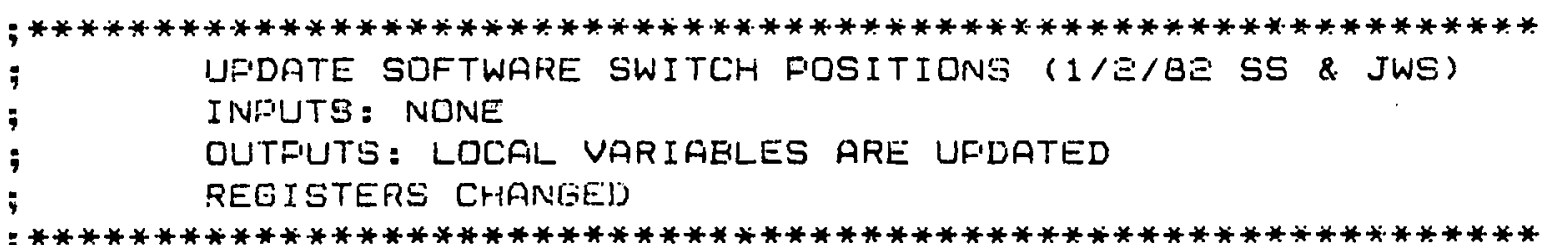

UFSFSIV: LDA RIS ;A/D RERDING SWITCH \#I

CALL SWSET ;RETURN STRTE OF SWITCH

STA SFSW1 ;SAVE STATE OF SWITCH 1

LDA R14 ; A/D READING SWITCH \#E

CALL SWBFT ; HETURN STTATE OF SWITEH

STA SFSWE ; SAVE STATE OF SWITCH

LDA RIJ ;A/D READING SWITCH \#Z

CALL SWSFT ; RETURN STATE OF SWITCH

STA SFSW ; SAVE STATE OF SWITCH 3

LDA RIE ;A/D READING SWITCH \#4

CALL SWIEFT ; RETURN STATE OF SWITCH

STA SFSW 4 :SAVE STATE OF SWITCH 4

READ DISFLAY SWITCH SETTINGS, SET SUFTWARE SWITCHES

SWITCH $8-$ DOWN=COOLING, UF =HEATING

SWITCH 4 - DOWN=AUTO, UP=MANIJAL 
$721:$

7シさ：

72르:

$724:$

7อ:

7EE:

7푼

7 7ㅅ:

$7=$

$734:$

7引1:

73:

$733:$

734:

$735:$

$736:$

$737:$

738 :

$739:$

$740:$

$741:$

$74:=$

$743:$

$744:$

$745:$

746 :

$747:$

$748:$

$749:$

7 可口:

751 :

75 르:

75

$754:$

755 :

$75 E:$

$757:$

$759=$

$7 \in \emptyset:$

TEL:

7EЕ:

$7 \in 3:$

$7 \in 4:$

7ES:

TE,E:

$7 E \%:$

768 :

7ES:

$770:$

771 : SFSW1:

77Ë: SFSWE:

$77 \Xi:$ SFSW :

774: SFSW4:

$775:$ SFSWS:

77E: SFSWE:

777 : SMODE:

SWITCH $E-$ DQWN=OFF, UP=ON (SFSWS)

SWITCH 1 - DOWN=OFF, UFI=ON (SFSWE)

MVI A, 'H' ;ASSUME HEATING MODE

STA SMODE ; SOFTWARE MODE

MUI A, DE ;ASSUME SWITCHES ARE AUTO

STA SFSWS ; SOFTWARE SWITCH \#S

STA SFSWE

LDA RIE

MOV B,A TSAVE DATA

CHECK DISFLAY SWITCH B (XDERQI)

ANI QURBH ;CHECK FOR HEATING MODE

CFI DUA ;SWITCH 8 DOWN?

INZ DSWSO ;NO, HEATING MODE CONTINUE

COOL ING MODE SET SOFTWARE FLAG

MVI $A$, , $C$,

STA SMODE ;STORE SOFTWARE MODE

CHECK DISFLAY SWITCH 4 (QXDD)

MOV A, B FESTTRE DATA

ANI DQI4H ;CHECK FOR MANUAL MODE

CPI DU \$SWITCH 4 DOWN?

IZ DSWSEX ;YES, EXIT

MANUAL MODE SELECTED

CHECK DISFLAY SWITCH $\cong$ (DDXD)

MVI $\quad A, \square 1$

STA SFSWS ;SOFTWARE SWITCH $Z$ ON

MUV A, B FESTORE DATA

ANI. QUEH ;CHECK FOR SWITCH E UH

CFI DQ ;SWITCH E DOWN?

JNK. DSWS1 ;NO, CHECK SWITCH 1

DISFLAY SWITCH E (DUXQD) IS OFF

$X R A \quad A \quad A \quad=Q$

STA SFSW5 ; SOFTWARE SWITCH \#S OFF

CHECK DISFLAY SWITCH 1 (RQROX) SETTING

MVI. A, $\square I$

STA SFSWE ;GSSUME SWITCH \#E ON

MOU $A, B$;RESTORE DATA

ANI VISIH ;CHECK FOR SWITCH 1 UF

CAI

JNZ DSWSEX ;NO, SWITCH 1 UP, EXIT

DISFLAY SWITCH 1 (BUDXX) IS OFF

XRA A

STA SFSWE :SWITCH \#E IS DFF

778 :

$779:$

$780:$

; $* * * * * * * * * * * * * * * * * * * * * * * * * * * * * * * * * * * * * * * * * * * * * * * * * * * * * * * * * * * *$

RETUFN SOFTWARE SWITCH POSITION. 
781 : ;

78E: ;

$783:$

784 : ;

785: ;

78E: ;

787:

$788:$

$789:$

$790:$

791:

79: :

$793:$

$794:$

$795:$

79E:

$797:$

$798:$

799:

BQ10:

801:

Qดि:

$803:$

8017:

$845:$

8DE:

807:

8D8:

8RI :

810:

Q11:

81: :

$813:$

814:

8.5:

घ16:

817 :

818:

819:

8E: :

Q21 :

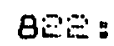

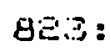

QE4:

8อ:

BEE:

827 :

$8=8$ :

8 8:

8.20:

831: :

B3: :

83.3:;

8.34:;

835:

ESE:

A37:

638:

859:

Q4D:

;

;

INPUT: (A) - READING OF SWITCH TO CHECK. (R15=1-RIZ=4)

$* * * * * * * * * * * * * * * * * * * * * * * * * * * * * * * * * * * * * * * * * * * * * * * * * * * * * * * * * * * * * * *^{*} * * *^{*} * *$
SOFTWARE SWITCH POSITION EQUATES AND VALUES

;

SWON

ACTUAL READINGS: $10=O N$, $2 A=O F F, F F=A U T O(1 \Xi / 24 / 81 \mathrm{JWS})$

SWSON EQU DIDH ;DQ - IC IS ON

SWSOFF EQU DISH ;1D-94 IS OFF

SWSAUTD EQU

BFFH ;95 - FF IS AUTO

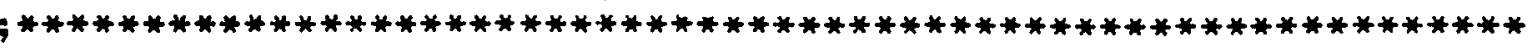

SWSFT: PUSH B

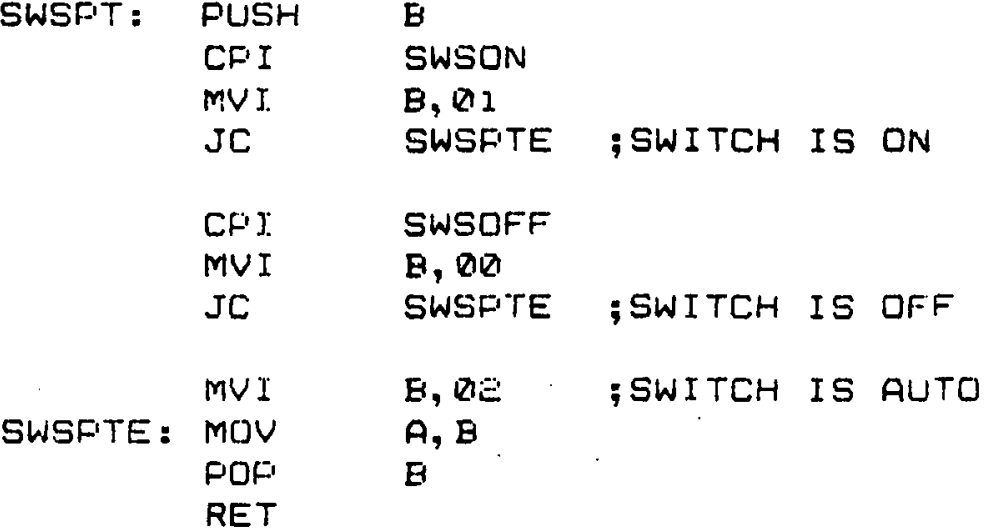

; ************************************************************ ; READ DISFLAY INPUT SWITCHES (1/E/8E SS \& JWS)

; INFUT: NONE

; OUTFUT: (A) - SETTING OF DISFLAY SWITCHES

; ***********************************************************

DISFSW EQU ICOUH ;ADDRESS OF DISFLAY CONTROL SWITCH

; $* * * * * * * * * * * * * * * * * * * * * * * * * * * * * * * * * * * * * * * * * * * * * * * * * * * * * * * * * * *$

DISFRSI:LDA DISFSW ;READ DISFLAY SWITCH SETTING

AIVI DIFH GLEAR UFFER NIEELE

RËT"

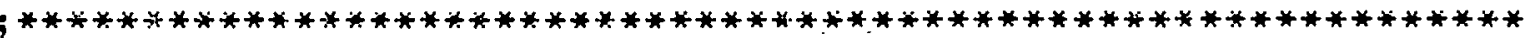

; CONTROL HEAT FUMP ROUTINE ( 1 E/EB/BI JWS)

; DISAEI.E./ENAFI F HFAT FUMF (RELAY \#E)

; *************************************************************

CTRLhF: LDA FRELE ;RELAY \#E CONTROi- VARIAEi_e

MOV $C, A$

LDA SFSW4 ;SOFTWARE SWITCH \#4.

MVI E, RELAYE:RELAY \#E EIT FATTERN

MUI $\left[1, D_{2}\right.$;FROGRAM/MANUAL EXECLITION CODE

CALL UFRELS ; TURN (ON/OFF) RELAY \#E

RET

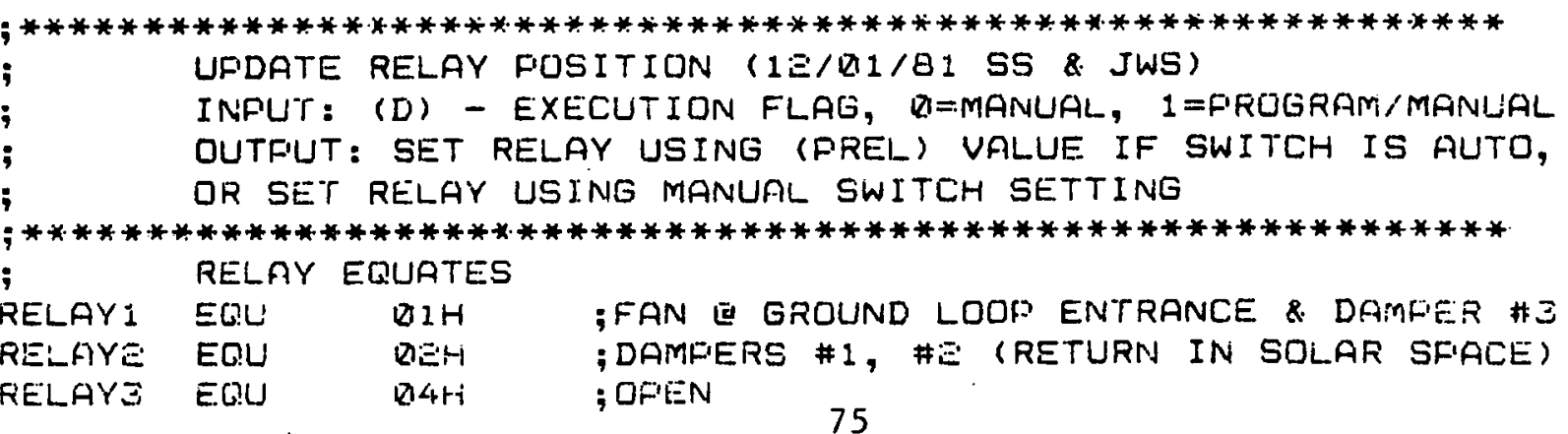




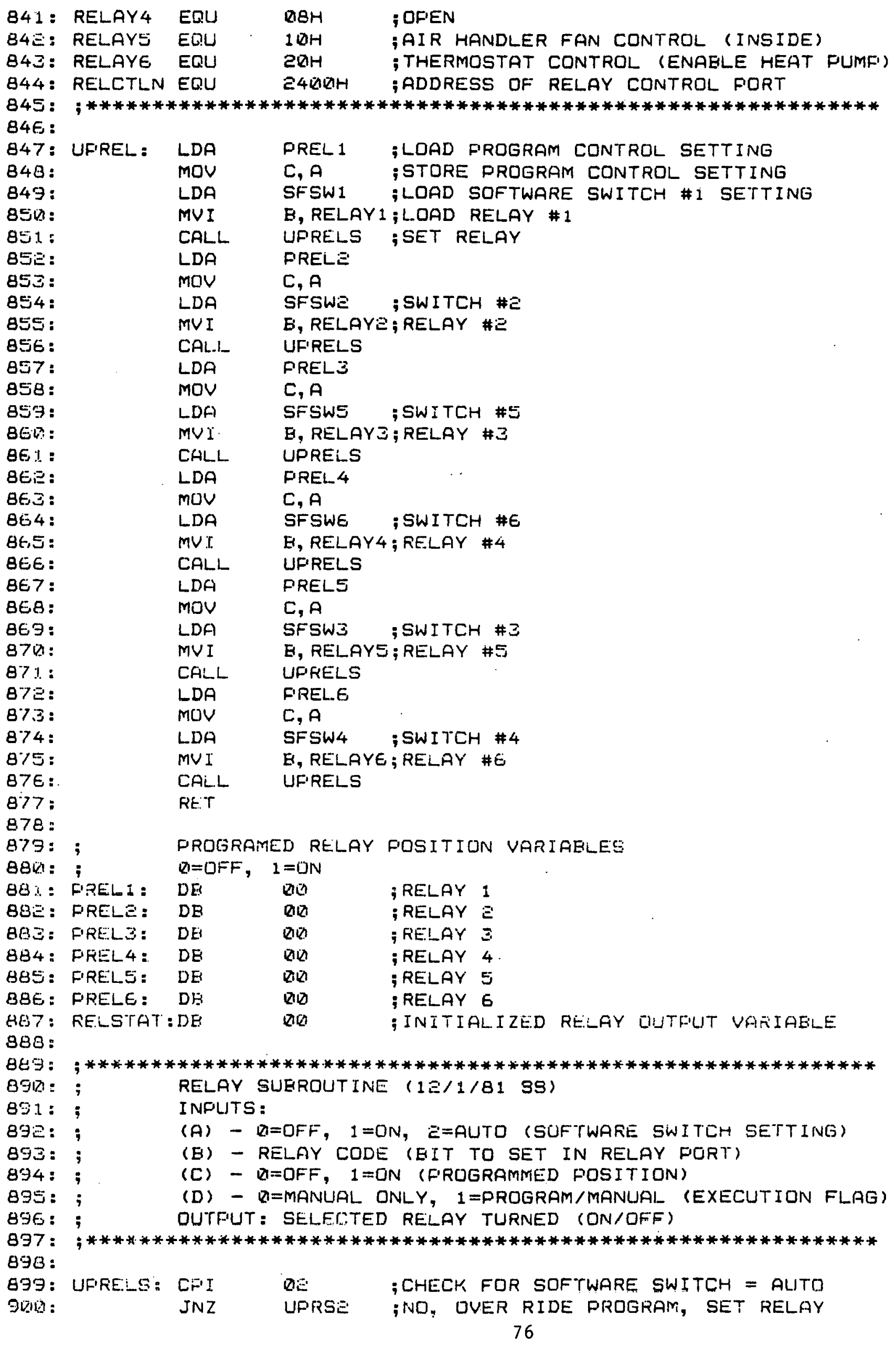


90:

903:

904:

905:

gQE:

907 :

908:

969:

910:

911:

1ㅡ:

$91 \Xi:$

914:

$915:$

9גE:

917:

918:

919:

9Еญ:

9E1: ;

ЭЕE: ;

9อง:

924:

9Es:

ЭEE:

$927:$

9Е日:

9.5:

$930:$

931:

$932:$

933:

954:

$935:$

93E:

$937:$

$938:$

$939:$

940:

$94 !:$

94E:

943:

944:

945:

946 :

947 :

948:

949:

9 的:

951:

95อ:

953:

954:

955:

95E:

957 :

$950:$

$959=$

ЭED:
;

SOFTWARE SWITCH IS IN AUTO POSITION

MOV $A, D$;GET EXECUTION FLAG

CFI DO

$\mathrm{JZ}$

UFEND

; CHECK FOR MANUAL ONLY

;EXECUTE MANUAL SETTINGS ONLY, EXIT

UF'RSE: $\begin{array}{ll}\text { MOV } & A, C \\ \text { CPI } & D D\end{array}$

JNZ UFRSZ

MOV $A, E$

CALL

JMFF

iYES, ITS OFF

; USE PROGRAMMED PUSITION TO SET RELAY

; IS THE RELAY OFF?

;NO, ITS ON

UFRSE: MOV A, B

CALL

RELAYON ; CUT THE RELAY ON

UFEND: RE'

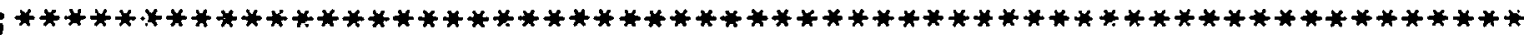

RELAY (DN) ROUTINE (1E/Ë/Bi SS.\& JWS)

INFUT: (A) - RELAY CODE, EIT(S) TO SET IN RELAY PORT

OUTFUT: UPDATE (RELSTAT). VARIABLE \& SET RELAYS

; $* * * * * * * * * * * * * * * * * * * * * * * * * * * * * * * * * * * * * * * * * * * * * * * * * * * * * * * * * * *$

RELAYON:FUSH H ; HAVE REGISTERS

PUSH F'SW ;SAVE RELAY CODE

LXI. H, RELSTAT

ANA $M$ CHECK STATE

JNZ RELONEXX ; RELAY (S) ON, EXIT

; RELAY (S) OFF, CUT IT/(THEM) ON

POF FSW ;RESTOFE (A)

FUSH PSW

ORA M ;SET RELAY (S)

MOV M, A ;UPDATE RELAY STATE (RELSTAT)

STA RELCTLN ;SET RELAYS, WRITE TO FORT

RELUNEX : FIOF' FISW

FOP $\quad H$

RET

; $* * * * * * * * * * * * * * * * * * * * * * * * * * * * * * * * * * * * * * * * * * * * * * * * * * * * * * * * * * * * *$

; RELAY (OFF) RUUTINE ( $1 E / \Xi \Xi / 81$ SS \& JWS)

INFUT: (A) - RELFY CODE, EIT(S) TO SET IN RELAY FORT

OUTFUT: UFDATE (RELSTAT) VARIAELE \& SET RELAYS

RELAYOF:FUSH H

HUSH FSW

LXI H, RELSTAT

ANA $M$;CHECK STATE

JZ RELLOFEX ; RELAY (S) OFF, EXIT

; RELAY(S) ON, CUT IT/(THEM) DFF

POP PSW ;RESTORE (A)

PUEH FEW

XRA $M$;CLEAR FLAG

MUV M,A ;STORE NEW STATE

RELOFEXXPOF

RELCTLN ; SET RELAY (S), WRITE TO FORT

FSW

H 
SE 1:

962:

S63:

ЭE4:

$9 E 5:$

SEE:

YE 7 :

$9 \in 8$ :

SE :

$970:$

971:

97อ:

973:

974:

975:

976:

977 :

378:

979:

980:

381 :

98E:

$983:$

984:

$985:$

98E

387:

988:

$389:$

э9u:

991:

$99 \mathrm{E}:$

$99 \Xi:$

394:

$395:$

996.

997:

978 :

999:

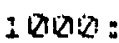

160:

100:

$10123:$

181414:

10ख5:

$10 R E:$

$1007:$

tकbe:

1 Qराख:

1 हो:

1011:

1iㄹ:

1101 3 :

1014:

1015:

101. 5 ;

1017 :

1018:

1019:

$10 \mathrm{a}$ :

RET

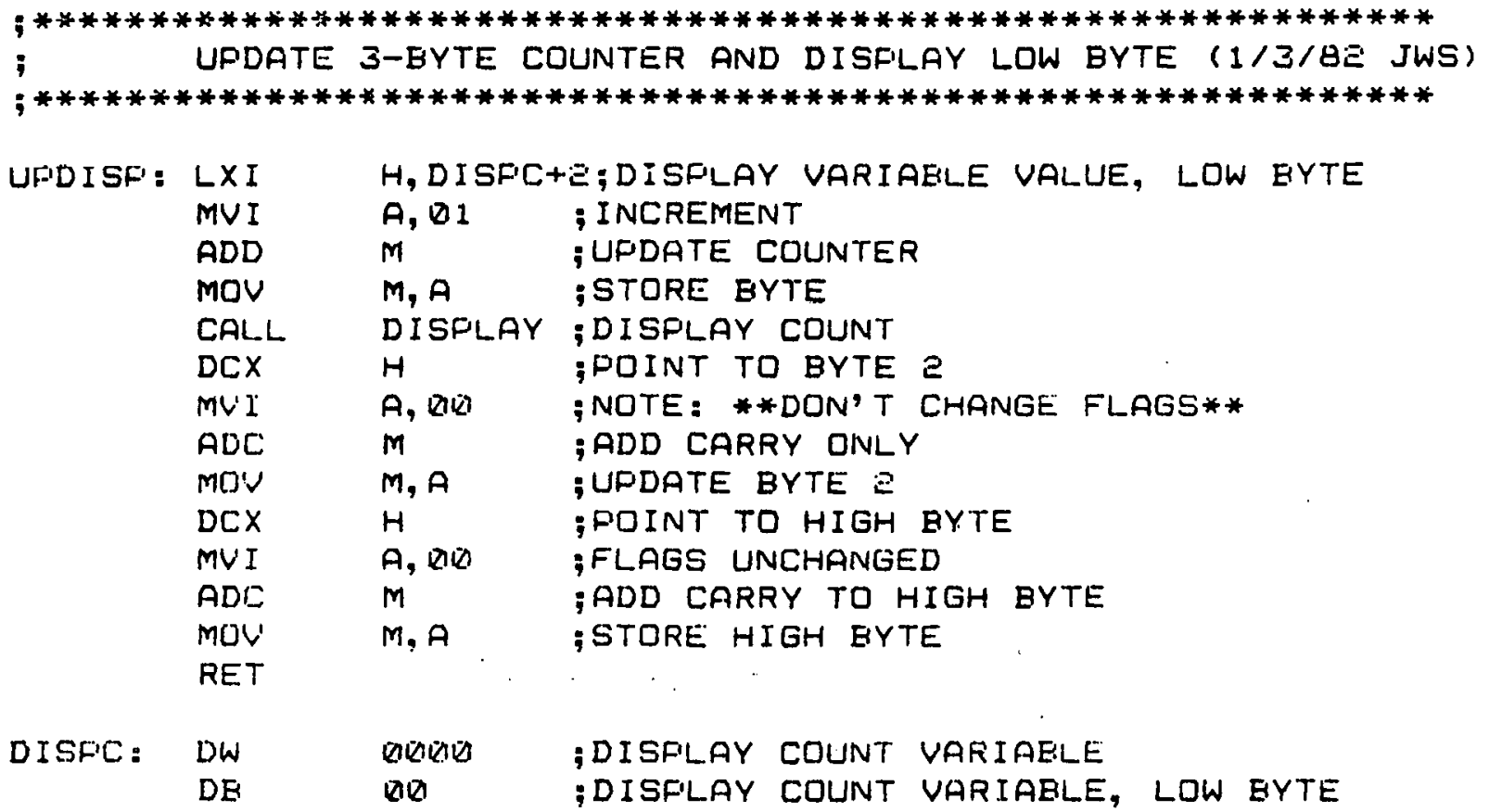

; $* * * * * * * * * * * * * * * * * * * * * * * * * * * * * * * * * * * * * * * * * * * * * * * * * * * * * * * * * * * *$

; DUTFUT (A) TO DISFLAY (11/24/81. SS \& JWS)

; INFUT: (A) - HEX DATA TD EE DISFLAYED

; OUTFUT: ALL REGISTERS FRESERVED

; $* * * * * * * * * * * * * * * * * * * * * * * * * * * * * * * * * * * * * * * * * * * * * * * * * * * * * * * * * * * *$ DISCNTL EOU EQUQH ;ADDRESS OF DISPLAY CONTROL PORT

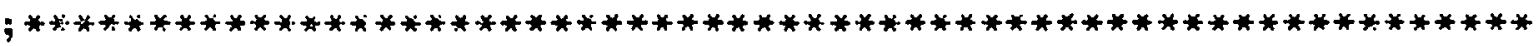

DISFLPY:STA DISCNTL ; WRITE HEX DATA TO DISFLAY

RET

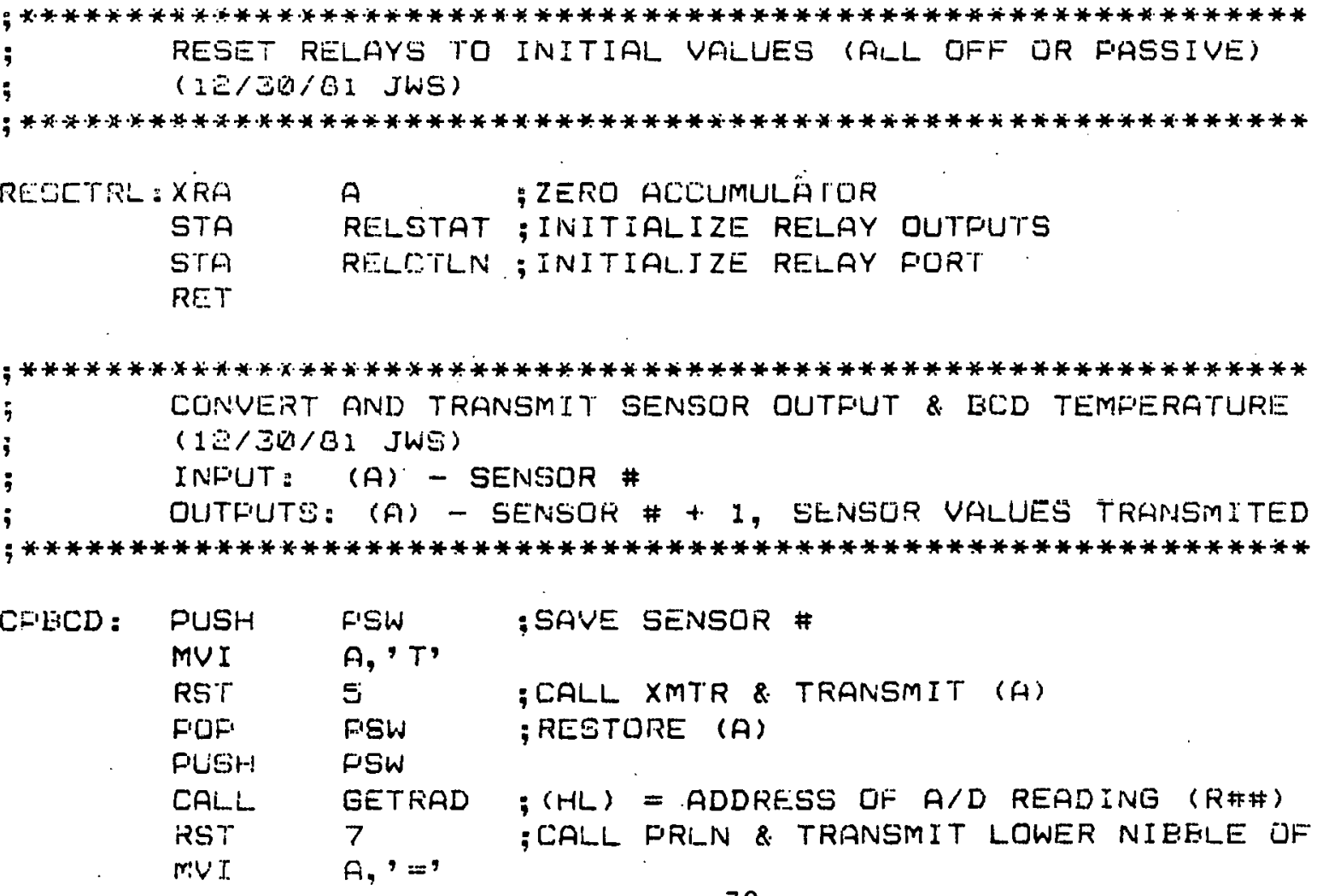




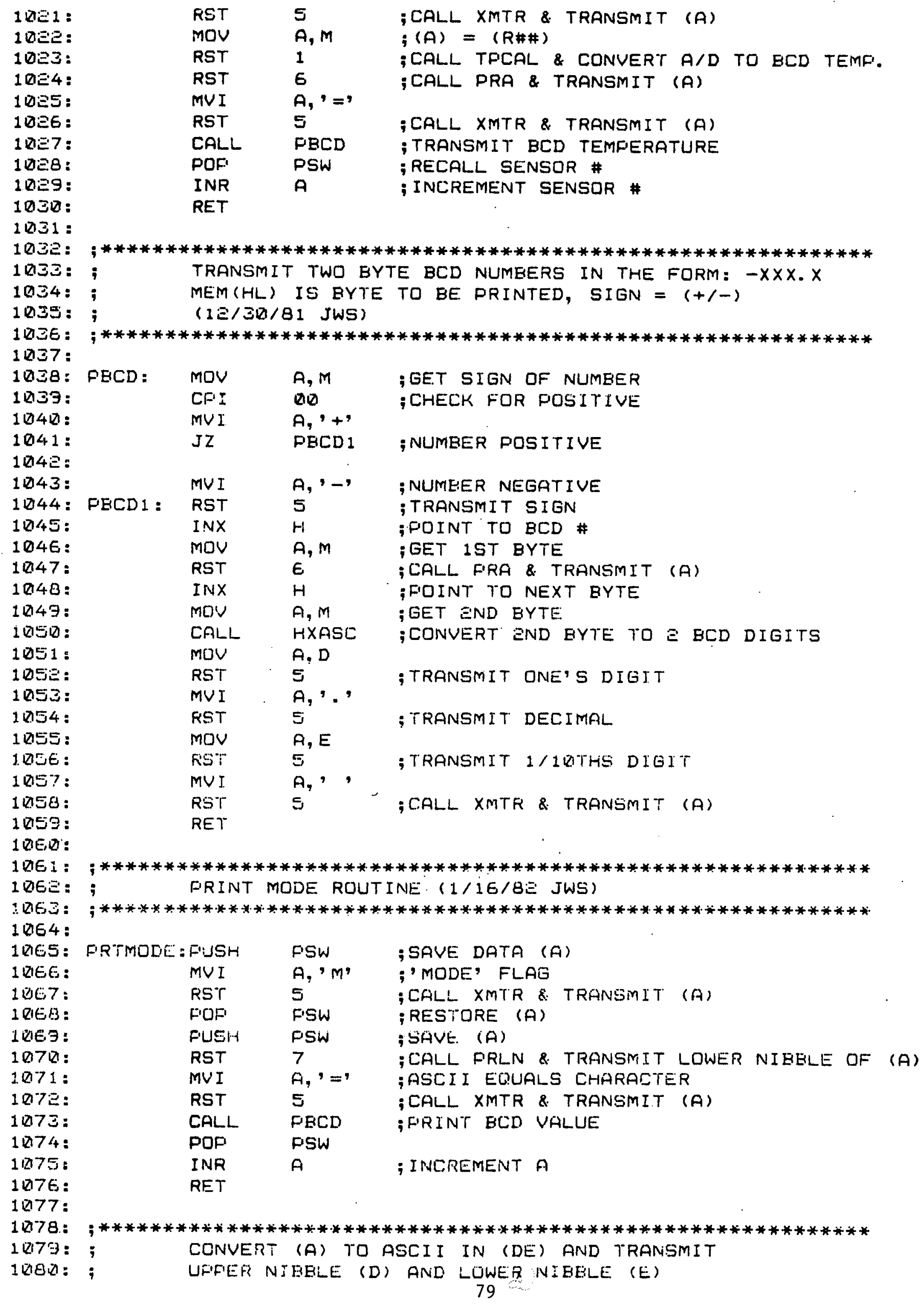


1081: $148 \mathrm{C}$ :

1083.

1084:

1 1685:

1R日E:

1087:

1038:

1089 :

1050:

1091:

1ष9E:

1093:

$1094:$

1095:

1096:

1097:

1098:

1039:

1100:

110i:

11QE:

$1183:$

$11014:$

$1105:$

$11 \nabla E$ :

$1107=$

1108 :

11.29:

1118:

1111:

1112 :

$1113:$

1114 :

1115:

1116:

1117 :

I11E:

1119:

$11 \geq 0$ :

11E: :

11ㄹ: ;

11E: :

$11 \Xi 4$ :

$11 E 5$ :

11อย:

1127 :

$11 \geq 8$ :

11.29 :

1130 :

1131:

$1130:$

$1133:$

1134:

$1135:$

$1,36:$

1137 :

1138 :

1135 :

1. 401 :

;

$\cdot * * * * * * * * * * * * * * * * * * * * * * * * * * * * * * * * * * * * * * * * * * * * * * * * * * * * * * * * * * * * *$

PRA: CALL HXASC ;CONVERT EINARY (A) TO HEX (DE)

MOV $A, D$

RST $\quad 5$;CALL XMTR \& TRANSMIT (A)

MOV $A, E$

RST 5 ;CALL XMTR \& TRANSMIT (A)

RET

;*************************************************************10

; CONVERT TO ASCII AND TRANSMIT LOWER NIBELE OF (A)

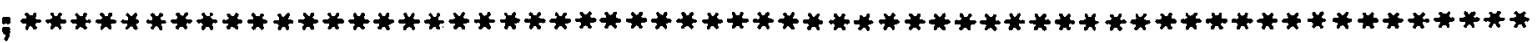

PRLN: CALL HXASC ; CONVERT BINARY (A) TO HEX (DE)

MOV $A, E$

RST 5 ;CALL XMTR \& TRANSMIT (A)

RET

; $* * * * * * * * * * * * * * * * * * * * * * * * * * * * * * * * * * * * * * * * * * * * * * * * * * * * * * * * * * * *$

MATH. LIB

VERSION

E. 5

$2 / 23 / 8=$

MATH IS A COLLECTION OF MATH AND UTILITY SUBROUTINES USED IN THE "SYSTEM".

SOFTWARE EY STEVE STEVENS \& JEFF W. SHIRLEY

; $* * * * * * * * * * * * * * * * * * * * * * * * * * * * * * * * * * * * * * * * * * * * * * * * * * * * * * * * * * * *$

$; * * * * * * * * * * * * * * * * * * * * * * * * * * * * * * * * * * * * * * * * * * * * * * * * * * * * * * * * * * * *$ ; TIME DELAY ROUTINE (1/31/82 JWS)

; $* * * * * * * * * * * * * * * * * * * * * * * * * * * * * * * * * * * * * * * * * * * * * * * * * * * * * * * * * * * *$

DELAY: LXI H, 587 ; LOAD DELAY VALUE $=0.01 \mathrm{SEC}$.

CALL WAIT ;MEL WAIT LOOP

DCF $\quad A$;DECREASE \# OF HUNDRETHS

JNZ DELAY ;CONTINUE LOOFING

RET"

; $* * * * * * * * * * * * * * * * * * * * * * * * * * * * * * * * * * * * * * * * * * * * * * * * * * * * * * * * * * * *$

; SIGNED EINARY COMPARE ROUTINE (1/31/8? JWS)

; IIVPIJI: \#S IN MEM(DE) \& MEM(HL)

; OUTFUT : $\operatorname{MEM}(H L)=\operatorname{MEM}(D E)$ - ZERD FLAG SET

MEM(HL) $>M E M(D E)$ - CARRY FLAG SET

MEM(HL) (=MEM(DE) - CARRY FLAG CLEAR

; $* * * * * * * * * * * * * * * * * * * * * * * * * * * * * * * * * * * * * * * * * * * * * * * * * * * * * * * * * * * *$

CMFEES: XEHE

LDFX

Cinfo $m$

$;-=1$ \& $+=0$, REVERSE OF $\#$ G

XCHE

; SIGN OF MEM(DE)

JNZ

CMFESE ;SIGNS DIFFERENT, FLAGS SET, EXIT

INX H H

INX D

CALL CIMFE iSIGNS THE SAME, CHECH NUMEER

DCX D

$\operatorname{DCX} \quad H$

CMFESE : RET 


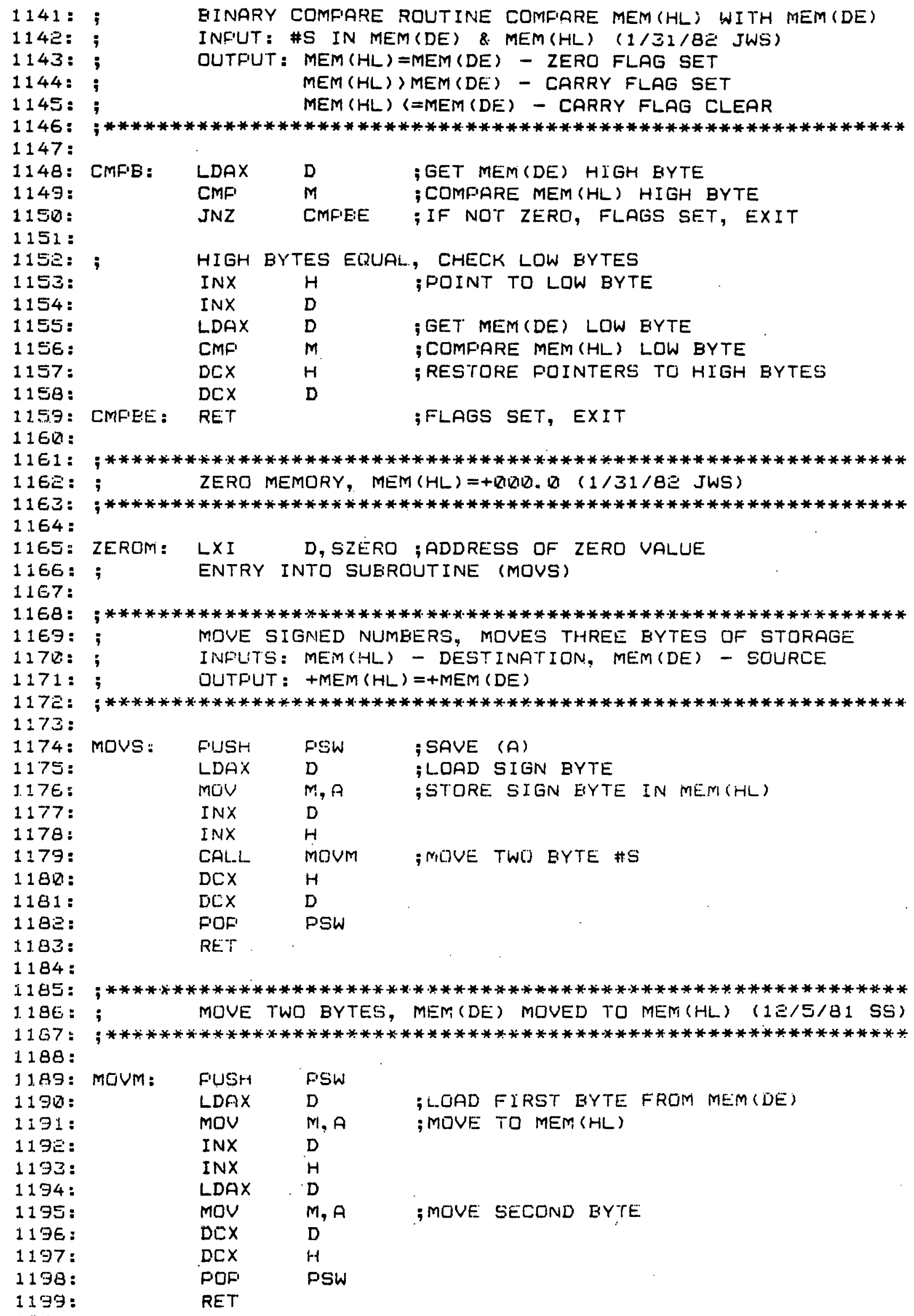


1E以1:

1อดล:

1ट円こ: ;

1อD4:

1205:

$1: R \in$

1 라:

1 롱

1Еㅂ:

1E1ద:

1己11:

1こ1ミ:

1리:

1อ14:

1도:

$1 \Xi 16:$

1Е17:

1อ18:

$1 \geq 1.9:$

1อコけ:

$1=1$ :

1こゴ :

1こシさ:

1 른

1른:

1こコも:

1อㄹ:

1르으:

1Ёت:

1Еコ约：

1Eさ1:

1モコこ:

1こする:

1ㄹㄴ:

1 콩

1ЕコE:

$1=3 \%$

1 こ๐ :

1こコア:

$1 E 40:$

$1=141=$

1こムも:

1주:

1Е44:

$1 \div 45:$

$1=4 E:$

$1 \Xi 47:$

$1 \div 48:$

$1=49:$

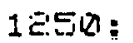

1 러네 :

1 1Ë5:

1E5:

1Е54:

$1=55:$

$1 E 56:$

1E57:

1 1 58 :

1도연

$1 E \in$ :
; ************************************************************* ; CONVERT (A) TO A VALID BCD NUMEER (\#\#) (1E/15/B1 SS) ; BINARY VALUE OF $\triangle E \Xi H=99 D$ IS LIMIT, WRAFING OCCURS

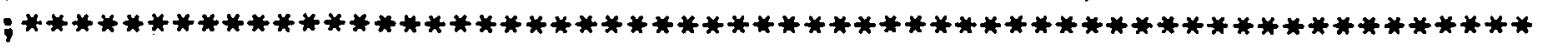
BCD : CPI QUD ;CHECK FOR ZERO JZ BCDEE ;ZERO IS A VALID BCD NUMEER

\begin{tabular}{|c|c|c|c|}
\hline & FUSH & $\mathbf{B}$ & ; SAVE REGISTER (B) DATA \\
\hline & MOV & $\mathbf{B}, \mathbf{A}$ & ; SAVE BINARY VALUE \\
\hline & $X \cap A$ & $A$ & ;ZERO BCD \# \\
\hline \multirow[t]{9}{*}{ BCDLF: } & $A D I$ & $\nabla 1$ & ; INCREMENT ECD \# \\
\hline & $D A A$ & & ;CONVERT (A) TO PACKIED ECD NUMEER \\
\hline & MOV & $C, A$ & ;SAVE ECD \# \\
\hline & MOV & $A, B$ & ; RECALL EINARY VALUE \\
\hline & SEI & $\nabla 1$ & ; DEC.REMENT EINARY VALUE \\
\hline & $J Z$ & ECDE 1 & ; IS EINARY VALUE ZERO? \\
\hline & mav & $\mathrm{B}, \mathrm{A}$ & ;NO, SAVE CURRENT EINARY VALUE \\
\hline & MOV & $A, C$ & ; RECALL CURRENT ECD \# \\
\hline & JMiF' & ECDLF & ; REPEAT LOUF \\
\hline BCDE 1 : & MOV & $A, C$ & ; RECALL FACKED BCD \# \\
\hline & FOP & $\mathrm{B}$ & FESTORE (B) \\
\hline$E C D$ & RE:T & & \\
\hline
\end{tabular}

; ************************************************************ ; BCD ADDITION ROUTINE - MEM (HL) $=M E M(H L)+M E M(D E)$

; THO EYTE ADDITION USING MEMORY POINTERS (DE.) \& (HL) ; GENERAL FORM OF ECD NUMEERS: \#\#\#.\# (ABSDLUTE VALUES) (1己/QIS/BI SS)

; $* * * * * * * * * * * * * * * * * * * * * * * * * * * * * * * * * * * * * * * * * * * * * * * * * * * * * * * * * * * *$

ADDM: FUSH PSW

INX D

INX H

LDFIX D

$A D D \quad M$

DAF

$m, A$

DCX

$M, A$

$\operatorname{DC} x$

D

$H$

LDffX

D)

ADC $M$

; INCREMENT (DE)

DAR

M

MOV

$M, A$

FIOF

FSW

; LOAD (A) INDIFELT LISING ALDRESS (DE) ; ADD BYTE ADDRESSED EY (HL) TO (A) ; CONUERT (A) TO FACKED ECLD INUTEER

RET

;DECREMENT (DE)

; ADD EYTE ADDRESS (HIL) \& CARFY TO (A) ;CONVERT (A) TO FACKED ECD NUMIEER

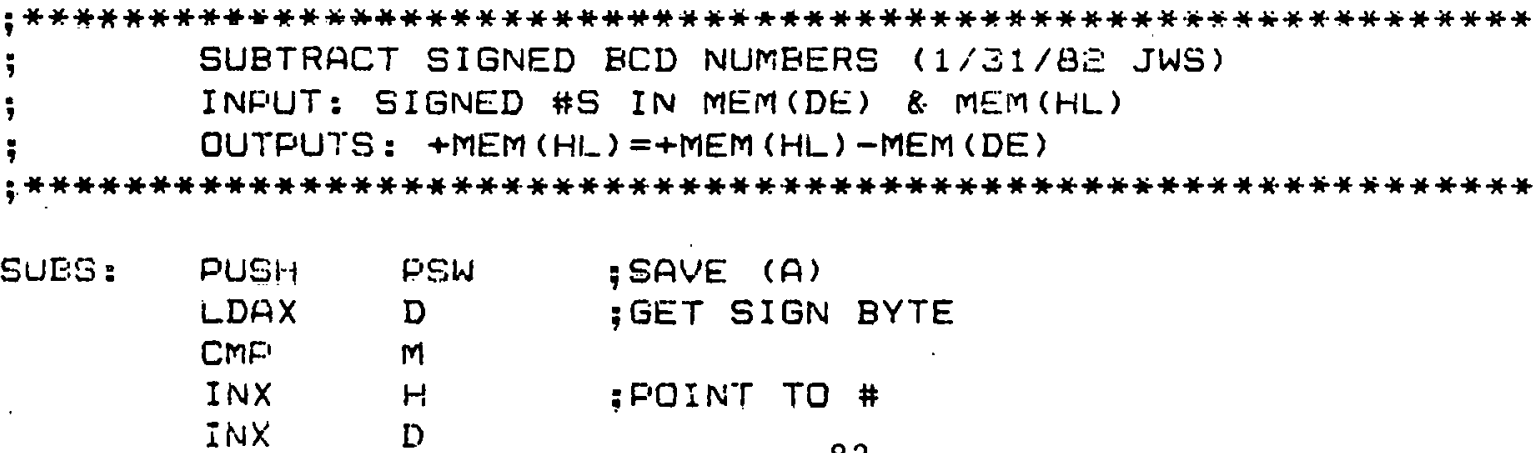




\begin{tabular}{|c|c|c|c|c|}
\hline $\begin{array}{l}1 \Xi \epsilon 1: \\
1 \Xi \epsilon \equiv:\end{array}$ & & $j z$ & SUBS 1 & ; NORMAL SUE. \\
\hline 1EES: & ; & RESULT & WILL EE T & THE DEFAULT SIGN OF MEIM(HL) \\
\hline $1 \geq 64:$ & & CALL & ADDM & ;SIGNS WILL BE THE SAME ADD \\
\hline $\begin{array}{l}1 \Xi \in 5: \\
1 \Xi \in E:\end{array}$ & & JMFI & SUBSE & \\
\hline $1 \Xi E 7:$ & SUBS1 : & PUSH & H & \\
\hline 1268: & & PUSH & D & \\
\hline $1 \Xi \in 3:$ & & & CMFB & \\
\hline 1こ7ロ: & & JC & SUBSE' & ;MEM $(H L)>\operatorname{MEM}(D E)$ \\
\hline 1อ71: & & & & \\
\hline 1ミ7こ: & & $X[H G$ & & \\
\hline $1273=$ & & $L X I$ & $H$, TEMFD & \\
\hline $1274:$ & & CALL & moum & ; MOVE MEM (HL) TO TEMFIT \\
\hline 1E75: & & POP & $H$ & ; RESTORE MEM(DE) POINTER \\
\hline $1 己 76:$ & & FUSH & $H$ & ; RE-SAVE (HL) \\
\hline $1 \Xi 77:$ & & $X C H G$ & & \\
\hline $1278:$ & & CALL & MOVM & ;MEM $(H L)=$ MEM (DE) \\
\hline $1279=$ & & LXI & D, TEMFD & ;CURRENT LOCATION OF MEM(HL) \\
\hline 1ËBQ: & & $D C X$ & $H$ & ;SET SIGN TO NEGATIVE \\
\hline 1こも1: & & MVI & $A, \otimes 1$ & \\
\hline 1CBË: & & MOV & $M, A$ & ;STORE NEGATIVE SIGN \\
\hline $1283:$ & & INX & $H$ & ;FOINT BACK TO \# \\
\hline $1284=$ & SUES: : & CALL & SUEM & \\
\hline $1 \geq 85:$ & & POF & D & \\
\hline $1 \supseteq 8 E:$ & & FOF & H & \\
\hline $1 こ 87:$ & SUESE: & $D C X$ & $H$ & ;FOINT TO SIGN BYTE \\
\hline $1 \geq 88:$ & & DCX & D & \\
\hline $1283:$ & & FOF & Fisw & ; RESTORE (A) \\
\hline $1 \Xi 90:$ & & RET & & \\
\hline iอ91: & & & & \\
\hline $1 \Xi \exists \Xi:$ & 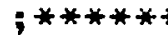 & $* * * * * * *+$ & $* * * * * * * * * *$ & 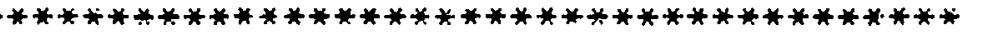 \\
\hline $1 \Xi 93:$ & ; & BCD SUI & BTRACTION & ROUTINE - MEM (HL) $=\operatorname{MEM}(H L)-\operatorname{MEM}(D E)$ \\
\hline $1294:$ & ; & TWO EY & TE SUETRAL & ACTION LISING MEMORY FOINTERS (DE) \& (HIL) \\
\hline $10955:$ & ; & GENERAL & L FORM OF & BCD NUMEERS: \#\#. \# (MEM(HL) > MEM(DE)) \\
\hline $1296:$ & ; & $(1 E / Q)$ & (8) 55) & \\
\hline $1 \Xi 37:$ & 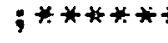 & 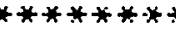 & $* * * * * * * * * *$ & 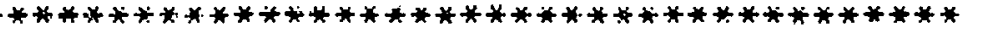 \\
\hline 1E98: & & & & \\
\hline $1939:$ & SI.JEM: & FiJSH & E & ; SAVE: (EC) \\
\hline 13010: & & MOV & $\mathrm{B}, \mathrm{A}$ & \\
\hline 13政: & & $X C: H G$ & & ;EXEHFINGE (HE) \& (DE) \\
\hline $130 三:$ & & INiX & D & \\
\hline $1303:$ & & INX & $H$ & \\
\hline $1304:$ & & LDAX & D & ;LOAD (A) INDIRECT USING FUINTER (DE) \\
\hline $1305:$ & & SUE & m & ; SUBTRACT MEM(HL) FROM (A) \\
\hline $13 \not 26:$ & & DAA & & ;COONVERT (A) TO FACKED EEDD NUMEER \\
\hline $13077:$ & & STAX & D & \\
\hline $13 \not 8:$ & & DCX & $H$ & \\
\hline 1309: & & $\operatorname{DCx}$ & D & \\
\hline $1310:$ & & LDAX & $\mathrm{D}$ & · \\
\hline 1こ11: & & SEE & $m$ & ; SUETRACT MEM (HL) WITH BORROW FFEUMM (A) \\
\hline $1 \Xi 1 \Xi:$ & & DAA & & ;CONVERT (A) TO FACKED BCD NUMEER \\
\hline $1313:$ & & STAX & D & \\
\hline $1314:$ & & MOV & $A, B$ & \\
\hline $1315:$ & & FOF' & E & \\
\hline $1316:$ & & $X \mathrm{CHG}$ & & \\
\hline $1317:$ & & RET & & \\
\hline $1 \Xi 18:$ & & & & \\
\hline $1319:$ & ; * & 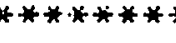 & $* * * * * * * * * *$ & $* * * * * * * * * * * * * * * * * * * *$ \\
\hline $1 \Xi \Xi \nabla:$ & ; & SHIFT & $M E M(H L)$ G & ITVE NIBEL..E TQ THE LEFT (BCD MULT. BY 1Q1) \\
\hline
\end{tabular}




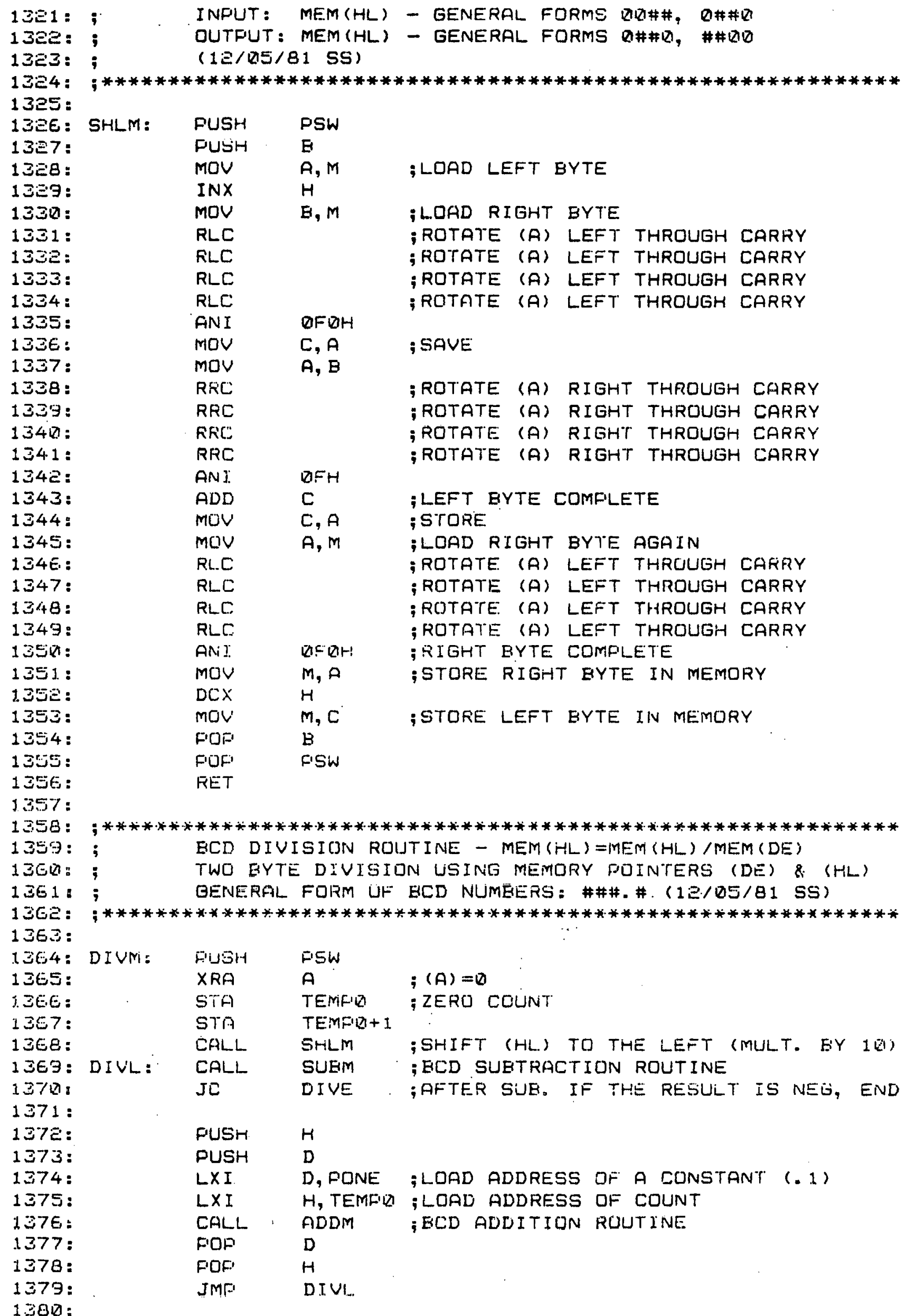




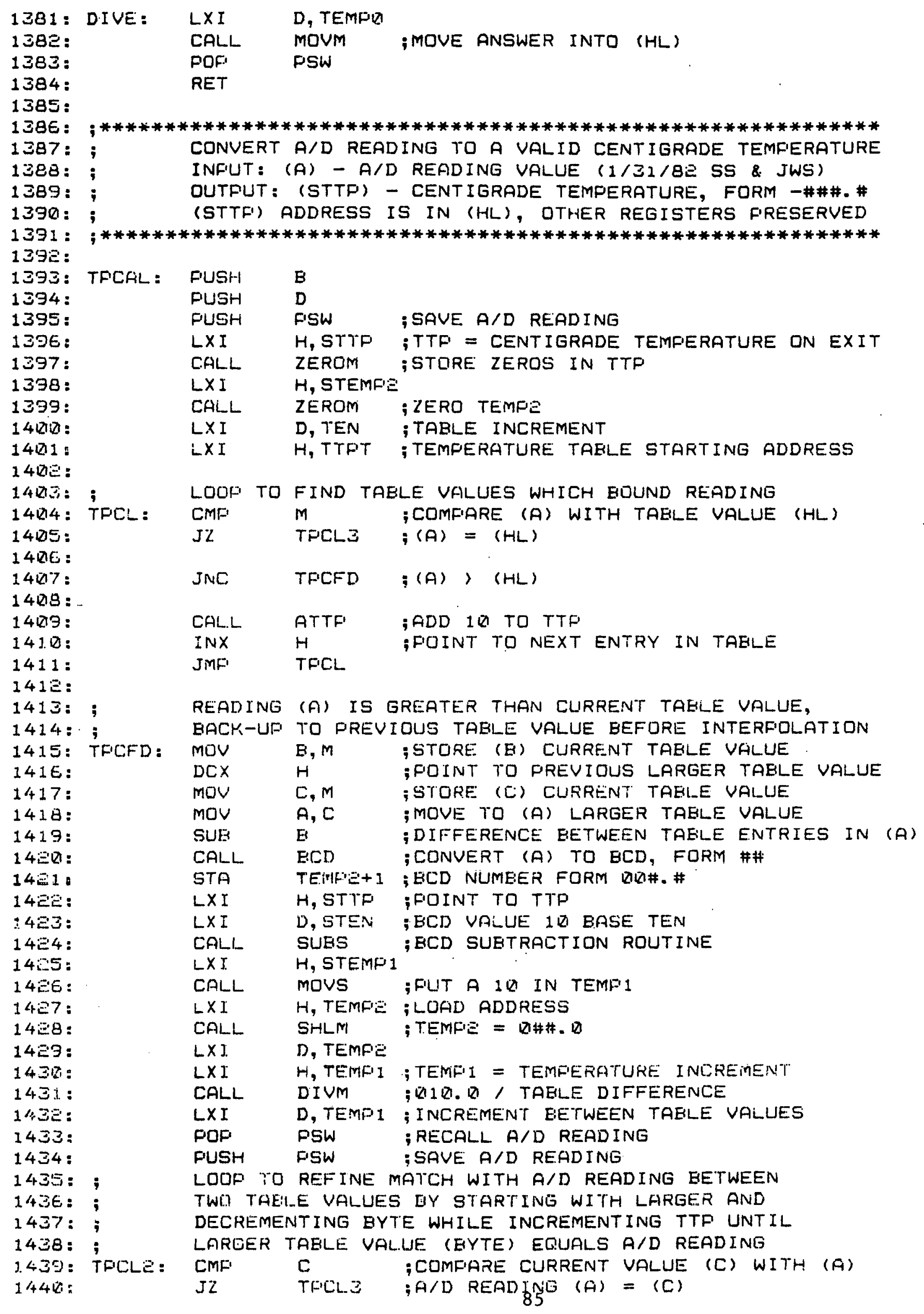


1441:

1440 :

$1443:$

$1444=$

$1445:$

$144 E:$

1447 :

$1448:$

1449:

145 :

1451:

145 :

$1453:$

1454 :

1455 :

145E:

1457 :

1458:

$1459:$

14EQ:

14E1:

$14 E \mathrm{Q}:$

14Eכ:

14E4:

$1465:$

$146 E:$

1467:

14E8:

1469:

$1470:$

1471:

$1472:$

$1473:$

1474:

1475 :

$1476:$

1477 :

1478:

1473:

$148 \mathrm{k}:$

14E1:

$148=$

$148.3:$

1483:

$1495:$

14BE:

$148 \%:$

14e日:

1489 :

1490:

1491:

$149=:$

$1493:$

1494:

1495 :

1. 496 :

1.497:

$1498:$

1479 :

1540 :

$\begin{array}{lll}\text { CALL } & \text { ATTE } & \text {; INCREMENT TEMFERATURE (RESULT) } \\ \text { DCR } & \text { C } & \text {;DECREMENT (C) CURRENT VALUE } \\ \text { JMF } & \text { TPCLE } & \end{array}$

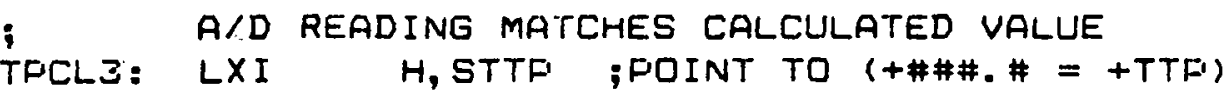

LXI D,STSD ;POINT TO (+DSQ.D $=+T S Q)$

- COMFUTE CENTIGRADE TEMPERATURE (TTP) = BCD READING - SD

CALL SUES ; SUETRACT SIGNED NUMEERS

TPCLED: POF FSW ;RESTORE A/D READING

POF-1 D

F'OFI B

RET

; ************************************************************

; ADD THE NUMBER IN MEM(DE) TO TTP (TEMPERATURE RESULT)

GENERAL FORM OF ECD NUMBERS: \#\#\#.\# (1E/DE/BI SS)

; $* * * * * * * * * * * * * * * * * * * * * * * * * * * * * * * * * * * * * * * * * * * * * * * * * * * * * * * * * * *$

ATTF: $\quad$ PUSH $H$

LXI H, TTF

CALL ADDM ;ECD ADDITION ROUTINE

POP H

RET

; $* * * * * * * * * * * * * * * * * * *-* * * * * * * * * * * * * * * * * * * * * * * * * * * * * * * * * * * * * * * * * * *$

; TEMFERATURE TAELE, EACH BYTE REFRESENTS A

; ID DEGREE CENTIGRADE: TEMFERATURE INCREMENT

; ************************************************************

ZEROUAL EQU DCTH ODEFINE ZERO VALUE READING

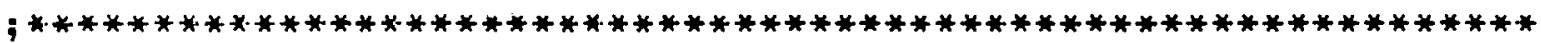

; INITIAL VALUE MUST BE LARGEST READING FOSSIBLE

TTFT: DE QRFF :TEMF $-5 \triangle \mathrm{C}$

DE DFEH TTEMF $-40 \mathrm{C}$

DE QFTH ;TEMF $-3 Q C$

DE RECH JTEMF -EV C

DE DDEH TTEMP $-1 Q C$ C $1 / 11 / 8 E$ JWS

DE DCTH ;TEMF Q $C 12 / D E / B I$ JWS

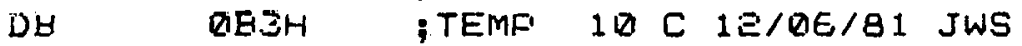

DE QICH TTEMF ED C $1 \overrightarrow{2} / 05 / 81$ JWS

DE DTBH ;TEMF ZQR C E/EE/BE JWS

DB DE4H ;TEMF 4D C E/Ë/BE JWS

$\mathrm{DB} \quad \mathrm{DHF}$

DE: D4QH

DE $234 \mathrm{H}$

DE $\mathrm{DECH}$

DE QEEH

DE DIDH

DE $\triangle 1 \mathrm{CH}$

DB $\square I E H$

DB DIAH

DB QI9H

DE $\square 18 H$

DEI DITH

DE $\square 1 E H$

IDE DIEH

DE $\square 15 H$

DE Q3.5H
ITEMF . SQ C $2 / Z E / B E$ JWS

TTEMP EQ C

; TEMP $7 G \mathrm{C}$

; TEMF $8 D C$

; TEMP $9 \square$ C

; TEMF 1 HIL $C$

- TEMP 118 C

; TEMF 1ER C

- TEMF 130 C

; TEMP 140 C

; TEMP $15 Q C$

; I"EMF 16 Q C

- TEMF 17R C

; TEMA $18 \square \mathrm{C}$

-TEMF $19 R$ C

TEMF EUL $8 \tilde{6}$ 


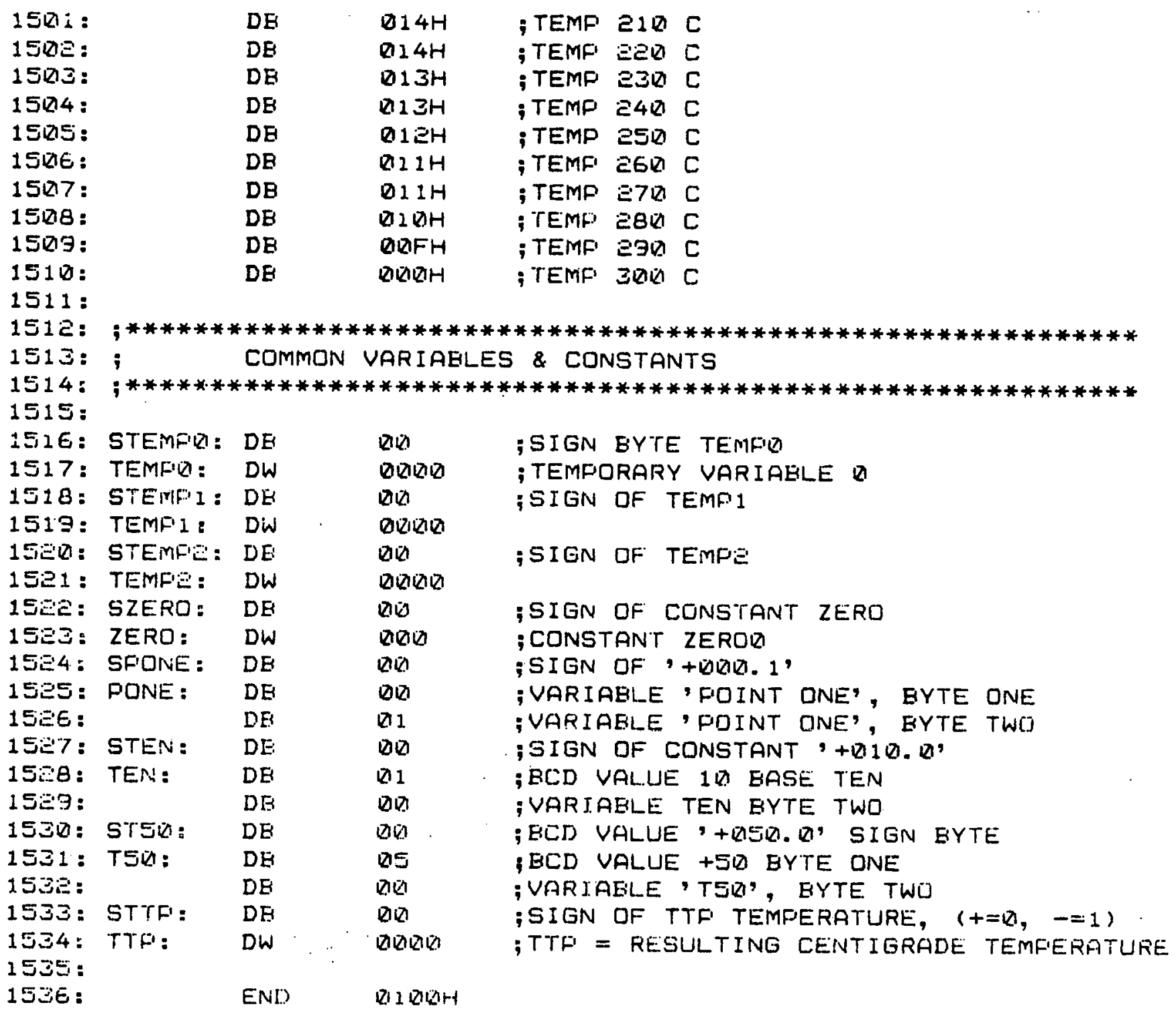




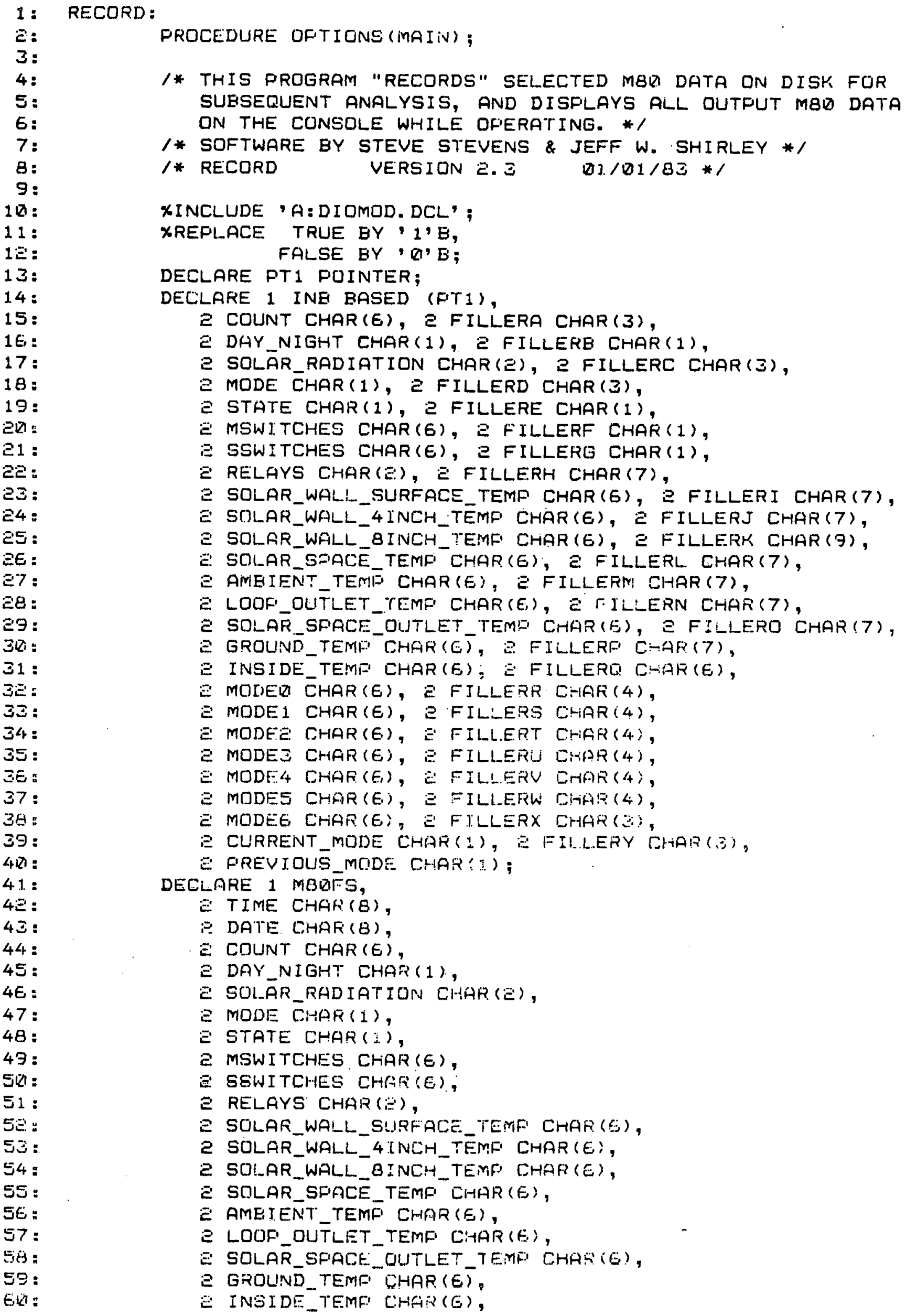


61:

6iे:

63:

E4:

65:

6E:

67 :

68 :

69:

$70:$

$71:$

7E:

$73:$

74 :

$75:$

7E:

77 :

78 :

$79=$

80:

81:

BE:

$83:$

84:

85:

$B E$ :

87 .

88 :

89 :

$\exists \overline{0}:$

$91:$

$92:$

$93:$

94 :

$95:$

ЭE:

97 :

38 :

$99=$

1000 :

地1:

$1 \nabla=$ :

$103:$

1 14:

$145:$

1 DUE:

$147:$

$10 \mathrm{R}:$

$109:$

110 :

11 i :

11 :

$113:$

$114:$

$115=$

126:

117:

$1 \div 8$ :

119:

j.
Z CURRENT_MODE CHAR (1),

¿ PREVIOUS_MODE CHAR (:);

DECLARE INBUFF (こ54) CHAR (1),

(FLAG1, FLAGE, STORE_FLAG) BI $\Psi^{\prime}(1)$,

( I, J, CTSD, CTSI, II, TP) FIXED;

DECLARE MBQTF FILE;

DECLARE PRELAYS CHAR (E), MAXCOUNT FIXED EINARY(7);

/ * INITIALIZE * /

PUT F'AGE;

CALLL SET_TIME (E, כQ); $/$ SET TIME ON ROW E, COI.UMN ZÜ */

CALL SET_DATE $(4,3 Q) ; \quad 1 *$ SET DATE ON ROW 4, COLUMN $3 \square * 1$

$\mathrm{J}=\mathrm{V}$;

CTSQ $=\square$

CTS1 = Q

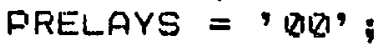

MAXCOUNT = $=$ O४;

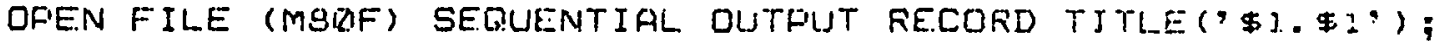

FUT FAGE SKIF(D) EDIT(, ***** SYNCHRONIZINIS WITH MER,

' DUTFUT DATA *****') (CDLUMN $(1 F), A, A)$;

CALL CONOUT (ASCII $(\otimes 7)) ; / *$ RING EELL *

CALL CONOUT (ASCII $($ BI) ); $/$ HOME CURSOR *

FLAG 1 = TRUE;

F'T $1 .=$ ADDR (INEUFF $(1)$ ); $/$ * INB STRLICTURE = INFIUFF GRATY *

* MAIN CONTRDL LOUP *

DO WHILE (FLAGI);

IF (RDSTAT()) THEN / * CONTRU: Q TO QUUT *

IF RANK(CDNINF()) $=17$ THEN GOTC EXIT;

FLAGE = TRUE;

* ChECK FOR DATA From MaQ *

DO WHILE (FLAGË);

IF (RDSTAT()) THEN /* CCINTROL O TU DLIIT */

IF RANK(CONINP()) $=17$ THEN GUTO EXIT;

IF (RANK(RDRDR()) = Qu.) THEN $/ *$ STARI QF HEADER *

IF (RANK(RDRDR ( ) = RIE) THEN / STPRT DF TEXT */

* store all data fróm mg: *

Di] :

$I=1 ;$

INBULF (I) = RDRDR( );

INEUJF (I) = RDRDS(); / READ CR, ZF AND DISCIATD *

DO WHILE. SFLAGE: ;

INEIJFF(I) $=$ FDRDR();

* END OF TEXT *

IF RANH(INALIFF(I)) = MO THEN FLAGE = FGILEE

$I=I+1$;

IF (RDSTAT()) THEN I* CONTROL O :O GLIT *

IF RANK(CONINE() $=17$ THEN GOYO EXIY, END;

END;

END;

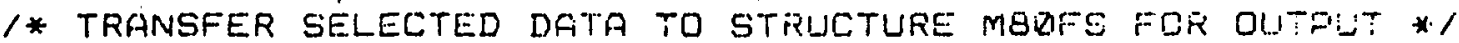
MEQFE. COUNTT = INE. COUNT;

MEZFS. DAY NIGHT = INE. DAY NIGHT;

MBQIFS.SOLARR_RADIATION = INEE. SOLAR_RADIATION;

MQOFS. MODE: = INE. MODE:

MBQFS. STATE = INB.STATE;

MBQFS. MSWITCHES = INE: MSWITCHES;

MBQFS. SSWITCHES = INE. SSWITCHES;

MBQFS. RELAYS = INE. RE:-AYS;

MBQTE. SOLAR_WAL!_GJREACE_TEMO =

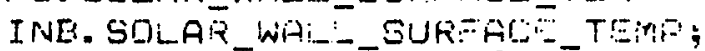


1 러:

1르:

1 롱

1อ4:

1255

1eE:

$127:$

1EB:

$1=9$ :

130 :

131 :

$13 \Xi:$

$133:$

$134:$

$135:$

1 IE :

137 :

138 :

$139:$

14 ㄷ:

141 :

$140:$

$143:$

144:

$145:$

146 :

147 :

148 :

$149:$

15 :

151 :

$15 \Xi:$

$153:$

$154:$

$155:$

156 :

$157:$

$1=8$ :

$159:$

$1 \in \mathbb{R}:$

$161:$

$1 E:$

$1 \in \Xi:$

1E4:

$165:$

1EE:

$167:$

IES:

IET:

$17 \%:$

$17:=$

170

$175:$

174 :

$175:$

$176:$

177 :

170:

$179:$

IBQ:
MBDFS. SQLAR_WALL_4INCH_TEMF- = INB. SOLAR_WALL_ 4 INCH_TEMF;

MBQFF. SOLAR_WALL_ $\bar{B}$ INCH_TEMF $=$

INR. SOLAR_WALL_EINCH $\bar{H}_{-}$TEMF;

MBQFS. SOLAR_SPACE_TEMF = INE. SOLAR_SPACE_TEMF;

MBQFS. AMBIENT_TEMF $=$ INE. AMEIENT_TEMF';

MBQAFS. LOOF_OUTLET_TEME = INE.LOOF'_OUTLET_TEMF';

MEQFS. SOLAR_SFACE_OUTLET TEMF' =

INE. SOLAR_SPACE__OUTLET̄_TEMF';

MBQFS. GROUND_TEMF = INB. GROUND_TEMF;

MQUFS. INSIDE_TEMP = INE. INSIDE_TEMF;

MBDFS. CURRENT_MODE = INE. CURRENT_MDDE;

MQDFG. FREVIOUS_MODE = INE.FREVIOUS_MODE;

MBDFS.TIME = TIME (); $/ *$ GET SYSTEM TIME *

CALL GET_DATE (MBQFS.DATE); / GET SYSTEM DFITE *

STORE_FLAG = FALSE;

IF MADיRF. STATE = QD, THEN

/ HeATING/COOLING SYSTEM IS DFF * 1

$\mathrm{DO}$

CTSI $=Q 7$

IF CTSD = MAXCOLMT THEN CTSQ = D;

IF CTSQ $=\emptyset$ THEN STORE_FLAG = TRUE;

END;

$C T S D=C T S Q+1 ;$

IF MBQTFS. STATE $=1$, THEN

/ HEATING/COOLING SYSTEM is ON *

$\mathrm{DO}$;

CTSR $=\mathbb{R}$

IF CTS1. = MAXCOCUNT THEN CTSI =

IF (FRELAYS $\sim=$ MBR:FS. RELAYE) TLEN CTSI = R;

IF (CTSI = Q) T!UEN STORE_FLAG = TRUE;

END:

CTSI = CTSI+ 1 ;

IF STORE_FLAG THEN

/* STURE: FLAG SET, DUTFUT TU DISH STRLOTURE riBHFS *

$\mathrm{DD}$;

END

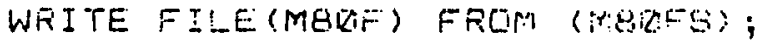

$J=J+1 ;$

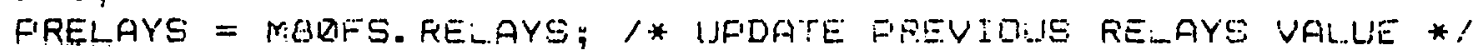

/ IJFDATE SCREEN */

FUT SKJF(D) LIST" (" ***** MEZ CONTROL SUMrGAFY ***** ",

, TIME = , MQQFS.TIME, DATE = , MQZES. SATE);

FUT SKIF EDIT (" (D=DAY/N=NIGHT) FHOTO-RESISTOR INDJEATES' ,$=$, MBQFS. DFY NIGHT) $(A)$;

FUT SKIP EDTT $("$ GOLFR RADIATICH REHDI:UG"

, = , MBQIES. SLLAR_RADIATIONI (A):

PUT SKIP EIST (' (H=FEATING, C=COOLING,"

, D=DEFROST) MODE = , MQRFS.MODE) (A);

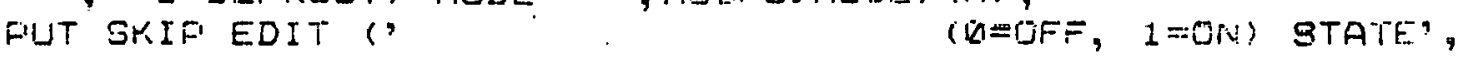

, = MBQFS. STATE) (A);

FUT SKIF EDIT (?

'= "MBRFS. MSWITCHES,"

MQDFS. SSWITCHES) (A);

FUT SKIF EDIT ("

, = ' MQDFES. RELAFYS (A);

MANDIF:- SWITCHES',

SOFTWARE SWITCHES = ,

RELAYY OUTFIJTS,

FUT SKIF EDIT (" SDLAR WALL TEMEERATURE AT,

' SURFACE = ", MEIZT:S. SOLAR_WALL_SLIFACE_TEMF', ${ }^{\prime}$ ') (A);

FUT SKIF EDIT $\%$ SQLAR WALL TEYFERFTURE AT',

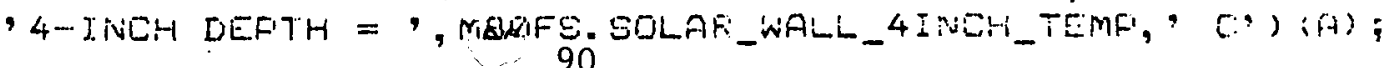


181:

$18 \mathrm{E}:$

185:

184:

$185:$

18E:

187 :

188:

189 :

$190:$

191:

19อ:

$193:$

194:

195 :

19E:

197 :

198:

199:

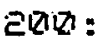

$201:$

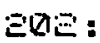

203:

2014:

EDIs:

ZUE:

Eख7 :

200:

EDי19:

리:

211:

E1E:

리응

214:

215:

ZIE:

E17:

도영

219:

$\because 2 Q_{1}$

a.

СE:

ㄹ:

E. 4 :

Ees:

$E E:$

Eะ7:

E:8:

로:

리:

E1.

こさ:

已コ一:

234:

อ35:

टजE:

237:

อ3e:

239:

$24+0:$

FUT SKIF EDIT \& SOLAR WA:LL. TEMFERATURE RT',

' B-INCH DEFTH = ', MQUKFS. SOLAR_WAL__BINCH_TEMF,' C', (A); PUT SKIP EDIT ' " SOLAR SFACE TEMFERATURE', ' = ',MBOFS.SOLAR_SFACE_TEMF,' $C$ ') (A);

PUT SKIF EDIT $("$ AMBIENT TEMFERATLRE', ' = ', MBDFS. AMEIENT_TEMF,' C') (A);

FUT SKIF EDIT $("$ GROUND LOOF OUTLET TEMFERATURE', ' = ', MBOFS.LQOF__QUTLET_TEMF,' $\left.C^{\prime}\right)(A) ;$

FUT SKIP EDIT, SOLAR SFACE OUTLET TEMPERATURE', ' = 'MEQFS.SOL_AF_SFACE_QUTLET_TEMF,' C' '(A);

PUT SKIF EDIT (' GROUND TEMPEFATURE AT NW', , FOUNDATION = ', MBZIFS. EROUND_TEMF,' $C$ ') (A);

FIJT SKIF EDIT (' ' =, MOQIFS. INSIDE_TEMF,' $\left.C^{\prime}\right)(A)$;

PUT SKIP EDIT ('CURRENT MODE = ", MEQTF. CURRENT_MODE,' PREVIOUS MOD MEQFS. FREVIUUS_MODE) (COLUMN (E9), $A, A, A, A)$;

PUT SKIF;

/ DRiginal data from mBQ * 1

FUT SKIF EDIT( (INEUFF(II) DO II = 1 TO 243$)$ ) (A(1));

FUT SKIF LIST ( $J$, RECORDS STORED');

FUT LIST (', ', RECORD COUNTDOWN =', MAXCOUNT - CTSA - CTSI); CALL CONOUT (ASCII (D1.)); $/$ * HOME CURSDR *

IF (RDSTAT()) THEN /* CONTROL Q TO GUIT *

IF RANK(CONINF()) $=17$ THEN FLAOI = FALSE;

FOSITION: END; /* END OF FLAGI LOOF *I

PROCEDURE (ROW, COLUMN); /* AESCLUTE CUREOR ADDRESSINE * 1 DECLARE (ROW, COLIJMN) FIXED EUNARY (T);

FUIT SHIP(O); / SYNC:HRONIZE OUTFUTH *

CALL CONUUT (ASCII $(E 7)) ; \%$ OUTFUT TO CONSOLE "ESC" */

CALL CONOUT (ASCII $(B 9)) ; 1 *$ OUTFUT TO CONSOLE ' $Y$, *

CALLL CONOUT(ASCII $(\Xi 1+R O W)) ;$ MOVE TO ROW FUSITION *

CALL CONOUT (ASCI I ( $31+$ COLLMN)); /* MCVE TO COLUMA FUSITION * SET_TIME: END FOSITION; / CLREGIR FOSITIONED, EXIT *

PROCEDURE (RCW, COLLUMN); / SET SYSTEM TIME *

I* THIS FRUCEDLIRE REGUUESTS THE CURRENTT TIME FRUTH THE CONSOLE. THE INPUT TIME IS VA-IDATED AIND S"DRED IN THE " CLOCH,

MEMORY LOCATIONS OF THE INTTERTEC SUFERERAIN, THF RRUTINIE

CAN REQUEST THE TIME FROM MOST POSITIONS OE THE SCNSOLE

WITH THE FROGRAMMING LIMITSS GIVEN RELDW. *!

DECLARE INEUT_TIME CHFIR(B), (CFTI, COTE) POINTER:

DECLARE I TIME EASED (CFT1),

$$
\begin{aligned}
& \text { E HOUFS CHAR(E), } \\
& \text { E COLONI CHAR(I), } \\
& \text { E MINUTES CHAR (E), } \\
& \text { E COLONE CHAR(I), } \\
& \text { E SECONDS CHAR(E); }
\end{aligned}
$$

DECLARE SYSTFE TIME CHAR (B) EASED (CFTE);

DECLARE (HRS, MIN, SEG, FIW, COLUMN) FIXED EYNARY $(Y$ );

DECLARE NUMBERS STATIC CHAR (:Q) INITIAL (' B:3.3456787');

DECLAFE COLON STATIC CHAR(1) INITIAL (':'), NOEXIT BIT(1);

IF ROW $\langle 1$ ! ROW $\rangle=$ ! COLUITN $(5$ ! COLUMN > 47 THEN STOE;

CFT1 = ADDF (INPUT_TIME);

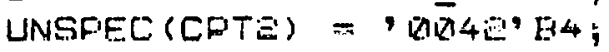

1* FOENT TU TIME IN INTERTEC *;

CALL ERASE_LINE $(R O W+3,1)$;

NOEXIT $=$ ' 1 ' $\bar{B}$;

DO WIIILE (NOEXIT):

CALL ERASE_LINE (ROW, 1 ); 
:-241:

e4:

터4:

$244:$

$245:$

E46:

247 :

E48:

249:

톰이 :

251:

른르:

25:

2054:

로:

ESE:

ㄷㄷㄴ

롱

259:

ÉG:

Ė 1 :

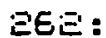

$\Xi \in \Xi$ :

EE4:

टES:

¿EE:

टET:

ЕE $\mathrm{A}$ :

EニE

깅

둔

크느:

273:

274 :

룯:

구:

추구

둥

구:

ERष:

쿠신

$28 \%$ :

Ee:

E04:

Ë85:

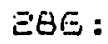

EB7 :

E自合:

루응

E910:

트:

E习: :

Еヨコ:

$294:$

Ë.5:

ËGE:

Ë7:

298:

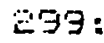

उBD:
CALL POSITION (ROW, COLUMN);

FUT EDIT('WHAT TIME IS IT? HH:MM:SS') (A);

CALL POSITION (ROW, COLUMN+28);

GET LIST (INFUT_TIME);

IF VERIFY (HOURS, NUMEERS) = \& VERIFY (MINUTES, NUMEERS) = D $\mathrm{DO}$; \&. VERIFY (SECONDS, NUMEERS) = THEN

HRS = HOURS;

MIN = MINUTES;

SEC = SECONDS;

IF HRS \& 34 \& MIN \& EU \& SEC \& EQ THEN

DO;

NDEXIT $=$ "B'B;

COLON $1=$ COLON;

END;

COLONE = COLON;

END;

IF NOEXIT $=$, 1 , E THEN

DO;

CALL FOSITION (ROW+1, COLUMNN-4);

FUT EDIT(ASCII $(121)$,' INVALID FORMAT, FLEASE, - RE-ENTER ', ASCII ( $13(2)$, ASCII (Q17) ) (A);

END):

END;

SYSTEM_TIME = INPUT_TIME;

END SET_TIME;

TIME:

PROCEDURE RE:TURIVS (CHARACTER ( 8$)$ );

1* assign cuRfEnt time *

1* THIS FROCEDURE REAdS MEMORY LOCATIONS (4E-4A) HEX IN THE

INTERTEC SUFEREFAIN TO RECALL THE CURRENT TIME. THE

TIME IS STORED AS 'HH:MM:SS' IN CHARACTER FORMAT. THIS

FROCEDURE RETUSUNS THE. 'TIME' CHARACTER STRING VARIABLE. * DECLARE CPT FOINTER, TIMIE CHAR (B) EASED (CFTT);

UNSFEC (CPT) = 'DU 4E' E4; / FOINT TO TIME IN INTERTEC *

RETURN (TIME); / RETURN TIME */

END TIME;

GET_DATE:

FROCEDURE (ANSWER); /* GET INTERTEC SYSTEM DA:E *

DECLARE ANSWER CHARACTER $(\&)$;

ANSWER = DATE ( ); $/$ * INITIALIZE USING DATE FUNETION * $/$

SUESTR(ANSWER, $7, \Xi)$ ) SUESTR (ANSWER, $1, \Xi$ ); $1 *$ TRRANSFER YY *

SUESTR (ANSWER, 1, E) = SUESTR (ANSWER, 3,2 ); $/ *$ TRANSFER MM *

SUESTR (ANSWER, 4, E) = SUESTR (ANSWER, $\Xi, \Xi) ; 1 *$ TRANSEFER DD *

SUESTR (ANSWER, 3,1 ) $=, 1$, ;

SUBSTR (ANSWER, $E, 1$ ) $=, 1, ;$

DATE :

END GET_DATE; / DATE AGSIGNED, EX:T *i

FROCEDURE RETURNS (CHARALTER(E));

/* THIS PRUCEDURE READS MEMIDRY LOCATIONS (4E-4D) GEXX IN THE

INTERTEC SUPERERAIN TO REQALL THE CLRRENT DATE. THE

DATE IS STURED AS 'MMDDYY' IN FACKED EIDD FORMAT. THIS

PROCEDURE RETURNS THE DATE IN A CHARACTER STRING IN THE

STANDARI PL/1 FORMAT: 'YYMMDL'. *I

DECLARE (CPQ, CPI) FDINTER, STRING CHAR (11),

SYSTEM_DATE CHAR( $\Xi$ ) BASED (CFU),

(DATE CHAR (E), DATEI CHAR (4), DATEE FIXED DEC (B, Q ))

BASED (CFI);

UNSFEC (CFD) = 'DQ4E' B4; /* FUINT TO DFTE IN INTERTEC *

CF1 = ADDF (STRING) $: 1 *$ "DUERLAY" STRINE = DATE, DATE:, DATEE *

DATE 1 = SYSTEM_DATE; / 2 READ SYSTEM DATE 
วอะ:

उอ3:

उЕ 4:

उEs:

उEE:

$3=7$ :

उE:

วอง:

उउQ:

उ31:

33E:

उ33:

334:

$335:$

उEE:

$337:$

338:

339:

340:

341:

34E:

343:

344:

345:

$346:$

347:

34日:

$347:$

$350:$

351:

35e:

$353:$

354 :

$355:$

उEE:

557 :

350 :

동

$\Xi \in Q:$

SUBSTR(DATE1, 4,1) = ASCII(DO); / SET SIGN EYTE IN DATEE *; STRING = DATEE; 1 * CONVERT DATEE TO CHARACTER DATA * 1 SUESTR (DATE, $1, \Xi)=$ SUESTR (STRING, $E, \Xi) ; \quad / *$ TRANSFER YY *1 SUBSTR (DATE, $3, \Xi)$ ) SUESTR(STRING, 10, 2 ); $/ *$ TRANSFER Mir * SUBSTR(DATE, $5, \Xi)=$ SUESTR(STRING, $8, \Xi) ; \quad / *$ TRANSFER DD * RETURN (DATE); /* RETURN ASSIGNED DATE * SET_DATE: END DATE;

FROCEDURE (ROW, COLUMN); / * SET SYSTEM DATE *

/* THIS PRUCEDURE REQUESTS THE CURRENT DATE FRDM THE CONSOLE. THE INFUT DATE IS VALIDATED AND STORED IN THE, DATE, MEMORY LOCATIONE OF THE INTERTEC SUFERBRAIN. THE ROUTINE CAN REQUEST THE DATE FROM MOST FOSITIONS OF THE CONSOLE WITH THE FROGRAMMINE LIMITS GIVEN BE:-OW. * DECLARE INPUT_DATE CHAR(B), (CFQ, CFI) FOINTER; DECLARE 1 DATE EASED (CPQ),
E MONTH CHAR (E),
2 SILASH1 CHAR (1),
D DAY CHAR(E),
Z SLASHE CHAR (1),
E YEAR 'CHAR(E);

DECLARE SYSTEM_DATE CHAR( $\Xi$ ) BASED (CF1);

DECLARE DATEI CHAR( 3 ) BASED (CPQ);

DECLARE DATEE FIXED DECIMAL $(15, \bigotimes)$ EASED (CFQ $)$;

DECLARE (MO, DY, YR, ROW, COL!JMN) FIXED BINARY (7);

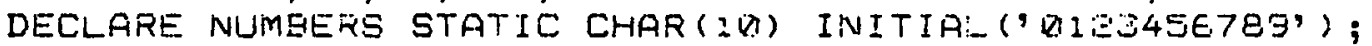

DECLARE NOEXIT EIT $(1)$;

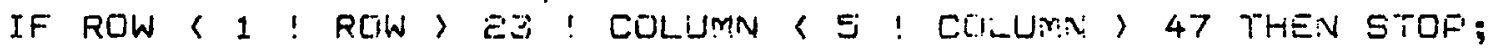
CFQ = ADDR (INFUT_DATE);

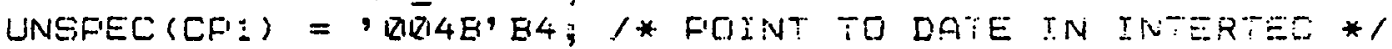

CALL ERASE_LINE $(R O W+1,1)$;

NOEXXIT=, $1, \bar{E}$;

DO WHILE (NOEXIT);

CALL ERASE_LINE (ROW, 1);

CALL FOSITION (ROW, COLUMN);

FUT EDIT("WHAT DATE IS IT? MNIDD/YY") (A);

CALL FUSITION (ROW, COLUMIN+IB);

GET LIST (INFUT_DATE);

IF VERIFY (MONTH, NUMEERS) = R VERIFY (DAY, NUNEEESS) $=\square$ $\mathrm{DO}$; \&. VERIFY (YEAR, NLIMEERS: = D THEN

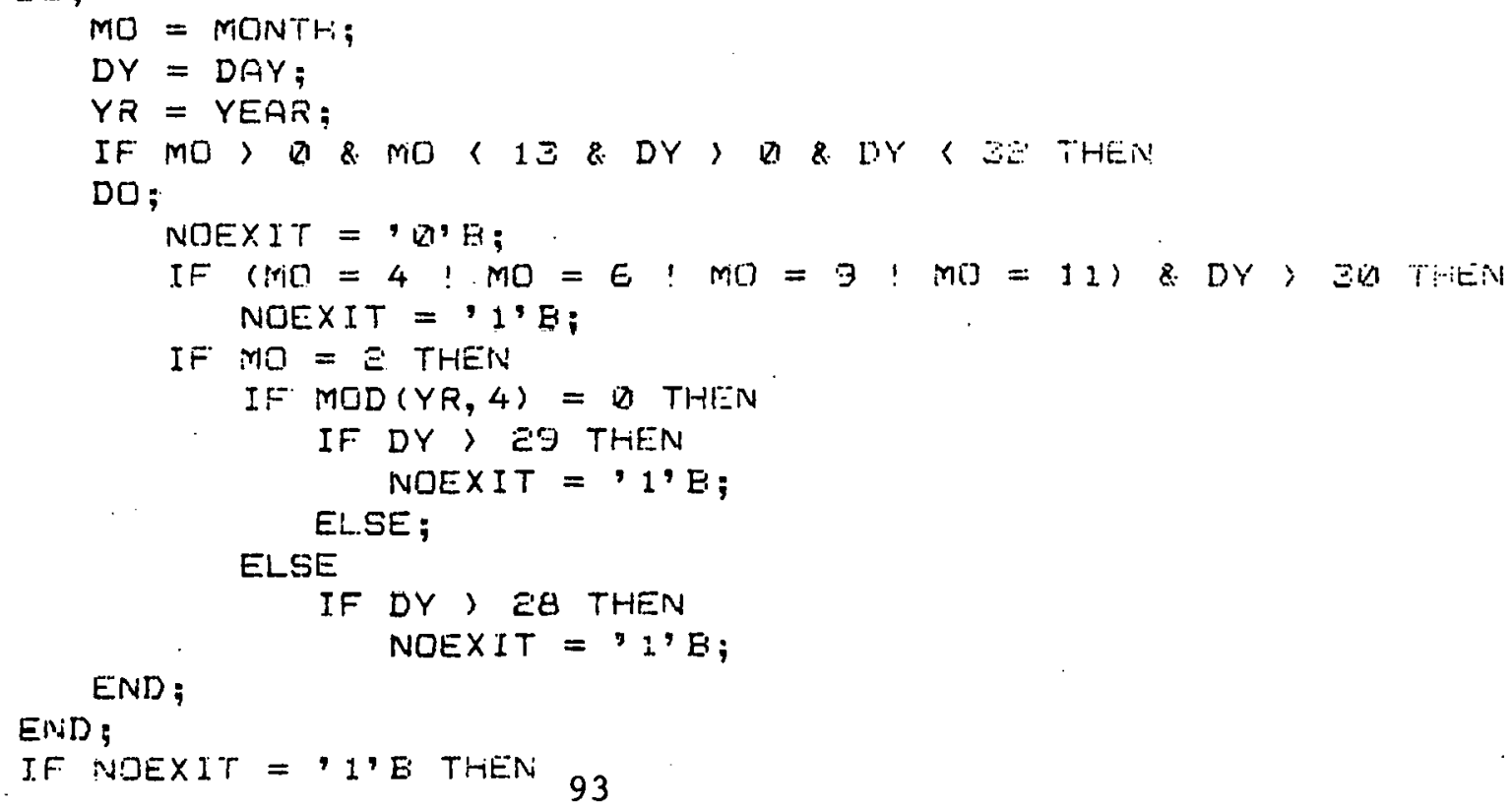




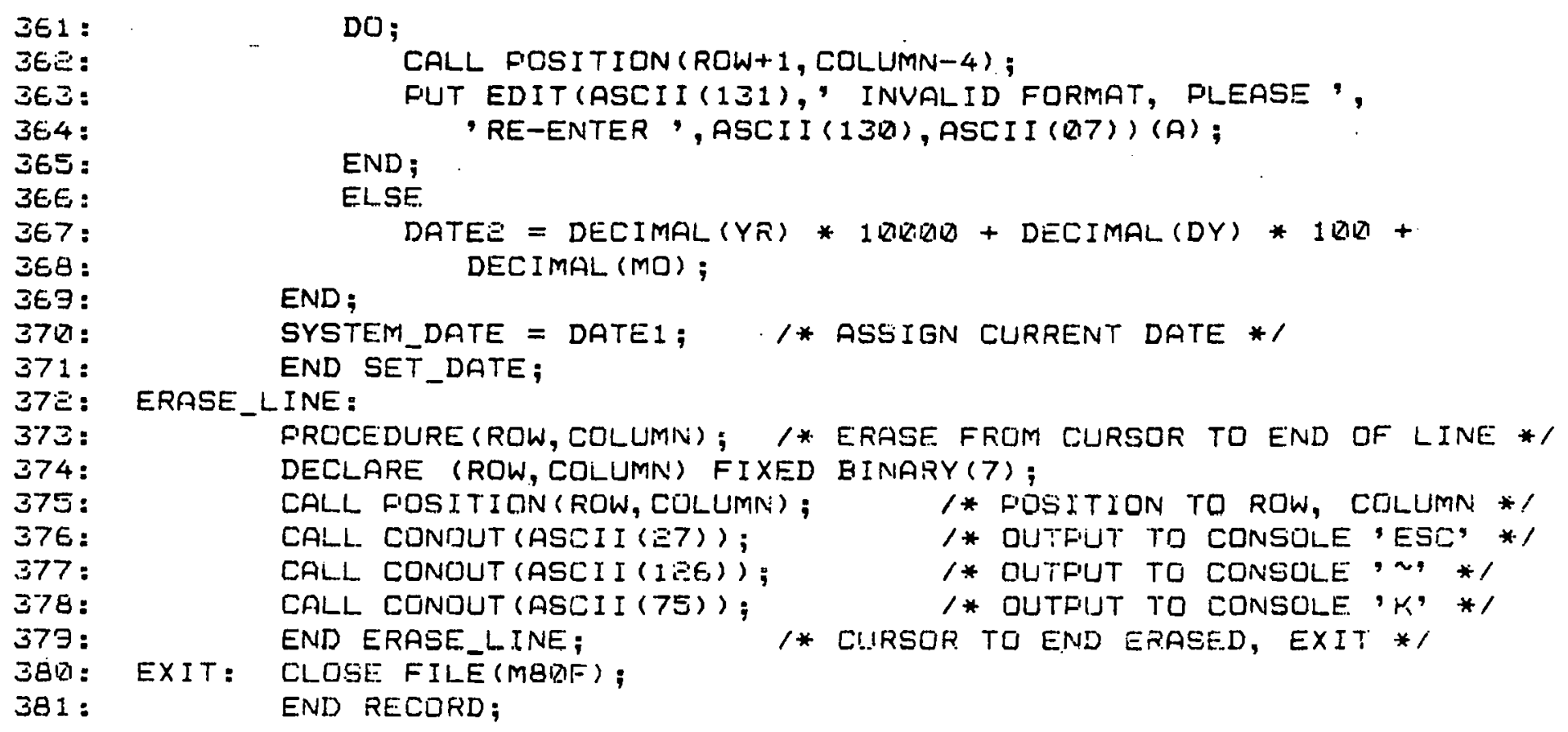

IE 1:

उEE:

उE $\Xi:$

उद 4:

उES:

उEE:

$3 \in 7$ :

उE8:

उE $3:$

$370:$

371:

37E:

$373:$

374:

$375:$

376 :

577 :

$378:$

379:

3801

381 :

DO;

CALL POSITION (ROW+1, COLUMN-4);

PUT EDIT(ASCII ( 131 )," INVALID FORMAT, PLEASE ',

, RE-ENTER ', ASCI I $(130), A S C I I(Q 7))(A)$;

END;

ELSE

DATEE = DECIMAL $(Y A) * 1 D Q R D+D E C I M A L(D Y) * 10 Q+$

END;

DECIMAL (MO);

SYSTEM_DATE = DATE $1 ;$ * ASSIGN CURRENT DATE * 1

ERASE_LINE:

END SET'_DATE;

FROCEDURE (ROW, COLUMN); /* ERASE FROM CURSOR TO END OF LINE * DECLARE (ROW, COLUMN) FIXED EINARY ( 7 );

CALL FOSITION (ROW, COLUMN);

* FOSITION TO ROW, COLUMN *

CALL. CONDUT (ASCII $(27)$ );

CALL CONOUT (ASCII $(I E E)$ );

/* outfut to consule 'esc' *1

CALL CONOUT (ASCII $(75)$ );

$1 *$ outfiut tO CONSOLE, $\cdots$ *

END ERASE_LINE;

/* OUTFIJT TO CONSOLE ' $K$ ' *

EXIT:

CLOSE: FILE (MBIF);

1* cursor tu end erased, exit *

END RECORD; 


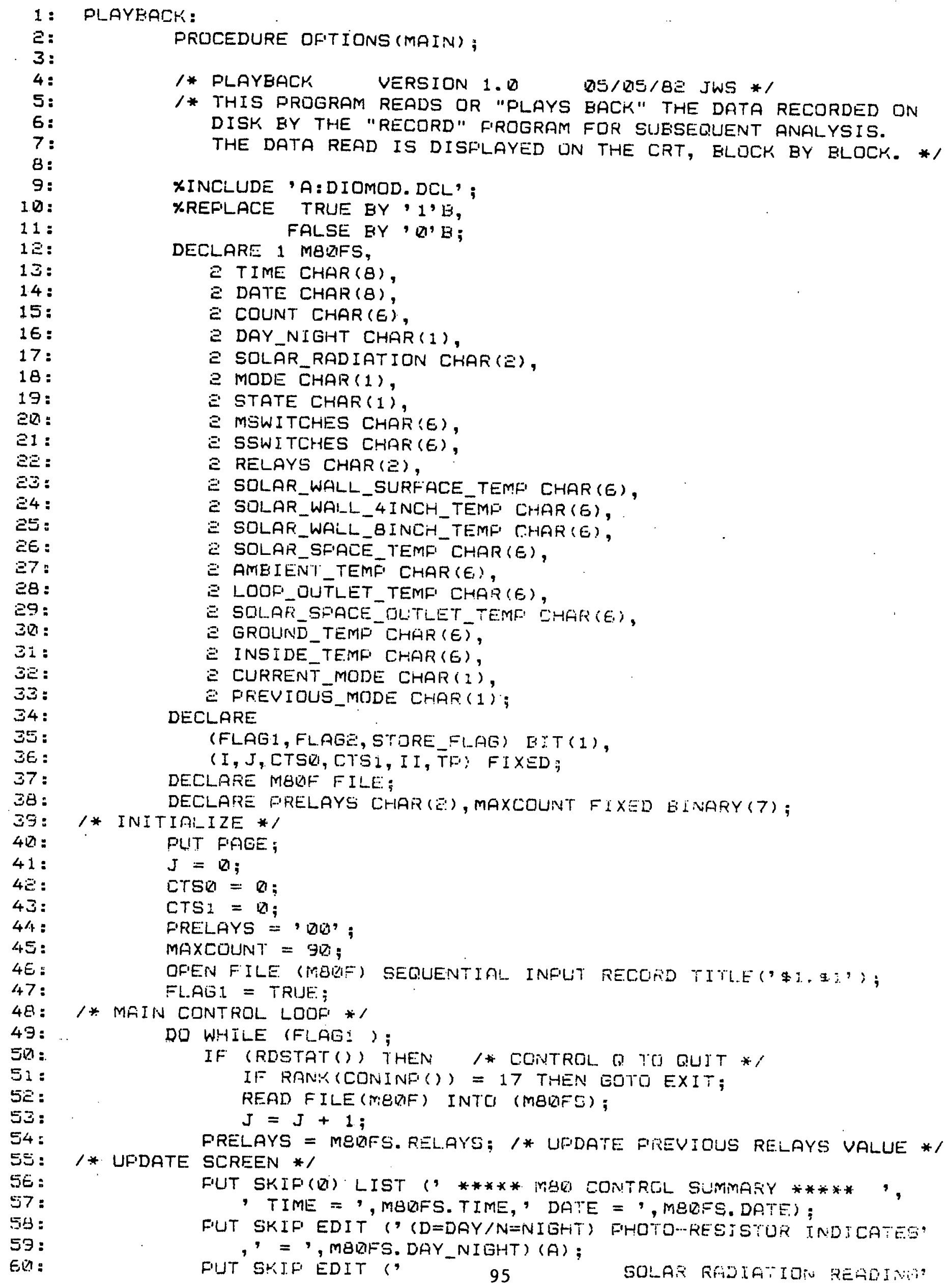


E1:

GE:

63:

64:

E5:

GE:

67:

68 :

E习 :

$70:$

$71:$

$72:$

73 :

74 :

$75:$

TE:

77 :

$78:$

$79=$

BD:

B1:

$82:$

BI:

84 :

85 :

$B E$ :

B7:

$88=$

89:

$90:$

91:

크믐

$93:$

94 :

$95:$

ЭE:

97 :

3日:

99 :

, = , MBQFS. SOLAR_RADIATION) (A);

PUT SKIP EDIT $\%$ (H=HEATING, C=COOLING,"

$, D=D E F R O S T)$ MODE $=$, MBQFS. MODE) (A);

FUT SKIP EDIT $($,

, = , MQQFS.STATE) (A);

FUT SKIF EDIT

, = 'MBVFS.MSWITCHES,

MBQIFS. SSWITCHES) (A);

FUT SKIP EDIT ('

, = , MBRIFS. RELAYS) (A);

FUT SKIP EDIT (' SOLAR WALL TEMFERATURE.AT ,

' SURFACE = ', MBUFS. SQLAR_WALL_SURFACE_TEMF', C, ) (A);

FUT SKIF EDIT (" SOLAR WALL TEMF'ERATURE AT ,

' 4-INCH DEFTH $=$ ", MBAFS. SOLAR_WALL_4INCH_TEMF', C') (A);

FUT SHIP EDIT (" SQLAR WALL TEMFERATURE AT',

' B-INCH DEFTH = ', MBLFS. SOLAR_WALL_BINCH_TEMF, ' C') (A);

FUT SKIF EDIT (" SOLAR SFACE TEMFERATURE',

' = , MBRFS. SOLAR_SPACE_TEMF,' $\left.C^{\prime}\right)(A)$;

PUT SKIF EDIT " AMEIENT TEMFEFATURE",

, = , MEQRFS. AMEIENT_TEMF, , C') (A);

FUT SKIF EDIT (" GROUND LOOF OUTLET TEMFERATURE',

' = 'MBQFS. LDOF_QUTLET_TEMF," C') (A);

FUT SKIF EDIT (" SOLAR SFACE QUTLET TEMFERATURE',

' = , MBÜFS. SOLAR_SFACE_OUTLET_TEMF', C') (A);

FUT SKIF EDIT (, - HEAT PUMF DLTTSIDE CDIL, ,

' TEMFERATURE = ', MBZIFS. GROUJND_TEMF,' C') (A);

FUT SKIF EDIT $('$ INSIDE TEMFEFATURE,

' = , MEQRF. INSIDE_TEMF', C', (A);

FUT SKIF EDIT ("CURRENTT MODE $=$ ', MQRFS. CURRENT_MODE,

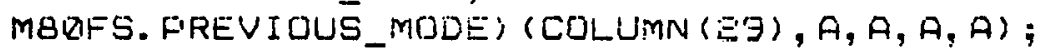

FUT SKIF';

FUT SKIF LIST (J,' RECORDS READ')

:FUT SKIF(E') LIST "SFACE EAR = CLNTINUE / "CTRL QI" = QUIT");

IF RANK (CONINF' () ) $=17$ THEN FLAG 1 = FFLSE;

CA!- CONOUT (ASCII $(\not 1))$;

* HOME CLRSOR *

EXIT: STOF;

* END OF FLAG 1 L.OOF * $/$

END F'L_AYEACK; 


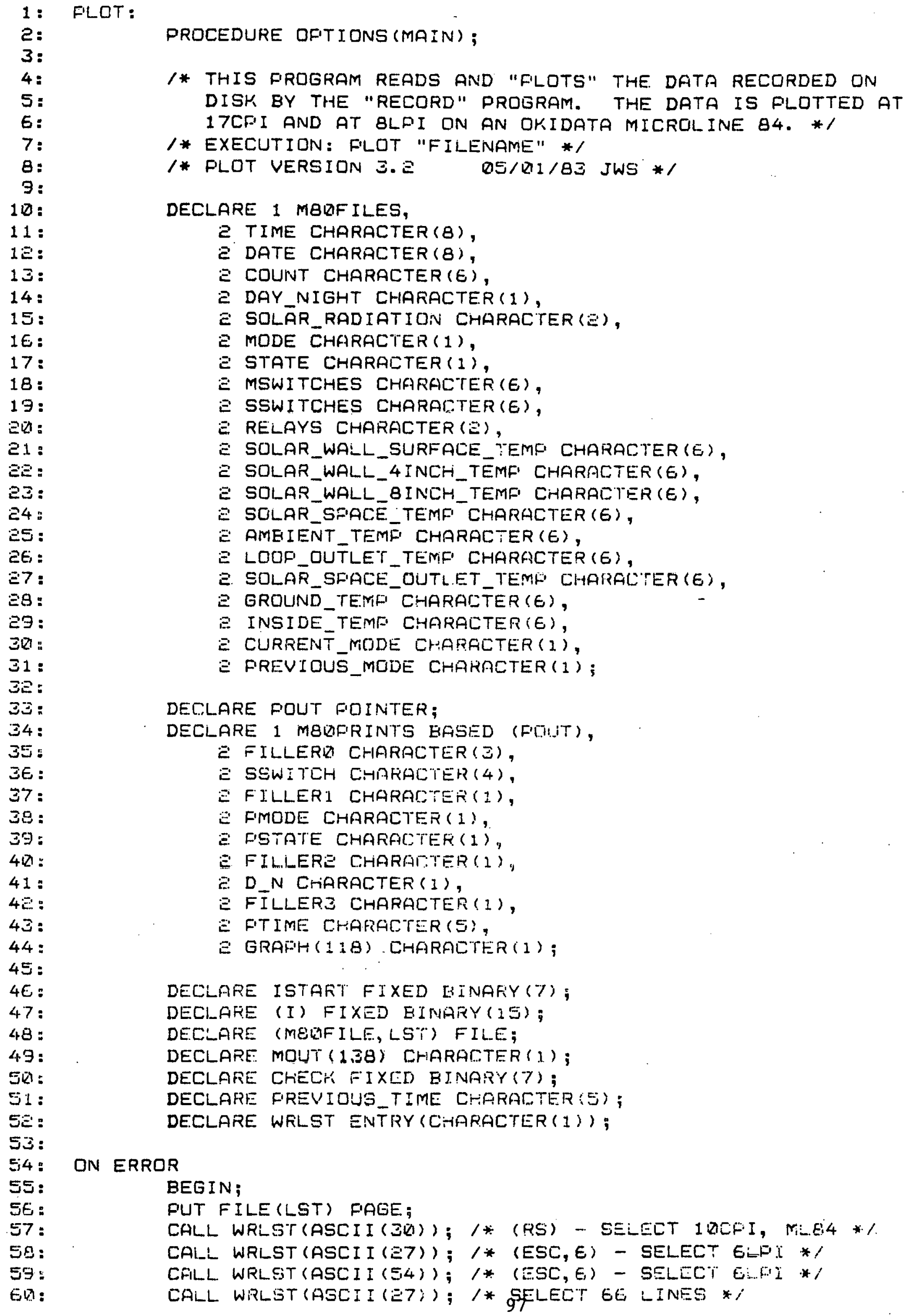

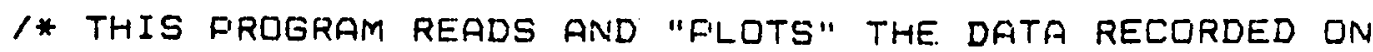
DISK BY THE "RECORD" PROGRAM. THE DRTA IS PLOTTED AT 17CFI AND AT 8LPI ON AN OKIDATA MICROLINE 84. *1

/* EXECUTION: FLOT "FILENAME" */

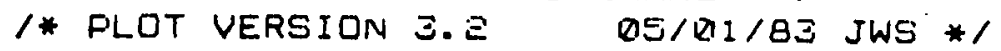

DECLARE 1 MBDF ILES,

2 TIME CHARACTER $(B)$,

¿ DATE CHARACTER ( 8 ),

$\Xi$ COUNT CHARACTER (E),

a DAY NIGHT CHARACTER(I),

2 SOLAR_RADIATION CHARACTER (E),

a MODE CHARACTER(1),

E STATE CHARACTER 1 ;,

$\Xi$ MSWITCHES CHARACTER (E),

I SSWITCHES CHARACTER(E),

Z RELAYS CHARACTER (E),

E SOLAR_WALL_SURFACE_TEMP CHARACTER(E),

E SOLAR_WALL_4INCH_TEMF CHARACTER (E),

E SOLAR_WALL_BINCH_TEMF CHARACTER(E),

2 SOLAR_SFACE_TEMF CHARACTER $(G)$,

$\Xi$ AMEIENT_TEMF CHARACTER $(E)$,

E LOUF_OUTLE'_TEMIF CHARACTER $(E)$,

ᄅ. SOLAR_SFACE_OUTLET_TEMF CHARFL'TER(E),

$\supseteq$ GROUND_TEMF CHARACTER $(\epsilon)$,

Z INSIDE_TEMF CHARACTER (E),

E CURRENT_MODE CHARRACTER(1),

E PREVIOUS_MUDE CHARACTER(1);

DECLARE FOUT FOINTER;

DECLARE 1 MBQRFINTS BASED (FOUTT),

E FILLERD CHARACTER ( $\Xi)$,

E SSWITCH CMARACTER (4),

E FILLERI CHARACTER(1),

E FMODE CHARACTER (1:,

E FSTATE CHARACTER(1),

E FILLLERE CHARATYTER ( 1 ),

E D_N CHARACTER ( 1 ),

E FILLER3 CHARACTER (1),

E FTIME CHARACTER (5:,

E GRAFH (118). CHARACTER(1);

DECLARE ISTAFT FIXED EINAFYY ( 7 );

DECL_ARE (I) FIXED EINARY (IS);

DECLARE (MELFILE, LST') FILE;

DECLARE MOUT ( 1.38 ) CHARACTER(1);

DECLARE CHECH: FIXED EINARY (Y);

DECLARE FIREVIOUS_TIME CHARACTER(S);

DECLARE WRLST ENTRY (CTARACTER(1));

ON ERROR

BEGIN;

FUT FILE (LST) FAEE;

CALL WRLST(ASCII (JW)); /* (PS) - SELECT 1 QCFI, ME E4 * 1

CALLL WRLST (ASCII $(E 7)) ; / *(E S C, E)$ - SELECT ELFI *

CFILL WRLST (ASCII $(54)) ; 1 *(E S C, E)$ - SELECT EIEI*

CALL WIRLST (ASCII (ETi); $/ *$ GFLECT GE LINES *; 


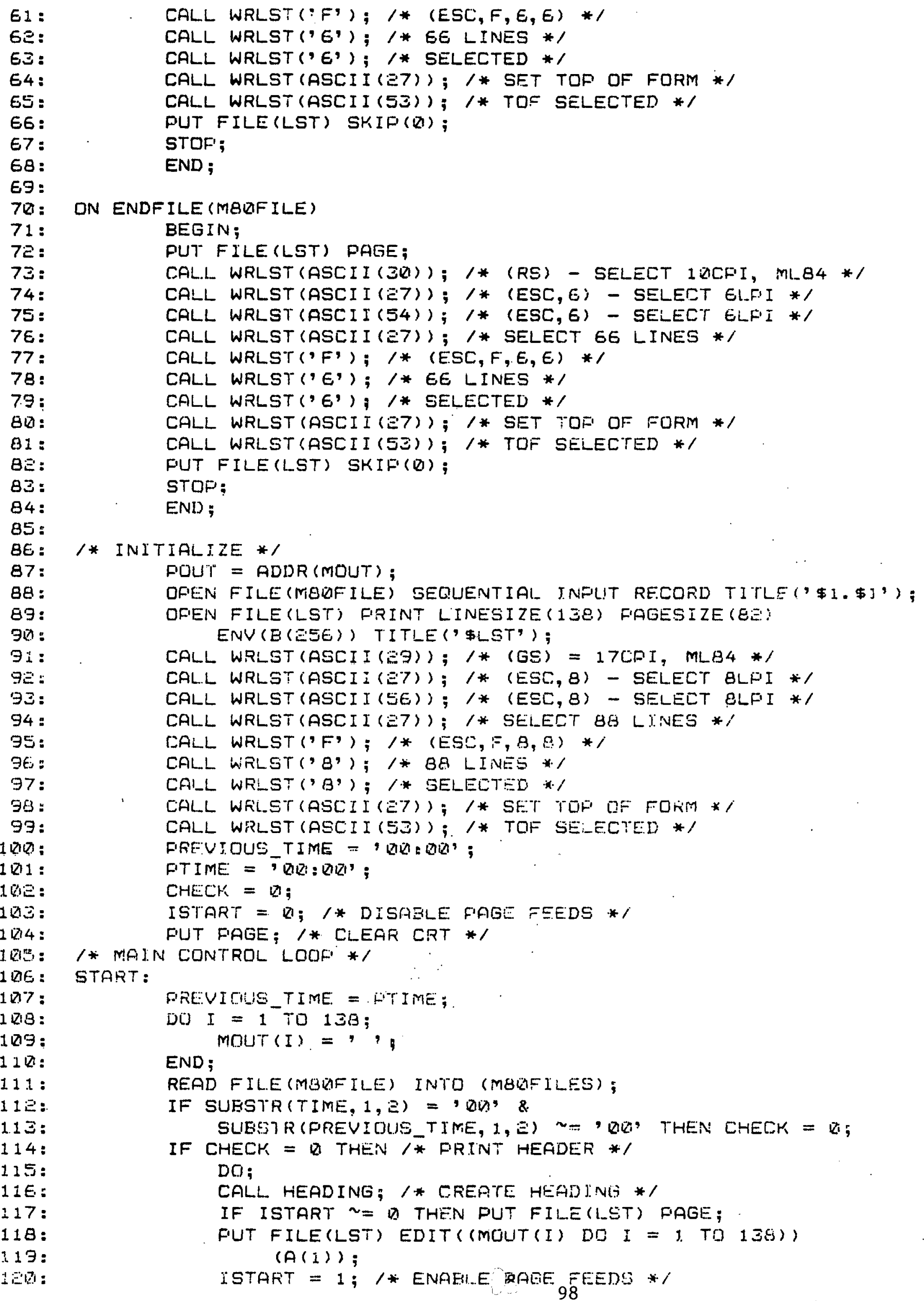


1อ1:

1 อะ:

1こコ:

1อ4:

125 :

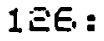

127 :

$1=8$ :

1อ9:

130 :

131:

1 ここ:

$133:$

134:

$135:$

1 उE:

137 :

138 :

$139:$

14D:

141:

14?:

$143:$

144 :

$145:$

$14 E$ :

$147:$

148:

149:

15Q1 :

151:

$15 E$ :

153:

154:

155:

156 :

157 :

158:

159:

$1 \in Q$ :

1E1:

$1 \in E$ :

$1 \in \Xi:$

IE4:

I. $65:$

$1 \in E$ :

$1 \in 7$ :

$1 \in B$ :

$1 \in \Xi:$

$170:$

171:

17E:

$173:$

174:

175:

17E:

177:

178:

J.T3:

$180:$

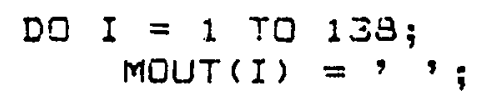

CALL. FLLTLIN;

PUT FILE(LST) SKIF EDIT((MOUT(I) DD I = 1 TO 138)) $(A(1))$;

CHECK $=$ CHECK + 1 ;

IF CHECK = $8 D$ THEN CHECK = $D$;

GOTO START;

FLTLIN:

FROCEDURE;

DECLARE I I FIXED EINAFYY(15);

/* CHECK FOR AND INDICATE MANUAL QVERfIDE *'

IF MSWITCHES = ' EEEEEE' THEN FILLER1 = '+';

SSWITCH = SUBSTR (SSWITCHES, $1, \Xi$ ) !! SUESTR (SSWITCHES, S, E);

D_N = DAY_NIGHT;

F'STATE = STATE;

PTIME = SUESTR (TIME, I, S);

PMIODE = MODE;

GRAFH (POSITION (B)) $=11$, ;

IF DAY_NIGHT = 'D' THEN /* DAY, FILOT RADIATION */ DI] ;

II = CONVERT (SOLAF_RADIATION);

II $=3 \Xi-I I$;

GRAFH (II) $=$, *';

END;

GRAPH (POEITION (INSIDE_TEMF') = 'I';

GRAFH (FOSITION (GRDUND_TEMF') ) = ' $M$ ';

GRAPH (POSITION (SOLAR_WALL__BINCH_TEMF') $=: 8^{\prime}$;

GRAPH (FOSITION (SOLAR_WALi__4INCH_TEMF) $)=4, ;$

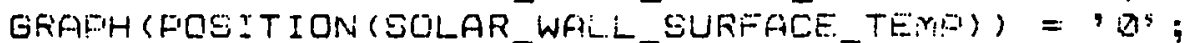

GRAFH (FOSITION (SDAOR_SFACE_UUTLET_TEMF') : $x$ ";

GRAFH (FUSITION (SOLAS_SFACE_TEMF) ) = ' + ';

GRAFH (FUSITIUN (AMEIENT_TEME)' = ' $A$ ';

GRFFH (FOSITION (LOOF_OLTLET_TERIF)! = , $B$;

RFTISRN;

END FLTLIN;

CUNUERT:

FROCEDURE (INFUT) RETURNS (FIXED EINARY (IS);

DECLARE IN:OUT CHARACTER(こ);

DELLARE KOUINT FIXED EINARYY (15);

DECLARE TCHAR CHARACTER(1);

TCHAR = SUESTR (INFUT, 1, 1);

KOUNT = NIJMEER (TCHAR) * 16 ;

TCHAR = SUESTR (INFUT, E, I):

KOUNT = KOUNT + NUMBER (TCHAR);

RETLRN ( $H$ OUNT);

END CONVERT;

NUMBER:

PROCEDURE (TCHRIR) RETURNS (FIXED EINARY (15));

DECLARE TCHAR CHARACTER $(I)$;

DECLIAFEE "PEMF' FIXED EINAFRY $(\vdots 5)$; 
181:

$18=:$

183 :

184:

185:

$18 E$ :

$187:$

188:

189:

$19 \not 2:$

191:

19อ:

193 :

194:

195:

$19 E$ :

197:

198:

199:

टप्रत:

Eख 1:

EQ⿱一𫝀:

टDS:

Eख4:

205:

EDE:

207 :

2018:

EQ9:

리니:

E11:

리르:

리:

E.14:

리도:

ENE:

217:

E18:

리:

Eथर:

전.1:

Eะ:

Ees:

2:4:

EES:

Eet:

Eะ7:

Eะ:

ออง:

ED:

E31:

こコこ:

E3:

ट34:

อ25:

EงE:

อง7:

IF TCHAR , ' 9 ' THEN

$\mathrm{DO}$;

IF TCHAR = 'A' THEN TEMF = 1D;

ELSE IF TCHAR = 'B' THEN TEMF = 11;

ELSE IF TCHAR = 'C' THEN TEMF = $1 \mathrm{e}$;

ELSE IF TCHAR $=$ 'D' THEN TEMF $=13$;

ELSE IF TCHAR = ' $E$ ' THEN TEMF $=14$;

ELSE IF TCHAR = 'F' THEN TEMF = 15 ;

END;

ELSE TEMF' = TCHAR;

RETURN (TEMFI);

END NUMEER;

FOSITION:

PROCEDURE (INFUT) RETURNS (FIXED BINARY (15));

DECLARE (CONSTANT, INFUT, MULTIFLIER) FLOAT EINARY (E4);

CONSTANT $=14 ;$

MULTIF'LIER $=$ 2. $\epsilon$;

RETURN (INPUT * MULTIFLIER + CONSTANT + D.5);

END FOSITION;

HEADING :

FROCEDURE;

DECLARE START FIXED BINARY (7);

START $=18$;

MOUT (E) = SUESTR (DFTE, ¿, B.);

MOUT $(\Xi)=$ SUASTF (DATE, $\Xi, 1)$;

$\operatorname{MOUT}(4)=$ SUESTR $(D A T E, 3, i)$;

$\operatorname{MOUT}(5)=$ SUESTR $(D A T E, 4,1)$;

$\operatorname{MOUT}(E)=\operatorname{SUBSTR}(D A T E, 5,1)$;

$\operatorname{MOUT}(7)=$ SUBSTR (DATE, 6,1$)$;

MOUTT $(B)=$ SUESTR (DATE, 7,1$)$;

MOUT $(9)=$ SUESTR $(D A T E, B, 1)$;

MUUT (START) $=$ ' - ';

MOLTT (START + FOSITIUN: $(-5))=, 5 ;$

MUUT (START + FOSITION (D)) = 'Q;

MCUTT (START + FUSITION $(5)$ ) = ,

MOUT (START + FOSITION $(10)-i)=$ " 1 ;

MOUT (STRRT + FOSITION $(10)$ ) = B';

MOUT (START + POSITIUN (1S) - i) = ' 2 ;

MOUT (START + FOSTTION (SE) ) = '5';

MOUT (START + FOSITION (EZI) - 1) = 'E';

MOUTT (START + FOSITION(ED) $=$ 'R';

MOUT (START + FUSITION $(E S)-1)=$, $:$;

MOUT (START + PUSITION $(E S)=95$;

MOUT' (START + FOSITIURU $(3 Q)-1$ - $=$ ' $3^{\prime}$;

MOUT(START + FOSITION $(30)$ ) = D';

MOUT (START + FOSITION (3E) - 1) = '3";

MOUT (START + FOSITION $(35)$ ) $=$, 5 ;

MOUT (START + POSITION (421) - 1) = 4 ';

MOUT (START + FOSITION(4B)) = ,

RETURN;

END HEADING;

END PLOT; 
DIR

\begin{tabular}{|c|c|c|c|c|c|c|c|c|c|c|c|}
\hline $\begin{array}{l}A: \\
A:\end{array}$ & $\begin{array}{l}\text { DOWNLOAD } \\
\text { FEBDBQZ }\end{array}$ & $\begin{array}{l}\text { COM } \\
\text { DAT }\end{array}$ & : & $\begin{array}{l}\text { TIME } \\
\text { MAKSYS }\end{array}$ & $\begin{array}{l}\text { COM } \\
\text { SUE }\end{array}$ & : & $\begin{array}{l}\text { DATE } \\
\text { SYSTEM }\end{array}$ & $\begin{array}{l}\text { COM } \\
\text { LIB }\end{array}$ & $:$ & $\begin{array}{l}\text { DOWNLOAD } \\
\text { MAKFLAY }\end{array}$ & $\begin{array}{l}\text { ASM } \\
\text { SUB }\end{array}$ \\
\hline$A:$ & MAKDOWN & SUE & : & PLOT & COM & $:$ & SYSTEM & $\mathrm{COM}$ & $:$ & PIP & $\mathrm{COM}$ \\
\hline$A:$ & FLAYEACK & $\mathrm{COM}$ & : & SYSTEM & ASM & : & SUBS & LIB & : & RECORD & $\mathrm{com}$ \\
\hline$A:$ & PLAYEACK & PLI & : & FEE1 382 & DAT & : & MAKFLOT & SUE & : & MATH & LIB \\
\hline A: & RECORD & FLI & : & MAKREC & SUE & : & PLOT & REL & : & TEST & DAT \\
\hline $\begin{array}{l}A: \\
A>I\end{array}$ & $\begin{array}{l}\text { DOE } \\
\text { OIR E: }\end{array}$ & LTR & : & STAT & COM & : & PLOT & F'LI & & & \\
\hline$B:$ & FEBR88E & DAT & $:$ & FEB1 18E & DAT & : & FEEII CBE & DAT & $:$ & FEB1 $38 \Xi$ & DAT \\
\hline E: & FEE148E & DAT & : & FEE15BE & DAT & : & FEBこ1 $18 \Xi$ & DAT & : & FEBEJ8E & DAT \\
\hline$B:$ & FEBESBE & DAT & $:$ & MARDIBE & DAT & $:$ & MARQIZBこ & DAT & : & MARQIZBE & DAT \\
\hline$B:$ & MARDBQE & DAT & : & MARQI9BE & DAT & $:$ & MAR 1 VAE & DAT & $:$ & MAR1 18E & DAT \\
\hline$B:$ & MAR1EBE & DAT & $:$ & MAREQREZ & DAT & : & MAREЗBこ & DAT & $:$ & MARESBE & DAT \\
\hline$B:$ & MARこヨ\&こ & $\mathrm{DAT}$ & $:$ & AFRロ78E & DAT & $:$ & AFR $198 \Xi$ & DAT & : & AFREEBE & DAT \\
\hline B: & AFRE7BE & DAT & : & MAYQ & DAT & $:$ & MAYDE,BE & DAT & : & MAY $148 \Xi$ & DAT \\
\hline$B:$ & MAY198E & DAT & : & MAYこBBE & DAT & $:$ & JUNR7Eこ & DAT & $:$ & JUN1 148E & DAT \\
\hline & $\begin{array}{l}\text { JUNE 48E } \\
\text { OIR. B: }\end{array}$ & DAT & : & IULฉEBE & DAT & & & & & & \\
\hline & JUL 188E & DAT & $:$ & FIP & $\mathrm{com}$ & ; & JULE78E & DAT & : & AUGAEBE & DAT \\
\hline & - AUGこロИ日こ & DAT & $:$ & AUG & DAT & : & OCTREBi & DAT & $:$ & OCT118्M & DAT \\
\hline & DECA78E & DAT & $:$ & DECRBB & $\mathrm{DAT}$ & $:$ & DEC $13 B E$ & DAT & : & $D E C, 13 \theta \Xi T$ & DAT \\
\hline$E:$ & DECE18E & DAT & $:$ & DECE5BE & DAT & $:$ & DEC318E & DAT & : & JAN 1483 & DAT \\
\hline & JANE18Z & DAT & : & FEEEGB & DAT & : & AF'RこRIB & DAT & : & MAY1983 & $\mathrm{DA}$ \\
\hline & MAYEQB & DAT & : & MAYこ78こ & DAT & & & & & & 1 \\
\hline
\end{tabular}
(p) 
$0021 \mathrm{HL} N \mathrm{~N}: 29$

$0900 \mathrm{HO} N \mathrm{~N}$ 01:35

0800 HO N $8 !: 58$

0200 H1 N 81:52

$080 \mathrm{H}$ HO N 01:59

0080 HO N 82:14

0000 HI N 02:18

0800 HO N 02:2E

8980 HO N 82:4!

0080 H1 N 02:43

0008 He N 02:51

6200 40 N 03:86

$0002 \mathrm{HL} \mathrm{N} 03: 07$

$0020 \mathrm{HO}$ N 03:15

008 HI N 23:2B

0900 HB N $03: 37$

0808 it N 83:51

0008 HO N 04:01

$0000 \mathrm{HI} N 04: 14$

0800 HO N O4:C2

0000 HI N 04:34

00000 HO N 04:44

8090 il $N 04: 55$

8800 HO N 85:BE

$0800 \mathrm{HI} N$ $\mathrm{BS}: \mathrm{i}: \mathrm{B}$

0080 HO N 85:Ci

0082 HI N 05:39

6000 HO N 05:45

$0000 \mathrm{HI}$ i $06: 81$

9009 Ho N 85::

0002 HI N 86:2́4

0000 HO N QE:34

$0803 \mathrm{HIN} 06: 44$

0000 :10 N 06:55

080 औ

0008 40 N 07:16

OeQR 41 N 07:27

0080 HO N 07:39

8001 HI N 07:50

$000840 \mathrm{~N} 08: 02$

0000 HI $N$ o8:

0820 Ho N 88:cit

0000 it $D$ 0E:3:

0000 H2 0 08:48

008: HI D $88: 55$

9803 HD D 09:08

8008 HE D 09::5

B0eO HI O 09:iE

0000 HO 0 09:ź

Q002 HO D 09:37

9098 til 0 09:41

bo0e Hio D 09:47

8000 48. I 10:06

B000 HI D 18:03

0800 Ho D 18:ie

Ooder Ho D 10:c5

0008 it! D 18:28

GUUi Hid o 18:35

8008 HO D . 18:58

$8008 \mathrm{H}$ H $10: 55$

OOBR HO D 11:83

0018 H1 D 11:18

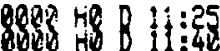

$0000 \mathrm{Hi}$ D $11: 41$

8080 HO D 11:48

Dop? He D 12:03

0000 41 D 12:84

opou Ho o 12:11

OQBB HO D $1 \mathrm{C}^{2}: 26$

0800 int D 12:29

0000 :10 D 1:2:35

$11 i 0$ Ho D $12: 58$

$1110 \mathrm{HI} \mathrm{D} \mathrm{13:02}$

$1110 \mathrm{HA}$ : $13: 08$
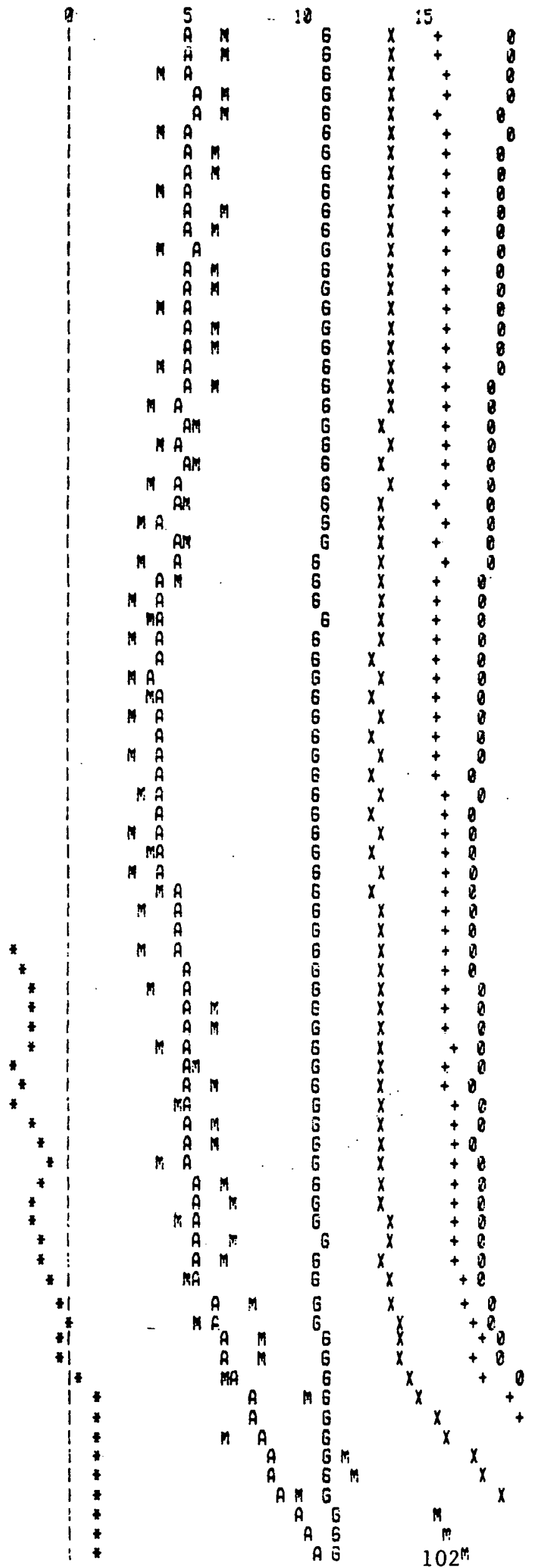

20

14
14

14

14

48 I

48

48 I

48

48

48

48

48.1

$48 !$

$48 I$

481

48

48 I

4

48 i

48 I

48 I

48 I

48 I

41

41

4 I

41

4

$4 !$

$48 !$

48 I

48.1

48 I

$\begin{array}{rr}4 & 1 \\ 4 & 1 \\ 48 & 1\end{array}$

48 I

$48 \quad 1$

$48 !$

$48+1$

48 I

48 II

!

I

I

25

38

35

48 
$82 / 11 / 82$

$111840 \quad 13.23$

$111040 \quad 0 \quad 13: 38$

$1118 \mathrm{~KB} \mathrm{D} 13: 53$

1110 HE D 14:08

1110 He D 14:23

1110 HO $0 \quad 14: 38$

1110 he D 14:54

1118 HB D $15: 09$

1110 HO D $15: 24$

$1110 \mathrm{HB}$ D $15: 39$

1118 Ho D 15:54

$111040016: 10$

1118 190 $016: 25$

1110 HO D $16: 40$

6013 HO D 16:55

6018 40 D 17:10

8018 HD 0 i7:25

8010 HO D 17:40

8080 Ho N $17: 56$

0800 HO N 18:11

8088 th N 18:26

$0080 \mathrm{H}$ N $18: 41$

0000 th $N$ 18:55

0000 HO N 19:11

0002 HO N 19:26

oge? Ho iv 19:41

0000 HO N 15:5E

$0000 \mathrm{HD} N 20: 11$

8000 HO N 20:26

$009040 \mathrm{~N} 20: 42$

O000 HO N 20:57

0000 40 N $21: 1 E$

8008 HO N 21:27

0000 HO N 21:42

0900 H. N 21:58

0000 Ho N $22: 13$

000240 N $22: 28$

0980118 is 22:43
5

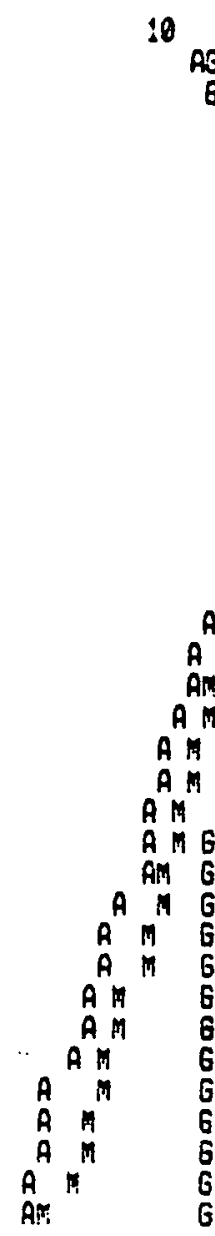

A

G

(1)

G

6
30

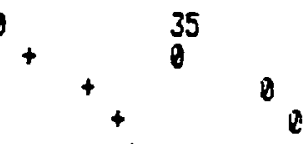
e

40

$G$
$G A^{A}$
6
$G$

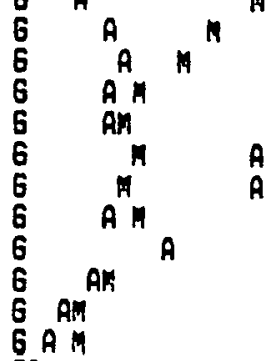

GA $A$

A $A$

6

$A G$

A 6

A 6

A 6

6

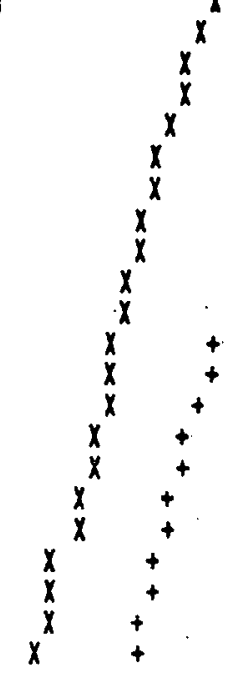

$x^{x}$

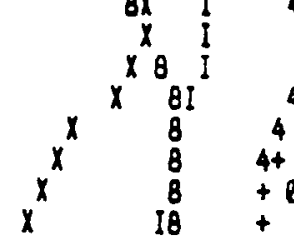$$
+\stackrel{+}{8}
$$

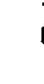

8 
$02 / 13 / 82$

2800 H: $218: 53$

0080 HO D 10:55

8000 tio D 11:18

$0800 \mathrm{HL} \mathrm{D} 11: 1 \mathrm{i}$

8090 ho D $11: 19$

0000 to $011: 34$

$8080 \mathrm{HI} D$ 11:36

0000 HO D $11: 42$

0810 HO D 11:57

0010 HI D 12:01

0818 HO D 12:87

1110 HO D 12:25

1118 Hil $012: 34$

I118 40 D 12:40

$1110 \mathrm{HO} 012: 55$

1110 HI D $13: 18$

1110 HQ D 13:16

1110 HO D 13:3!

$1118 \mathrm{HO}$ D $13: 46$

$1110 \mathrm{HI} D$ 13:5!

1118 HO D 13:57

1110 HO D $14: 12$

1110 HO D $14: \hat{2} 7$

1110 HO $014: 42$

1110 He D 14:57

1110 HO 0 15:12

1110 hil 0 15:27

1110 HO 0 15:42

1110 HO D $15: 58$

1118 HO 0 16:13

1118 HO D 16:28

$111040016: 43$

1118 HD $016: 58$

0010 HO $0 \quad 17: 13$

0010 HO D $17: 28$

0000 H. D 17:44

8080 10 N $17: 55$

o80a He in i8:14

0001 No N 18:25

2000 40 N 18:44

0008 tio N $18: 59$

8000 40 if 19:14

0008 $48 \times 19: \mathrm{C}^{5}$

0000 HI N 19:41

0000 He N 19:4e

$008040 \mathrm{~N} 20: 03$

$000041 N 20: 12$

0000 H $N 20: 17$

0008 HAN $20: 35$

0800 H N N $20: 48$

o08R HQ N 2i:0ड

$8080 \mathrm{HI}$ N. $21: 14$

0800 Ho N 21:20

802! 40 N 21:35

0080 HO $x$ 21:50

$088041 \mathrm{~N} \hat{c}^{2}: 03$

8000 He N E2:05

00020 HO N 22:24

000 - $40 \times 22: 39$

080: HI N $22: 51$

Q02: HQ : $2 E: 57$

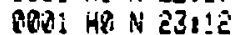

000: HI N $23: 25$

bo2: $H O$ N 23:3!

8QR: KO N 23:4E

Q00: H1 in $23: 50$

080: HI N $23: 53$

800: HO N

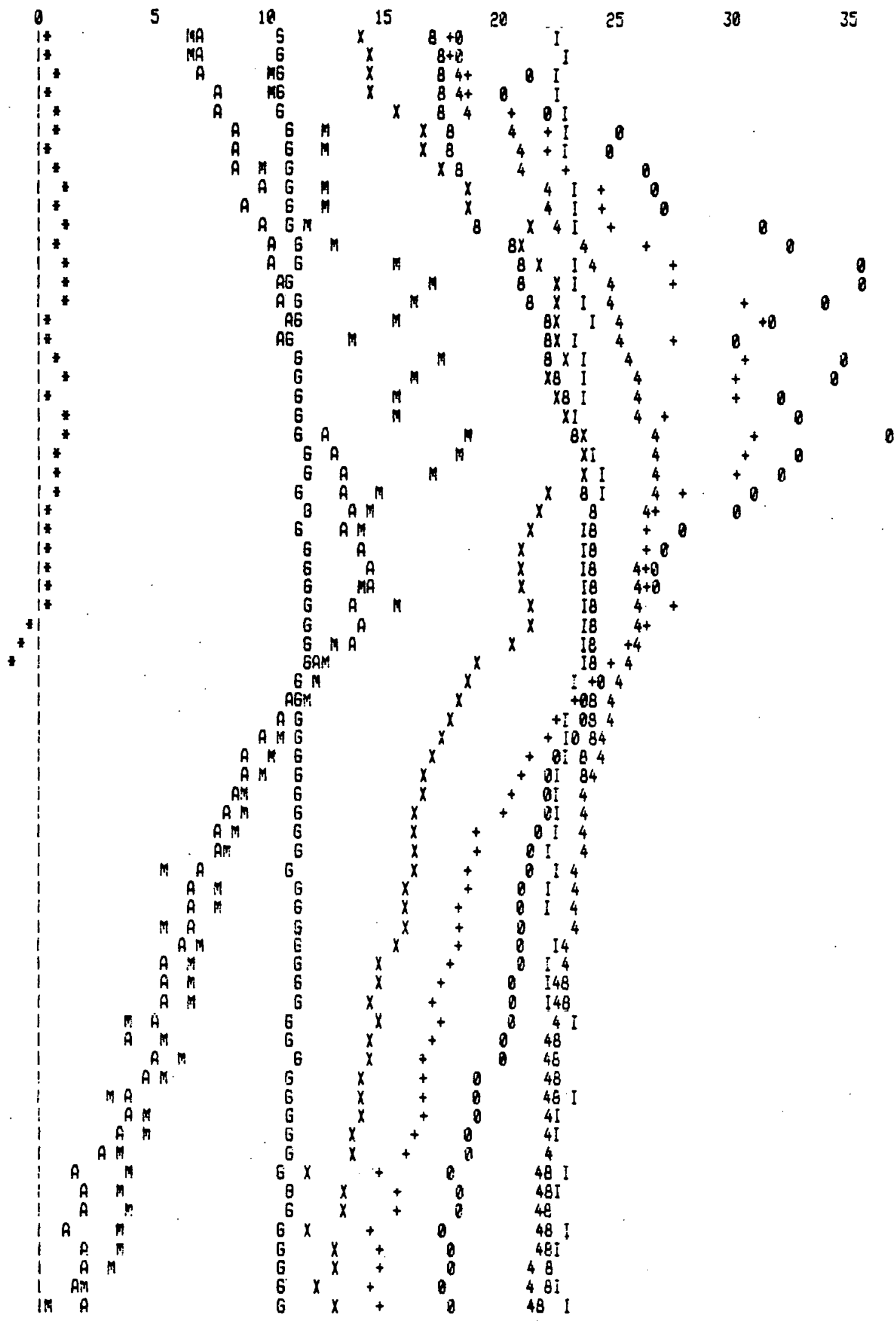


$02 / 14 / 82$

0001 Ho N $80: 13$ OQ8: H1 N 00:17

$0001 \mathrm{HO}$ N 08:24

608! Ho N $80: 39$

000 i HI N 80:4i

0001 HO N $20: 48$

$0001 \mathrm{HI} N \mathrm{OL}: 01$

800 ! HI N $81: 86$

0001 HO N 81:09

808: $H 1$ N $01: 23$

000: HO N 81:3ê

$0001 \mathrm{HI} N 81: 44$

800: HO N 81:52

$0001 \mathrm{H} 1 \mathrm{~N}$ 82:04

000i HO N 82:13

0001 HI N 82:25

0801 HO N OE:35

000: HI N 02:47

8001 :10 N QR:58

000: H1 N 83:09

000 i HI N 83:13

QQD1 HO N 83:20

0021 녀 $N$ B3:C3

008! HO N 03:40

0001 H1 N 83:50

0001 HO N $24: 82$

8001 HI N 84: i

$0901 \mathrm{HON} 04: 25$

0001 . $41 \times 04: 34$

008: HO N 04:47

800: HI N $34: 57$

Q0id: HO N 85:10

0001 H1 N 25:13

800: HO N $85: 33$

80181 41 N $85: 41$

080: त8 N $05: 55$

OQ81 HI N OE:DJ

OOB1 HO N OE::7

0821 41 N $86: 29$

$080140 N 25: 42$

0001 it $N$ BE:48

0001 HI N 87:03

0801 H8 N 07:04

2081 it N $07: 12$

$000 \mathrm{i}$ til $N$ 07:27

000: $10 \times 07: 29$

0020 H1 D 87:36

oper DI D $27: 51$

0080 H1 0 88:25

OQDé Hi $D$ O8:1!

Q808 41 D $88: 18$

8000 rib D $02: 33$

0008 t1 $008: 41$

0081 He D 88:5E

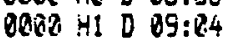

QQ0? 40 D 29::8

8008 41 D 09:25

Bebe tio D 89:40

$0000 \mathrm{HI}$ D 09:48

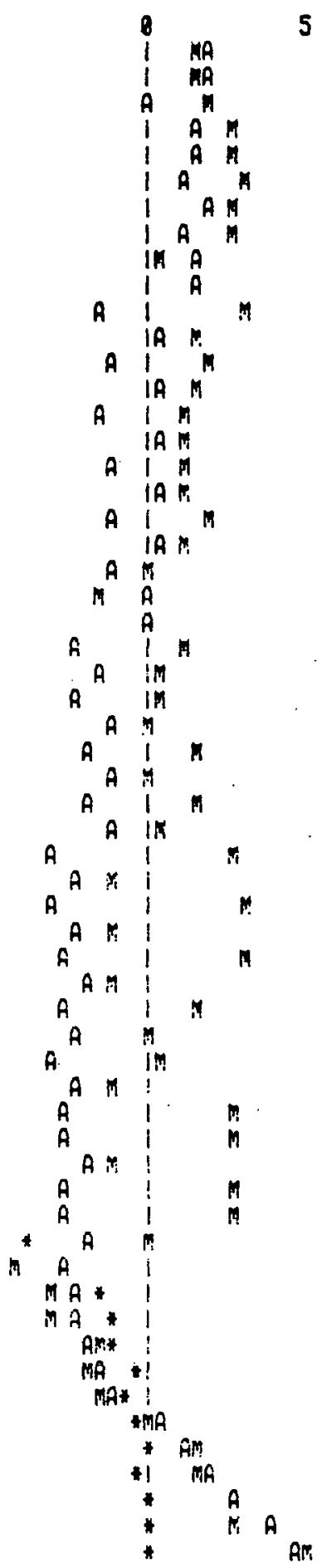

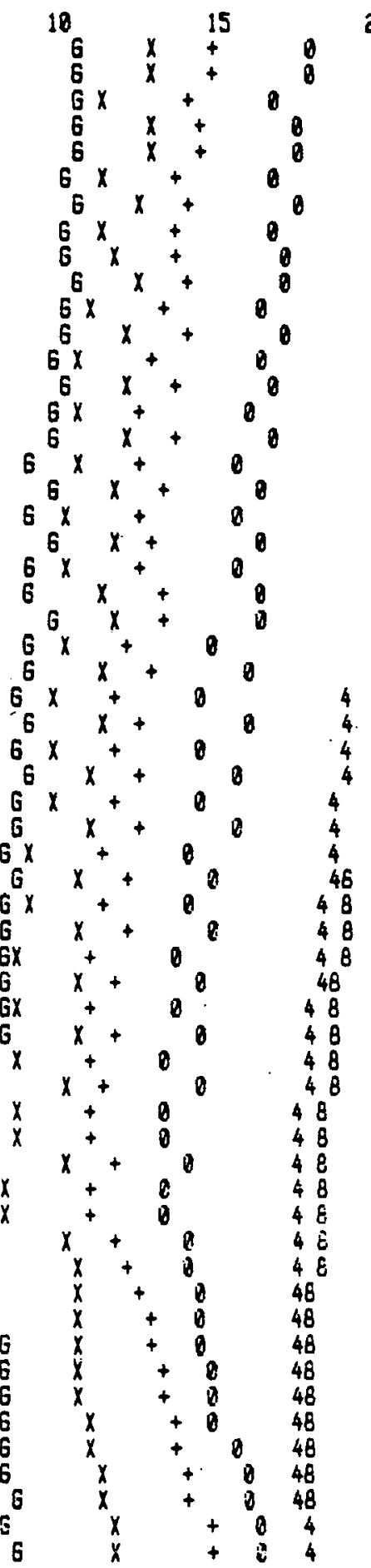

20

25

48.

$48 i$

48 I

$48 \mathrm{I}$

481

48 !

48 I

48 I

48 I

$48 \mathrm{i}$

$4 \mathrm{II}$

48

$48 \mathrm{I}$

$48 \quad 1$

481

48

48 I

48

48

8

$8^{8}$

8

48

48
8

8

48

8

8

1

I 
$23 / 38 / 82$

0001 Ho N $00: 28$

0081 HO N 80:43

0001 HI N 80:45

800: HO N 80:51

$000:$ HO N O1:86

0001 HI N $01: 15$

8081 tio N O1:Zi

0001 HO N $01: 36$

0801 HI N 01:40

$8001 \mathrm{HON}$ N1:48

0001 HO N 02:03

$00001 \mathrm{H1} N$ 02:03

0001 HO N 02:12

8001 HI N O2:25

080: HO N 02:34

0801 $41 \mathrm{~N}$ 0दि:45

$800140 \times 102: 54$

0001 H1 N 03:06

080: 40 N $83: 16$

0001 $41 \mathrm{~N}$ 03:28

028: HO N 83:39

0001 HI N 03:49

O8R: HO \& 84100

0001 HI N 04:10

Q001 $\mathrm{HO} N 04: \hat{c} 1$

0001 H1 N 84:31

0001 Ho N 04:44

0001 H1 N 04:53

080! He N 85:07

0901 HI N 05:16

800: ho iN 05:28

800141 N 05:38

002: 40 N 05:5!

0081 HI N 86:00

OOOI HO N BE:12

$0001 \mathrm{H1} N$ O5:26

080: HO \& 86:34

0001 H1 N 06:43

080: HO N 06:57

0001 HI N 07:06

0000 HI $D$ 07:06

$808040007: 20$

6002 HI D 07:28

000 HO D 07:41

Bope H1 D 07:49

$0002+10008: 03$

Q802. HI D 08:il

0008 HO D 08:24

000e Hi D 88:3?

0808 HA D 88:46

Beed Hi D 08:54

0080 HO D 89:06

9805 $\mathrm{Ki}$ D 89::4

0002 HO D 09:27

000? is 5 09:34

00000 He D 09:46

0000 HI D 09:5E

0000 HO D 10:87

0eQ2 HL D 18:17

00000 HO 0 10:26

$0010 \mathrm{H} 1 \mathrm{O} 10: 37$

0010 HO D 10:45

1110 it 0 10:57

1110 HQ $0: 1: 10$

$1110 \mathrm{Ki} O 11: 19$

1110 tid $011: 33$

$1118 \mathrm{Hi} 011: 42$

1110 40 D 11:55

$1110 \mathrm{Hi} \mathrm{D} 12: 04$

1110 HO D 12:14

$1110 \mathrm{HI} \mathrm{D} 12: 25$

11:0 HO D 12:35

$1110 \mathrm{HI} D 12: 47$

1110 Ho D le:57

$1110 \mathrm{HI} D$ 13:11

1110 HO 0 13:18

2.

$1110 \mathrm{H}: \mathrm{D} 13: 40$

$1110400.13: 46$

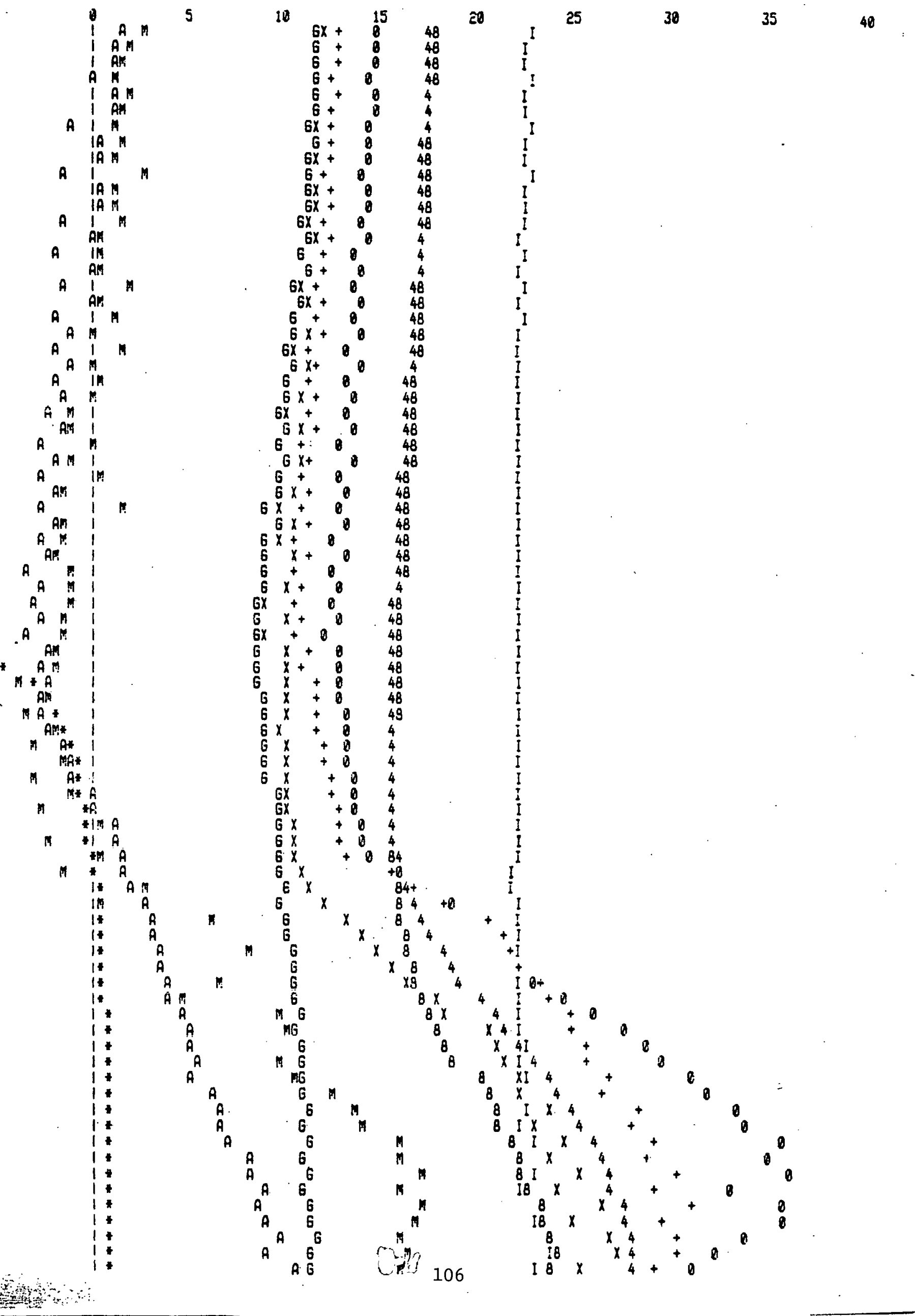


1113 tio $014: 0$ :

$1118 \mathrm{HI} \mathrm{D} \mathrm{14:0?}$

1118 HO D 14:13

1110 HB 0 14:2B

$1118 \mathrm{HI} \mathrm{D} \mathrm{14:41}$

111040 D $14: 48$

1110 HO D 15:83

1110 HI D 15:13

1118 HO D 15:20

1110 HO D 15:35

$1110 \mathrm{HL} D \quad 15: 37$

1118 HI D 15:42

0018 HI D 15:4é

o910 Ho D 15:45

$1110 \mathrm{H} 10 \mathrm{D} \quad 16: 88$

1110 H1 0 16:01

$111840016: 88$

1110 HO 0 16:23

$1110 \mathrm{H}: \mathrm{D} 16: 24$

$1110 \mathrm{HI} D \quad 16: 30$

$0010 \mathrm{HI} \mathrm{D} \mathrm{16:30}$

0810 HO D 16:35

$1110 \mathrm{HI} \mathrm{D} \mathrm{16:47}$

0810 HI D 16:47

8012 HO D 16:55

$\begin{array}{llll}1110 & H 1 & D & 17: 09\end{array}$

1110 HI D 17:11

0810 it 0 17:12

1110 HI D 17:15

0018 H1 D 17:15

0018 Ho D 17:18

0010 HI D $17: 30$

80:0 48 D $17: 37$

OOid 40 D 17:52

8018 HI D 17:54

0000 HI 0 17:55

Q082 40 D 18:02

080: 48 N 18:15

0808 41 N i8:50

0000 HO N 18:25

Qoe: 10 N 18:41

Q00: H1 N :8:55

8008 til N 18:55

0080 10 N 19:00

0001 HO N $19: 15$

0001 Ho N $99: 30$

O081 HO $119: 45$

$000:$ HD in $20: 00$

0001 Ho $N 28:=E$

Q00) 40 N 20:31

Q001 HI N $20: 33$

000 ! HI N 20:36

BQ8: HO N $20: 39$

008: HiO N 20:54

008: H1 N $2:: 84$

$808 \mathrm{HI} \mathrm{N} 21: 85$

008: HO $\mathrm{N} 21: 10$

000 : HO N 2::35

QDe: HI N

oeve Hi N $21: 30$

QRR: He 1 2: 137

0001 Ha N 21:50

Oude: $41 \mathrm{~N} 21: 53$

arder ril N $21: 55$

beo! tio v $22: 81$

Deei $\mathrm{HI} N$ 22:15

OQde! HO N $22: c \hat{c}$

0001 HO N 22:37

QQP : Hi N 2c:38

B08: HO N 22:44

bQN: HO N $22: 53$

8007 HI N 23:03

092. HO N 23:18

082: $4 B$ N $33: 25$

Q8D: HI N 23:E7

D00! $40 \leqslant 23: 35$

0081 Ho N 23:50

000! H1 in 23:51

000: $\mathrm{HO}$ N 23:58

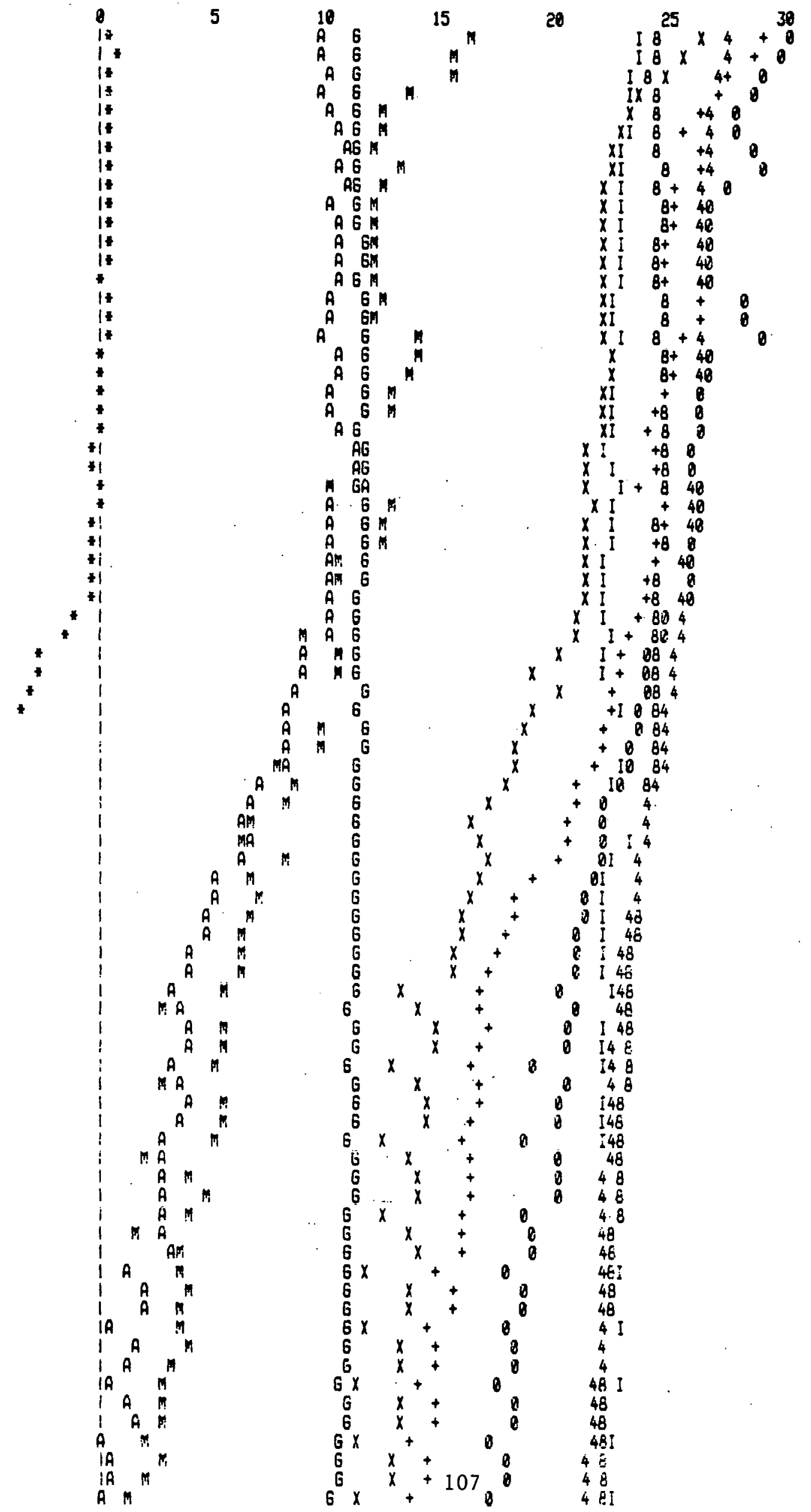

35 
03/89/82 ${ }^{-5}$

868: 40 N 88:14

800: H1 N 00:14

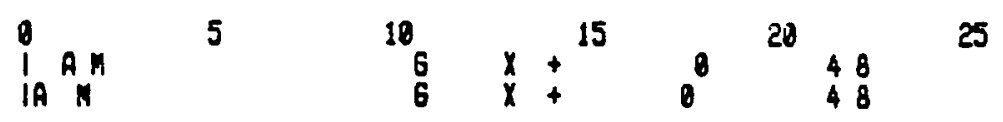

8 
0001 HO N 80:Z2

080: HI $N$ 00:35

8001 HO $N$ 00:45

0001 HI N 00:57

888i HO N 01:25

$0081 \mathrm{HI} N 81: 20$

8001 HD N 81:29

0801 H1 N 81:39

8081 HO N 01:50

080: H: N 82:82

0801 HO N Bc::13

0801 HI N 82:23

800: HO N 02:35

0001 HI N B2:44

0001 HO N B2:56

OQRI Hil N $03: 0 E$

0001 HO N 83:18

0001 H1 N 83:27

0001 HO $N$ 83:40

$0001 \mathrm{HI} N$ 83:49

000: $\mathrm{HO}^{\mathrm{N}}$ 04:02

000: HI N 84:!1

0901 i H N O4:25

$000: \mathrm{HI} N 24: 34$

0901 HO N 84:48

008: HI N 84:5E

000140 N 05:11

0001 HI N 05:20.

000: 40 N 05:33

$000:$ it N 05:4!

000 ! :10 N 05:56

$000:$ in: $N$ 06:04

ODDI HI N $86: 19$

080: HO N 06: i9

0001 HI N 06:28

000: $\mathrm{HI}$ N $06: 43$

Bo8: HO N 05:44

880i Hi N 86:5\%

$000 \mathrm{i} H \mathrm{H}$ 07:05

0080 ril 0 87:07

0008 H1 D 07:15

0000 in 0 07:30

000040 0 07:3!

0000 Hi $007: 33$

0080 H1 D 07:54

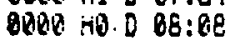

O200 HI $D$ OS: is

appe Ho D BE:30

0008 H: 0 88:39

OQED HO D B8:5?

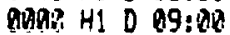

Q000 HE D 89:11

0000 til 0 89:13

o0ba Hil D 09:-59

0008 ho o 09:Ey

gege Hi D $09: 36$

$0808418009: 48$

0000 HID 09:59

oove Ho 0 10:87

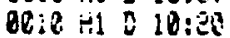

10010 $40010:=8$

$1110 \mathrm{HI}$ 0 $18: 4 \mathrm{c}$

1110 4H $010: 53$

$1110 \mathrm{HI} D 11: 0 \mathrm{C}$

1110 H: D 11:17

11:8 HQ D $11: 17$

1110 in $011: 26$

11:0 Ha $011: 35$

1110 40 $01: 54$

1118 He D 12:09

1110 HO D :2:24

1110 H8 0 12:40

1110 Ho $012: 55$

11:a 40 D 13:18

1118 HO D 13:26

11id tie D 13:4:

1110 Ho 13156

i110 tid D 14::C
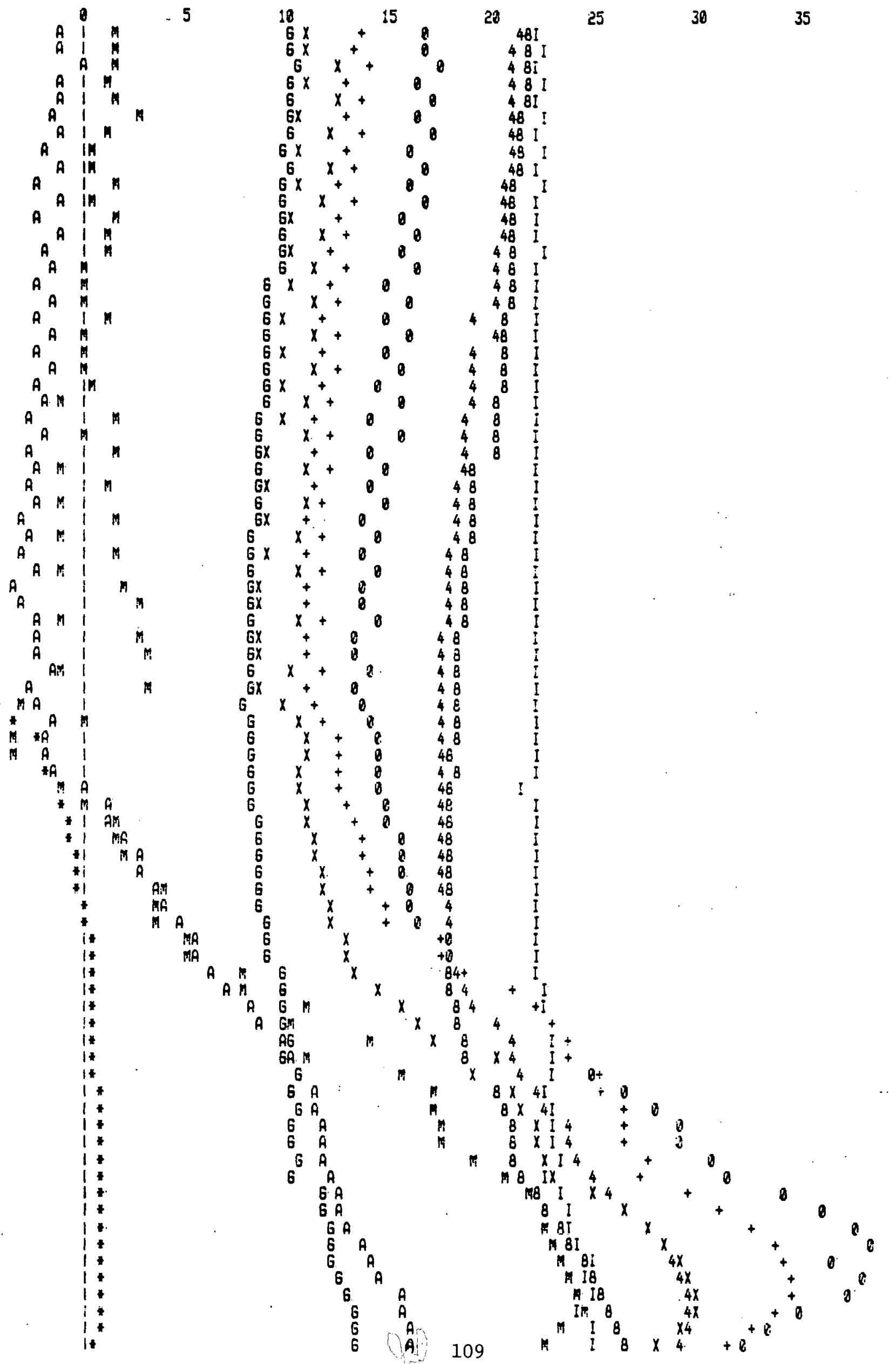
$03 / 09 / 82$

11:0 til D $14: 27$

$111040014: 42$

1118 HO $014: 58$

1110 HO D 15:13

$1110 \mathrm{HO} D$ 15:28

1110 HO $0 \quad 15: 44$

1110 HO D 15:59

1110 Ha $16: 14$

1110 HO $016: 30$

1110 HO D 16:45

1110 KO D 17:00

$1110 \mathrm{HQO} \quad 17: 15$

1110 HO D 17:30

1110 Ho 0 17:46

11:0 He D 18:0! *

1110 Ho N 18:16

goie HO N 18:3!

0010 H $N$ 18:46

$80 ! 0$ HO N 19:0:

8010 HO N 19:16

ooil rio N 19:31

0000 Ho N 19:46

$000040 \times 20: 0:$

02008 Ho $N 20: 16$

0000 HO N 20:3!

0000 H: N $20: 46$

$000040 \mathrm{~N} 21: 9 \mathrm{c}$

00000 HE N $21: 17$

obde the N 21:3e

0000 H 4 N 21:47

0080 HO N 22:8c

2000 $40 \mathrm{~N}$ ce:17

oror 40 i 22.33

$0098410 N 22: 48$

$0002 \div 10 \times 23: 03$

opor hi N 23:18

0002 He N 23:34

000340 N 23:49
5

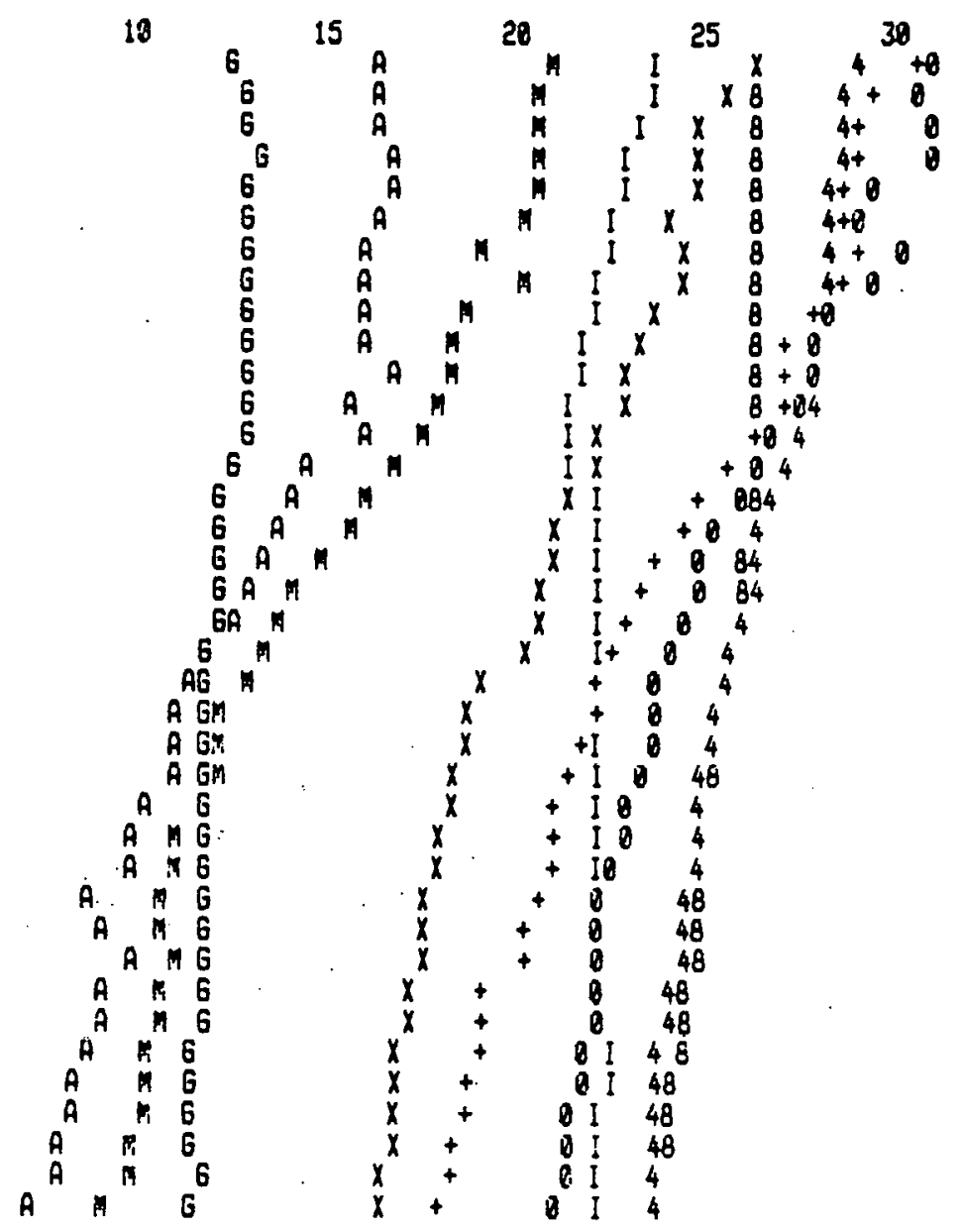

35 


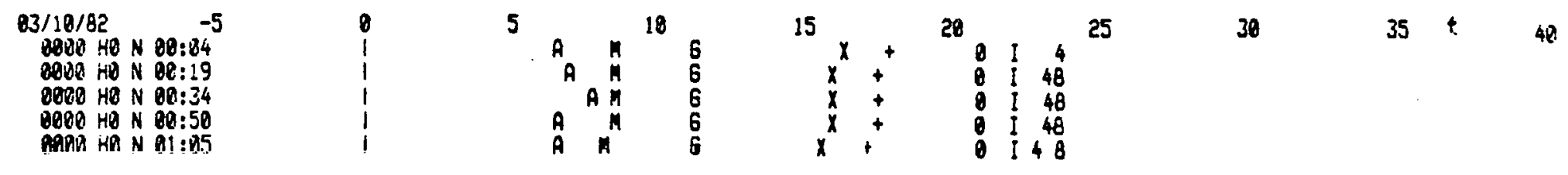


$6 x+20.148^{25}$ 
$-5$

808! HO N 80:13

0801 HI N 82:18

000! ${ }^{10} N 88: 25$

0881 HO N 88:48

$0201 \mathrm{H} 1 \mathrm{~N} 00: 5 \mathrm{~J}$

0001 HO N 01:20

8081 HO N 81:i5

800! HI N 01:19

$020 i \mathrm{i}$ N $01: 26$

$800 \div 40 \times 81: 41$

$289:$ Hi N 01:44

800: $48 \mathrm{~N}$ 01:51

208: $40 \mathrm{~N}$ 82:8E

$000:$ HI N 02:18

000: if N 02:17

8001 HO N OC: $3 \mathrm{e}$

802! H1. N O2:34

890: Ho N 02:4?

0801 HI N OE: $5 E$

$000140 \leqslant 03: 05$

808.1 h'1 N 83:17

800: HO N 03:26

0021 Hi N 03:48

000: 40 N 03:50

088: HI $\times 84: 83$

0001 HO N 04:12

$0081 \mathrm{HI} / 04: 24$

B08! Ho N 84:34

0001 hil N 04:46

8001 Ho N 04:56

0021 HI N 05:08

000140 N 05:18

DeC: HI N 85:29

080140 을 $35: 48$

806: Hil N 05:5:

0801 HP. $N$ 06:03

QB2: $H$ ! $N B E: 1 \tilde{C}$

Q80: 10 N $N$ OE: 24

DDOA Hi o OE:34

0800 HD J OE:47

Q982 ㄴ. D $06: 57$

8088 Ha 0 07:10

8000 it! $D$ 07:20

0080 Ho $507: 32$

0800 Hi D 07:41

8008. Ho D 87:53

0008 ب $508: 08$

Doge ito is $08:$ is

Q8Re ni! D B8:ट4

0000 40 \& $86: 37$

0082 H: D 08:48

0008 HO D 02:58

2008 Hi D 09::0

0020 He D 09:28

000? i o 69:30

Q48R HB 0 89:39

0000 in 0 83:5e

0000 HO D 10:80

0018 Ho D 10:15

Q010 Hi D:0:i5

80.10 He I 10:2:

1110 40 $0 \quad 18: 37$

i110 Hil D 18:33

1110 Ho D 10:46

1110 H! D 11:81

$1110 \quad 68011: 08$

$1: 10$ Ho $51: 24$

$1110 \mathrm{Hi} \mathrm{D} \mathrm{11:30}$

$11: 2$ ho D $11: 36$

1110 HO D 11:51

1118 HQ D 12:8?

1119 HO ग 12:2:

11:8 Ho \& 12:37

1110 He D 12:5

i118 Ha D 13:0E

$1110 \div 00$ : $3: 23$

1i16 HO D 13:36

$1110-00$ :3:54

1118 He \& $24: 89$

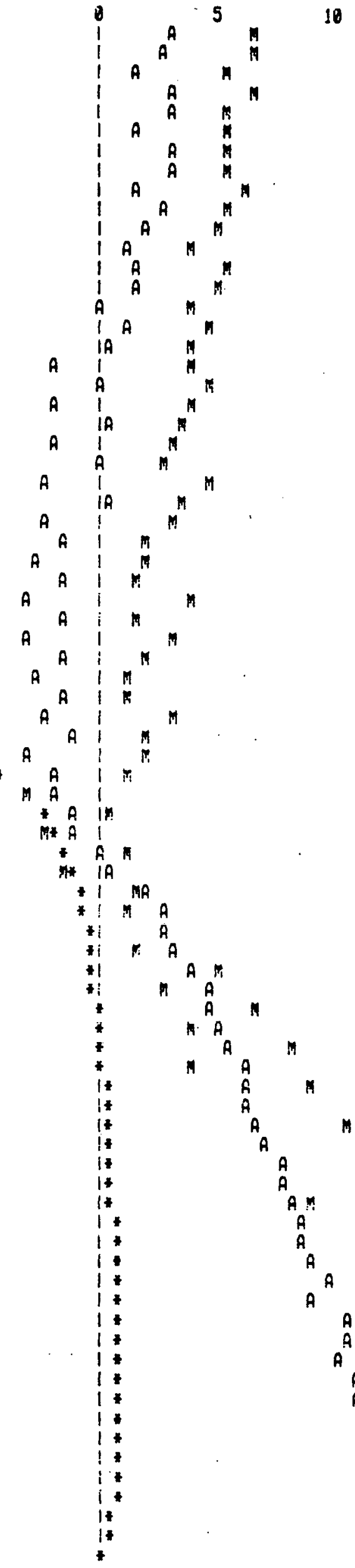

10

ax

15

2

$20 \quad 25$

25

39

35

40 


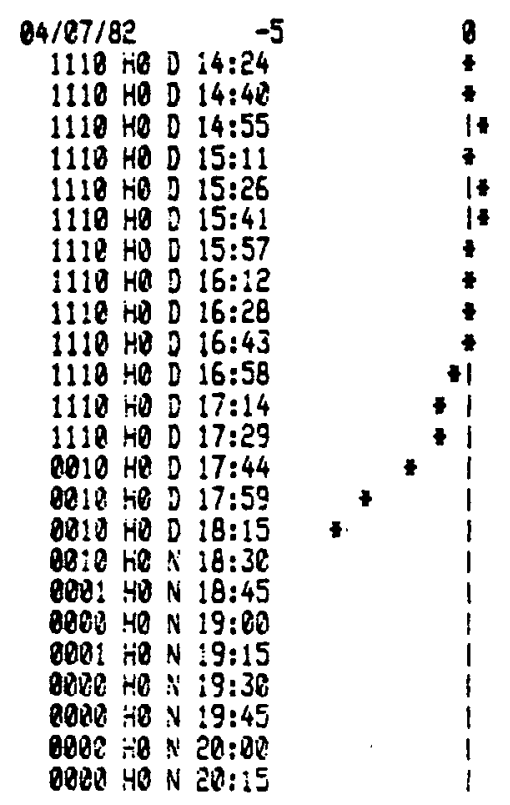

5

10

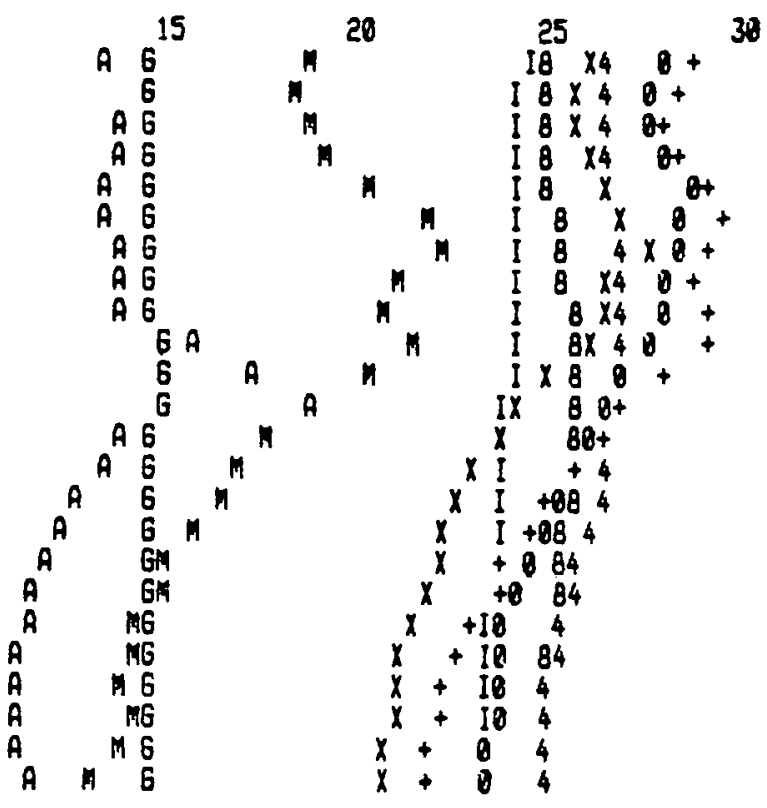


2080 C8 N $80: 29$

0080 Ca N 20:44

0008 CO N 08:59

0000 CO N 01:14

0000 CB N 01:30

8000 CO N 01:45

0800 CD N 82:80

0900 Co N 82:16

0800 CD N 82:31

0000 CO N 02:46

8000 CO N 83:81

0008 CD N 03:16

Dopa Co N 03:32

8000 CO N 83:47

0980 CD N $94: 82$

$0000 \mathrm{CD} N$ 04:17

0000 CO N 04:33

0800 CO N 84:48

2000 CO N 85:03

0000 CO N 85:19

000 CO N 05:34

obge Co N 25:49

0000 CO N 86:85

0800 Co N 86:20

DODE CD N BE:35

$0000 \mathrm{CO} N \mathrm{~N}$ 06:5:

8008 CO D 07:0E

8000 CO D 07:21

0090 CO D 87:37

8000 CO D 07:52

0080 CD D 88:07

0000 CO D 88:22

0080 Co D 88:38

0802 CO D 08:53

0000 CQ D 89:08

0000 Ca D 09:23

0008 CO D 09:39

0000 CO 0 89:54

oobe ce D 10:10

0800 CO D 10:25

Q001 CO D 10:40

0000 CD D $10: 56$

oena co 0 11:11

0000 CO D 11:27

0Q902 CB D 11:42

0000 Cl D $11: 57$

0002 CO D 12:05

o000 CE 0 12:21

0Q8Q Ci D 12:

0080 Co D 12:31

ORER CO D 12:4E

ooer CI D 12:47

ดuser L 0 12:57

0008 Co D 13:13

Q0Ba C1 D 13:15

ODen CO D I3:26

Oober CE D $33: 42$

0010 C1 0 13:44

000 CD $013: 56$

oQge? C1 0 14:10

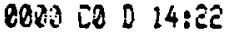

0080 C1 D 14:3:

DOAB CQ D 14:47

0020 Cl $D$ 15:01

8001 Co D 15:15

8080 Ci D 15:25

0000 CI D 15:41

0080 CO $D$ 15:43

ODoR C! 0 15:53

80014 C1 D 16:08

0002 CD is 16:12

0000 CI D 16:21

Q008 CI D 16:36

ooes ce i 16:38

8008 C: D 16:50

0000 C1 $0 \quad 17: 05$

ooge Ce 0 17:09

8000 Cl 0 17:2?

0808 CI D $17: 37$

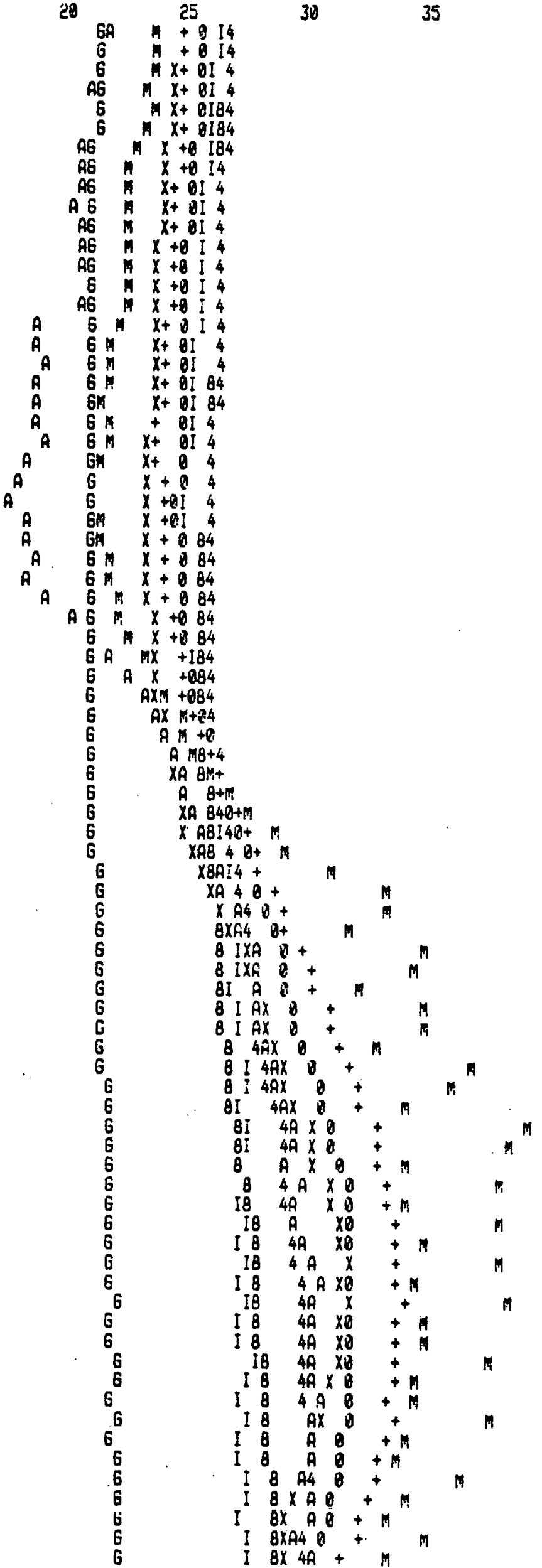




\begin{tabular}{|c|c|c|}
\hline 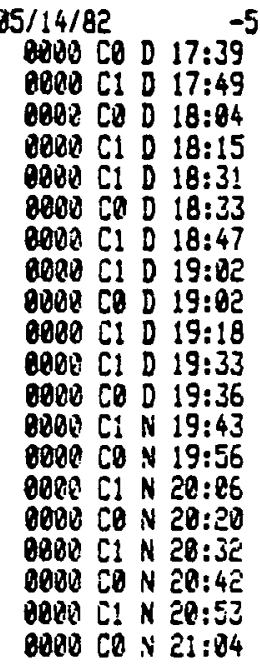 & 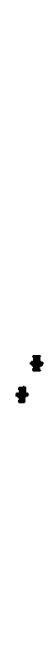 & 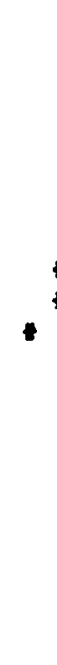 \\
\hline
\end{tabular}

10

15

28

6
6
6
6
6
6
6
6
6
6
6
6
6
6
6
6
6
6
6
6
6
6
6

25

$1 \times 49+M$

5

I $X A O+A$

I $\times B A O+$

I X8A04+

I $X$ BAO+

I $X B A D+$

IX $8 A+$

$1 \times 8 A 4$

I $\times A+4 M$

IA $8+A$

$1 \times A+4 M$

I $X \mathrm{AB}+4 \mathrm{M}$

I $X A+4$

IX $A+\theta 4$

IA +84

IA +84

AIX +084

AX +084

A +084

IA +084 
$86 / 14 / 82 \quad-5$ 


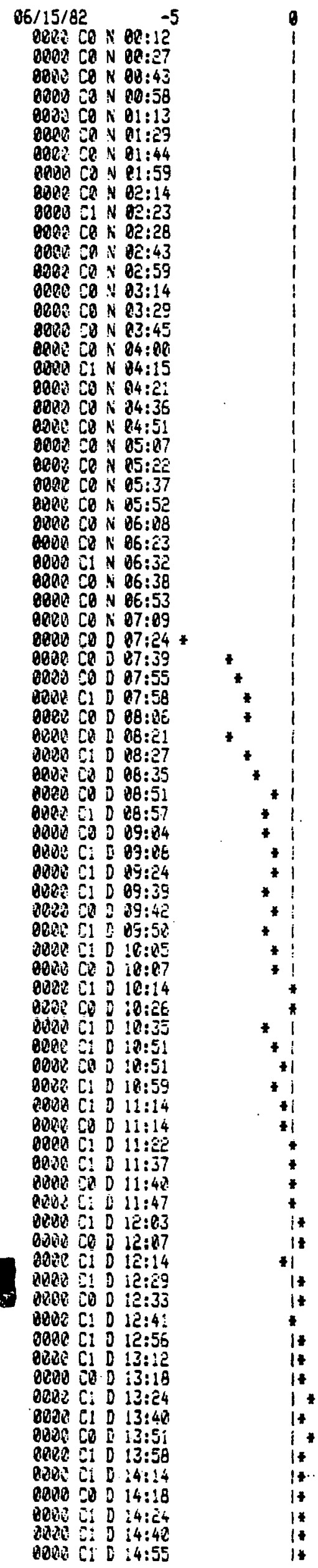

0000 ca N 00.5

$0903 \mathrm{co} \times 01: 13$

(2000

$2000 \mathrm{CO} N \mathrm{~N} 04: 2$

o8do Cy i 84:36

0008 $c 0 \mathrm{~N} 05: 07$

8002 $\mathrm{CO}$ i $05: 23$

0008 co N 06:08

$6 x+8$
$6 x+84$

A $6 X+04$

A $6 X+14$

A $6 x+4$

A $6 X+4$

A. $6 m x+4$

A. $6 m x+4$

R6 $\max +4$

A $6 \mathrm{Am} X+4$

A 6 Sn $x+4$

A6 $x+4$

A6 $x+884$

6 $x+84$

$69 x+084$

$6+084$

GA +084

GA $x+284$

GA $X+1884$

$6 x+84$

6 AiX+Bi

6 AIX $X+14$

GAI $x+34$

8 IA +84

6 IA +4

G IA +4

6 IA $8+4$

6 iA $8+4 \pi$

6. IA $8+4$.

$G$ IAXB +m

$\begin{array}{ll}G & I X A+r \\ G & I X A+m \\ G & A X B+m\end{array}$

6 I $\times 8 \mathrm{~B}+8 \quad A$

6 I: $X A+$

$G$ i $X^{2} A+A$

${ }_{6} I$ I $\quad B A 4 A+B$

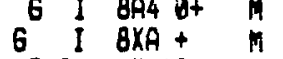

6 I $\quad \times 4 A+$

6 I $8 \times A B+$

$G$ I. $\quad 8 \times 4 A+$

.

$6: B \times A+$

118 
06/:5/82 Q0812 $6 ! 315: 11$

0800 CO D 15:18

8020 i I D $15: 24$

0000 Cl D 15:40

Q8000 CO D 15:54

8988 CI D 16:80

8828 CI D 16:16

0800 CO D 16:19

8000 C1 D 16:28

0000 c1 0 16:43

0800 CO D $16: 48$

oeve CI D 16:55

0003 CR D 17:07

OUBe CI D 17:15

8803 CI D 17:38

0000 CO 0 17:33

opee C1 D 17:4C

0820 CO D 17:57

oove Cl D 18:05

000 CO D 18:16

o日er CI D 18:24

0800 C1 D 18:48

8202 Ca D 18:40

0006 C1 D 18:49

Q000 CR D 19:0!

0080 CI 0 19:08

oobe Co D 19:21

0000 is 0 19:31

BRed CR D 19:45

0000 CI o 19:53

8808. C8 I 20:8: -

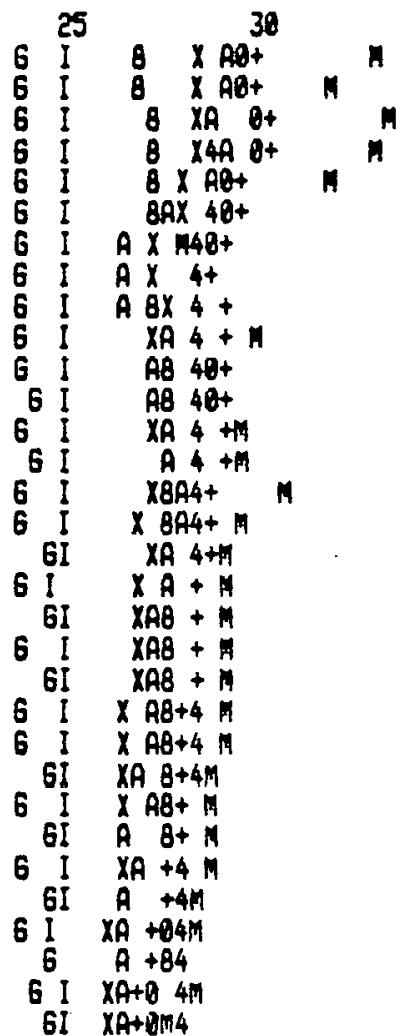

35 


\section{7/27/82}

0.80 Co N $85: 58$

3000 Ci $N$ OE:04

OOBO CO N O6:13

boed CI N 86:25

0909 Co N 26:35

$8000 \mathrm{Cl} N$ 06:50

0088 Co N 07:00

0080 Ca D 87:16

0000 Cᄂ 0 07:20

0000 CD 0 07:30

0894 CI D 07:45

009 CO D 07:54

0801 C1 D 08:03

0080 CD D 8B:19

Dode CO $D$ 88:35

9080 C1 D 88:37

0008 CO D 88:47

Q000 C1. D 89:08

0008 co 0 89:12

0098 C1 D 09:24

0082 CO D 89:33

0000 CI D 89:46

0008 CD D 18:81

0000 C1 D 10::3

8080 CD $318: 23$

0000 C1 D 10:35

0000 CE D 10:4E

0908 CI D 10:58

000R CO D 11:11

0902 Cl D $11: \hat{c}^{3}$

000 CO D 11:38

0080 C1 D 11:49

co00 CO D 12:03

0000 Ci D 12:13

ogar Ca $012: 27$

b800 Cl D 12:36

opere CO D 12:48

0803 Ci 0 :2:58

Q008 Ci D i3:13

OQBu C2 D : $3: 14$

060? il 0 13:23

0000 C: $013: 38$

0080 CO D 13:41

0908 C1 D 13:50

ober C: D i4:05

Dapio CO D 14:09

o8e? C: D 14:17

OQne $-514: 33$

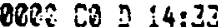

Dobe C1 D 14:43

0000 CQ 0 14:58

O000 C1 D 15:09

DODE CE D IE:

0080 CI D 15:3i

000 Ce E is:45

Quede is i 15:54

oebe co 5 16:18

abea $11016: 19$

OQR Ci L IE:J5

oato? CO D le:37

bee: C: D 1E:47

20082 010 17:28

Q8De ce $17:: 4$

0000 S1 D 17:0̂

088? C: D 17:37

poper co $077: 46$

Bane E 0 i $7: 55$

0003 ह1 $D$ i8:11

0200 C6 $018: 13$

obar is $018: 20$

QQ00. Co D $18: 33$

anpia CI D 18:4.

0002 C1 \& 18:57

0080 CO D 18:57

beve [1 \& 19:27

adab Ci 0 19:23

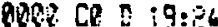

ODOO Ci D :9:34

008? is a 19:50
10

15

20

25

ค 6 IM

30

35

48
A6ITH4

A6. 4

6X 14

A+Gin 4

A6P 14

AlGm 4

A 6 \% 4

AIEM 4

A68) 4

$6+84$

68 4

69841

EA94

GAO4M

$6+8 A$

$6 X+A \quad M$

$6+0 A$

$6 \begin{aligned} & x+A \\ & X+A\end{aligned}$

$6+A \quad M$

${ }_{6}^{6} X^{4}+A+A M$

$\begin{array}{ll}6 & \times 4+A \\ 6 & 8 \times 4+A\end{array}$

IG $8 \times 4+A$

$G B X+A$

Gi $8 \times 4+A$

$G \& \times B+A$

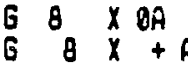

GI $8 \quad 4 X+\hat{A}$

$684 x 0+A$

Gi $8 \quad 4 \times 0+R$

$68+80+A$

GI $84 \times \theta A$

$G \quad 8 \times B$

$6 \quad 8 \quad 4 X 0 . A$

6I $84 X 8 A+$

$6 \quad 8 \quad 4 X \quad 0 A$

GI $8 \times 48 A$

G: $8 \times 48+A$

$6 \quad 8 \times 4+A$

G1 $8 \times 4 A$

$G A \times B+$

6 AmX B+

GI $A$ XmO+

G. $X A Q+T$

$6 \times A$ M

G! Xa4t

$6 \quad X+A \quad M$

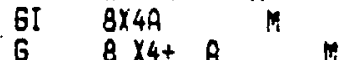

6. $84 x+A$

6: $\quad 84 x+A$

$\begin{array}{ll}6: & 8 x+ \\ 6 & 8 \times 0+9\end{array}$

6! $84 \times 8+8$

GI $8 \times 48+A$

G $8 \times 4+A$

G! $3 x y+A$

E $\quad \hat{8} x+$

$G \quad X+A$

$6 \quad x \theta+A$

$G^{G} \quad X^{B+} B+A$

$G \quad \times B+A$
$16 \times \dot{B}+4$

$\times 8+4 \quad A$

$\times 8+4 A^{A}$

$x+4 A$

$x+4 A$

$X+4 G$ m
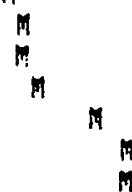

H
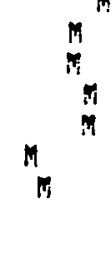
0080 is $N$ 20:01

8002 [I N $20: 17$

$0000 \mathrm{CO} N 20: 18$

$6 x+8 A$ 
$88 / 20 / 8 ?$

0000 C1 $100: 35$

$0000 \mathrm{CD}$ N 80:42

0800 CI N 08:5!

$0080 \mathrm{CO} N$ 81:86

0000 C1 $N$ 01:18

0000 CO N 81:31

8000 C1 N 01:41

0800 CD $\times 81: 50$

B080 CI N Q2:04

0000 CO N 02:15

8000 CI N 8E:29

8080 CO N 02:38

9090 CI N Q2:52

0000 CO N 83:81

0900 Co $183: 16$

0000 CI N 03:19

0000 CO N 83:28

$0000 \mathrm{CD} N \mathrm{~N}$ 83:44

0008 CI N 83:49

9080 Ca N 83:58

8RAOC CO N 84:13

0000 CI N 84:17

0008 CO $N 04: 24$

0000 Co $1104: 40$

o0en Ci N 84:43

0080 CO N 04:51

0006 Ca N 85:86

0000 Ci N 05:15

opode CO N 85:23

0080 CD N 85:39

0080 CI $N$ 85:51

0004 Co $N$ 85:58

$0008 \mathrm{co} N 06: 14$

0001 CD N OE: 29

0080 Cl N. $80: c^{\circ}$

gope $00 \mathrm{~N} 06: 36$

0000 CO N 86:5é

8000 CO N 07:07

0808 Ce 0 07:22 *

9802 C1 0 87:37

Qbee Ce D 27:45

DORA CD 0 08:08

gove Cl D 88:14

0000 CO 0 08:ट̂́

0008 CD D $08: 37$

908R Ci $208: 48$

Q002 CO D OE:49

0000 Ci D Be:55

gave Cl is 89:15

0008 CA $D$ 09:32

DROP C1 D 89:35

0000 CE D 05:50

O000 CI i 16:C:

OBeO CO D 10:1:

OPBe CI D 18:22

1080 CO D 10:31

0002 CI D $18: 43$

8000 c0 $010: 54$

0008 C $\mathrm{D} 11: 07$

$0008 \mathrm{co} \mathrm{D} 11:: 8$

Bon? C: D 11:ćt

9000 $62 \mathrm{D} 11: 38$

OBQA Cl D 11:49

8008 co o lê:Re

0004 Cl D 12:13

0008: CO 0 12:24

Qod: C: 0 lê:34

$00003 \mathrm{CO} 0$ 12:45

Q002 $\mathrm{C}$ I $\mathrm{D}$ 12:55

0000 CO $013: 10$

Base C: D 13:20

8000 C1 D $13: 35$

Coba 28 D $13: 37$

pooe C1 D 13:46

oder CO D 14:8R

0090 Ci D 14:65

Q800 C: 15 14:23

ODQR Ce D $14: 24$

DQRE $[10$ i $14: 3 e$
5

10.

15

20

25

30

35

42

A 198

A $\times 6+\times 8$

A II 60

A $96+\times 8$

A MI 6084

A $16+884$

A 5084

A MIG+O 84

A MSX 4

$A$ AIG +84

AF I +6 B 4

A MisX 04

A MIE 04

A MIGX 8

A MIEX 04

A 7 IE $0 \quad 84$

$A$ I 16084

A ISXO 84

A 1 +6 84

$A$ I 1604

A In IG 4

A $M+604$

A I IG 14

A II IG 04

A $M+G \quad 4$

A +684

A 1604

A 1604

$A$ P +6884

A. +68 84

A $+60 \quad 84$

A +6884

A $M+60$.

A $M+604$

A 11 \% +684

A 604

A 1 X $\quad X 08$

A $X 604$

A $1 \times 604$

A $1+68$

f $17 \times 6884$

A $1 \times 6084$

A 1 X6 084

A I IG+Q8.64

AM $6+B_{4}$

A $\mathrm{AG}+\mathrm{B}_{4}$

A $: 6 x+34$

AI $6+24$

IAGX +84

AGX +84

IAG $X+184$

AG $x+84$

IAG $x+90$

IG $x+8 \%$

If $6 x+8.4 x$

I6A $\times 8+$

I. $G A Q+1)$

I GRBI 40+

I. $G$ BA $\& \Delta+n$

I $G A B \times B+$

I. 6 BAX $0^{+}+$

I 6 BaX4 $0+$

I 6 A $4 x 0+A$

I 6 8 $9 \times 0+M$

$16894 \times 0$ +

I G $8 A \times 0$

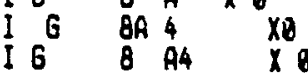

as $x x^{+}+$

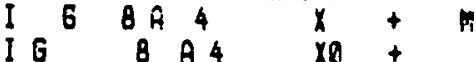

18 8 A 4 XO

16 BA 4 OX

I $6 \quad 8 \mathrm{~A}_{4} \times \mathrm{Ba}^{\circ}$

$1_{6}^{6} \quad 894 \quad a x$

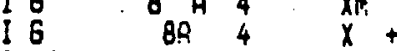

$a^{x}+$

it

$0 x+$ in 


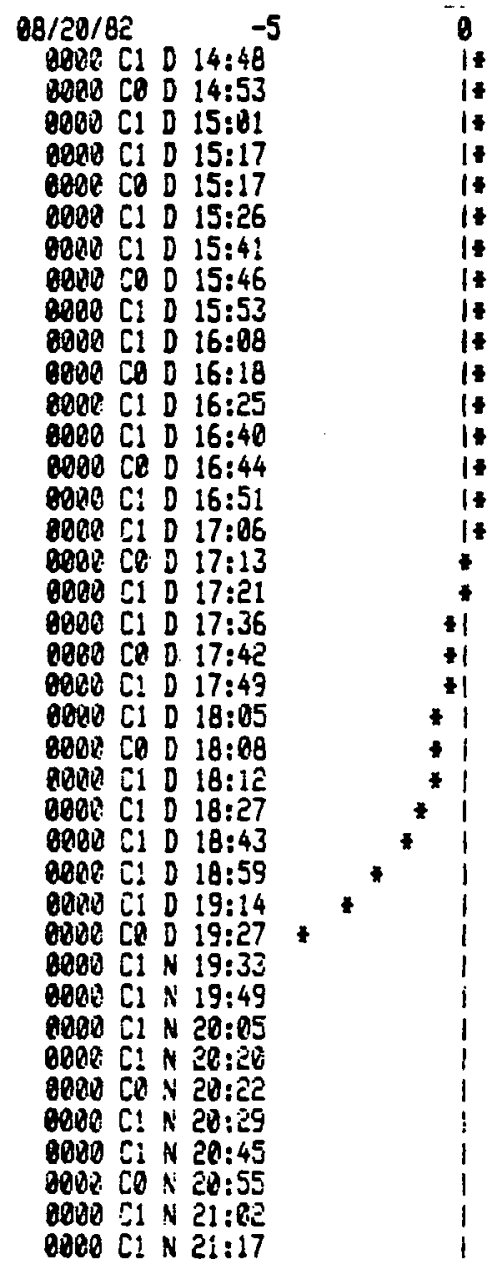

9080 C1 D $15: 26$

0000 C1 D 15:4?

(2000 15.53

0000 CI D 16:08

Dave C: $D$ 16:5

2068 C1 0 17:06

2000 C1 017.21

0000 C1 D 17:36

ogr C1 18

9980 C1 D 18:43

opde CR o 19:27

CI N 19:33

$000 \mathrm{Cl} 20.05$

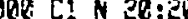

0900 1 N 21:8

0000 CI N $2 i: 17$

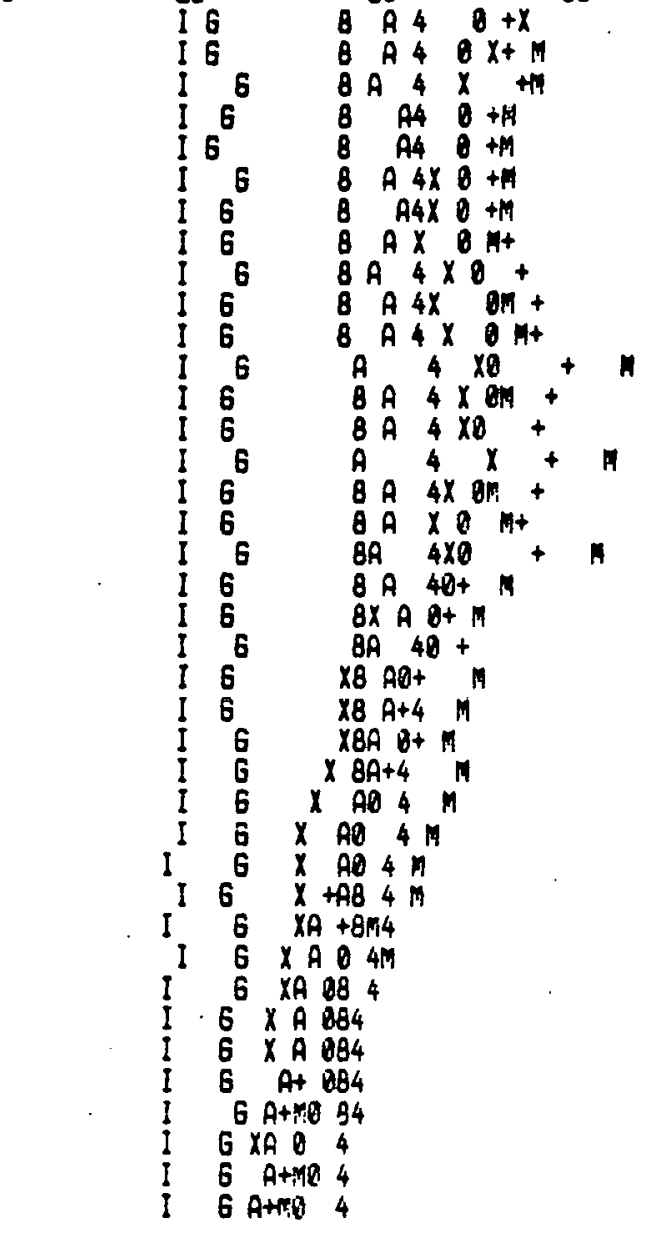


10

1111 Cl D 10:33

1111 CI D 10:48

1111 CI D 11:83

1111 C1 D 11:18

1111 CI D 11:33

1111 C1 D 11:48

111 CI 0 12:83

1111 CI D le:18

1111 CI D 12:34

1111 CI D 12:49

IIII CI D 13:04

1111 CI D 13:19

1111 CI D $13: 35$

1111 CI D i3:50

1111 C! D 14:05

1111 C1 0 14:20

1111 CI D 14:3E

1111 CI D 14:51

1111 CI D 15:86

1111 CI D 15:21

1111 CI D 15:37

1111 CI D 15:5e

1111 C1 D 16:07

1111 Cl D 16:22

1111 Cl D 16:38

1111 CI D $16: 53$

1111 CI D 17:88

1111 CI D 17:23

111: CI D 17:39

1111 C1 D i7:54

1111 CI D 18:89

1111 CI D 18:24

1111 CI D 18:48

1111 CI D 18:55

1111 CI D 19::0

1111 CI N 19:25

1111 Cl N 19:48

1111 C1 N 19:55

11 i1 C! N $20: 18$

1111 C1 N $20: 26$

111! CI N 28:4!

1111 CI $\vee 20: 56$

1111 CI N 21:11

1111 C1 N $21: 26$

1111 CI N 21:41

1111 CI N 21:56

111i CI N ट2:11

111i 6! * $32: 25$

111. Ci N $5 \mathrm{c}: 4$

1111 CI N Cेट:5E

1111 Cl N 25:11

1111 CI N 23:26

11il CI N $23: 41$

$1111 \mathrm{CIN}$ ह3:56
15

6
6
6
6
6
6
6
6
6
6
6
6
$6 H$
6
6
6

20

$x+40 \quad 25$

$x+A 84$

$X+A 884$

$X+B A B$

$x+204$
$x+204$

$x+A$

$x+A \theta$

$x+14$

$x+18 A$

$x+81 B A$

$x+80 A$

$x+B$ BA

$x+140$

$x+10 A$

$x+8844$

$x+804 \mathrm{~A}$

$x^{x}+884 A$

$x+04 A$
$x+04 A$

$x+804 \mathrm{~A}$

$x+084 A$
$+884 A$

$x+84 A$

$x+084 A$

$x+884 I A$

$x+884 I A$

$x+\theta$ Baia

$x+B$ 84IA

$x+8$ 84ia

$x+084$ IA

$+84 A$

$x+0$ A I

+0 RI

+ A4 1

+ A A I

+0 A 41

txe A $4 I$

$+\times 0$ A 4 I I

$+\times 0$ A 41

$+A 4$

$+A 4 I$
$+0 A 4$

+0 A 48

$+\quad A$

$+$

$+$

$++A$

$+A$

$+A B$

$+X A B$

$+R D$

$+A B$

$+A 0$ 
$25 / 01 / 83 \quad-5$

1111 C1 $N$ 00:12

111i CI N 80:27

1111 CI N 80:4Cे

$11 i 1$ C1 N 00:58

1111 C1 N 81:13

1111 CI N 01:28

1111 C1 N $81: 43$

1111 CI N $01: 59$

1111 C1 N 02:16

1111 C1 $N$ O2:29

1111 C1 N OE:45

1111 CI N 03:A0

1111 CI $N$ 03:15

111! C1 N $03: 31$

1111 CI $N$ 03:46

1111 C1 N 04:0!

1111 CI N 84:17

1111 CI N 04:3c

1111 C1 N 04:47

111! CI N 25:03

111! C1 N 85:18

1111 C1 N 05:33

1111 C1 N 85:49

1111 CI N $06: 04$

I111 CI QE:

i111 CI $N$ os:35

1111 C1 N 06:5B

111i CI D 87:25

1111 C1 D $07: 2$

1111 C1 0 07:36

1111 C1 0 07:5?

111 ! C1 D 08:87

1111 CI O Q8:23

$111 ! \mathrm{C}: D 08: 38$

$1111 C 1 D$ 08:53

111. C1 D 09:88

1111 CI $D$ Q9: है

III C: D 89:38

1111 C1 D 89:53

111! CI 0 10:06

1111 CI D 10:2

$111 j$ C $D$ 18:30

1111 C1 D 18:5

1111 C! D 11:89

1111 C1 D 11:24

$1111 \mathrm{C}: 041: 39$

1111 C1 $0: 1: 54$

1111 C 0 12:20

1111 Cl 0 1रि:25

1111 Cl 0 12:42

1111 C1 $012: 55$

111: C: D 13:18

1111 C1 0 13:ế

111: Cl D 13:4!

1111 Cl $0 \quad 13: 56$

112! C1 D 14::1

$1111 \mathrm{Cl} D \mathrm{~B}: \mathrm{e}$ ?

1111 C1 $014: 43$

1111 CO D 14:4E
5

10

15

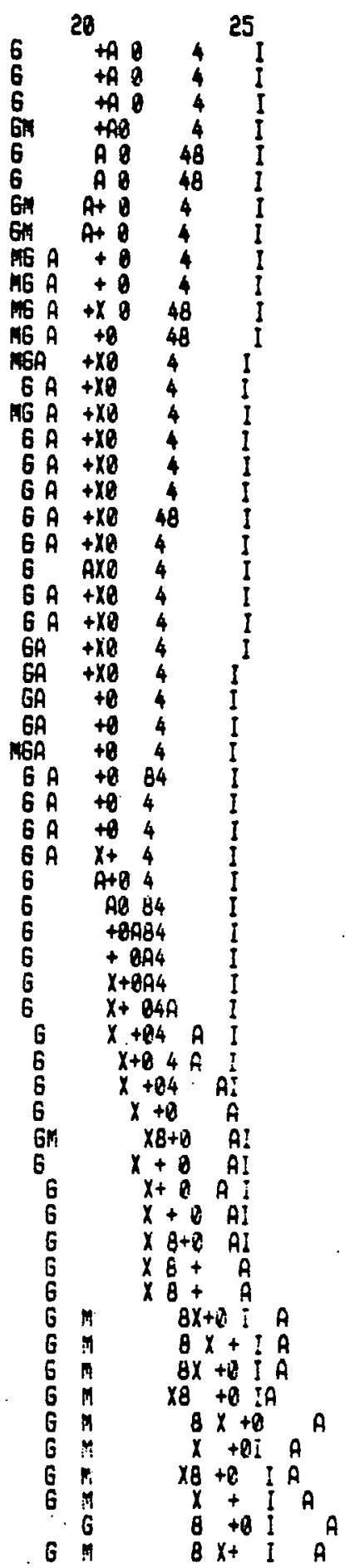

38

35 
05/20/83

0002 C: $N$ 21:28

$0800+C 1 N 21: 43$

$8888+C I N 21: 44$

$8080+C 1 N 21: 44$

$8080+C 1 N 21: 45$

$0000+C 1 N 21: 45$

$0002+C 1$ N $21: 50$

$0000+C l$ i c $1: 50$

$0080+C 1 \wedge 21: 51$

8000 CI N 22:06

8000 Cl N 22:21

$0000 \mathrm{Cl} N 22: 36$

0028 CI N ट2:51

$0880 \mathrm{CO} N 22: 54$

0000 C1 N 23:05

0000 C1 N $23: c 0$

0090 CD N 23:21

9002 C1 N 23:30

Q00e CQ is 23:44

0000 Ci N $33: 54$
25

AX +184

A +084

A $x+84$

A $+\infty 84$

A $x+84$

A $x+84$

$A+884$

$A+884$

A+0184

$X A+84$

$X A+084$

$X A+884$

AI +084

AI +884

Al +084

A+ 884

$A+884$

$A I+B 84$

A +884

$A X+B \quad B 4$ 


\begin{tabular}{|c|c|}
\hline 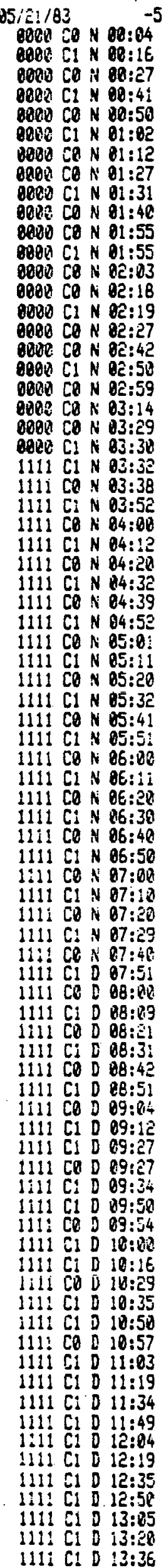 & ${ }^{*}+$ \\
\hline
\end{tabular}

(2)

0038 CI $N$ o1:82

adon Ca N Bă:42

8Bob Cl N OĈ:50

agar 1103.38

1111 CO N 84:00

1111 CI $N$ 04:12

C1 $N 443$ $6 A^{A}+x+014$

- $6 A X+B I 4$ $6 \mathrm{~A}+\mathrm{O} 14$

A $6 \mathrm{~A} X+0$ I

$6 A+B$ is

M $A \quad X+084$

$6 \mathrm{~A}+084$

月6 $A \quad X+B 84$

$196 A+884$

A $A A+8$

$M G A+B$ 4I

MG $A \quad x+8 \quad 4$

$M 6 A+04 i$

$M G A \quad x+0 \quad 4$

$M G A+0$ 4I

M6 $A \quad x+8 \quad 4$

MG $A+B$ 4I

MG $A$ X $x+8$ 84?

$6 A+B$ 4I

ne. $A X+8$ 84I

$6 \quad A+B$ 84I

NG $A X+B \quad B 4^{\circ}$

$6 \quad A+\theta \quad 84:$

InS $A X+0 B 4:$

6 A+Q 84

mG $A X+064 I$

6 A $84 i$

MG $A X+84 I$

ME A+B 84:

MG $A X+84$

6 A $084^{\circ}$

$6^{6} \quad+R 084$

6 tAO4

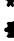

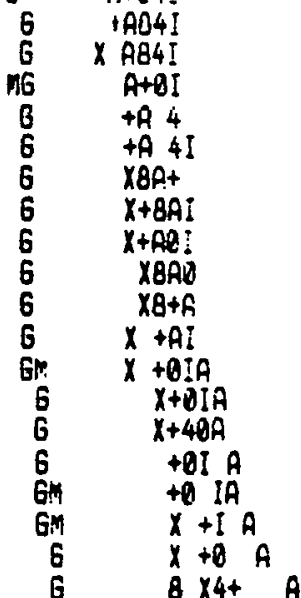




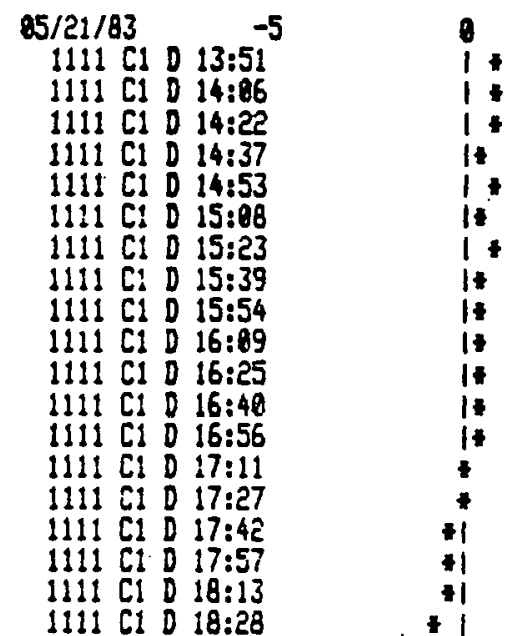

15

20

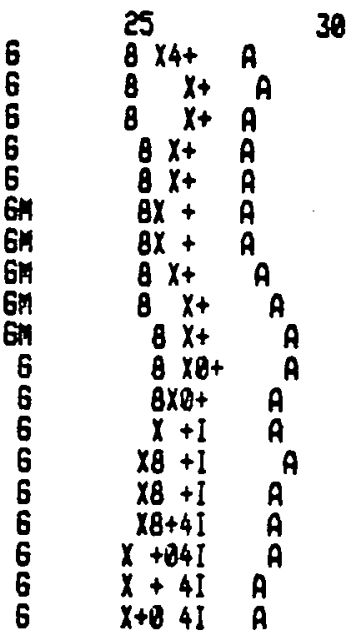

35

$\therefore$

40

IIII CI D 18:13

$\begin{array}{ll}x+4 & A \\ x+B & 4 I\end{array}$ 